\title{
Studies and reflections on type 2 diabetes care in general practice. Perspectives of patients and professionals
}

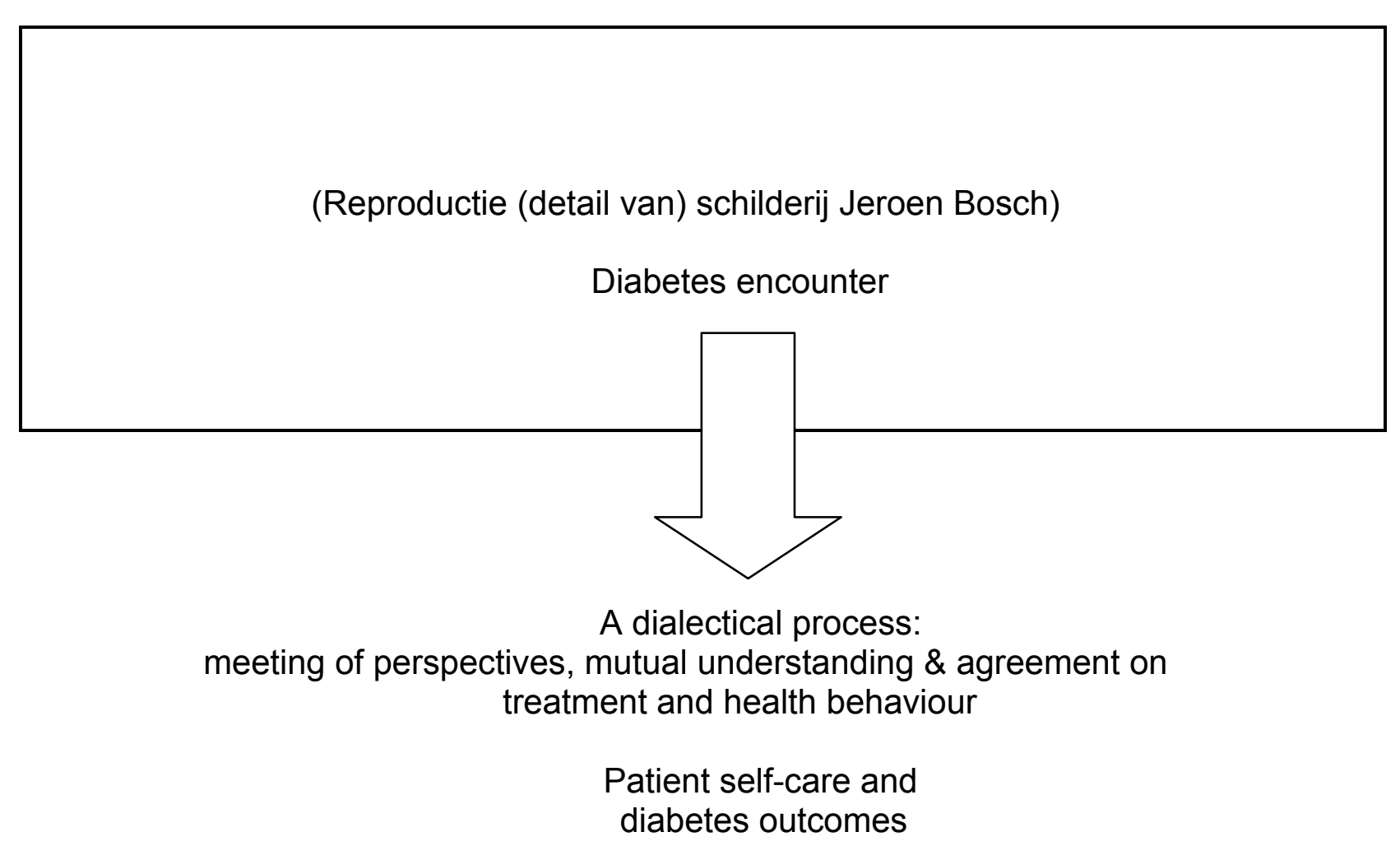

\section{Henk van Dam}




\section{ERRATA}

BIJ PROEFSCHRIFT ' STUDIES AND REFLECTIONS ON TYPE 2 DIABETES

CARE IN GENERAL PRACTICE - PERSPECTIVES OF PATIENTS AND

PROFESSIONALS' VAN HENK VAN DAM (Universiteit Maastricht 2005)

Blz.16. Referenties bij chapter 1.

- $\quad$ Ref.27 is weggevallen en moet zijn: 'Michie S, Miles J, Weiman J. Patientcentredness in chronic illness: what is it and does it matter? Patient Educ Couns 2003;51:197-206.'

- Ref.35 is weggevallen en moet zijn:'Sullivan M. The new subjective medicine: taking the patient's point of view on health care and health. Soc Sci Med 2003;1595-1604.'

Blz.33. Bronvermelding moet zijn:'Huisarts Wet 1998;41:10-5.'

Blz.74 regel 6. Na 'hart-vaatziekte' ontbreekt: 'NNT 60'

Blz.74 regel 7. Na 'acetylsalicylzuur' ontbreekt: 'NNT 40'

Blz.123. 'Submitted' moet zijn: 'In press'

Blz.144. Referenties chapter 7.

- Ref.29 is weggevallen en moet zijn: 'Groeneveld Y. Introduction of structured diabetes care in general practice. Thesis, Leiden University, the Netherlands 2000.'

Blz.154 regel 21. Na 'duration' moet de referentie zijn: '[111,112].'

Blz.158 regel 25. '128,130]' moet zijn: '128-130].'

Blz.160 regel 17. '125-129]' moet zijn: '125-130].'

Blz.174-176: Volgorde (nummering) van de referenties niet geheel correct. 
Picture on front page: Hiëronymus Bosch: Carrying the crucifix (after 1500) - detail. Kindly provided by the Museum van Schone Kunsten, Gent (B).

Voorpaginaplaat: Hiëronymus Bosch: De Kruisdraging (na 1500) - detail. Vriendelijk ter beschikking gesteld door het Museum van Schone Kunsten te Gent (B). 
Studies and reflections on type 2 diabetes care in general practice. Perspectives of patients and professionals

H.A. VAN DAM 
The studies presented in this thesis were conducted at the Maastricht Care and Public Health Research Institute (CAPHRI), which participates in the Netherlands School of Primary Care Research (CaRe), acknowledged in 1995 by the Royal Dutch Acadamy of Science KNAW)

Financial support for the printing of this thesis was kindly provided by the Board of the Primary Healthcare Center ' Withuis', Venlo; Board of the General Practitioners' Association Branch Region Limburg Noord (RHV), Venlo; Board of Zorggroep Noord-Limburg, Venlo; public pharmacy 'Jaspers', Venlo; Pfizer Farmaceuticals Nederland BV, Capelle aan den IJssel; Océ Nederland NV, Venlo; Novo Nordisk BV, Alphen aan de Rijn; Lifescan Benelux, Beerse (B); Mrs.A, Venlo

Journals that permitted to reprint the study papers in this thesis: Huisarts en Wetenschap (General Practice \& Science), Patient Education and Counseling

\section{CIP-DATA KONINKLIJKE BIBLIOTHEEK, DEN HAAG}

Dam, Henk A van

Studies and reflections on type 2 diabetes care in general practice. Perspectives of patients and providers

Thesis Maastricht - with references, and a Summary in Dutch

ISBN 12-34567-89-0

NUGI 345/678

(c) 2005, HA van Dam, Venlo/Maastricht

Universiteit Maastricht

Departments of General Practice and Department of Health Education and Counselling

P.O. Box 616, 6200 MD Maastricht

Gezondheidscentrum Withuis, Straelseweg 193, 5914 AL Venlo

Tel. +31-77-3517652, fax +31-77-3589705

e-mail vandam-hylkema@home.nl

Print $A B C$ Venlo 


\title{
Studies and reflections on type 2 diabetes care in general practice. Perspectives of patients and professionals
}

\author{
PROEFSCHRIFT
}

ter verkrijging van de graad van doctor aan de Universiteit Maastricht, op gezag van de Rector Magnificus, Prof.mr.G.P.M.F. Mols, volgens besluit van het College van Decanen, in het openbaar te verdedigen op vrijdag 23 september 2005

door

Hendrik Arie van Dam 


\section{Promotores:}

Prof.dr.H.F.J.M. Crebolder

Prof.dr.H.W. van den Borne

\section{Co-Promotor:}

Dr.F.G. van der Horst

\section{Beoordelingscommissie:}

Prof.dr.A. Nieuwenhuijzen Kruseman (voorzitter)

Prof.dr.G.E.H.M. Rutten (Universiteit Utrecht)

Prof.dr.J. van Eijk

Prof.dr.J. Metsemakers

Prof.dr.P. Curfs 
"An important part of forming collaborative alliances with patients is, to recognize the distinction between practitioner and patient perspectives in type 2 diabetes"

(Clark M, Hampson SE in: Comparison of patients' and healthcare professionals' beliefs about and attitudes towards type 2 diabetes. Diabet Med. 2003;20(2):152-4) 


\section{CONTENTS}

Chapter $1 \quad$ General Introduction (Algemene inleiding) 11

Chapter $2 \quad$ Quality of Life 19

Metabole regulatie, functionele toestand en kwaliteit van leven bij type 2 diabeten: een exploratieve studie (Diabetes control, functional status, and quality of life in type 2 diabetes patients: an exploratory study)

Chapter $3 \quad$ Non-attendance-1

Wegblijvende diabeten - literatuurstudie en raadpleging van

Nederlandse huisarts-deskundigen (Non-attending diabetics - Literature review and interviews of Dutch GP experts)

Chapter $4 \quad$ Non-attendance-2 49

Wegblijven van patiënten met diabetes mellitus type 2 - een echt probleem? (Non-attendance in persons with type 2 diabetes - a real problem?)

Appendix: 69

Commentaren en discussie in ingezonden brieven (Comments and debate in letters to the editor)

Chapter 5 Social support 77

Social support in diabetes - a systematic review of controlled intervention studies (Sociale steun bij diabetes - een systematische review van gecontroleerde interventiestudies)

Chapter 6 Interaction 99

Provider-patient interaction in diabetes care: effects on patient self-care and outcomes - a systematic review (De interactie tussen zorgverlener en patiënt in diabeteszorg: effecten op patiëntenzelfzorg en uitkomsten - een systematisch literatuuronderzoek)

Chapter $7 \quad$ Patient obstacles and expert recommendations 119

Obstacles in the management of type 2 diabetes: the perspectives of patients and experts (Belemmeringen in de aanpak van type 2 diabetes: de perspectieven van patiënten en experts)

Chapter $8 \quad$ Patient-centredness and the dialectical process in diabetes care $\quad 147$

Chapter 9 Discussion 
This thesis is written in two languages. Some of the study papers are in Dutch, some in English. The General Introduction, Patient-centredness and the dialectical process in diabetes care, and Discussion chapters, are in English only. Abstracts of all the studies, and the Summary chapter, are in both languages. Acknowledgements and Curriculum Vitae are in Dutch only.

Dit proefschrift is tweetalig. Sommige studieverslagen zijn in het Nederlands, andere in het Engels. De hoofdstukken Algemene Inleiding, Patiëntgerichtheid en het dialectisch proces in diabeteszorg, alsmede Discussie, zijn alleen in het Engels. De samenvattingen van alle studies, en de algemene Samenvatting, zijn in beide talen. Dankwoord en Curriculum Vitae zijn in het Nederlands.

For reasons of consistency within this thesis, some terms have been standardized throughout the text. As a consequence, in some places the text may differ from the text of the articles as they have been published. E.g. in some chapters the terms 'Non Insulin-Dependent Diabetes', 'NIDDM', or 'Type II diabetes' have been replaced by 'type 2 diabetes'.

Terwille van de samenhang binnen dit proefschrift zijn sommige termen in de tekst gestandaardiseerd. Als gevolg hiervan kan de tekst op enkele plaatsen afwijken van de tekst van de gepubliceerde artikelen. Zo zijn in enkele hoofdstukken de termen 'Non Insulin-Dependent Diabetes', 'NIDDM', of 'Type Il diabetes' vervangen door 'type 2 diabetes'. 
Voor Nelleke, Daan, Liesbeth, Peter, Loes en Hanneke 


\section{CHAPTER 1}

\section{GENERAL INTRODUCTION}

(Algemene inleiding) 


\title{
GENERAL INTRODUCTION
}

\author{
(Algemene inleiding)
}

Type 2 diabetes is a common medical condition, with a prevalence in US and Western European populations, and the Netherlands, of approximately 8 percent in the age group of 50-75 years [1-4]. Both micro- and macrovascular diabetes complications threaten the patient's well-being and quality of life. It may have a great impact on a person's life, his family and other parts of his personal environment.

It is not only the condition's physical symptoms and complications that affect a person's quality of life. Even before complications are present, the burden the condition places upon a patient's daily life will have an impact on his well-being. Because of its chronic and progressive character, diabetes requires gradually increasing medical treatment and lifelong health behaviour changes [5].

Living with the condition, and with the demands that its treatment and management imposes upon one's life, may cause psychological distress. Depression, anxiety, and eating disorders are far more common in persons with diabetes as compared to people without the condition [6-10]. These problems in turn may cause obstacles to good self-care and treatment adherence [11]. In a proportion of the patient group, a vicious circle of long lasting poor diabetes control, diabetes symptoms, complications, and psychological distress occurs. In the long run this might cause patients to drop out from treatment or to experience what is called 'diabetes burnout' [12]. On the average, two out of every three persons with type 2 diabetes show poor adherence to the medication prescription, and about 30 per cent show poor blood glucose and other clinical outcomes' control $[13,14]$.

Type 2 diabetes mellitus has an increasing impact on societies as well as on individuals. Since the early 1990s, it is obvious that type 2 diabetes is becoming a worldwide health problem. The International Diabetes Federation estimated the world wide prevalence to be 194 million in 2004. The World Health Organization forecasted a more than doubling of the prevalence, from 150 million in 2000 to 333 million in 2025 [15-18]. This is frequently referred to as a worldwide 'epidemic' or 'explosion'. In the Netherlands, the epidemic is well underway. The prevalence of diagnosed type 2 diabetes was estimated to be 250,000 (or $1.7 \%$ of the population) in 1990, and 450,000 to $500,000(2.8-3.1 \%$ ) in 2003 , with an annual increase (incidence) of at least 60,000 now [19]. Undiagnosed were 300-400,000 cases in 2003. More active case finding by health care professionals probably boosts the incidence and prevalence numbers. From the total health care budgets of western European countries, 2-7 percent was spent on diabetes care [20]. The average Dutch general practitioner with a patient list of about 2,000 to 2,500, will now have 60 to 100 patients with diagnosed type 2 diabetes in his practice. 
Care, not cure, is the central focus. Most of the management of type 2 diabetes lies in the hands of the patient [21]. Providers need to offer good diabetes care, provide evidence-based lifestyle recommendations and treatment advice, and support selfcare [22-29]. Patients are expected to be responsible for handling the diabetes: taking the medical checks and diabetes education, adapting to having diabetes, and perform good self-care and adherence to treatment in daily life $[25,26]$. Patients and professionals often seem to live in separate health care worlds, and their perspectives, values, and views may widely differ [22, 30-34]

In chronic diseases, relevant patient outcomes not only include statistics on survival and clinical data, but subjective outcomes as well, such as functional status, quality of life, and patient satisfaction [35,36]. These latter subjective patient outcomes may even constitute the most important outcome of diabetes care, as stated by the Dutch Diabetes Federation and the World Health Organization [37,38]. As cure or 'fixing' of diabetes is impossible, care must focus on relief of complaints and improving physical, psychological, and social functioning of the patients. Prevention of late complications and other sequelae from the condition is important, beyond intermediate clinical outcome goals like improved blood glucose, blood pressure, blood lipids, or body weight. This may forge a new paradigm in diabetes care, as ultimately it is the patient himself who decides what he wants from diabetes care and what he is willing to do for it [35,39]

Professional treatment of type 2 diabetes comes down to recommending and supporting lifestyle changes and prescribing medication. The treatment aims at achieving good metabolic (blood glucose) control, as well as control of blood pressure and blood lipids. 'Good control' means that both blood glucose and $\mathrm{HbA} 1 \mathrm{c}$, blood pressure and lipids levels are within the normal or acceptable ranges. There is strong evidence that this can be effective for preventing diabetes complications [24,40-53]. A range of dietary, lifestyle, and medication treatment options is at hand.

Professional providers of diabetes care are expected to have expertise about diabetes, to follow up professional guidelines, to provide patients with regular checks and education, to advise on self-care and lifestyle changes, and to prescribe medication when necessary (care). In acute situations, e.g. when the patient has a hypoglycaemic coma, a heart attack, a sudden loss of vision, or a threatening foot ulcer, the provider is expected to provide acute help and treatment (cure).

Type 2 diabetes is one of the most complex conditions that is managed in general practice in many Western countries such as the UK, Portugal, the Netherlands, and the Scandinavian countries. Up until the 1980s, newly diagnosed patients in the Netherlands usually were referred to hospital specialists, and were treated by them for the rest of their life. Since that time this policy has changed. The so-called 'substitution of care' from hospitals to primary care was urged partly by policy makers and politicians for economic reasons. Hospitals lost their financial interest in the group of patients with type 2 diabetes, as their budgets became maximized. At the same time general practice (GP) has been further professionalized. As a consequence, GP involvement in diabetes care increased enormously [54]. In the Netherlands case-finding and diagnosis nowadays are mainly done by GPs who also 
treat the majority (70-80\%) of people with type 2 diabetes. Hospital admission or referral to outpatient clinics is restricted to persons with serious complications or difficult management of control.

The quality of professional type 2 diabetes care has vastly improved over the past decades. This goes for the biomedical knowledge (of aetiology, risk factors, clinical course, and complications), diagnostic and treatment options (e.g. blood testing, medication) and therapeutic guidelines (lifestyle and self-care, oral medication and insulin, treatment targets), and for education of health care professionals, cooperation of professionals, patient education, and financial arrangements for refunding of laboratory and treatment costs. These improvements brought the diabetes population as a whole better survival rates, and better prevention of some diabetes complications - such as amputations and blindness - as compared to the situation of some decades ago [24,40-48].

Still, even while this improvement is evident, it holds for a proportion of the patient population only $[48,55,56]$. For many, obstacles and barriers still occur $[13,14]$. Cardiovascular morbidity and mortality hardly show improvements over the past decades $[26,48,55,57,58]$. Many questions about diabetes and its treatment have not yet been resolved [22,26,27,59-63]. Will it be possible to improve diabetes control and patient-perceived quality of life by maximizing active patient participation in Dutch primary care-based diabetes care? Greenfield et al demonstrated the power of activating patients in diabetes care almost twenty years ago $[64,65]$.

More than ten years ago we performed a study on metabolic control and quality of life in GP treated type 2 diabetes patients [66]. 'Doctor-oriented' and 'patient-oriented' variables were distinguished, and the relationships between diabetes control $(\mathrm{HbA} 1 \mathrm{c})$, diabetes complications, and comorbidity as registered in the medical records on one hand, and patient reported quality of life, functional status, perceived control and support on the other were studied. One of the tentative conclusions of the study was that patient perceived professional support (from the GP) impacts upon diabetes control. Only nearly half the patient group showed 'objective' good metabolic control (according to the standards at that time), while a much greater part of the patient group reported 'subjective' good control. It was suggested that providers of care should learn more about patients' views and perceptions, and obstacles to diabetes care, relative to the providers' own views and perceptions.

This first study sparked our interest in issues like patient perspective and interactions between patients and providers of diabetes care. Hence, studies of these themes followed and became part of this thesis. We questioned to what extent patient nonattendance in primary diabetes care would exist. Next came reviews of intervention trials of social support and provider-patient interaction, and their effects on patient self-care and diabetes outcomes. Furthermore, we were interested in the obstacles that patients would report regarding patient self-care and professional diabetes care.

The results of these studies stimulated reflection on ways to improve the effectiveness of diabetes care when needed.. A recent paper reflecting on this matter is included in this thesis and pays special attention to the patient's perspective in relation to the provider's, in the context of their mutual interaction [67]. Moreover, it elaborates on patient-centredness, patient empowerment, and an effective dialectical 
process in diabetes encounters. The paper offers elements for a new concept of the patient-provider interaction in (primary) diabetes care [35,39].

The author's scientific interest in the role of patient, provider, and their interactions in diabetes care, started and grew during his work as a family physician in the cities of Rotterdam and Venlo from the early 1970s on, and as a part-time researcher at Maastricht University since 1992.

\section{Outline of the thesis}

A study of the relationships between diabetes control, diabetes complications, and comorbidity as registered in the medical records on one hand, and patient reported quality of life, functional status, perceived control and support on the other, is presented in chapter 2. Aspects of patient non-attendance are studied in two papers (chapters 3 and 4). A systematic literature review on social support interventions in diabetes care is presented in chapter 5 , and a review on patient-provider interaction interventions in chapter 6 . Then follows a study of patient-reported obstacles to selfcare and treatment, and experts' comments and recommendations for improvements (chapter 7). Chapter 8 presents a paper reflecting on patient-centredness and the dialectical features of the patient-provider dialogue in diabetes care.

In Chapter 9 a discussion of the results is presented. Also, some methodological issues, which were not addressed in previous chapters, are put forward. Recommendations with regard to general practice diabetes care, education of professional providers, and further research, are given. A summary chapter (10) gives a comprehensive overview of the thesis. 


\section{References}

1.Mooy JM, Grootenhuis PA, De Vries H, Valkenburg HA, Bouter LM, et al. Prevalence and determinants of glucose intolerance in a Dutch caucasian population. The Hoorn Study. Diabetes Care 1995;18:1270-3.

2.Pogach LM, Hawley G, Weinstock R, Sawin C, Schiebe H, et al. Diabetes prevalence and hospital and pharmacy use in the veterans Health Administration (1994). Use of an ambulatory care pharmacyderived database. Diabetes Care 1998;21:368-73.

3.Harris MI, Flegal KM, Cowie CC, Eberhardt MS, Goldstein DE, et al. Prevalence of diabetes, impaired fasting glucose, and impaired glucose tolerance in U.S. adults. The Third National Health and Nutrition Examination Survey, 1988-1994. Diabetes Care 1998;21:518-24.

4.Berger B, Stenström G, Chang YF, Sundkvist G. The prevalence of diabetes in a Swedish population of 280,411 inhabitants. A report from the Skaraborg Diabetes Registry. Diabetes Care 1998;21:546-8.

5.Östgren CJ, Lindblad U, Ranstam J, Melander A, Rästam L. Glycaemic control, disease duration and betacell function in patients with type 2 diabetes in a Swedish community. Skaraborg Hypertension and Diabetes Project. Diabetic Med 2002;19:125-9.

6.Rubin R, Peyrot M. Psychological issues and treatments for people with diabetes. J Clin Psychol 2001;57:457-78 .

7.Snoek FJ, Skinner TC (eds). Psychology in diabetes care. London: John Wiley \& Sons Ltd 2000. ISBN 0-471-97703-9.

8.Rubin R, Peyrot M Was Willis Right? Thoughts on the interaction of depression and diabetes. Diabet Metabol Res Rev 2002;18:173-5.

9.Pouwer F. Monitoring of psychological well-being in outpatients with diabetes mellitus. Thesis VUMC, Amsterdam 2001.

10.Anderson R, Freedland K, Clouse R, Lustman P. The prevalence of comorbid depression in adults with diabetes. A meta-analysis. Diabetes Care 2001;24:1069-78.

11.De Groot M, Anderson R, Freedland K, Clouse C, Lustman P. Association of depression and diabetes complications: a meta-analysis. Psychosom Res 2001;63:619-30.

12.Polonsky W. Diabetes burnout - what to do when you can't take it anymore. Am Diab Ass, Alexandria 1999.

13.Cramer J. A systematic review of adherence with medication for diabetes. Diabetes Care 2004;27:1218-24.

14. Harris M. Health care and health status and outcomes for patients with type 2 diabetes. Diabetes Care 2000;23:754-58.

15.Zimmet PZ, McCarty DJ, de Courten MP. The global epidemiology of NIDDM and the Metabolic Syndrome. J Diabetes Complic 1997;11:60-8 .

16.King H, Aubert RE, Herman WH. Global burden of diabetes, 1995-2025: prevalence, numerical estimates, and projections. Diabetes Care 1998;21:1414-31.

17.World Health Organisation. The World Health Report: Life in the $21^{\text {st }}$ century, a vision for all. Geneva: WHO 1998.

18.International Diabetes Federation (IDF). Facts and figures available at: http://www.idf.org/home/index.cfm?node=6.

19.Dekker JM, Van der Kraan M, Nijpels G, De Vegt F, Kostense PJ, et al. Schatting van het aantal nieuwe patiënten met diabetes mellitus type 2 in Nederland: ruim 65.000 per jaar in de leeftijdsgroep vanaf 50 jaar. Ned Tijdschr Geneesk 2003;147:1419-23 (Estimate of the number of new patients with type 2 diabetes mellitus in the Netherlands: at least 65,000 per year in the age group of 50 years and above). [In Dutch].

20.Zimmet P. The burden of type 2 diabetes: are we doing enough? Diabetes Metab 2003;29:6S9-18 [Free Full Text/diabetesmetabolism/com].

21.Snoek FJ. Bij hoog en bij laag. Inaugurele rede. Vrije Universiteit/VUMC, Amsterdam 2004.

22. Wolpert HA, Anderson BJ. Management of diabetes. Are doctors framing the benefits from the wrong perspective? Br Med J 2002;323:994-6.

23.Jones $\mathrm{H}$, Edwards I, Vallis TM, et al. Changes in diabetes self-care behaviors make a difference in glycemic control. The Diabetes Stages of Change (DISC) study. Diabetes Care 2003;26:732-7.

24.Pinkney J. Prevention and cure of type 2 diabetes - Weight loss is the key to controlling the diabetes epidemic. Editorial. Br Med J 2002;325:232-3.

25.Peterson KA, Spann SJ. Primary care for patients with type 2 diabetes - moving beyond hyperglycemia. Summary. J Fam Pract 1998;47(Suppl):S63-64. 
26.Koenigsberg MR, Bartlett D, Cramer JS. Facilitating treatment adherence with lifestyle changes in diabetes. Am Fam Phys 2004;69:309-16,323-4

27.Michie S, Miles J, Weiman J. Patient-centredness in chronic illness: what is it and does it matter? Patient Educ Couns 2003;51:197-206 .

28.Balint M. The doctor, his patient and the illness. London: Pitman 1957. (De dokter, de patiënt, de ziekte. Utrecht: Het Spectrum 1975).

29.Bensing JM. Bridging the gap. The separate worlds of evidence-based medicine and patientcentered medicine. Patient Educ Couns 2000;39:17-25 .

30.Ary DV, Toobert D, Wilson W, Glasgow RE. Patient perspectives on factors contributing to nonadherence to diabetes regimens. Diabetes Care 1986;9:168-72

31.Cohen MZ, Tripp-Reimer T, Smith C, Sorofman B, Lively S. Explanatory models of diabetes: patient-practitioner variation. Soc Sci Med 1994;38:59-66.

32.Clark M, Hampson SE. Comparison of patients' and healthcare professionals' beliefs about and attitudes towards type 2 diabetes. Diabet Med 2003;20:152-4.

33.Freeman J, Loewe R. Barriers to communication about diabetes mellitus: patients' and physicians' different views of the disease. J Fam Pract 2000;49:507-12.

34.Garay-Sevilla ME, Malacara JM, Gutiérrez-Roa A, González E. Denial of disease in type 2 diabetes mellitus: its influence on metabolic control and associated factors. Diabet Med 1999;16:23-44.

35.Sullivan M. The new subjective medicine: taking the patient's point of view on health care and healt. Soc Sci Med 2003;1595-1604.

36.Van den Bos GAM, Klop R. Uitkomstindicatoren voor kwaliteitsbewaking van zorg voor chronisch zieken en gehandicapten. Tijdschr Soc Gezondheidsz 1995;73:209-13. (Outcome indicators for quality assurance of care for the chronically ill and disabled). [In Dutch].

37.Nederlandse Diabetes Federatie. Zorgstandaard voor goede diabeteszorg. (Standard of Care for good diabetes care). NDF: Amersfoort 2003 [In Dutch] [Free Full Text/diabetesfederatie.nl].

38.World Health organisation (WHO). The World Health Report. Mental Health: New understanding, new hope. WHO: Geneva 2001.

39.Pawlson LG. Chronic illness: implications of a new paradigm for health care. J Qual Improvem 1994;20:33-9.

40.WHO. Definition, diagnosis and classification of diabetes mellitus and its complications. Part 1 : Diagnosis and classification of diabetes mellitus 1-59. WHO: Geneva 1999.

41.Renders CM, Valk GD, Griffin SJ, Wagner EH, Eijk JThM van, Assendelft WJJ. Interventions to improve the management of diabetes mellitus in primary care, outpatient and community settings. Cochrane Database Systematic Reviews 2001;1:CD001481.

42.De Fine Olivarius $\mathrm{N}$, Beck-Nielsen $\mathrm{H}$, Andreason AH, Hørder M, Pedersen PA. Randomised controlled trial of structured personal care of type 2 diabetes mellitus. $\mathrm{Br}$ Med J 2001;323:970-5.

43.Lauritzen T, Borch-Johnsen K. Multifactorial intervention in the management of type 2 diabetes. Intern Diab Monitor 2004;16:8-14.

44.Gaede $\mathrm{P}$, Vedel $\mathrm{P}$, Larsen N, et al. Multifactorial intervention and cardiovascular disease in patients with type 2 diabetes. N Engl J Med 2003;348:383-93.

45.Lipsky ML, Sharp LK. Preventive Therapy for Diabetes: lifestyle changes and the primary care physician. Editorial. Am Fam Phys 2004;69:269-71.

46.UK Prospective Diabetes Study (UKPDS) Group. Intensive blood glucose control with SU or insulin compared with conventional treatment and risk of complications in patients with type 2 diabetes UKPDS 33). Lancet 1998;352:837-53 .

47.UK Prospective Diabetes Study (UKPDS) Group. Effect of intensive blood glucose control with metformin on complications in overweight patients with type 2 diabetes (UKPDS 34). Lancet 1998;352:854-65 .

48.Shaughnessy AF, Slawson DC. Blowing the wistle on review articles - What should we know about the treatment of type 2 diabetes? Editorial. Br Med J 2004;328:280-2.

49.UK Prospective Diabetes Study (UKPDS) Group. Tight blood pressure control and risk of macrovascular and microvascular complications in type 2 diabetes (UKPDS 38). $\mathrm{Br}$ Med $\mathrm{J}$ 1998;317:703-13.

50.Hansson L, Zanchetti A, Carruthers SG, et al., for the HOT Study Group. Effects of intensive blood pressure lowering and low dose aspirin in patients with hypertension: principal results of the Hypertension Optimal Treatment (HOT) randomised trial. Lancet 1998;351:1755-62 .

51.Pyorala K, Pedersen TR, Kjekshus J, et al. Cholesterol lowering with simvastatin improves prognosis of diabetic patients with coronary heart disease. A subgroup analysis of the Scandinavian Simvastatin Survival Study (4S). Diabetes Care 1997;20:614-20 
52.Antiplatelet Trialists' Collaboration. Collaborative overview of randomised trials of antiplatelet therapy-1. Prevention of death, myocardial infarction, and stroke by prolonged antiplatelet therapy in various categories of patients. Br Med J 1994;308:81-106.

53.Collins R, Armitage J, Parish S, Sleight P, Peto R, for the Heart Protection Study Collaborative Group. MRC/BHF Heart Protection Study of cholesterol lowering with simvastatin in 5963 people with diabetes: a randomized placebo-controlled trial. Lancet 2003;361:2005-16 .

54.Khunti K, Ganguli S, Bakr K, Lowy A. Features of primary care associated with variations in proces and outcome of care of people with diabetes. Br J Gen Pract 2001;51:356-60.

55.Winocour PH. Effective diabetes care: A need for realistic targets. Br Med J 2002:324:1577-80.

56. Hirsch IB. The Burden of diabetes (care). Commentary. Diabetes Care 2003;26:1613-4.

57.Evans JMM, Wang J, Morris AD. Comparison of cardiovacular risk between patients with type 2 diabetes and those who had a myocardial infarction: cross sectional and cohort studies. $\mathrm{Br}$ Med $\mathrm{J}$ 2002;324:939-42.

58.Stevens R, Kothari V, Adler AI, Stratton IM, Holman RR. The UKPDS Risk Engine: a model for the risk of coronary heart disease in type 2 diabetes (UKPDS 56). Clin Sci 2001;101:671-9.

59.Gray RPR, Yudkin JS. Cardiovascular disease in diabetes mellitus. In: Pickup JC, Williams G (Eds). Textbook of diabetes. $2^{\text {nd }}$ Edn. Oxford: Blackwell Sciences Ltd 1997.

60.Rutten GEHM, Verhoeven S, Heine RJ, et al. NHG-Standaard Diabetes Mellitus type 2 (eerste herziening). Huisarts Wet 1999;42:67-84. [in Dutch].

61.Alberti KGMM, Gries FA. Management of non-insulin dependent diabetes mellitus in Europe: a consensus view. Diabet Med 1999;5:275-81.

62.Alberti G. A desktop guide to Type 2 diabetes mellitus. European Diabetes Policy Group 19991989 International Diabetes Federation European Region. Diabet Med 1999;16:716-30.

63. Hunt LM, Pugh J, Valenzuela M. How patients adapt diabetes self-care recommendations in everyday life. J Fam Pract 1998;46:207-15.

64.Greenfield S, Kaplan SH, Ware JE. Expanding patient involvement in care: Effects on patient outcomes. Ann Int Med 1985;102:520-8 .

65.Greenfield S, Kaplan SH, Ware JE Jr, et al. Patients' participation in medical care: effects on blood sugar control and quality of life in diabetes. J Gen Int Med 1988;3:448-57.

66.Van Dam HA, Crebolder HFJM, Van der Grinten RF, Wouters A, Van der Horst FG. Metabole regulatie, functionele toestand en kwaliteit van leven bij type 2 diabeten: een exploratieve studie. (Diabetes control, functional status, and quality of life in type 2 diabetes patients: an exploratory study). Huisarts Wet 1995;38:618-22 (In Dutch). Chapter 2 in this thesis.

67.Van Dam HA, Ryckman RM, Van den Borne HW, Crebolder HFJM, Van der Horst FG. Patientcentredness and the dialectical process in diabetes care. (submitted). Chapter 8 in this thesis. 


\section{CHAPTER 2}

Metabole regulatie, functionele toestand en kwaliteit van leven bij type 2 diabeten: een exploratieve studie in de huisartspraktijk

(Diabetes control, functional status, and quality of life of type 2 diabetics an explorative study in GP) 
Metabole regulatie, functionele toestand en kwaliteit van leven bij type 2 diabeten: een exploratieve studie in de huisartspraktijk

(Diabetes control, functional status, and quality of life of type 2 diabetics an explorative study in GP)

Van Dam HA, Crebolder HFJM, Van der Grinten RF, Wouters A, Van der Horst FG

Reprinted from: Huisarts Wet 1995;38(13):618-22. 


\section{SAMENVATTING}

Bij 116 patiënten met diabetes mellitus type 2 werd de samenhang onderzocht tussen ziekte-/artsfactoren (metabole regulatie/HbA1c, comorbiditeit en complicaties) en patiëntfactoren (functionele toestand/COOP-WONCA, kwaliteit van leven, ervaren regulatie en ervaren gezondheid, ervaren sociale en professionele steun, en achtergrondgegevens). Uit trapsgewijze logistische regressie-analyses blijkt dat alleen de patiëntfactoren 'ervaren regulatie' en 'ervaren professionele steun' (van de huisarts) een onafhankelijke bijdrage leveren aan de metabole regulatie. 'Ervaren regulatie' hing vooral samen met 'functionele toestand' en (veel minder) met 'duur van de ziekte', en 'ervaren professionele steun' met 'type behandelaar' (huisarts). Bij de huisartsenzorg voor type 2 diabeten lijkt expliciete aandacht voor elementen uit het referentiekader van de patiënt essentieel. Gesuggereerd wordt om dit op te nemen in de nationale NHG-Standaard over type 2 diabetes.

\section{ABSTRACT}

The interrelations between disease/doctor related factors and patient related factors were studied in a population of 116 GP-patients with type 2 diabetes mellius. Disease/doctor related factors: diabetes control (HbA1c), comorbidity, and complications. Patient related factors: functional status (COOP/WONCA), quality of life score, perceived diabetes control, perceived health, perceived social and professional (GP) support, and general background data. Exploratory study on data from questionnaire, laboratory tests and other data from medical records. Stepwise logistic regression analysis showed that only the patient related factors 'perceived diabetes control' (odd's ratio 3.15) and 'perceived professional support' (odd's ratio 4.59) independently contributed to diabetes control. 'Perceived diabetes control' independently contributed to functional status (odd's ratio 4.82) and (much less strong) to duration of type 2 diabetes (odd's ratio 1.08); 'perceived professional support' to type of professional (GP) (odd's ratio 5.60). In GP care for patients with type 2 diabetes, explicit attention to patient related factors is essential. It is suggested that the national NHG-guideline on type 2 diabetes should incorporate this view.

Key words: Diabetes mellitus, Non-insulin-dependant; Family practice; Functional status; Quality of life. 


\section{Inleiding}

Bij de begeleiding van type 2 diabeten staat het bereiken en handhaven van een aanvaardbaar bloedsuikergehalte centraal [1,2]. Ondanks de inspanningen van de behandelaars blijkt echter een groot deel van de patiënten niet adequaat gereguleerd [3-6].

Bij het opsporen van de factoren die de regulatie mede bepalen, kan men uitgaan van het referentiekader van de arts of van de patiënt. Bij artsen gaat het voornamelijk om het bloedsuikergehalte en om secundaire complicaties $[7,8]$. Patiënten plaatsen de diabetes primair in de context van hun dagelijks leven; voor hen staan de functionele toestand en de kwaliteit van leven op de voorgrond $[9,10]$.

Die verschillende percepties werken door in het verloop van consulten. Ze blijken ook van grote invloed op de compliantie [12-15]. Gesteld wordt dat psychosociale begeleiding door de hulpverlener noodzakelijk is, voordat de patiënt ontvankelijk kan zijn voor theoretische en praktische informatie [16,17].

Eerder werd gevonden dat de relatie tussen enerzijds de bloedsuikerregulatie of het hebben van complicaties, en anderzijds het welbevinden of de functionele toestand van de patiënt, niet sterk is. $[8,18]$ De patiënt geeft vaak pas informatie over de belemmeringen die de ziekte voor zijn dagelijks functioneren betekent, wanneer daar expliciet door de arts naar wordt gevraagd; huisartsen doen dat vaak niet $[10,18]$.

Uit het voorafgaande wordt niet duidelijk in hoeverre afstemming van de diabetesbehandeling op de emotionele beleving, de functionele toestand en de ervaren kwaliteit van leven van de patiënt van invloed kan zijn op de compliantie en daarmee op de bloedsuikerregulatie. Er blijkt behoefte aan studies in deze richting [19]. En als geen ander is de huisarts in de gelegenheid het referentiekader van de arts af te stemmen op het referentiekader van de patiënt; hij vervult als het ware een scharnierfunctie tussen de wereld van de patiënt en die van de medische professie [20].

Deze overwegingen hebben geleid tot de volgende vraagstelling:

In hoeverre is er bij type 2 diabeten een samenhang tussen enerzijds artsfactoren als metabole regulatie, complicaties en comorbiditeit, en anderzijds patiëntfactoren als functionele toestand, kwaliteit van leven, door de patiënt ervaren regulatie en gezondheid, en ondervonden sociale en professionele steun?

\section{Methode}

Gekozen werd voor een transversale, exploratieve onderzoeksopzet. Het onderzoek vond plaats in 1993 binnen een tijdsbestek van zes weken in de vijf huisartspraktijken van het gezondheidscentrum Withuis te Venlo ( $n=9.600)$. In het kader van het Registratienet Huisartspraktijken (RNH)[21] is voor alle patiënten een gestandaardiseerde Probleemljst beschikbaar, die voortdurend up-to-date wordt gehouden. Aan de hand hiervan konden patiënten die langer dan een jaar bekend zijn met type 2 diabetes (volgens criteria van de NHG-standaard) worden geïdentificeerd.

Alle type 2 diabeten die aldus werden opgespoord, ontvingen een brief waarin de eigen huisarts het onderzoek toelichtte en verzocht om deelname. Aan patiënten die 
instemden, werd vervolgens een vragenlijst gestuurd en werd toestemming gevraagd informatie uit het medisch dossier te mogen verzamelen.

De te onderzoeken variabelen zijn als volgt geoperationaliseerd.

- Artsfactoren. Voor het vaststellen van de metabole regulatie is het gemiddelde berekend van de laatste twee in de vooraf gaande twaalf maanden bepaalde percentages geglycosileerd hemoglobine-c $(\mathrm{HbA} 1 \mathrm{c})$. Op groepsniveau bestaat er een sterke relatie tussen nuchtere bloedsuikerwaarden en HbA1c [22]. Deze laatste parameter wordt meer en meer beschouwd als de gouden standaard; hij geeft informatie over de gemiddelde bloedsuikerwaarde gedurende de voorafgaande twee tot drie maanden. In eerste instantie hanteerden wij een driedeling: 'goed' $\leq 8$ procent, 'matig' 8,1-10 procent en 'slecht' $>10$ procent. Ten behoeve van de regressieanalyses werd een tweedeling gemaakt: 'goed' $\leq 8$ procent en 'slecht' $>8$ procent.

Naast de min of meer specifieke diabetescomplicaties (retinopathie, neuropathie, nefropathie, diabetische voet), zijn aspecifieke aandoeningen als hart- en vaatziekten tot de complicaties van diabetes gerekend.

Als comorbiditeit die kan leiden tot verminderde functionele toestand en kwaliteit van leven zijn geregistreerd: artrotische en reumatische aandoeningen, hartfalen, kanker, longfunctiestoornissen, dementie, depressie, ziekte van Parkinson, CVA en problemen met overlijden van partner in het voorafgaande jaar.

- Patiëntfactoren. De 'functionele toestand' werd bepaald aan de hand van de eerste vier COOP/WONCA-kaarten [23,24], die betrekking hebben op de functionele gevolgen van de ziekte; de overige twee COOP/WONCA-vragen werden niet gebruikt omdat ze gericht zijn op een algemene beoordeling van de gezondheidstoestand.

De ervaren 'kwaliteit van leven' gedurende de voorafgaande maand kon door de patiënt worden weergegeven door het plaatsen van een kruis op een horizontale scorelijn van $100 \mathrm{~mm}$ lengte: de 'visual analogue scale', met aan het linker einde de slechtst mogelijke, en rechts de best mogelijke kwaliteit van leven [25].

De 'ervaren diabetesregulatie' en de 'ervaren gezondheid' werden door de patiënt gescoord op een vijfpuntsschaal $[26,27]$. De ondervonden 'sociale steun' werd vastgesteld aan de hand van vragen naar de ervaren praktische en emotionele steun door de mantelzorg: partner, kinderen, familie. De 'ervaren professionele steun' werd bepaald aan de hand van vragen naar de ondervonden praktische en emotionele steun door de huisarts. Steeds kon gescoord worden op een vijfpuntsschaal [28].

Als achtergrondvariabelen zijn geregistreerd: leeftijd, geslacht, opleiding (drie niveaus) en aantal huisgenoten; voorts de duur van de diabetes, de behandelwijze (dieet, tabletten of insuline) en het type behandelaar (huisarts of internist).

Voor de statistische bewerkingen is gebruik gemaakt van het computerprogramma BMDP [29]. Bivariate samenhangen zijn bepaald met Spearman rangcorrelaties [30]. Om de onafhankelijke bijdragen van variabelen aan de metabole regulatie te bepalen, werd een logistische regressie-analyse uitgevoerd [31]. Een test van de interne consistentie van te clusteren variabelen - zoals onder meer de vier COOP/WONCA-vragen - is verricht met behulp van de Cronbach's alfatoets [32]. 


\section{Resultaten}

Er waren 205 personen geregistreerd met de diagnose diabetes mellitus, van wie 173 met type 2 diabetes. Zeven personen bleken overleden, tweemaal was de diagnose diabetes op onjuiste gronden gesteld, en bij één patiënt was de diagnose korter dan een jaar bekend.

Op het schriftelijk verzoek om medewerking aan de resterende 163 personen reageerden er 21 negatief, van wie velen met een expliciete reden als 'te ziek', 'geen behoefte', 'geen tijd'. Daarom is afgezien van het verzamelen van verdere gegevens over deze groep.

De vragenlijst werd vervolgens toegezonden aan de 142 niet-weigeraars, van wie er 116 de lijst ingevuld terugstuurden. De respons was derhalve 71 procent (116 van 142). Tabel 1 geeft de achtergrondgegevens van de respondenten.

Opvallend is dat patiënten de regulatie vaker als 'goed' beoordeelden dan feitelijk het geval was (tabel 2). Bij de helft van de populatie waren geen complicaties geregistreerd en bij meer dan 60 procent geen comorbiditeit. De functionele toestand werd vaker als 'goed' beoordeeld dan kwaliteit van leven (respectievelijk 64 en 37 procent). Ongeveer de helft beoordeelde de eigen gezondheid als 'goed'. Eenderde noemde de sociale en professionele steun 'goed'.

De correlatie van de metabole regulatie met de overige variabelen was zwak (tabel 3, $\mathrm{r}<0,30$ ). Comorbiditeit had sterkere correlaties met functionele toestand, kwaliteit van leven en ervaren gezondheid dan complicaties. De functionele toestand hing sterk samen met ervaren gezondheid en kwaliteit van leven.

De hoogte van het $\mathrm{HbA} 1 \mathrm{c}$ bleek alleen enige samenhang te hebben met de behandelwijze (insuline) (tabel 4). Het hebben van complicaties hing samen met leeftijd, duur van de diabetes en type behandelaar (internist). Comorbiditeit hing alleen samen met leeftijd. De functionele toestand was slechter bij een hogere leeftijd en beter bij een groter aantal huisgenoten. De kwaliteit van leven verbeterde ook bij meer huisgenoten, zij het minder sterk.

Het aantal complete datasets dat voor tabel 5 gebruikt is, bleek minder dan 80 te zijn. $\mathrm{Bij}$ de eerste regressie is de metabole regulatie (grenswaarde 8 procent) ingevoerd als afhankelijke variabele. De ervaren regulatie en ervaren professionele steun (van de huisarts) bleken een onafhankelijke bijdrage te leveren aan de variantie van de metabole regulatie (Odd's ratio resp. 3.15 en 4.59). Bij de tweede stap werden deze twee variabelen elk als afhankelijke variabele onderworpen aan een volgende regressieanalyse. Daarin bleken twee andere patiëntfactoren onafhankelijk bij te dragen aan de ervaren regulatie: functionele toestand (Odd's ratio 4.82) en (veel minder sterk) duur van de diabetes (Odd's ratio 1.08). Aan ervaren professionele steun deed type behandelaar (huisarts) dat (Odd's ratio 5.60).

\section{Beschouwing}

De gevonden prevalentie van 1,7 procent, de leeftijds- en geslachtsverdeling en duur van de ziekte zijn conform de verwachtingen [33]. Ten aanzien van de groep nonrespondenten is, gezien de redenen tot weigeren, de veronderstelling gerechtvaardigd dat deze gemiddeld een slechtere gezondheid had. Hiermee dient bij de interpretatie van de resultaten rekening te worden gehouden. 
Het antwoord op de vraagstelling van deze studie luidt, dat de patiëntfactoren 'ervaren regulatie' en 'ervaren professionele steun' een duidelijke samenhang tonen met de kwaliteit van de metabole regulatie. Op zijn beurt blijkt de ervaren regulatie vooral samen te hangen met de functionele toestand en in mindere mate met de duur van de diabetes; de ervaren steun van de huisarts hangt vooral af van het type behandelaar (huisarts). Andere - door ons niet onderzochte - variabelen kunnen overigens ook van invloed zijn geweest. Te denken valt aan de kwaliteit van de artspatiëntrelatie, en aan opvattingen, kennis, zelfvertrouwen, angst en ontvankelijkheid voor complicaties bij de patiënt [34].

Wat betekent dit alles voor de dagelijkse praktijk? De bevindingen onderstrepen dat expliciete aandacht voor wat wij patiëntfactoren noemen een vaste plaats verdient in de professionele begeleiding van type 2 diabeten. Stelselmatig vragen naar hoe de patiënt zijn regulatie inschat, en beoordelen van de functionele toestand, zouden in het consult kunnen worden meegenomen. Ook zou gevraagd moeten worden naar de ervaringen met de professionele steun, om deze eventueel te kunnen bijstellen. Het verdient overweging de NHG-standaard in de hier aangegeven richting aan te passen, en studies naar toepassingsmogelijkheden en effecten van een dergelijk beleid uit te voeren.

\section{Dankbetuiging}

Wij danken Karin Aretz, V. Schrijnemaekers en Paula Rinkens, research-assistenten, voor het uitvoeren van de statistische bewerkingen, en de centrumassistenten Sonja Kuypers en Toos van Gerwen voor hun hulp bij het verzamelen van meetgegevens betreffende de metabole regulatie van de patiënten. 
Tabel 1 De onderzoekspopulatie. Percentages, tenzij anders aangegeven $(n=116)$

\begin{tabular}{|c|c|c|c|}
\hline Geslacht & & Duur diabetes & \\
\hline - Man & $45 \%$ & - Gemiddeld & $9,4 \mathrm{jr}$ \\
\hline - Vrouw & $55 \%$ & - Spreiding & $1-35 \mathrm{jr}$ \\
\hline Leeftijd (jaren) & & - Duur 1-2jr & $16 \%$ \\
\hline - Gemiddeld & $66,7 \mathrm{jr}$ & - Duur 3-10jr & $53 \%$ \\
\hline - Spreiding & $28-91 \mathrm{jr}$ & - Duur >10jr & $31 \%$ \\
\hline - Leeftijd <60 & $25 \%$ & Behandelaar & \\
\hline$-60-69$ & $36 \%$ & - Huisarts & $71 \%$ \\
\hline$-\geq 70$ & $40 \%$ & - Internist & $23 \%$ \\
\hline $\begin{array}{l}\text { Aantal } \\
\text { huisgenoten }\end{array}$ & & - Huisarts + Intern. & $5 \%$ \\
\hline 0 & $28 \%$ & - Geen & $1 \%$ \\
\hline 1 & $52 \%$ & Behandelwijze & \\
\hline$>1$ & $20 \%$ & - Dieet & $23 \%$ \\
\hline Opleiding & & - Tabletten & $52 \%$ \\
\hline - LO & $68 \%$ & - Insuline & $25 \%$ \\
\hline$-\mathrm{VO}$ & $29 \%$ & & \\
\hline -HBO/Academisch & $4 \%$ & & \\
\hline
\end{tabular}


Tabel 2 Frequentieverdeling van arts/ziekte- en patiëntfactoren. Percentages $(n=116)$

\begin{tabular}{|l|l|l|l|}
\hline & Goed & Matig & Slecht \\
\hline Arts-/ziektefactoren & & & \\
\hline 1 Regulatie (HbAlc) & 45 & 37 & 18 \\
\hline 2 Complicaties & 49 & 38 & 13 \\
\hline 3 Comorbiditeit & 63 & 21 & 16 \\
\hline Patiëntfactoren & & & \\
\hline 4 Functionele toestand (COOP 1-4) & 64 & 15 & 21 \\
\hline 5 Kwaliteit van leven & 37 & 31 & 32 \\
\hline 6 Ervaren regulatie & 68 & 27 & 5 \\
\hline 7 Ervaren gezondheid & 53 & 39 & 8 \\
\hline 8 Sociale steun & 34 & 38 & 28. \\
\hline 9 Professionele steun & 37 & 26 & 37 \\
\hline
\end{tabular}

HbAlc: goed <8\%; matig 8,1-10\%; slecht $>10 \%$. Complicaties en Comorbiditeit: 'goed' 0 ; 'matig' 1; 'slecht' >1 
Tabel 3 Kruistabel van bivariate Spearman rangcorrelaties tussen de arts- en patiëntfactoren $(n=116)$.

\begin{tabular}{|c|c|c|c|c|c|c|c|}
\hline & 1. MR & 2. CO & 3. CM & 4. $\mathrm{FT}$ & 5. KL & 6. ER & 7. EG \\
\hline \multicolumn{8}{|l|}{$\begin{array}{l}\text { Arts- en } \\
\text { ziektegerichte } \\
\text { factoren }\end{array}$} \\
\hline $\begin{array}{l}\text { 1. Metabole } \\
\text { regulatie (MR) }\end{array}$ & - & .14 & .13 & $.26^{*}$ & .18 & $.20^{*}$ & $.28^{*}$ \\
\hline $\begin{array}{l}2 . \\
\text { Complicaties } \\
\text { (CO) }\end{array}$ & - & - & $.22^{*}$ & $.23^{*}$ & $-.18^{*}$ & -.11 & $-.26^{*}$ \\
\hline $\begin{array}{l}3 . \\
\text { Comorbiditeit } \\
\text { (CM) }\end{array}$ & - & - & - & $-.36^{*}$ & $-.31^{*}$ & .17 & $-.30^{*}$ \\
\hline \multicolumn{8}{|l|}{ Patiëntfactoren } \\
\hline $\begin{array}{l}\text { 4. Functionele } \\
\text { toestand (FT) }\end{array}$ & - & - & - & - & $.38^{*}$ & $.26^{*}$ & $.58^{*}$ \\
\hline $\begin{array}{l}\text { 5. Kwaliteit van } \\
\text { Leven (KL) }\end{array}$ & - & - & - & - & - & $.21^{*}$ & $.47^{*}$ \\
\hline $\begin{array}{l}\text { 6. Ervaren } \\
\text { Regulatie (ER) }\end{array}$ & - & - & - & - & - & - & $.17^{\wedge}$ \\
\hline $\begin{array}{l}\text { 7. Ervaren } \\
\text { gezondheid } \\
\text { (EG) }\end{array}$ & - & - & - & - & - & - & - \\
\hline
\end{tabular}

${ }^{*} \mathrm{p}<0.05 . \wedge 0.05<\mathrm{p}<0.10$ 
Tabel 4 Correlatietabel van bivariate Spearman rangcorrelaties van enerzijds de artsfactoren en anderzijds achtergrondvariabelen en sociale en professionele steun $(n=116) p<0.05:$ t $0.05<p<0.10$

\begin{tabular}{|l|l|l|l|l|l|l|l|}
\hline & 1 & 2 & 3 & 4 & 5 & 6 & 7 \\
& MR & CO & CM & FT & KL & ER & EG \\
\hline Leeftijd & -.15 & $34^{*}$ & $.29^{*}$ & & -.13 & .02 & .11 \\
\hline Geslacht & .05 & .02 & -.04 & -.16 & .07 & .06 & .01 \\
\hline Aantal huisgenoten & .06 & -.16. & -.04 & $.32^{*}$ & $.23^{*}$ & .09 & $17 f$ \\
\hline Opleiding & .06 & -.13 & -.05 & .11 & .05 & .06 & .10 \\
\hline Duurdiabetes & .15 & $.28^{*}$ & .02 & -.19 & -.09 & -.16 & .15 \\
\hline Behandelwijze & $.21^{*}$ & $.17^{*}$ & .04 & .07 & .17 & .11 & .02 \\
\hline Behandelaar & .13 & $.27^{*}$ & .06 & .11 & -.01 & .12 & .12 \\
\hline Sociale steun & .02 & .04 & .14 & .05 & -.10 & -.10 & .04 \\
\hline Professionele steun & .05 & .01 & .12 & -.10 & -.16 & & -.01 \\
\hline
\end{tabular}


Tabel 5 Twee opeenvolgende, stap gewijze, logistische regressie-analyses: (7) Metabole regulatie op alle andere variabelen; vervolgens (2) de twee meest aan de metabole regulatie con tribuerende variabelen op do overige. Odd's Ratio's OR (en 95\% Betrouwbaarheidsinterval BI)

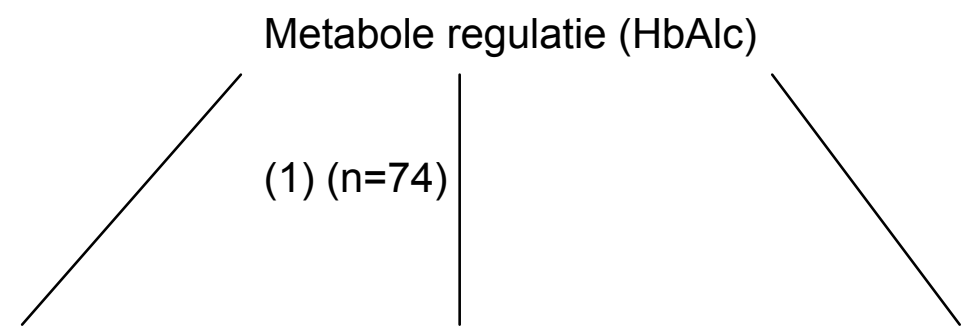

Ervaren regulatie

Constante

Professionele steun

$\mathrm{OR}=3.15(\mathrm{Bl}: 1.02-9.74)$

$\mathrm{OR}=0.13(\mathrm{BI}: 0.03-0.52) \quad \mathrm{OR}=4.59(\mathrm{BI}: 1.40-15.0)$

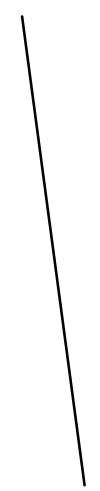

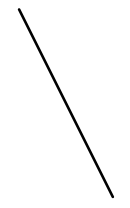

Functionele toestand

$\mathrm{OR}=4.82$

(BI: 1.56-14.90)

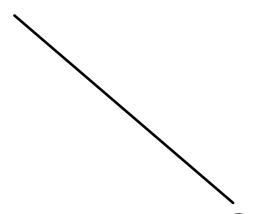

Constante

$\mathrm{OR}=0.37$

(BI: 0.11-1.20)

(2) $(n=79)$
Duur diabetes

$\mathrm{OR}=1.08$

(BI: 1.01-1.16)

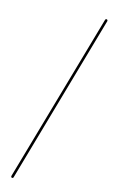

Constante $\mathrm{OR}=0.71$

(BI: 0.31-1.63)

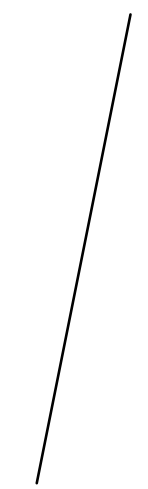

Behandelaar

$\mathrm{OR}=5.60$

(BI: 1.93-16.20) 


\section{Literatuur}

1 Cromme PVM, Mulder Dzn .JD, Rutten GEHM, Zuidweg J. Diabetes Mellitus Type II. Huisarts Wet 1989;32:15-8.

2 World Health Organization - International Diabetes Federation Europe. Diabetes care and research in Europe: The St. Vincent Declaration. Diabetic Med 1990;7:360.

3 Crebolder HFJM. Diabetes mellitus type II. De kwaliteit van de behandeling door de huisarts. Diab Prakt 1990;3(3):4-6.

4 Koch JLM. Effectiviteit van educatie en systematische huisartscontrole van diabetespatiënten. Een onderzoek in enkele huisartspraktijken. Nijmegen: Katholieke Universiteit Nijmegen, 1992.

5 Reenders K, Rutten GEHM, De Nobel E, et al. Met de standaard als maatstaf. Diagnostiek en behandeling van diabetes mellitus in 19 huisartspraktijken. Huisarts Wet 1990;33:379-83.

6 Rutten GEHM, Van Eijk JThM, Beek M, Van der Velden HGM. De type-II diabeet: hoe staat het ermee? Een explorerend onderzoek in acht huisartspraktijken. Huisarts Wet 1988;31:124-9.

7 Nathan DM. Medical progress: long-term complications of diabetes mellitus. N Engl J Med 1993;328:1676-85.

8 Reenders K. Complicaties van niet-insuline-afhankelijke diabetes mellitus in de huisartspraktijk. [Dissertatie]. Nijmegen: Katholieke Universiteit Nijmegen, 1992.

9 Van der Horst FG. Meulders W. Een beetje suiker. Een onderzoek onder oudere diabetespatiënten. Tweede, gedeeltelijk herziene uitgave. Maastricht: Rijksuniversiteit Limburg, 1982.

10 Verhoeven S. Behandeling, controle en metabole instelling van patiënten met diabetes mellitus type II, en de prevalentie van late complicaties bij deze patiënten [Dissertatie]. Rotterdam: Erasmus Universiteit Rotterdam, 1989.

11 Stimson 0, Webb B. Going to see the doctor. Consultation process in general practice. London/Boston: Routledge \& Kegan Paul, 1975.

12 DiMatteo MR, DiNicola DD. Achieving patient compliance. The psychology of the medical practitioner role. New York: Pergamon Press, 1982.

13 Visser AP, Gulikers HDW, Kok GJ, et al. Determinanten van het afwijken van het dieetadvies bij type II diabeten. Implicaties voor patiënten-educatie. Tijdschr Soc Gez

1991;69:177-83.

14 Gordon D, Fisher SG, Wilson M, et al. Psychological factors and their relationship to diabetes control. Diabetic Med 1993;10:530-4.

15 Hulka BA, KupperLL, Cassel JC, Mayo F. Doctor-patient communication and outcomes among diabetic patients. J Community Health 1975;1:15-27.

16 Kok GJ. Sociaal-psychologische aspecten van patiëntenvoorlichting. In: Cuisinier MCJ, et al., red. Patiëntenvoorlichting in de eerste lijn. 's-Gravenhage, 1989.

17 Van der Horst FG, et al. Compliance en patiëntenvoorlichting. In: Demoiseaux V, et al., red. Patiëntenvoorlichting, een interdisciplinaire benadering. Assen: Van Gorcum, 1987.

18 Crebolder HFJM, Van der Horst FG, Seegers G. Klachten van type II diabeten in relatie tot bloedsuikerwaarden en overgewicht. Huisarts Wet 1990;33:384-7.

19 Sowden AJ, Sheldon TA, Alberti G. Shared care in diabetes. Better evaluation is needed. BMJ 1995;310(3):142-3.

20 Freidson E. Patients' views of medical practice. New York: Russell Sage, 1961.

21 Metsemakers JFM, Höppener JA, Kocken RJJ, Limonard CBG. Computerised health information in the Netherlands. A registration network of family practices. Br J Gen Pract 1992;42:102-6.

22 Nathan DM, SingerDE, Flurxthal K, Good son JD. The clinical information value of the glycosilated hemoglobin assay. N Engl JMed 1984;310:341-6.

23 Nelson EC, Wasson J, Kirk J, et al. Assessment of function in routine clinical practice: Description of the COOP chart method and preliminary findings. J Chron Dis 1987;40(Suppl):55-63. 
24 Van Weel C, Scholten JHG. De Dartmouth COOP Functional Health Assessrnent Charts/WONCA. Een eenvoudig instrument om de functionele toestand van patiënten in de huisartspraktijk te meten. Huisarts Wet 1992;35:376-80.

25 De Haes JCJM. Kwaliteit van leven van kankerpatiënten [Dissertatie]. Leiden:

Rijksuniversiteit Leiden, 1988.

26 Van der Horst FG. Gezondheid en niet werken. Maastricht: Rijksuniversiteit Limburg, 1988.

27 Van der Horst FG. Effecten van een diabetesspreekuur op de gezondheid, en de rol van het zelfbeeld. Tijdschr Soc Geneeskd 1985;14:605-9.

28 De Witte LP. After the rehabilitation center. A study into the course of functioning after discharge from rehabilitation [; Maastricht: Rijksuniversiteit Limburg, 1991.

29 Dixon WJ, Broun HB, Engelmann L, Jennrich RI. BMDP. Statistical software manual. Berkeley: University of California Press, 1990.

30 Van Houwelingen JC, Stijnen Th, Van Strik R. Inleiding tot de medische statistiek. Utrecht: Bunge, 1993:189-93.

31 Hosmer DW, Lemeshow S. Applied logistic regression. New York: John Wiley and Sons, 1989:82.

32 Van Breukelen GJP. Analyse van vragenlijsten: betrouwbaarheid en interne consistentie. Statistisch Bulletin van de Vakgroep Methodologie en Statistiek, Rijksuniversiteit Limburg. Maastricht, 1995.

33 Van de Lisdonk EH, Van den Bosch WJHM, Huygen FJA. Lagro-Janssen ALM. Ziekten in de huisartspraktijk. Utrecht: Bunge, 1990.

34 Van Ballegooie E, Heine RJ, red. Diabetes mellitus. Utrecht: Bunge, 1991. 


\section{CHAPTER 3}

\section{Wegblijvende diabeten - literatuuronderzoek en raadpleging van Nederlandse huisarts-deskundigen}

(Non-attending diabetes patients - A literature review, and consultation of

Dutch experts) 


\section{Wegblijvende diabeten - literatuuronderzoek en raadpleging van Nederlandse huisarts-deskundigen}

(Non-attending diabetes patients - A literature review, and consultation of Dutch experts)

HA van Dam,HFJM Crebolder, S Külcü, S van Veenendaal, FG van der Horst

Reprinted from: Huisarts Wet 1998;41(1):10-5 


\section{SAMENVATTING}

Inleiding. Wegblijven van controle en behandeling van diabeten is een fenomeen waarover, ook in Nederland, veel onduidelijkheid bestaat.

Methode. Om het vóórkomen, de achtergronden en de gevolgen van dit fenomeen te onderzoeken, werd een literatuuronderzoek uitgevoerd en werden Nederlandse huisarts-deskundigen geraadpleegd.

Resultaten. Het literatuuronderzoek over de voorafgaande 15 jaar, vond tien publicaties over poliklinische populaties van type 1- en type 2 diabeten en slechts één studie over diabeten in de huisartspraktijk. Wegblijven van diabeten heeft hierin een spreiding tussen 1 en 44 procent. Er worden uiteenlopende en tegenstrijdige kenmerken en motieven van wegblijvers vermeld. De huisarts-deskundigen noemden wegblijfpercentages tussen 0 en 17 procent, gemiddeld ongeveer 5 procent. Het absolute aantal wegblijvende type 2 diabeten was per huisartspraktijk relatief gering (0-6 personen), maar in heel Nederland gaat het waarschijnlijk om tienduizend patiënten die een jaar of langer wegblijven van controle. Bij nieuw ontdekte diabeten met alleen een voedingsadvies lijkt de kans op wegblijven groter.

Conclusie. Nader onderzoek is gerechtvaardigd om te kunnen beoordelen of wegblijven wel een reëel gezondheidsprobleem is en of, waarom, wanneer en hoe er iets tegen ondernomen zou moeten worden.

\section{ABSTRACT}

Introduction. There is much unclearity - also in the Netherlands - about the phenomenon of non-attendance of people with diabetes.

Methods. To study its prevalence, backgrounds, and possible effects, a literature search was executed, and Dutch GP diabetes experts were interviewed.

Results. The literature search, covering the preceding 15 years, retrieved ten publications about studies in hospital outpatients (type 1 and type 2 diabetes), and only one study in general practice. In these studies, the range of non-attendance frequencies was 1 to 44 per cent, and differing and sometimes contradictory characteristics of non-attending patients were presented. Dutch GP diabetes experts estimated frequencies from 0 to 17 percent, with a mean of 5 . The absolute number of non-attending persons with type 2 diabetes per GP is low (0-6 persons), but their total national number might amount to ten thousand. The chance of non-attendance seems higher in newly diagnosed patients with only dietary treatment.

Conclusion. Further research is warranted - to judge whether non-attendance is a real health problem and if, why, when and how interventions against it should be undertaken. 


\section{Inleiding}

Diabetes mellitus type 2 wordt in Nederland gerekend tot de aandoeningen die door de huisarts gecontroleerd en behandeld kunnen worden. Betrokkenheid van de patiënt en samenwerking tussen behandelaar en patiënt is hierbij vereist. Aan een goede diabeteszorg dragen aan de kant van de huisarts deskundigheid, interesse, adequate voorlichting en een goede praktijkorganisatie bij, en aan de kant van de patiënt kennis, inzicht, motivatie en therapietrouw. Aan beide aspecten van deze zorg blijkt vaak het een en ander te mankeren.

In veel huisartspraktijken kunnen organisatie en inzet voor een optimale diabeteszorg worden verbeterd [1-3]. Non-compliantie bij de patiënt kan een belangrijke oorzaak zijn van een niet-optimale metabole regulatie [4]. Dit roept vragen op, onder meer over de afstemming van verantwoordelijkheden tussen behandelaar en patiënt, en over de kwaliteit van de communicatie en werkrelatie tussen arts en patiënt [5-7]. De NHG-Standaard 'Diabetes Mellitus type II' geeft als richtlijn een controlefrequentie van eens per drie maanden - of vaker wanneer nodig - met een uitgebreidere controle eenmaal per jaar. Op basis van deze richtlijn is één consult per jaar bij de (huis)arts een absoluut minimum. Het missen van een of twee afspraken door vergeetachtigheid, door een onduidelijk systeem van vervolgafspraken of door andere gezondheidsproblemen is bij type 2 diabeten in de huisartspraktijk echter niet ongewoon.

Het gedurende langere tijd wegblijven van controles en behandeling is een speciale vorm van non-compliantie, die wel 'non-attendance' wordt genoemd. Wij stellen als vertaling het Nederlandse woord 'wegblijven' voor. Dit houdt in dat de patiënt gedurende langere tijd niet terugkomt voor een - noodzakelijk geachte - controle en behandeling.

Nog niet eerder is onderzocht in welke mate het fenomeen wegblijven voorkomt, en in hoeverre het een probleem oplevert voor de gezondheidstoestand van diabeten.

Aangenomen mag worden dat meer inzicht hierin van nut kan zijn bij de individuele en collectieve benadering van deze patiënten en bij de organisatie van de zorg. Deze vaststelling heeft geleid tot de volgende vraagstellingen:

- In welke omvang doet het fenomeen wegblijven zich voor bij (type 2) diabeten?

- In hoeverre onderscheiden wegblijvers zich van andere patiënten? Gaat het hier om een aparte groep? Onttrekken zij zich bewust aan professionele hulp? Wat zijn hun motieven?

- Lopen deze wegblijvers extra gezondheidsrisico's?

- Welke adviezen en maatregelen worden voorgesteld om (de gevolgen van)

wegblijven tegen te gaan?

\section{Methoden}

Voor het onderzoek zijn twee zoekstrategieën gevolgd.

Eerst is een literatuuronderzoek uitgevoerd. Via Medline werd over de periode januari 1980 t/m maart 1996 naar artikelen gezocht met als zoektermen '(non-)attendance', '(non-)adherence' en 'no-show'. In een tweede ronde werden deze termen gebruikt in 
combinatie met 'diabetes mellitus (type 2/NIDDM)'. Via literatuurreferenties bij de gevonden artikelen werd verder gezocht. Voorts werden de indices van Huisarts en Wetenschap en The Practitioner/Tijdschrift voor Huisartsgeneeskunde geraadpleegd over de periode januari $1984 \mathrm{t} / \mathrm{m}$ maart 1996 op basis van dezelfde zoektermen. De kwaliteit van de gevonden literatuur is beoordeeld aan de hand van de volgende criteria: relevantie voor de huisartspraktijk, hypothese, studie-opzet, patiëntenselectie, respons, statistische analyse en interne consistentie.

Vervolgens is een aantal Nederlandse huisarts-diabetesdeskundigen geraadpleegd van wie bekend was dat zij konden beschikken over relevante informatie. Deze raadpleging vond plaats door middel van een kort, gestructureerd interview (telefonisch of schriftelijk). De voorgelegde vraag was: beschikt u over kwantitatieve en kwalitatieve gegevens betreffende het gedurende 12 maanden of langer wegblijven van controle van door de huisarts begeleide type 2 diabeten, in eigen praktijk dan wel in huisartsgeneeskundig onderzoek?

\section{Resultaten}

\section{Literatuur}

De opbrengst van het literatuuronderzoek bedroeg tien publicaties over wegblijvende diabetespatiënten.[8-17]. Alle publicaties op één na hadden betrekking op poliklinisch behandelde populaties van zowel type 1 als type 2 diabeten. Over uitsluitend type 2 diabeten werden geen publicaties aangetroffen.

Doelstelling, hypothese en onderzoeksopzet werden in deze publicaties adequaat beschreven. Dat geldt ook voor de selectie van de patiëntenpopulatie en de statistiek. Correctie voor grote uitval (non-respons) is in drie publicaties niet uitgevoerd $[8,10,11]$.

Ondanks deze beperkingen kan een aantal gegevens uit de gevonden publicaties op een verantwoorde wijze worden gebruikt voor het beantwoorden van de vraagstellingen.

\section{Prevalentie van wegblijven}

In zeven van de tien publicaties wordt besproken hoe vaak het wegblijven van controle voorkwam; dat varieerde van 1 tot 43 procent van de onderzochte diabetespopulatie (tabel 1). Daarbij werden overigens niet in alle gevallen dezelfde criteria gehanteerd.

- Kemple publiceerde, als enige, wegblijfgegevens over de diabetespatiënten van een gezondheidscentrum (in het Verenigd Koninkrijk). Het percentage wegbljvers liep terug van 14 naar 9 procent tijdens een project waarbij jaarlijks werd gelet op de resultaten van de geleverde diabeteszorg [8]. 
- Hammersley et al. stelden vast dat het wegblijven samenhing met de aard van de behandeling. Van de patiënten die alleen met dieet werden behandeld, bleef 11 procent langer dan een jaar weg. Bij de patiënten die orale antidiabetica kregen, was dat 6 procent, en bij de insulinegebruikers respectievelijk 4 procent (Ix daags) en 1 procent $(\geq 2 x$ daags) [12].

- Ook Graber et al. vonden dat de behandelwijze van belang was. Van de patiënten met alleen dieet viel 35 procent uit, van de groep met orale antidiabetica 16 procent en van de insulinegebruikers 10 procent. $\mathrm{Na}$ het eerste consult bleef gemiddeld 12 procent weg van de vervolgafspraak. Van de groep patiënten die wel voor controle terugkwamen (88 procent), bleef 35 procent na zes maanden weg, en 34 procent na nog eens zes maanden. Het wegblijven was het sterkst onder patiënten die ver weg woonden, niet met insuline behandeld werden of rookten. Over het hele eerste jaar bleef 43 procent van de totale groep onderzochte diabeten weg [13].

\section{Wegblijven in Nederland}

De telefonische en schriftelijke rondvraag onder de Nederlandse huisarts-diabetesdeskundigen leverde het volgende op:

- Het Nijmegen Monitonng Project is een longitudinaal interventieproject, waarin sinds 1986 gegevens worden verzameld door 24 huisartsen in 20 praktijken [18-19]. Volgens De Grauw was het percentage wegblijvers onder de 547 patiënten met diabetes type 2 die door de huisartsen werden gecontroleerd, in 19867 procent tegen 3 procent in 1995.

- Querido beschreef in 1995 een zorgproject ten behoeve van type 2 diabeten in een uit drie huisartspraktijken bestaand gezondheidscentrum [20-21]. Van de 51 patiënten over wie ten tijde van onze enquête gedetailleerde gegevens beschikbaar waren, was 8 procent één jaar of langer niet bij de huisarts verschenen.

- Reenders leidde in 1995 het Diabetesproject Assen-Hoogeveen, dat betrekking had op 507 type 2 diabeten in 19 praktijken [22-23]. Hij antwoordde op de enquête dat 5 procent twaalf maanden of langer wegbleef.

- Van der Does had een deel van de 'Hoorn-studie' onder zijn hoede. Een groep van 164 diabeten die onder behandeling van de huisarts waren, werd gedurende twee jaar gevolgd [24]. Ruim 7 procent bleef minimaal een jaar weg. Na correctie voor onduidelijke diagnose en onduidelijkheid over de hoofdbehandelaar werd het percentage wegblijvers 6 procent. Onder de nieuw ontdekte diabeten was het aandeel wegblijvers echter veel hoger: 17 procent.

- Dekker leidt vanaf 1995 een onderzoek naar het managen van type 2 diabeten in een aantal Amsterdamse huisartspraktijken [25]. Van de 829 patiënten in deze studie verscheen ruim 4 procent twaalf maanden of langer niet bij de huisarts op controle. Het wegblijven varieerde van 0 tot 6 patiënten per praktijk (0-13 procent).

- Zes huisartsen in Gezondheidscentrum Hoensbroek-Noord vonden in 1995 in het kader van een kwaliteitsbewakingsproject een gemiddeld percentage wegblijvers van bijna 6 procent onder de 253 type 2 diabeten (spreiding 4-8 procent) [interne 
rapportage, 26]. Dit gezondheidscentrum hanteert een recall-systeem, waarmee wegblijvers eenmaal worden opgeroepen.

- Cromme, huisarts te Twello, promoveerde in 1991 op een studie naar glucose-

Tabel 1. Gegevens uit de literatuur over wegblijven van diabetespatiënten

\begin{tabular}{|l|l|l|l|}
\hline Bron & $\mathbf{n}$ & $\begin{array}{l}\text { Criterium (duur } \\
\text { wegblijven) }\end{array}$ & $\begin{array}{l}\text { Percentage } \\
\text { wegblijvers }\end{array}$ \\
\hline & & & $9-14$ \\
Kemple [8] 1994 & 223 & $\geq 13$ maanden & 1,4 \\
Scobie [9] 1983 & 972 & $\geq 12$ maanden & 12 \\
Kellett [10] 1988 & 131 & $\geq 12$ maanden & 18 \\
Lloyd [11] 1990 & 715 & $\geq 1 \mathrm{Ix}$ & $1-11$ \\
Hammersley [12] 1985 & 1117 & $\geq 12$ maanden \\
Graber et al [13] 1992 & 422 & $\geq 12$ maanden & 44 \\
Lemain \& Moser [14] & 531 & $\geq 6$ maanden & 34 \\
1996 & & & \\
\hline
\end{tabular}

tolerantie onder ouderen in Twello [27]. In een telefonische mededeling schatte hij het percentage wegblijvers onder type 2 diabeten in zijn praktijk op 0 .

- Verhoeven, huisarts in Heerde, promoveerde in 1989 op een dissertatie over type 2 diabetes in de huisartspraktijk [28]. Hij schatte in een telefonische reactie dat 5-10 procent van de 63 type 2 diabeten in zijn praktijk één jaar of langer wegbljft.

\section{Kenmerken van wegblijvers}

In tabel 2 is weergegeven welke kenmerken bij de groep wegblj vers werden vastgesteld.

In de meeste publicaties werden bij wegblijvers meer gezondheidsproblemen en risicofactoren gevonden. Zo vonden Kellett et al. dat wegblijvers vaker rookten en alcohol dronken, vaker alleenstaand en vaker werkloos waren [10]. Hammersley et al. vonden dat wegblijvers langer diabetes, en vaker hoge HbAlc-waarden en overgewicht hadden. Fors overgewicht is een voorspeller van het wegblijven, stellen zij. Daarnaast vonden zij bij de wegblijvers vaker hogere bloeddrukwaarden, neuropathie en retinopathi [12]. Ook Jennings et al. constateerden dat wegblijvers van een diabetesvoorlichtingsdag langer diabetes, vaker overgewicht en hogere bloedgiucosewaarden hadden [29]. Zowel Hammersley et al. als Graber et al. vonden de hoogste wegblijfpercentages onder diabeten die alleen dieet kregen voorgeschreven [12-13]. Van der Does constateerde dat nieuw ontdekte type 2 diabeten vaker wegbleven dan langer bekende diabeten; nieuwe diabeten zijn in veel gevallen patiënten met overgewicht die eerst met alleen adviezen over voeding en vermagering worden behandeld [24]. 
Anderzijds vonden Kellett et al. geen verschillen in gemiddelde HbA1c-waarden en leeftijd [10]. Graber et al. vonden geen verschillen in leeftijd, geslacht, soort diabetes, relatief gewicht, HbAlc-waarden en duur van de diabetes [13].

Concluderend: de wegblijvende diabetespatiënten vormen waarschijnlijk een heterogene groep. Verschillende onderzoekers noemen allerlei, soms tegenstrijdige, kenmerken.

\section{Gevolgen van wegblijven}

Over de gevolgen van het wegblijven zijn de gegevens schaars. Hammersley ei al. vonden bij de wegblijvers stijgende HbA1c-waarden, diastolische hypertensie, neuropathie en retinopathie [12]. Kelleti et al. vonden daarentegen bij een substantiële subgroep van de wegblijvers - 13 van de 38 - een verbetering van de HbA1c-waarden [10]. Kennelijk zijn ook de gevolgen van wegblijven niet eenduidig te interpreteren.

\section{Motieven van wegblijvers}

Tabel 3 geeft een overzicht van de motieven van patiënten om weg te blijven.

- Lloyd et al. zond vragenlijsten aan wegblijvers en vond als redenen: niet in de stad, te ziek, andere arts, vergeten, geen tijd vanwege werk, opgenomen in ziekenhuis, verwacht geen nut van controle, en nog enkele andere motieven [11].

- In Nederland vond Beukema-Siebenga bij patiënten - niet specifiek diabeten - die vijf jaar of langer hun huisarts niet bezochten als motieven: geen klachten, klachten niet erg genoeg, vertrouwt meer op zelfzorg, ongeloof in mogelijkheden van de arts, eerder slechte ervaringen met arts [30].

- Van der Steen ondervroeg patiënten die - ongeacht de klachten - de huisarts bezochten. Bijna 8 procent kwam niet terug op of omstreeks de afgesproken controledatum. Met wegblijven hingen vele factoren samen, onder andere: langere duur van de ziekte, als minder bedreigend ervaren aandoening, minder klachten, weinig sociale steun, lange wachttijd en minder empathisch gedrag van de arts [31].

- Cohen et al. ontdekten grote verschillen in denkwijze over de ziekte diabetes tussen hulpverleners en patiënten. Patiënten leggen de nadruk op sociale problemen en de invloed van de ziekte op de kwaliteit van leven, terwijl hulpverleners diabetes voornamelijk zien als een pathofysiologisch regulatieprobleem. Ook bleken patiënten zich vaak onvoldoende bewust van de ernst van de aandoening. Hulpverleners wisten vaak weinig over de denkwijze van hun diabetespatiënten te weten, terwijl dat andersom wel het geval was [32]. 


\begin{tabular}{|c|c|c|}
\hline \multicolumn{2}{|l|}{ Tabel 2. Kenmerken van wegblijvers $\left({ }^{*}\right)$} & \multirow[b]{2}{*}{ Geen verschi } \\
\hline Kenmerk & Wel verschil & \\
\hline \multicolumn{2}{|l|}{ Achtergrondkenmerken } & \\
\hline - lagere leeftijd & & 10,13 \\
\hline - (meer) mannen & 17 & 13 \\
\hline - ongetrouwd, relatieproblemen & 10 & \\
\hline - werkeloos, lage economische status & 10 & 29 \\
\hline - slechte arts-patiënt-relatie & 13,32 & \\
\hline \multicolumn{2}{|l|}{ Diabeteskenmerken } & \\
\hline - duur van de ziekte & 12,29 & 13 \\
\hline - hoge HbAlc-waarden & 12,29 & $10,13,15$ \\
\hline - type diabetes & & 15 \\
\hline - compliantie (volgen van dieet) & 12 & \\
\hline \multicolumn{2}{|l|}{ Risicofactoren } & \\
\hline - roken & 10,13 & \\
\hline - alcoholgebruik & 10 & \\
\hline - overgewicht & 12,17 & 13,25 \\
\hline - hypertensie & 12,17 & \\
\hline - hoge lipidenspiegel & 17 & \\
\hline \multicolumn{2}{|l|}{ Complicaties } & \\
\hline \multicolumn{2}{|l|}{ - psychosociale problemen } & \\
\hline - comorbiditeitlcomphcaties 12 & & 29 \\
\hline${ }^{*}$ De cijfers verwijzen naar de nummer & liist. & \\
\hline
\end{tabular}




\begin{tabular}{|l|l|}
\hline Tabel 3 Motieven van wegblijvers ( ${ }^{*}$ ) & In studies: \\
\hline Te druk met werk, afspraak vergeten & $11,12,15,17$ \\
\hline Geen steun van familie & 15 \\
\hline Te ziek op het moment van de afspraak & 11 \\
\hline Moeite met voorschriften in dagelijkse routine & 15 \\
\hline Niet ziek genoeg, geen klachten, vindt zichzelf geen diabeet & 12,30 \\
\hline Voor de diabetes naar een andere hulpverlener & 11 \\
\hline Vertrouwen in zelfzorg & 30 \\
\hline Houdt niet van ziekenhuizen & 17 \\
\hline Vindt polikliniek/controle/huisarts niet nuttig & $11,30,32$ \\
\hline Afstand tot ziekenhuis te groot & 13,17 \\
\hline Slechte arts-patiëntrelatie, slechte ervaring met arts & 30,31 \\
\hline * De cijfers verwijzen naar de nummers de literatuurlijst. & \\
\hline
\end{tabular}




\begin{tabular}{|l|l|}
\hline $\begin{array}{l}\text { Tabel } 4 \text { Adviezen om (de gevolgen van) wegblijven tegen te gaan } \\
\left(^{*}\right)\end{array}$ & In studies: \\
\hline Oproepbrief, telefoontje of vragenlijst aan alle wegblijvers & $\begin{array}{l}9,10,12, \\
17\end{array}$ \\
\hline $\begin{array}{l}\text { Schriftelijke of telefonische herinnering vooraf bij elke (nieuwe) } \\
\text { afspraak }\end{array}$ & 11 \\
\hline Betere samenwerking tussen ziekenhuis- en eerstelijns diabetesteams & 16 \\
\hline $\begin{array}{l}\text { Centrale controle van follow-up door automatiseren van } \\
\text { vervolgafspraken }\end{array}$ & \\
\hline voor alle diabeten in een bepaalde regio & 12,16 \\
\hline $\begin{array}{l}\text { Kortere wachttijden door betere Organisatie van } \\
\text { poliklinieklspreekuren }\end{array}$ & 12 \\
\hline Avond- of weekendspreekuren om patiënten die wegblijven vanwege & \\
\hline druk werk tegemoet te komen & 11 \\
\hline Verbeteren van de arts-patient relatie & $11,13,32$ \\
\hline Volhardend aanbieden van voorlichting over: bloedsuikercontrole, & 12 \\
\hline gewichtsreductie, en het voorkômen van ulcera en amputaties aan & 29 \\
\hline voeten & \\
\hline Bepaalde gespecialiseerde huisartsen leveren gestructureerde & \\
\hline diabeteszorg & \\
\hline * De cijfers verwijzen naar de nummers in de literatuurlijst. & \\
\hline
\end{tabular}




\section{Adviezen en maatregelen}

Verschillende auteurs doen suggesties voor interventies om het wegblijven te verminderen of te voorkomen (tabel 4). Sommige auteurs geven adviezen op grond van hun persoonlijke mening. Vier interventiestudies beschrijven het effect van interventies in de dagelijkse praktijk.

- Kemple beschrijft dat het wegblijven van 14 tot 9 procent verminderde door systematische - jaarlijkse - monitoring van de diabeten in een gezondheidscentrum [8].

- Kellett et al. constateerden dat alle 55 wegblijvers na een formele schriftelijke uitnodiging ('recall') alsnog de diabetespolikliniek gingen bezoeken [10].

- De Grauw: In het Nijmegen Monitoring Project worden jaarlijks gegevens over de eigen diabetespatiënten teruggerapporteerd aan alle deelnemende huisartsen; het wegblijven verminderde daardoor van 7 tot 3 procent $[18,19]$.

- Estey beschrijft een interventie bestaande uit vier telefonische contacten en een huisbezoek in een periode van drie maanden. De experimentele groep ging de bloedsuikerwaarde vaker meten dan een controlegroep. Tussen beide groepen ontstond echter geen verschil in HbAlc-waarden en in relatief gewicht [15].

\section{Beschouwing}

Ons onderzoek maakt duidelijk dat over het wegblijven van diabeten nog veel onduidelijkheden bestaan. Het fenomeen is ook in Nederland nauwelijks in kaart gebracht. Gegevens over beïnvloedende factoren, motieven en gevolgen zijn schaars.

Het literatuuronderzoek leverde slechts een beperkt aantal publicaties op, die bovendien hoofdzakelijk betrekking hadden op beschrijvend onderzoek onder poliklinische populaties van type 1 en type 2 diabeten. Daarin worden uiteenlopende - en soms tegenstrijdige - kenmerken van wegblijvers gerapporteerd. Causale verbanden kunnen al helemaal niet worden gelegd. Onduidelijk blijt of mensen wegblijven omdat zij er slechter of beter aan toe zijn, of andersom. Wel is in twee studies gevonden dat de kans op wegblijven groter was bij diabeten die met alleen dieet werden behandeld. Eén publicatie geeft cijfers van wegblijven bij diabeten in een Engels gezondheidscentrum [8].

Uitgaande van de mededelingen van de geraadpleegde Nederlandse deskundigen zou ongeveer 5 procent van de type 2 diabeten wegblijven, met een spreiding van 0 17 procent. Mogelijk zijn deze cijfers te optimistisch; in de onderzochte praktijken wordt immers bijzondere aandacht besteed aan de begeleiding van deze patiënten. Hoewel het aantal wegblijvers per huisartspraktijk relatief gering zal zijn, gaat het in zijn totaliteit om grote aantallen. Ongeveer driekwart van de 250.000 in Nederland bekende type 2 diabeten wordt begeleid door de huisarts; 5 procent daarvan is bijna 10.000 [33]. Deze wegblijvers lopen de passend geachte zorg mis. Op landelijke 
schaal zijn de gezondheidseffecten van het wegblijven misschien aanzienlijk, en dat geldt zeker voor bepaalde subgroepen.

Ook in de gevonden Nederlandse studies blijkt bij nieuw ontdekte diabeten en bij diabeten die alleen met een voedingsadvies worden behandeld (vaak 'beginnende' type 2 diabeten) de kans op wegblijven het grootst. De bevinding dat een groep Japanse jongeren met type 2 diabetes zeer hoog scoorde wat wegblijven betreft, kan hierbij passen [17]. Chronisch zieke mensen worstelen vaak emotioneel met het aanvaarden van hun ziekte. Het proces van verwerken van de kort tevoren gestelde diagnose vertoont volgens Cox vaak overeenkomst met een rouwproces: verlamming, ontkenning en uitvluchten zoeken, boosheid en dramatiseren, en tenslotte berusten en aanvaarden [34]. Zij ervaren vaak angst en schaamte, en voelen zich minderwaardig in contacten met anderen [4]. De eerste reactiefase ('verlamming, ontkenning en uitvluchten zoeken') kort nadat de diabetes is vastgesteld, of bij een latere verslechtering van de metabole regulatie, brengt wellicht een verhoogd risico op wegblijven met zich mee. Hierbij kunnen uiteenlopende factoren een rol spelen: schuldgevoelens over het niet kunnen volhouden van het dieet, frustraties over het eigen overgewicht, ergernissen over de houding van hulpverleners, en een slecht inzicht in de ernst van de ziekte. De motieven die patiënten zelf opgeven voor wegblijven zijn divers. Sommige ervan zijn relevant voor de huisartspraktijk en gelden ook voor andere aandoeningen: afspraak vergeten, afstand te groot, geen tijd vanwege het werk, negatief oordeel over het nut van controle-afspraken, zich niet ziek voelen, en meer vertrouwen op zelfzorg. Daarnaast blijken hulpverleners en patiënten vaak verschillend te denken over diabetes mellitus, en weten hulpverleners weinig over de denkbeelden van hun patiënten. Veel wegblijvers onderschatten de ernst van de aandoening. Mogelijk leidt dit alles tot slechte communicatie en afstemming, en tot een verschil van mening over de speerpunten in de behandeling.

Door enkele auteurs werd geconcludeerd dat factoren als weinig sociale steun, alleenstaand zijn, slechte toegankelijkheid en organisatie van de zorg, evenals een slechte arts-patiëntrelatie, wegblijven kunnen bevorderen. Systematisch monitoren van de resultaten van de geleverde diabeteszorg is de basis van de enige gevonden publicatie over wegblijven van diabeten in de huisartspraktijk. De meest genoemde suggestie voor het verminderen van wegblijven is het gebruik van een oproepsysteem (recall). Bigby et al. en Vikander ei al. vonden dat telefonisch of schriftelijk oproepen van wegbljvers even effectief was bij algemene interne poliklinieken

$[35,36]$.

De frequentie van wegblijven van diabetescontroles en de hieraan verbonden gezondheidsrisico 's blijken onvoldoende onderzocht te zijn. Dat geldt ook voor de eventuele gezondheidswinst die met een vermindering van het wegblijven zou kunnen worden behaald. Daarom is het op dit moment nog voorbarig te pleiten voor een 'campagne tegen het wegblijven'. Het onmiskenbare gebrek aan kennis over wegblijven van type 2 diabeten in de huisartspraktijk rechtvaardigt wel nader onderzoek.

\section{Dankbetuiging}

Met dank aan de geraadpleegde huisartsdiabetesdeskundigen voor het leveren van 
gegevens uit hun praktijk of onderzoek (waarvoor zij soms hun gegevens opnieuw moesten bewerken), en aan drs. Irmgard Eijkelberg, staffunctionaris van het Coördinatiecentrum Chronisch Zieken Limburg (Synchron), voor het kritisch doorlezen en becommentariëren van het manuscript voor dit artikel. 


\section{Literatuur}

1 Van der Horst FG, Meulders M. Een beetje suiker. Een onderzoek onder oudere diabetespatiënten. Maastricht: Rijksuniversiteit Limburg, 1982.

2 Konings GPJM, Wijkel D, Rutten GEHM. Lukt het werken volgens de NHG-Standaard Diabetes Mellitus Type II? Huisarts Wet 1995;38:IO-4.

3 Konings GPJM, Rutten GEHM, Wijkel D. Waarom werken huisartsen niet volgens de NHGStandaard Diabetes Mellitus Type II? Huisarts Wet 1995;38:602-7.

4 Van der Horst FG, et al. Compliance en patiëntenvoorlichting. In: Demoiseaux V et al, redactie. Patiëntenvoorlichting, een interdisciplinaire benadering. Assen: Van Gorcum, 1987.

5 Stewart M, Brown JB, Weston WW, et al. Patient-centered medicine. Transforming the clinical method. Thousand Oaks CA, Sage Publications, 1995.

6 Stimson G, Webb B. Going to see the doctor. Consultation process in GP. London/Boston: Routledge \& Kegan Paul, 1975.

7 Balint M. Dokter, patiënt, ziekte. Utrecht/Antwerpen: Spectrum, 1965.

8 Kemple T. Systematic care of diabetic patients. Br J Gen Pract 1994;44:216.

Scobie IN, Rafferty AB, Franks PC, et al. Why patients were lost from follow-up at an urban diabetic clinic. BMJ 1983;286:189-90.

10 Kellett J. Diabetic clinic attendance and metabolic control; a pilot pan clinic study. Ann Intern Med 1988;139:95-7.

11 LloydJ, SheriffR, FisherM, etal. Non-attendance at the diabetic clinie. Pract Diab 1990;16:191-5.

12 Hammersley MS, Holland MR, Walford S, et al. What happens to defaulters from a diabetic clinic? BMJ 1985;29I:1330-2.

13 Graber AL, Davidson P, Brown AW, et al. Dropout and relapse during diabetes care. Diab Care 1992;15:1477-83.

14 Lemain IK, Moser EC. Het niet verschijnen op het controlespreekuur van de diabetespoli ('Noshow'). Rapport VU-Ziekenhuis, Inwendige Geneeskunde. Amsterdam, 1996.

15 Estey AL, Meng TH, Mann K. Follow-up intervention; its effect on compliance behavior to a diabetes regimen. Diab Educ 1990;13:79-80.

16 Sullivan FM. Whose problem is the diabetic who does not attend a hospital clinic? Scott Med J 1988;33:259-60.

17 Kawahara R, Amemiya T, Voshino M, et al. Dropout of young non-insulin dependent diabetics from diabetes care. Diab Res Clin Pract 1994;24:18I-5.

18 De Grauw WJC. Nijmegen Monitoring Project 1986-95. Schriftelijk verslag. Nijmegen, 1996.

19 De Grauw WJC, Van de Lisdonk EN, Van den Hoogen HJM, et al. Screening for microalbuminuria in type 2 diabetic patients: The evaluation of a dipstick test in general practice. Diab Med 1995: 65763. 
20 Querido JD, Von Veh V. De zorg voor type-II-diabeten in een achterstandsbuurt. Evaluatie van een zorgproject in drie huisartspraktijken. Huisarts Wet 1995;38:246-9.

21 Querido JD. De prevalentie van diabetes mellitus type II in een achterstandsbuurt. Een onderzoek in drie huisartspraktijken. Huisarts Wet 1995 ;38:250-4.

22 Miedema K, Veltmaat LJ, Reenders K. Overschakelen op insuline bij NIADM-patiënten in de huisartspraktijk. Een onderzoek naar belemmerende factoren. Huisarts Wet 1995;38:614-7.

23 Reenders K. Complicaties van niet-insuline afhankelijke diabetes mellitus in de huisartspraktijk [dissertatie]. Nijmegen: Katholieke Universiteit Nijmegen, 1992.

24 Van der Does FEE. Influence of glycemic control on well-being and cardiovascular risk indicators in type 2 diabetes. A randomised trial in general practice [dissertatie]. Amsterdam: Vrije Universiteit, 1997.

25 Dekker J. Verslag Diabetesproject Amsterdam 1996/97.

26 Geboers f1, Van Montfort P, Mokkink H, et al. Ontwikkeling van een kwaliteitssysteem in de huisartspraktijk. Eindrapportage Werkgroep Onderzoek Kwaliteit 1992-1996. Nijmegen: Katholieke Universiteit Nijmegen, 1996.

27 Cromme PVM. Glucose tolerance in a typical Dutch community [dissertatie]. Amsterdam: Vrije Universiteit, 1991.

28 Verhoeven S. Behandeling, controle en metabole instelling van patiënten met diabetes mellitus type II, en de prevalentie van late complicaties bij deze patiënten [dissertatie]. Rotterdam: Erasmu Universiteit Rotterdam, 1989.

29 Jennings AM, Mackinnon M, Sparkes $P$, et al Education for patients with established NIDDM: disparities between patients who do and do no attend. Diab Care 1990; 13:79-80.

30 Beukema-Siebenga H. To go or not to go. An ex plorative study on people who seldom consult general practitioner [dissertatie]. Groningen Rijksuniversiteit Groningen, 1995.

31 Van der Steen JJ. Terugkomtrouw in de huisari spraktijk [dissertatie]. Leiden: Rijksuniversite Leiden, 1987.

32 Cohen M, Tripp T, Smith C, et al. Explanatory models of diabetes patient - practitioner variation. Soc Sci Med 1994;38:59-66.

33 Stuurgroep Toekomstscenario's Gezondheidszorg. Chronische Ziekten in het jaar 2005: scenario's voor diabetes mellitus 1990-2005 (deel 1). Utrecht/Antwerpen: Bohn, Scheltema \& Holkema, 1990.

34 Cox S. How I coped emotionally with diabetes in my family. Prof Care Mother Child 1994;4:139-41.

35 Bigby JA, Giblin EM, Goidman L. Appointment reminders to reduce no-show tares. A stratified analysis of their cost-effectiveness. JAMA 1983;250:1742-5.

36 Vikander T, Pamicky K, Demers R, et al. New patient no-shows in an urban family practice centre: analysis and intervention. J Fam Pract 1986;22:263-8. 


\section{CHAPTER 4}

Wegblijven van patiënten met diabetes mellitus type 2 - een echt probleem?

(Non-attendance in persons with type 2 diabetes - a real problem?) 


\section{Wegblijven van patiënten met diabetes mellitus type 2 - een echt probleem?}

(Non-attendance in persons with type 2 diabetes - a real problem?)

HA van Dam, HFJM Crebolder, I Eijkelberg, M van Nunen, FG van der Horst

Reprinted from: Huisarts Wet 2000;43(9):380-4

Appendix A: Commentaren en discussie in ingezonden brieven (Comments and debate in letters to the editor) 


\section{SAMENVATTING}

Inleiding. Wegblijven van controle en behandeling door patiënten met type 2 diabetes mellitus is een vorm van non-compliantie. Een deel van de wegblijvende patiënten zou extra gezondheidsrisico's lopen. Hoe vaak komt wegblijven door patiënten met type 2 diabetes bij de huisarts voor? Hoe hangt wegblijven samen met metabole regulatie en andere patiënt-, arts- of praktijkkenmerken?

Methode. Exploratief onderzoek naar de prevalentie van wegblijven in de huisartspraktijk en de kwaliteit van de metabole regulatie bij wel en niet wegblijvende patiënten, naar de samenhangen van wegblijven en regulatie onderling en met patiënt-, arts- en praktijkfactoren. Achtendertig huisartsen vulden vragenlijsten in, enerzijds over zichzelf, hun praktijk en de opzet van hun diabeteszorg, anderzijds over alle 964 type 2 diabetespatiënten waarvan zij de hoofdbehandelaar zijn.

Resultaten. Gemiddeld acht procent van de patiënten bleef een jaar of langer weg, spreiding per huisarts 0 tot $30 \%$ ( 0 tot 8 patiënten). De metabole regulatie was matig: gemiddelde nuchtere bloedglucosewaarde van alle patiënten $8,3 \mathrm{mmol} / \mathrm{l}$. Slecht gereguleerd was de helft (nuchter bloedglucose $>8 \mathrm{mmol} / \mathrm{l}$ ) of eenderde $(\mathrm{HbA} 1 \mathrm{c}>8,5 \%)$ van de patiënten; goed gereguleerd eenderde (nuchter glucose en HbA1c). Een kwart van de patiënten had sterk overgewicht (Body Mass Index >30). Van een groot deel van de patiënten ontbraken HbA1c- en Body Mass Indexwaarden. Wegblijven hing in multipele logistische regressie-analyse samen met goede regulatie, mannelijk geslacht, minder comorbiditeit, minder intensieve behandelwijze, ontbreken van een eigen diabetesprotocol en minder goede acceptatie van de ziekte door de patiënt. Goede regulatie hing samen met wegblijven, minder intensieve behandelwijze en solo werkende huisarts.

Conclusies. Wegblijven bestaat maar lijkt een virtueel probleem. In de groep wegblijvers is de metabole regulatie niet slechter en er bestaan niet meer gezondheidsproblemen dan bij de niet-wegblijvers. Wegblijven kan daarom niet gezien worden als indicator van de kwaliteit van de geboden diabeteszorg. Wanneer goed georganiseerde zorg wordt geleverd (goede praktijkorganisatie, adequate behandelwijze, behandel- en samenwerkingsafspraken, educatie en ondersteuning van de patiënten), kan volstaan worden met 1 of 2 herinneringsoproepen voor wegblijvende patiënten. De eigen verantwoordelijkheid van de patiënt wordt dan voldoende gerespecteerd.

\section{ABSTRACT}

Introduction. Persons with type 2 diabetes do not always show up in due time for their diabetes checkups and treatment. One could conclude that these patients with non-attendance may damage their health with this.

Methods. Explorative study of relationships between non-attendance, diabetes control, and patient, doctor, and practice characteristics. Thirty-eight general practitioners filled in two questionnaires about themselves, their practices and organisation of diabetes care, and a total of 964 persons with type 2 diabetes treated in their practices.

Results. Eight per cent of patients showed non-attendance for 12 months or more, range 0 - 30 per cent (0-8 patients) per doctor. Diabetes control was fair but suboptimal: mean Fasting Blood Glucose $8,3 \mathrm{mmol} / \mathrm{l}$. Forty-seven per cent of patients with non-attendance had good control (FBG $<6,7$ ), while twenty-eight percent of attending patients had good control. Non-attendance was related to good control, male gender, less multi-morbidity, less intensive treatment, lacking of a local protocol of diabetes guidelines, and worse acceptance of diabetes by patient. Good diabetes 
control was related to non-attendance, less intensive treatment, and single-handed practice.

Discussion. Non-attendance does exists but appears not to be detrimental for patients' health. Good diabetes care must be offered by general practices, including patient education and enhancement of self-management e.g. good use of diabetes clinics, attendance to diabetes care, and professional care that fits patient preferences. Patients that do not show up on diabetes visit appointments, may be recalled by the practice once or twice. If patients continue to be non-attendant, this may be accepted, as being their responsibility. 


\section{INLEIDING}

Wegblijven van controle en behandeling door mensen met diabetes kan beschouwd worden als een specifieke vorm van non-compliant gedrag. Wij spreken van wegblijven als de patiënt twaalf maanden of langer niet voor controle bij de behandelend hulpverlener is geweest. Bij een inventariserend onderzoek in 1996 in enkele Nederlandse huisartspraktijken en diabetesprojecten in de huisartspraktijk zijn percentages tussen 0 en 17 gevonden. Voor de gemiddelde Nederlandse huisartspraktijk werd het percentage wegblijvers geschat op 5 tot 10 procent $[1,2]$. Uit de gegevens over 2.351 door huisarts-diabetologen gecontroleerde type 2 diabetespatiënten in genoemd onderzoek was een gemiddeld wegblijfpercentage van 4,4 te berekenen.

De geraadpleegde literatuur noemt een reeks factoren die al dan niet causaal kunnen samenhangen met het wegblijven van diabetespatiënten. Deels betreft het arts- en praktijkgebonden factoren, deels patiëntgebonden factoren. Over onderzoek van wegblijven in de huisartspraktijk is echter nauwelijks gepubliceerd.

Voor de prognose van type 2 diabetespatiënten hebben goede metabole regulatie en adequate behandeling van bloeddruk en andere cardiovasculaire risicofactoren bewezen belang [3]. Over de mate waarin welke kenmerken van geleverde diabeteszorg deze risicofactoren het sterkst beïnvloeden, stemmen de gegevens uit onderzoek niet erg overeen. Pringle constateert dat een goede metabole instelling van type 2 diabetespatiënten in de huisartspraktijk samenhangt met interesse voor diabetes bij de behandelend arts, goede praktijkoutillage, samenwerking met een diëtist en goede organisatie van de diabeteszorg, met insulinebehandeling, mannelijk geslacht van de patiënt, kortere diabetesduur en kleiner aantal diabetescomplicaties [4]. Dunn daarentegen vindt juist geen duidelijke (bivariate) correlaties tussen goede metabole en bloeddrukregulatie of minder diabetescomplicaties enerzijds en gebruik van een apart register van diabetespatiënten, een oproepsysteem, beter registreren van $\mathrm{HbA} 1 \mathrm{c}$-waarden, volgen van richtlijnen of diabetesnascholing door artsen en praktijkverpleegkundigen anderzijds [5]. Welke rol de terugkomtrouw van patiënten (het al dan niet wegblijven) speelt in de reeks van mogelijke factoren die de uitkomsten van diabeteszorg bepalen, is niet duidelijk. Dat is het onderwerp van onze studie. 
Op grond van het voorgaande zijn de volgende onderzoeksvragen geformuleerd:

* Wat is de (punt)prevalentie van wegblijven - twaalf maanden of langer - van door de huisarts begeleide patiënten met type 2 diabetes?

* Hoe is de kwaliteit van de metabole regulatie van wel en niet wegblijvende patiënten?

* Wat is de samenhang van wegblijven en metabole regulatie met patiënt-, arts- en praktijkgebonden kenmerken?

\section{METHODE}

Wat betreft de selectie van deelnemende huisartsen en patiënten: de studie is binnen een periode van drie maanden in 1996/97 uitgevoerd bij huisartsen deelnemend aan het Registratienet Huisartspraktijken (RNH) [6]. Het RNH is een gegevensbestand waarin medische problemen van - in de periode van het onderzoek - ongeveer 60.000 patiënten uit de geautomatiseerde patiëntregistratie van 50 huisartsen worden verzameld. Dat bestand is beschikbaar voor wetenschappelijk onderzoek en onderwijs. Huisartsen die minder dan een jaar deelnamen aan het RNH zijn niet aangeschreven, bij hen kon worden aangenomen dat hun patiëntregistratie nog niet volledig was. Van de tweeënveertig aangeschreven RNH-huisartsen hebben er achtendertig (90 procent) deelgenomen aan het onderzoek. Deze 38 huisartsen en hun praktijkassistentes werken in veertien $\mathrm{RNH}$-praktijkgroepen: drie solopraktijken, zes groepspraktijken en vijf gezondheidscentra.

Via het RNH zijn alle diabetespatiënten van deze huisartsen geïdentificeerd: 1719 personen met verschillende typen diabetes. Uit deze groep geëxcludeerd zijn door de huisartsen de patiënten met type 1- en zwangerschapsdiabetes en met type 2 diabetes die niet door henzelf behandeld werd. In de studie geïncludeerd zijn de 964 patiënten met type 2 diabetes met de eigen huisarts als hoofdbehandelaar. Dertien van de 38 huisartsen konden het totaal aantal bij hen bekende personen met type 2 diabetes opgeven; daarvan behandelden zij gemiddeld 68 procent zelf (spreiding 35 tot 91 procent).

Wat betreft de onderzochte variabelen: aan de huisartsen zijn vragen voorgelegd betreffende henzelf, de praktijk waarin zij werken en de door hen behandelde patiënten met type 2 diabetes. Over henzelf: leeftijd, geslacht en ervaring, 
opvattingen over, belangstelling voor en nascholing in het voorafgaande jaar in diabeteszorg. Ook is gevraagd naar de mate waarin de artsen de ('oude', uit 1989 daterende) NHG-Standaard Diabetes Mellitus Type II volgen en de mate waarin de artsen zichzelf danwel de patiënt verantwoordelijk achten voor het (tegengaan van) wegblijven [12]. Voor laatstgenoemde vraag is gebruik gemaakt van een Visual Analogue Scale (VAS), waarbij de respondent een kruis zet op een gestandaardiseerde lijn van $100 \mathrm{~mm}$ lengte. Bij het nulpunt acht de arts zichzelf geheel verantwoordelijk en bij het eindpunt de patiënt. Aan de hand van de uitkomsten kan onderscheid worden gemaakt tussen huisartsen die minder of meer geneigdheid hebben de verantwoordelijkheid voor terugkomtrouw bij de patiënt te leggen.

Verder zijn door de artsen vragen beantwoord over hun praktijk(groep): aantal ingeschreven patiënten, aantal samenwerkende artsen, organisatievorm, vestigingsgebied en organisatie van de diabeteszorg: wel of niet apart diabetesspreekuur, gebruik van een lijst diabetespatiënten, een oproepsysteem en een diabetesprotocol en samenwerking met andere disciplines. De huisartsen is tevens gevraagd vooraf het percentage wegblijvende type 2 diabetespatiënten in de eigen praktijk te schatten.

Voor elk van de 964 geïncludeerde type 2 diabetespatiënten hebben de 38 huisartsen een vragenlijst ingevuld betreffende duur van de diabetes, metabole regulatie (bloedglucosewaarden in millimolen per liter, $\mathrm{HbA1c}$ in procenten en wel de meest recente van eventueel meerdere vermelde uitslagen, voor wegblijvende patiënten de laatstvermelde in de voorafgaande periode van maximaal drie jaar), lichaamsgewicht en lengte, behandelwijze (wel of geen orale antidiabetica respectievelijk insuline) en controlefrequentie, datum van laatste controle (waaruit de duur van wegblijven tot de datum van invullen berekend kon worden), leeftijd en geslacht, nationaliteit, opleidingsniveau (in drie niveaus) en werk- en woonomstandigheden (respectievelijk wel of geen betaald werk en wel of niet alleenwonend). Verder is gevraagd naar geregistreerde gegevens (wel, niet, onbekend) over roken, comorbiditeit, diabetescomplicaties en doorgemaakte 'life events' (ernstige, door de arts geregistreerde gebeurtenissen in de voorafgaande vijf jaar, zoals overlijden van partner, suïcide in de familie, ongevallen). Tenslotte is gevraagd naar het oordeel van de artsen over de kennis van en attitude tegenover diabetes van elke patiënt, het nakomen van de laatste afspraak, de algemene 
therapietrouw, sociale en emotionele steun, acceptatie en eventuele belemmeringen bij het omgaan met de ziekte.

Statistiek: De statistische betekenis van gevonden verschillen tussen de groepen wel- en niet-wegblijvende patiënten zijn getoetst door berekening van (ruwe, ongecorrigeerde) Odd's Ratios (OR). De OR's voor verschillen worden als statistisch significant beschouwd wanneer het $95 \%$ betrouwbaarheidsinterval niet de 1,0 omvat. Ondanks de exploratieve opzet van onze studie kan toch, aan de hand van deze OR's, een indruk worden verkregen van de verschillen in relatieve kans op het voorkomen van onderscheiden kenmerken bij wel- en niet-wegblijvende patiënten. Verder zijn in een multipel logistisch regressiemodel de onafhankelijke, onderling gecorrigeerde bijdragen van afzonderlijke variabelen aan wegblijven of goede regulatie getoetst. Daarin zijn als afhankelijke, binaire variabelen ingevoerd wegblijven $(\geq 12$ maanden, ja/nee) respectievelijk goede kwaliteit van diabetesregulatie (het toen geldende afkappunt: een nuchtere bloedglucosewaarde $<6,7 \mathrm{mmol} / \mathrm{l}=$ goed, $\mathrm{ja} / \mathrm{hee}$ ) en als onafhankelijke variabelen die waarvoor bij vergelijking van de verschillen tussen wel- en niet-wegblijvende patiënten een betekenisvolle ruwe OR was geconstateerd. Het regressiemodel corrigeert stap voor stap voor eventueel onderlinge samenhangen tusen de variabelen, ook confounding genoemd [7]. Voor de mate van samenhang in de regressies zijn behalve regressiecoëfficiënten ook OR's berekend. Ook hier worden de OR's van verschillen als statistisch significant beschouwd wanneer het 95\% betrouwbaarheidsinterval niet de 1,0 omvat. De analyses betreffen drie niveaus: patiënten $(n=964)$, artsen $(n=38)$ en praktijkgroepen $(n=14)$. Gebruik is gemaakt van het statistiekprogramma Statistical Package for the Social Sciences (SPSS) versie 8,0 [8].

\section{RESULTATEN}

Tabel 1 geeft informatie over de huisartsen en hun praktijken. De overgrote meerderheid van de artsen heeft meer dan vijf jaar praktijkervaring. Driekwart heeft in het voorbije jaar nascholing over diabetes gevolgd. Het gemiddeld aantal door de huisartsen gecontroleerde type 2 diabetespatiënten bedraagt 25,4. De artsen schatten vooraf het percentage wegblijvers in de eigen praktijk gemiddeld op 12 procent (spreiding 3 tot 50 procent). Een grote meerderheid van de 38 artsen geeft 
vooraf aan het nuchtere bloedglucosegehalte en het $\mathrm{HbA} 1 \mathrm{c}-$ percentage als criterium voor beoordeling van de regulatie van de patiënten te gebruiken.

Tabel 2 geeft informatie over de 964 door de huisarts behandelde type 2 diabetespatiënten. Bij 46 van de type 2 diabetespatiënten (bijna 5 procent) is niet geregistreerd wanneer het laatste diabetesconsult plaats had gevonden ('missing'), zodat bij hen de duur van het wegblijven niet berekend kan worden. Bij de overige 918 personen is dat wel mogelijk. Van deze groep zijn 71 patiënten, bijna 8 procent, twaalf maanden of langer weggebleven. Over de 38 individuele huisartsen is de spreiding van wegblijvende patiënten 0 tot 30 procent, nul tot acht personen per arts. De hoogste score (30 procent) betreft een huisarts met drie wegblijvende van in totaal tien type 2 diabetespatiënten. Bij negen huisartsen is geen van de type 2 diabetespatiënten weggebleven, bij negen huisartsen meer dan 10 procent. Op de VAS-vraag naar de verantwoordelijkheid voor het tegengaan van wegblijven zetten de huisartsen hun kruis gemiddeld op 70 mm, met een spreiding tussen 45 en 100 $\mathrm{mm}$. Het zwaartepunt van deze verantwoordelijkheid wordt derhalve bij de patiënt gelegd. Tegelijk hebben 35 van de 38 huisartsen positief geantwoord op een andere vraag of tegengaan van wegblijven onderdeel van hun eigen beleid is. De huisartsen melden bij driekwart van de patiënten dat zij de laatste afspraak goed zijn nagekomen en bij 38 procent dat zij in het algemeen een goede therapietrouw vertonen.

Wat betreft de metabole regulatie van de onderzochte patiënten het volgende. De gemiddelde bloedglucosewaarde nuchter bedraagt $8,3 \mathrm{mmol} / \mathrm{l}$ en niet-nuchter 9,5 mmol/l, de gemiddelde HbA1c-waarde is 7,9 procent (tabel 2).

Bij veertien van de 38 huisartsen zijn geen $\mathrm{HbA1c}$-waarden geregistreerd, bij twee geen nuchtere bloedglucosewaarden. Bij 81 procent van de patiënten ontbreekt de uitslag van het $\mathrm{HbA} 1 \mathrm{c}$ en bij 23 procent die van de nuchtere bloedglucose. Op grond van deze bevindingen werd besloten niet het $\mathrm{HbA1c}$-percentage maar de nuchtere bloedglucosewaarde als maat van de metabole regulatie te gebruiken.

Goed gereguleerd (nuchter bloedglucose $<6,7 \mathrm{mmol} / \mathrm{l}$ volgens de toen geldende, eerste versie van de NHG-Standaard Diabetes Mellitus Type II) is gemiddeld 29 procent van alle geïncludeerde patiënten, met een spreiding tussen 0 en 50 procent 
per huisarts. Slecht gereguleerd $(>8,0 \mathrm{mmol} / \mathrm{l})$ is gemiddeld 47 procent, met een spreiding tussen 27 en 70 procent.

Van de wegblijvende patiënten is gemiddeld 47 procent goed gereguleerd en 40 procent slecht, van de niet-wegblijvers 28 respectievelijk 48 procent (Tabel 3). De Quetelet Index (QI) is bij 67 procent van de patiënten niet te berekenen; van de overige heeft ongeveer een kwart een QI-score hoger dan 30. Geregistreerde bloeddruk- en lipidenwaarden zijn niet in de studie betrokken.

Een profiel van de arts- en praktijkkenmerken en van de wegblijvende type 2 diabetespatiënten kan worden afgeleid uit tabel 3. Onder de wegblijvers vinden wij relatief meer mannen, meer patiënten die zonder medicamenten behandeld worden en meer patiënten met goede nuchtere bloedglucosewaarden dan onder de nietwegblijvers. Comorbiditeit en diabetescomplicaties komen bij wegblijvers minder vaak voor dan bij niet-wegblijvers. Voor complicaties is dit verschil niet significant. Er is geen verschil tussen huisartsen met relatief veel of weinig wegblijvende patiënten, wat betreft hun VAS-score over de verantwoordelijkheid voor het tegengaan van wegblijven.

De scores voor compliantiekenmerken (volgen van voorschriften en acceptatie), kennis en emotionele steun, door de artsen beoordeeld, zijn voor de groep wegblijvers lager, terwijl bij hen vaker het bestaan van belemmeringen genoemd wordt.

Tabel 4 toont de resultaten van logistische regressie-analyse voor de kans op wegblijven en op een goede metabole regulatie. Minder wegblijvers treffen we aan bij de niet-solopraktijken en bij praktijken waar een diabetesprotocol en/of oproepsysteem voorhanden is en verder bij het bestaan van comorbiditeit, intensievere behandelwijze en (door de arts beoordeelde) goede acceptatie van de diabetes door de patiënt. Gebruik van een oproepsysteem draagt in de regressie overigens niet bij aan een kleinere kans op wegblijven. De kans op wegblijven is groter bij mannelijk geslacht van de patiënt en bij goede diabetesregulatie.

De kans op goede metabole regulatie (nuchtere bloedglucose $<6,7 \mathrm{mmol} / \mathrm{l}$ ) is groter bij wegblijven en bij een nageschoolde huisarts, kleiner bij een niet-solo huisarts en intensievere behandelwijze. 


\section{BESCHOUWING}

Samenvattend kunnen de onderzoeksvragen als volgt beantwoord worden:

${ }^{*}$ Gemiddeld is bijna 8 procent van de door de deelnemende huisartsen begeleide patiënten met type 2 diabetes een jaar of langer weggebleven, met een spreiding van 0 tot 30 procent onder de huisartsen.

*De metabole regulatie van de bestudeerde groep type 2 diabetespatiënten is matig. Afhankelijk van de gebruikte parameter en het gekozen afkappunt is er sprake van slechte regulatie bij eenderde ( $\mathrm{HbA} 1 \mathrm{c}>8,5$ procent) tot bijna de helft (nuchter bloedglucose $>8,0 \mathrm{mmol} / \mathrm{l}$ ) van de betrokken patiënten. Opgemerkt wordt dat slechts bij 29 procent van de patiënten het HbA1c geregistreerd is en bij 77 procent het nuchter bloedglucose.

*Voor het bestaan van een belangrijke subgroep wegblijvende patiënten met slechte regulatie en veel complicaties of comorbiditeit, ten opzichte van de niet-wegblijvers, worden geen aanwijzingen gevonden. Integendeel, onder de wegblijvers bevinden zich juist relatief meer patiënten met goede regulatie en zonder comorbiditeit dan onder de niet-wegblijvers.

Wegblijvende patiënten zijn vaker man, hebben vaker een goede diabetesregulatie, minder vaak een intensieve behandelwijze, minder vaak comorbiditeit en minder vaak door de huisarts als 'goed' ingeschatte acceptatie van de diabetes. In de praktijk waar zij zijn ingeschreven ontbreekt vaker een eigen diabetesprotocol. Veel andere patiëntkenmerken (waaronder kennis, leeftijd, nationaliteit, opleiding, arbeidsof woonsituatie, rookgedrag) en andere arts- en praktijkkenmerken vertonen met wegblijven geen samenhang. Verrassend is dat in de regressie het bestaan van een oproepsysteem niet blijkt bij te dragen aan (minder) wegblijven.

Een goed gereguleerde diabetes vinden we vaker bij wegblijvende patiënten, patiënten met alleen dieetbehandeling en met een solo-huisarts die diabetesnascholing volgde.

Onze studie kent sterke en zwakke kanten. Bijzonder is het analyseren van gegevens op drie niveau's - op dat van de artsen, van de praktijkgroepen en van de patiënten -, maar niet nieuw. De besproken studies van Pringle en Dunn doen hetzelfde $[4,5]$. Het focussen op wegblijven is wel nieuw. Wat betreft de externe validiteit: de onderzochte patiëntenpopulatie is redelijk vergelijkbaar met die in 
andere Nederlandse studies voor wat betreft leeftijds- en geslachtsverdeling en andere demografische gegevens [13-17].

De studie kent enkele beperkingen. De deelnemende huisartsen werken allen in geautomatiseerde onderzoekspraktijken en zijn in hoge mate georganiseerd in samenwerkingsverbanden, zoals groepspraktijken en gezondheidscentra. De invloed hiervan op de prevalentie van wegblijven en op de kwaliteit van de metabole regulatie van type 2 diabetespatiënten is niet geheel duidelijk. Een andere beperking van de studie is dat de patiëntgegevens niet rechtstreeks bij de patiënten, maar alleen bij huisartsen en assistentes werden verzameld. Een deel van de patiëntkenmerken - met name persoonsgebonden variabelen als therapie- en terugkomtrouw, belemmeringen, steun, acceptatie en kennis - is gemeten via de antwoorden van de huisarts op betreffende vragen. Gevolg was dat zulke kenmerken, in de regressie onafhankelijke variabelen, zijn aangeleverd door personen met kennis van afhankelijke variabelen (wegblijven, regulatie). Huisarts- en patiëntcompliantie zijn daardoor moeilijk te onderscheiden en de 'schuld' voor bijvoorbeeld wegblijven of een slechte regulatie zou al te gemakkelijk bij de patiënt kunnen worden gelegd. Dit kan informatie-bias hebben opgeleverd. In de regressieanalyse komt hiervan alleen slechte acceptatie van de diabetes door de patiënt als significant samenhangend met wegblijven naar voren (tabel 4). Vanwege de exploratieve en retrospectieve opzet van de studie dateren de gegevens over wegblijvende patiënten per definitie uit een eerdere periode dan die over nietwegblijvende patiënten. Bovendien kunnen geen causale verbanden tussen de gemeten variabelen worden vastgesteld.

Opmerkelijk is dat veel klinische patiëntgegevens ontbreken, zoals $\mathrm{HbA} 1 \mathrm{c}$, nuchter bloedglucose en Quetelet Index. Dit in contrast met door de huisartsen vooraf opgegeven criteria (nuchter bloedglucose, HbA1c, werken volgens de NHGStandaard). Hieruit blijkt dat toepassen van landelijke richtlijnen, zoals de ('oude') Standaard, of van eigen normen, niet gemakkelijk is. Deze vaststelling is niet nieuw [10-12]. Het ontbreken van relatief veel gegevens over de metabole regulatie van de patiënten relativeert tevens de betekenis die wordt gegeven aan uitspraken die daarmee verband houden.

De gevonden prevalentie van wegblijven (bijna 8 procent) is bijna tweemaal zo hoog als die was berekend bij Nederlandse huisarts-diabetologen elders. Hij komt overeen 
met wat op grond van literatuuronderzoek verwacht werd (5 tot 10 procent), maar is lager dan de deelnemende artsen zelf vooraf schatten (12 procent). Het absolute aantal patiënten dat wegblijft is 0 tot 8 patiënten per huisarts. Wanneer onze bevindingen representatief zouden zijn voor alle nu in Nederland bekende type 2 diabetespatiënten (250.000 tot wellicht 350.000 personen), dan zouden steeds 20 tot 28.000 van hen (8 procent) een jaar of langer niet gecontroleerd worden $[1,9]$.

Naast de vraag naar omvang en determinanten van wegblijven is de vraag aan de orde wie verantwoordelijk is voor (tegengaan van) dit wegblijven. Hoe ver gaat de verantwoordelijkheid van de (huis)arts om wegblijven te voorkomen of te beperken, waar ligt die van de patiënt? Daarenboven rijst de vraag of wegblijven beschouwd kan worden als een indicator voor de kwaliteit van de geleverde diabeteszorg.

De uitkomsten van onze studie lijken paradoxaal. Wegblijvende diabetespatiënten hebben vaker een goede metabole instelling dan niet-wegblijvende patiënten en zij hebben minder vaak comorbiditeit. De gedachte dringt zich op dat het fenomeen wegblijven wellicht een virtueel probleem is: het komt weliswaar voor - gemiddeld blijft bijna 8 procent van door de huisarts gecontroleerde patiënten met type 2 diabetes een jaar of langer weg van diabetescontrole - maar het lijkt weinig of geen 'gevolgen' voor de regulatie en mogelijk voor de prognose van deze patiënten te hebben. Uit onze bevindingen kan niet worden afgeleid dat de mate van wegblijven een indicator is voor de kwaliteit van de geboden diabeteszorg in de betreffende huisartspraktijk. De kwaliteit van de diabetesregulatie is een betere indicator, samen met andere klinische parameters (bloeddrukwaarden, gewicht, lipiden, optreden van complicaties en mortaliteit), subjectieve gegevens (ervaren kwaliteit van leven, functionele toestand) en/of procesmatige gegevens over het uitvoeren van richtlijnen. De grote variantie in percentages goed- of slecht gereguleerde patiënten per huisarts illustreert dit punt.

Er zijn grenzen aan de verantwoordelijkheid van de hulpverleners, zoals door de deelnemende huisartsen bij de beantwoording van betreffende vragen is aangegeven. Die gedachte sluit aan bij de waarschuwing van Frans Meijman in dit tijdschrift voor 'een betuttelend oproepsysteem' en 'een attitude van politionele acties van de dokter' tegen wegblijven [18]. Toch is en blijft de huisarts verantwoordelijk voor het bieden van optimale diabeteszorg. Daarvoor zijn allerlei zaken nodig. Naast een goede praktijkorganisatie zijn behandel- en samenwerkingsafspraken gewenst 
van huisartsen met praktijkassistente, (diabetes)verpleegkundige, diëtiste en andere artsen om te werken volgens de (inmiddels herziene) NHG-Standaard. De arts dient zich (ook) in diabetes te blijven nascholen, tijdig te starten met orale of insulinebehandeling, te zorgen voor permanente patiënteducatie en aandacht te hebben voor emotionele acceptatie door en steun aan de patiënt. Enige controle op de terugkomtrouw van de patiënten behoort daarbij, eventueel met hulp van een oproepsysteem. De inzet van praktijk- of diabetesverpleegkundigen kan bijdragen aan bewaking van de kwaliteit van de zorg.

Ten aanzien van het wegblijven door patiënten bevelen de auteurs de volgende gedragslijn aan. Wanneer goede diabeteszorg wordt geleverd, zoals net omschreven, en een patiënt blijft weg van diabetescontroles, dan valt het te overwegen één- of tweemaal op te roepen. Volhardt de patiënt in wegblijven, dan lijkt het logisch dit te accepteren als behorend bij zijn of haar eigen verantwoordelijkheid. Op deze wijze respecteert de huisarts de eigen verantwoordelijkheid en autonomie van de patiënt.

\section{DANKBETUIGING}

Onze dank gaat uit naar de deelnemende huisartsen en hun assistentes. Verder bedanken wij het Coördinatiecentrum Chronisch Zieken (Synchron) te Hoensbroek dat de studie mogelijk heeft gemaakt en zijn medewerkers Drs.Haske van Veenendaal, Drs.Margreet Jansen en Drs.Henk Derks. Dr.Hubert Schouten van de afdeling Methodologie en Statistiek van de Universiteit van Maastricht danken wij voor zijn critisch commentaar met betrekking tot de toegepaste statistiek. 


\section{LITERATUUR}

1. Van Dam HA, Crebolder HFJM, Kulcu S, Van Veenendaal H, Van der Horst FG. Wegblijvende diabeten. Een literatuuronderzoek en raadpleging van Nederlandse huisarts-deskundigen. Huisarts Wet 1998; 41 (1): 10-5.

2. Van Dam HA, Kulcu S, Van Veenendaal H. Literatuur en deskundigen over non-attendance bij type 2 diabeten. Synchron-brochure 1996. Besproken in: Ned Tijdschr Geneeskd 1997;141 (3): 174-5.

3. United Kingdom Prospective Diabetes Study Group. Intensive blood glucose control with sulphonylureas and insulin compared with conventional treatment and risk of complications in patients with type 2 diabetes: UKPDS 33 Lancet 1998;352:837-53.

4. Pringle M, Stewart-Evans C, Coupland et al. Influences on control in diabetes mellitus: patient, doctor, practice, or delivery of care? BMJ 1993; 306: 630-4.

5. Dunn N, Pickering R. Does good practice organization improve the outcome of care for diabetic patients? Brit J Gen Pract 1998; 48: 1237-40.

6. Metsemakers JFM, Höppener JA, Kocken RJJ, Limonard CBG. Computerized health information in the Netherlands. A registration network of family practices. Br J Gen Pract 1992; 42: 102-6.

7. Schouten HJA. Klinische Statistiek. Een praktische inleiding in methodologie en analyse. Houten: Bohn Stafleu Van Loghum, 1999.

8. Huizingh KRE. Inleiding SPSS 9,0 voor Windows en Data Entry. Ook voor SPSS 7,5 en 8,0. Schoonhoven: Academic Service, 1999.

9. Stuurgroep Toekomstverkenningen Gezondheidszorg. Chronisch zieken in het jaar 2005. Deel 1. Scnario's over diabetes mellitus 1990-2005. Utrecht/Antwerpen: Bohn, Scheltema en Holkema, 1995.

10. Konings GPJM, Rutten GEHM, Wijkel D. Waarom werken huisartsen niet volgens de NHGStandaard Diabetes Mellitus Type II? Huisarts Wet 1995; 38 (13): 602-7.

11. Konings GPJM, Wijkel D, Rutten GEHM. Implementatie van een standaard. Kenmerken van huisarts, praktijk en organisatie van de diabeteszorg die samenhangen met het al dan niet volgen van de NHG-Standaard Diabetes mellitus Type II. Huisarts Wet 1996; 39 (12):560-3.

12. Cromme PVM, Mulder Dzn JD, Rutten GEHM, Zuidweg J, Thomas S. NHG-Standaard Diabetes Mellitus Type II (1989). In: Rutten GEHM, Thomas S (red), NHG-Standaarden voor de huisarts. Nederlands Huisartsen Genootschap, Utrecht: Bunge, 1993. (Herziene versie verscheen in 1999).

13. Reenders K, Van den Hoogen HJM, Van Weel C. Functionele toestand, complicaties en comorbiditeit bij 249 NIDDM-patiënten. Huisarts Wet 1992; 35 (10): 386-90.

14. Verhoeven S. Behandeling, controle en metabole instelling van patiënten met diabetes mellitus type II en de prevalentie van late complicaties bij deze patiënten. [Dissertatie]. Rotterdam: Erasmus Universiteit Rotterdam, 1989.

15. Bouma M, Dekker JH, Schellevis FG, Van Eijk JTM, Heine RJ. Effect van invoering van geprotocolleerde zorg door de huisarts op de glykemische instelling van niet van insuline afhankelijke diabetes mellitus-patiënten; voorlopige resultaten. Ned Tijdschr Geneeskd 1996; 140 (13): 746-7.

16. Jacobs ML, Akkerhuis KM, Van Dijk MJ, Kuis FBM, Veldkamp RTM, Weber RFA. Betere diabetesregulatie door strikt toepassen van de Standaard 'Diabetes Mellitus type II' van het Nederlands Huisartsen Genootschap. Ned Tijdschr Geneesk 1995; 139 (24): 1241-5. 
17. Van Dam HA, Crebolder HFJM, Van der Grinten RF, Wouters A,Van der Horst FG. Metabole regulatie, functionele toestand en kwaliteit van leven bij type II diabeten. Een exploratieve studie in de huisartspraktijk. Huisarts Wet 1995; 38 (13): 618-22.

18. Meijman FJ en Reenders K. Autonomie en zorgzaamheid bij diabeteszorg. Huisarts Wet 1999;42(2):45. 


\section{TABEL 1: KENMERKEN VAN HUISARTSEN EN PRAKTIJKGROEPEN}

Huisartskenmerken ( $\mathrm{n}=38)$

Gemiddelde of percentages (spreiding), SD*

\section{Leeftijd}

$44 \mathrm{jr} \quad(33-60)$

Geslacht $=$ man

$87 \%$

Jaren ervaring als huisarts $\quad 15 \mathrm{jr}$

Diabetesnascholing in laatste jaar

$76 \%$

$\mathrm{SD} \pm 7,4$

VAS-score: wie verantw.voor wegblijven

Tegengaan van wegblijven is beleid

$70 \mathrm{~mm}(45-100)$

$42 \%$

Vooraf door de artsen geschat \% wegblijvers12\% (3-50)

Door de artsen (vooraf) opgegeven criterium

voor beoordeling van de kwaliteit van

de regulatie

HbA1c 71\%; nuchter bloedgluc. 89,5\%

Zegt (vooraf) de NHG-standaard te volgen $74 \%$

Aantal patiënten per huisarts

2000; verdeling: <1500(11\%), 1500-2350(57\%), 2350-2700(21\%) en $>2700(11 \%)$

Aantal type 2 diab.door HA behandeld $\quad 25,4 \quad(1-61) \quad$ SD \pm 16

Huisartsen $(n=38)$ en praktijkgroepen $(n=14)$

Vestigingsgebied $=$ stad

$24 / 38=71 \%$

Praktijkvorm=solo

$3 / 38=8 \%$ (15\% van de patiënten)

Eigen diabetesprotocol aanwezig

$14 / 38=38 \%$

Oproepsysteem aanwezig

$13 / 38=34 \%$

Assistente doet zelfstandig diab.spreekuur

$10 / 38=26 \%$ (in $29 \%$ van de praktijkgroepen)

$\left({ }^{*} \mathrm{SD}=\right.$ Standaarddeviatie $)$ 


\section{TABEL 2: PATIËNTKENMERKEN ( $n=964)$.}

$\underline{\text { Kenmerk }}$

$\underline{\text { missing* }}$

Leeftijd

$$
\begin{aligned}
& <50 \mathrm{jr} \\
& 51-70 \mathrm{jr} \\
& >70 \mathrm{jr}
\end{aligned}
$$

Geslacht $=$ man

Duur diabetes

$$
35=4 \%
$$

$$
>2 \mathrm{jr}
$$

Behandelwijze: alleen dieet

tabletten

$30=3 \%$

insuline

Wegblijven $\geq 12$ mndn

Gemiddelde of percentage (spreiding), SD,

$$
69 \mathrm{jr} \quad \text { (33-95) } \quad \mathrm{SD} \pm 11,4 \mathrm{jr}
$$

$7 \%$

46

47

$45 \%$

7,3 jr (0-55) SD $\pm 6,9$ jr missing

\section{$71 \%$}

$23 \% \quad)$

$70 \quad)$

missing

$7 \quad)$

$8 \% \quad(0-30)$

missing

in HAgroepen met 1-2 artsen $11 \%$

in HAgroepen met 3-5 artsen 6

Quetelet Index $(\mathrm{kg} / \mathrm{m} 2)$ gemiddeld 28

$649=67 \%$

$$
\begin{array}{ll}
\text { goed gewicht }(\mathrm{QI}<27) & 55 \% \\
\text { matig overgew. }(\mathrm{QI} 28-30) & 20 \\
\text { sterk overgewicht }(\mathrm{QI}>30) & 25
\end{array}
$$

Nuchter bloedgluc.(mmol/l) gemiddeld $\quad 8,3$

$219=23 \%$

$$
\begin{array}{ll}
\text { goed }<6,7 & 29 \% \\
\text { matig } 6,7-8,0 & 24 \\
\text { slecht }>8,0 & 47
\end{array}
$$

HbA1c (\%) gemiddeld $777=81 \%$

$7,9 \quad(5,0-13,9) \quad$ SD $1,7 \quad$ missing

$\begin{array}{ll}\text { goed }<7,0 & 30 \% \\ \text { matig 7,0-8,5 } & 40 \\ \text { slecht }>8,5 & 30 \\ \text { 'aanwezig' } & 58 \% \\ \text { it 'aanwezig' } & 79\end{array}$

( ${ }^{*} \mathrm{SD}=$ Standaarddeviatie. Missing= aantal patiënten/percentage met ontbrekende gegevens) 
TABEL 3: VERSCHILLEN TUSSEN WEGBLIJVERS EN NIET-WEGBLIJVERS.

Percentages en ruwe Odd's Ratios (OR) voor de verschillen, met $95 \%$

betrouwbaarheidsinterval, afgerond tot een decimaal achter de komma*.

Huisartskenmerken ( $\mathrm{n}=38$ )

\begin{tabular}{|c|c|}
\hline $\begin{array}{l}\text { WEGBLIJVERS } \\
>12 \text { maanden }\end{array}$ & $\begin{array}{l}\text { NIET- } \\
\text { WEGBLIJVERS }\end{array}$ \\
\hline$(\mathrm{n}=71)$ & $(n=847)$ \\
\hline
\end{tabular}

$\underline{\mathrm{OR}(95 \% \mathrm{BI})}$

1.Diabetesnascholing gevolgd $\quad 75 \%$

Praktijkkenmerken ( $\mathrm{n}=14)$

2.Praktijkvorm niet-solo (duo/groep)78

3.Eigen diabetesprotocol 24

$24 \quad 44$

$84 \%$

$0,6(0,3-1,0)$

4.Oproepsysteem

30

44

$0,6(0,3-1,0)$

Patiëntkenmerken ( $\mathrm{n}=964)$

5.Geslacht 'man' 56

$56 \quad 44$

44
28

$0,4(0,2-0,7)$

6.Nuchter bldgluc.goed $(<6,7 \mathrm{mmol} / \mathrm{l}) 47$

48

$0,5(0,3-0,9)$

7.Comorbiditeit aanwezig

$\begin{array}{ll}\text { (slecht }(>8,0) & 40 \\ \text { anwezig } & 68\end{array}$

80

$1,6(1,0-2,7)$

$2,3(1,3-4,1)$

$0,6(0,4-1,3))$

8.Intensievere behandelwijze

(insuline en/of orale antidiabetica) 45

9.Volgt voorschriften 'goed' 18

78

$0,5(0,3-0,9)$

10.Acceptatie 'goed'

41

$0,2(0,1-0,4)$

11.Kennis 'goed'

49

$0,3(0,2-0,6)$

12.Belemmeringen 'aanwezig'

19

35

$0,2(0,1-0,5)$

57

42

$0,4(0,2-0,8)$

13.Emotionele steun 'aanwezig'

13

25

$1,8(1,1-2,9)$

$0,5(0,2-0,9)$

* Alleen kenmerken waarbij de 1,0 niet binnen het 95\%-betrouwbaarheidsinterval ligt zijn opgenomen. Alleen is 'Nuchter bloedglucose 'slecht' $(>0,8)$ ' ter illustratie aan 6 toegevoegd, waarvoor dit criterium niet geldt. ( $N=918$, missing $46=5 \%)$ 


\section{TABEL 4: LOGISTISCHE REGRESSIE VOOR WEGBLIJVEN EN GOEDE METABOLE REGULATIE MET DE VARIABELEN UIT TABEL 3}

Odd's Ratios (OR) voor wegblijven (4A) en goede regulatie (4B), gecorrigeerd voor de andere variabelen, met 95\%- betrouwbaarheidsintervallen (95\%-B.I.), regressiecoëfficiënten $(B)$ en significantieniveau's $(p)$. Behalve voor $p$ zijn de getallen afgerond tot een decimaal achter de komma.

4A. Wegblijven (Wb).

1. $\mathrm{Wb}$ - Diabetesnascholing gevolgd

2. Wb - Praktijkvorm niet-solo

3. $\mathrm{Wb}$ - Eigen diabetesprotocol aanwezig

4. $\mathrm{Wb}$ - Oproepsysteem aanwezig

$\underline{\text { OR }} \quad \underline{(95 \%-B . I .)} \quad \underline{\text { B }} \quad \underline{\text { p-sign. }}$

5. $\mathrm{Wb}-$ Geslacht $=$ man

6. Wb - Nuchter bloedgluc.goed $(<6,7 \mathrm{mmol})$

7. $\mathrm{Wb}$ - Comorbiditeit aanwezig

8. Wb - Intensievere behandelwijze

9. Wb - Volgt voorschriften 'goed'

10.Wb - Acceptatie 'goed'

11.Wb - Kennis 'goed

12.Wb - Belemmeringen 'aanwezig'

13.Wb - Emotionele steun 'aanwezig'

( $\mathrm{Wb}$ - Constante

$\begin{array}{lccl}0,9 & (0,4-1,9) & -0,1 & 0,799 \\ 1,6 & (0,6-4,2) & 0,5 & 0,346 \\ 0,3 & (0,1-0,6) & -1,4 & 0,001^{* *} \\ 0,9 & (0,4-1,8) & -0,1 & 0,691 \\ 2,2 & (1,1-5,0) & 0,8 & 0,016^{* *} \\ 1,8 & (1,0-3,3) & 0,6 & 0,082^{*} \\ 0,5 & (0,2-1,0) & -0,7 & 0,045^{* *} \\ 0,3 & (0,2-0,6) & -1,1 & 0,001^{* *} \\ 0,7 & (0,3-1,8) & -0,3 & 0,510 \\ 0,2 & (0,1-0,6) & -1,4 & 0,003^{* *} \\ 0,7 & (0,3-1,7) & -0,3 & 0,461 \\ 0,6 & (0,3-1,2) & -0,4 & 0,182 \\ 0,8 & (0,3-2,2) & -0,2 & 0,666 \\ - & - & 1,5 & 0,043^{* *}\end{array}$

4B. Goede Regulatie (GR).
1. GR - Diabetesnascholing gevolgd
2. GR - Praktijkvorm niet-solo
$2,0 \quad(1,0-2,5)$
$0,5 \quad 0,061^{*}$
$0,5 \quad(0,2-0,8)$
$-0,8 \quad 0,013^{* *}$
3. GR - Eigen diabetesprotocol aanwezig
1,3
$(0,8-1,7)$
$0,2 \quad 0,417$
4. GR-Oproepsysteem aanwezig
5. GR - Geslacht = man
6. GR - Wegblijven ( $\geq 12$ maanden)
1,3
$(0,8-2,0)$
$0,2 \quad 0,279$
1,2
$(0,8-1,7)$
$0,2 \quad 0,353$
7. GR - Comorbiditeit aanwezig
2,2
$(1,3-3,7)$
$0,6 \quad 0,065^{*}$
0,9
$(0,6-1,4)$
$-0,1 \quad 0,659$
8. GR - Intensievere behandelwijze
$0,3 \quad(0,2-0,4)$
$-1,3 \quad 0,000 * *$
9. GR - Volgt voorschriften 'goed'
$1,3 \quad(0,8-2,0)$
$0,2 \quad 0,324$
10.GR - Acceptatie 'goed'
$1,3 \quad(0,8-2,0)$
$0,2 \quad 0,304$
11.GR - Kennis 'goed'
1,3
$(0,5-1,3)$
$0,3 \quad 0,261$
12.GR - Belemmeringen 'aanwezig'
1,3
$(0,6-1,2)$
$0,2 \quad 0,272$
13.GR - Emotionele steun 'aanwezig'
1,4
$(0,9-2,0)$
$0,3 \quad 0,153$
( $G R$ - Constante
$0,7 \quad 0,128)$

De dertien variabelen uit tabel 3 zijn als onafhankelijke, 'verklarende' variabelen voor wegblijven respectievelijk goede regulatie in de regressie ingevoerd. Voor 'nascholing gevolgd' is $n=38$ (huisartsen), voor 'praktijkvorm niet-solo', 'eigen diabetesprotocol' en 'oproepsysteem' is $n=14$ (praktijkgroepen) en voor de overige variabelen is $n=712$ (patiënten met complete datasets).

De variabelen gemarkeerd met * of ** zijn statistisch significant met een p van respectievelijk $<0,1$ en $<0,05$ en een $95 \%$ BI dat niet de 1,0 omsluit. 


\section{APPENDIX}

Commentaren en discussie in ingezonden brieven

(Comments and debate in letters to the editor) 
INGEZONDEN

\section{Wegblijven diabeten 1}

Van Dam et al. trekken ten onrechte conclusies over de metabole regulatie van patiënten met diabetes mellitus type 2 die wegblijven van controle \{Huisarts Wet 2000;43(9):380-384), en hun artikel wekt op verkeerde gronden de suggestie dat het niet-toepassen van systematische controle geen nadelige invloed zou hebben op de diabeteszorg. Onze belangrijkste punten van kritiek zijn:

- Het onderzoeksdesign is niet geschikt om de eerste vraagstelling (vergelijking van de metabole regulatie tussen wegblijvers en niet-wegblijvers) te beantwoorden. Daarvoor had de metabole regulatie in beide groepen op hetzelfde tijdstip moeten zijn bepaald. Van Dam et al. hebben echter de metabole regulatie van de wegblijvers niet bepaald nâ hun wegblijven, maar in plaats daarvan de waarden van de laatste controle genomen, dat is dus minimaal 12 maanden eerder. Vanwege ditzelfde probleem zou de tweede vraagstelling zich dienen te beperken tot de samenhang tussen 'wegblijven' en kenmerken van praktijk, huisarts en patiënt.

- Omdat het HbAlc bij $81 \%$ van de patiënten ontbrak, namen Van Dam et al. daarvoor in de plaats het nuchtere bloedglucose als uitkomstmaat. Die parameter die ook nog bij $23 \%$ van de patiënten bleek te ontbreken - is naar huidige inzichten ongeschikt om in wetenschappelijk onderzoek de glycemische regulatie te bepalen.

- De gebruikte analysetechnieken zijn niet optimaal gekozen. Voor dit onderzoek is een regressieanalyse minder geschikt dan multilevel-technieken Het is overigens een misvatting dat bij regressieanalyse automatisch gecorrigeerd wordt voor overige variabelen. Deze techniek is slechts een hulpmiddel om, in combinatie met kritisch inhoudelijk denken, tot een juiste interpretatie te komen. De diverse niveaus (praktijk, huisarts, patiënt) waarop variabelen zijn verzameld, zijn niet onafhankeljk van elkaar. Wij hebben de stellige indruk dat bij een multilevel-analyse de verklaarde variantie op het niveau van de praktijk (denk aan de variabele oproepsysteem; in dit onderzoek bleef bij negen huisartsen niet één patiënt weg, bij negen andere lag dat percentage boven de $10 \%$ ) de bijdrage van de andere niveaus vrijwel geheel zal overvleugelen.

Andere punten van kritiek zijn: - de onderzoeksgroep omvat slechts $55 \%$ van de bronpopulatie; de afzonderlijke bijdrage van de exclusiecriteria en de spreiding hiervan per praktijk worden niet vermeld; - van wegblijvers is niet vermeld hoe lang zij niet gecontroleerd zijn; - de aanbeveling om een of twee oproepen te plaatsen en het vervolgens aan de eigen verantwoordelijkheid van de patiënt over te laten is als interventie niet onderzocht. Kortom: Van Dam et al. zetten de huisarts op het verkeerde been met hun onderzoek naar het wegblijven van patiënten met diabetes mellitus type 2 .

W.J.C. de Grauw, huisarts, H.J.M. van den Hoogen, statisticus, dr. E.H. van de Lisdonk, huisarts

\section{Wegblijven diabeten 2}

De conclusie van Van Dam et al. dat wegblijvende diabeten geen slechtere regulatie 
hebben dan compliante patiënten (Huisarts Wet 2000; 43(9):380-4) en de suggestie van Zaat dat wegblijvende diabeten misschien wel groot gelijk hebben (Huisarts Wet 2000;43(9):374) vragen om een reactie.

Van Dam et aL gebruiken als maat voor de regulatie de nuchtere glucosewaarde. Bij 211 van de 918 diabeten ontbrak deze waarde echter. Toch zijn deze patiënten niet uitgesloten. Hoe waren deze 211 diabeten met niet-nuchtere en dus hogere waarden verdeeld over beide groepen?

$\mathrm{Er}$ is een groot verschil tussen beide groepen in therapievorm: bij de wegblijvers werd $55 \%$ alleen met dieet behandeld, bij de compliante groep $22 \%$. Zou het niet mogelijk zijn dat de diagnose diabetes bij een aanzienlijk deel van de wegblijvers destijds op onjuiste gronden is gesteld, en dat deze mensen dus geen diabeet (meer) zijn? Wegblijven zou vooral schadelijk kunnen zijn bij patiënten die klachtenvrij blijven rondlopen, maar wel hoge glucosewaarden hebben - bijvoorbeeld $>10$ of $>15 \mathrm{mmoL} / \mathrm{l}$ - omdat er een grote kans op ontregeling bij infecties en stress is. Hoe groot is dat aantal?

De metingen van de (al of niet) nuchtere glucosewaarden vonden voor beide groepen op verschillende tijdstippen plaats: bij de wegblijvers gemiddeld een jaar eerder dan bij de niet-wegblijvers. Wanneer de huisartsen in de tussentijd hun normen strakker zijn gaan hanteren, is het verschil alleen al daardoor te verklaren. De wegblijvers hadden een bijna even slechte regulatie als de niet-wegblijvers. In die zin maakt het allemaal niet uit. Interessant zou de vergelijking zijn tussen wegblijvers en niet-wegblijvers in een populatie diabeten die veel beter zijn ingesteld. Wegblijven is uiteraard de keuze van de patiënt, maar zou het niet de verantwoordelijkheid van de dokter kunnen (moeten?) zijn om deze mensen te informeren over de voors en tegens van die keuze?

Klaas Reenders, huisarts te Hoogeveen

\section{Naschrift}

De Grauw et al. stellen dat ons artikel 'de huisarts op het verkeerde been zet' wegens de suggestie dat nalaten van controle geen nadelige invloed heeft. Zij hebben nog andere kritiekpunten. Ook Reenders is bezorgd en vraagt of het niet de verantwoordelijkheid van de huisarts is de wegblijvers te informeren over de voors en tegens. Wij vonden dat de wegblijvende groep diabetespatiënten relatief meer goed gereguleerde en minder slecht gereguleerde personen omvatte dan de groep niet-wegbljvers. De samenvatting bij het artikel bevat hierover een fout. In de zin ' $47 \%$ van de wegblijvers was goed gereguleerd, tegen $40 \%$ van de niet-wegblijvers' moet het tweede percentage 28 zijn. Kortom, met de wegblijvers 'lijkt het mee te vallen'. De metabole regulatie van wel/niet-wegblijvende patiënten is op verschillende tijdstippen bepaald; dat hebben wij vermeld. Van de wegblijvers werd meer dan de helft met alleen dieet behandeld, van de niet-wegblijvers $22 \%$; ook dit werd genoemd. Dat in eerstgenoemde groep vaker ten onrechte de diagnose 'diabetes' was gesteld (Reenders) lijkt ons onwaarschijnlijk. HbA1c-waarden ontbraken bij $81 \%$ van de patiënten, nuchtere glucosewaarden bij $23 \%$; zeker, 
teleurstellende feiten. Wij kozen - pragmatisch - voor gebruik van het nuchtere bloedglucose voor bepaling van de regulatie. In eerder onderzoek werd een hoge Pearson-correlatie $(0,79)$ tussen nuchtere-bloedgiucosewaarden en HbA1cpercentages gevonden [1]. De NHG-Standaard Diabetes Mellitus Type 2 verwijst ook naar deze samenhang [2]. Wij zijn het eens met De Grauw er al. dat meting van $\mathrm{HbAlc}$-waarden op hetzelfde tijdstip bij alle ingesloten patiënten eleganter zou zijn geweest. De opzet van ons onderzoek maakte dat niet mogelijk. De Grauw et al. stellen dat multilevel-techniek geschikter is dan de door ons toegepaste regressieanalyse. Ten tijde van ons onderzoek (1997-1998) was deze methode nog niet algemeen beschikbaar. Regressieanalyse is echter een acceptabele techniek, ook voor correctie van variabelen. Op voorhand is het niet aannemelijk dat multilevel-techniek tot andere conclusies zou hebben geleid. Van de groep van 1719 personen met diagnosecode T90 (alle typen diabetes) vormde de groep met type-2diabetes een deel. Uit deze 'bronpopulatie' recruteerden wij de 964 patiënten voor ons onderzoek: de door de huisarts gecontroleerde type-2-diabeten. Exclusiecriteria werden niet toegepast en er waren geen uitvallers. In aanvullend onderzoek onder dertien deelnemende huisartsen vonden we dat zij gemiddeld 68\% van hun type-2diabetespatiënten controleerden. Door inkortingen is in het artikel de duur van het wegblijven niet vermeld. Deze is echter wel bekend: spreiding 1 tot 10 , gemiddelde ruim 2, mediaan 5 jaar.

Conclusie.

Bij het oproepen van wegblijvers gaat het om de balans tussen verantwoordelijkheden van arts, diabetesteam en patiënt. Het ontslaat de huisarts niet van de plicht ieder contact te gebruiken om wegblijven en eventueel slechte regulatie te bespreken. Hierin zijn wij het eens met Reenders. Goede, systematische controle van alle diabetespatiënten blijft uitgangspunt. Ons standpunt blijft:

wegblijven van type 2 diabetespatiënten in de huisartspraktijk is een reëel fenomeen dat nauwkeurige diabeteszorg rechtvaardigt, inclusief bewaking van de terugkomtrouw, maar is geen reden voor een heksenjacht.

Henk van Dam

Harry Crebolder

Frans van der Horst

Irmgard Eijkelberg

Martijn van Nunen.

1 Crebolder $\mathrm{H}$, Van Eijndhoven M. De begeleiding van type II diabeten. Huisarts Wet 1986;29 (Suppl H\&P I0):16-9.

2 Rutten GEHM, Verhoeven S, Heine RJ, et al. NHG-Standaard Diabetes Mellitus Type 2 (eerste herziening). Huisarts wet 1999;42:67-84.

\section{Wegblijven diabeten 3}

De uitspraken van Zaat op basis van een artikel van McCormack \& Greenhlagh [1] (Huisarts Wet 2000;43(9):374) doen geen recht aan de uitkomsten van de UKPDS en diverse andere onderzoeken. De uitkomsten van de UKPDS lijken inderdaad teleurstellend, wanneer naar het gemiddelde verschil in $\mathrm{HbAlc}$ van $0,9 \%$ wordt gekeken. Toch zou volgens recente, maar nog niet gepubliceerde uitkomsten elk 
procent verlaging samenhangen met een vermindering van risico. Daarnaast is behandeling van met name diabetes mellitus type 2 niet alleen gebaseerd op de regulering van de glucosestofwisseling, maar ook op de beïnvloeding van het rooken leefgedrag, de bloeddruk en het vetspectrum; diabetes mellitus type 2 is immers een cardiovasculaire aandoening.

Effecten van de behandeling bij diabetes mellitus kunnen ook worden uitgedrukt in 'numbers needed to treat' (NNT) - het aantal incidenten dat wordt voorkómen door behandeling. Het volgende overzicht is gebaseerd op de uitkomsten van de UKPDS, de HOT, de 4S, de CARE en een aantal artikelen over acetylsalicylzuur[2].

Om één microvasculaire complicatie te verhinderen bij behandeling gedurende vijf jaar:

- per 1\% HbAlc-verlaging NNT 72

- per 10/5 mmHg bloeddrukverlaging NNT 28

Om één macrovasculaire complicatie (myocardinfarct en/of CVA) te verhinderen bij behandeling gedurende vijf jaar:

- per $1 \%$ HbA1c-verlaging NNT 20

- per I0/5mmHg bloeddrukverlaging NNT 12

- LDL-verlaging tot $<2.6 \mathrm{mmol} / \mathrm{l}$ bij patiënten met manifeste hart-vaatziekte NNT 6

- LDL-verlaging tot $<3,4 \mathrm{mmot} / \mathrm{l}$ bij patiënten zonder manifeste hart-vaatzjekte

- gebruik van acetylsalicylzuur

Het zal duidelijk zijn dat de traditionele koppelingen tussen enerzijds

glucoseregulatie en microvasculaire complicaties en anderzijds cardiovasculaire risicofactoren en macrovasculaire complicaties niet meer gelden: beïnvloeding van de glucoseregulatie en regulering van de bloeddruk hebben immers beide effect op zowel micro- als macrovasculaire complicaties.

Bij duidelijkheid over de NNT's is het aan de individuele behandelaar om op basis van de beschikbare gegevens en in overleg met de patiënt te bezien of een potentiële risicoreductie inderdaad de moeite waard is. Dat kan er misschien toe leiden dat de nadruk wat verschuift van de glucoseregulatie naar correctie van een verhoogde bloeddruk en vetspectrumafwijkingen, met name wanneer het om nog kleine verschillen met de streefwaarden gaat.

\section{H.J.G. Bilo, L Ubink-Veltmaat. Isala Klinieken, Zwolle}

(1) McCormack J, Greenhlagh T. Seeing what you want to see in randomised controlled trials: version and perversions of UKPDS data. BMJ 2000;320:1720-3.(2) Colwell JA. Aspirin therapy in diabetes. Diabetes Care 1997;20:1767-71.

\section{Naschrift}

Bilo \& Ubink nemen een aantal onderzoeken samen en stellen dan een rijtje NNT's op. Alleen de verlaging van de bloeddruk met $10 / 5 \mathrm{mmHg}$ en de verlaging van het LDL-gehalte bij patiënten met een manifeste hart-vaatziekte zijn 'aantrekkelijk laag'. Hoe verkoop ik het mevrouw Jansen om én drie soorten pillen voor haar bloeddruk te slikken én insuline te spuiten om haar $\mathrm{HbA1c}$ te laten dalen, als ik haar evens moet vertellen dat ik wel 20 mevrouwen moet behandelen om één infarct of CVA uit te stellen? Bovendien zijn de dalingen in het rijtje van Bilo \& Ubink zelfs in gestructureerde zorgprojecten niet haalbaar. Uit een overzicht van beide auteurs 
blijkt dat de HbA1c-waarden in transmurale diabetesprojecten in West-Brabant en Hoorn met 0,3-0,4\% daalden, en de systolische bloeddruk met 2,9 mmHg [1]. Die dalingen zijn weliswaar significant, maar dat komt alleen door de grote aantallen.

Ook Groeneveld kon geen duidelijke daling in allerlei parameters vinden bij de evaluatie van het Diabetesproject Leiden; slechts $0,4 \%$ verschil in HbA1c tussen interventie en gewone zorg, en geen verbetering van bloeddruk, gewicht en bloedvetten [2]. De patiënten in de interventiegroep kostten per jaar wel 2,5 maal meer dan de controlepatiënten.

Hoe je het wendt of keert, de uitkomsten van al het onderzoek blijven teleurstellend voor de gewone huisarts en de patiënt. De discussie over het nut van gestructureerde en strenge zorg is dus helemaal nog niet gesloten, in tegendeel.

Joost Zaat (hoofdredacteur Huisarts en Wetenschap)

1. Bilo BLG, van Nunen F, van Ballegooie E, Meyboom-de Jong 8, Ubink-Veltmaat LJ. Transmurale zorgvormen van diabetes mellitus; een verkenning van de situatie anno 2000. Zwolle: Isalaklinieken, 2000

2. Groeneveld Y. Introduction of structured diabetes care in general practice. [Dissertatie] Leiden: Universiteit Leiden, 2000.

\section{Wegblijven diabeten 4}

Van Dam et al. suggereren dat het wegblijven van patiënten met diabetes mellitus type 2 geen 'echt probleem' is (Huisarts Wet 2000;43(9):380.). Of deze conclusie getrokken mag worden op basis van dit artikel, is de vraag.

Wegblijvers en niet-wegblijvers worden verdeeld in goed- en slechtgereguleerden op basis van de nuchtere-glucosewaarde. Deze waarde is echter niet in alle gevallen een maat voor de kwaliteit van de metabole regulatie: een slechte nuchtere glucose kan bestaan bij goed gereguleerde patiënten en moet volgens de Standaard bij een goed $\mathrm{HbA} 1 \mathrm{c}$ worden beschouwd als een momentane uitschieter; omgekeerd blijkt uit nog niet gepubliceerd onderzoek van Rutten et al. dat nuchtere glucoses $<7 \mathrm{mmol} / \mathrm{l}$ ook kunnen voorkomen bij een $\mathrm{HbA} 1 \mathrm{c}>7 \%$.

Niet-nuchtere glucoses van patiënten die meer dan een jaar zijn weggebleven, worden vergeleken met die van niet-weggebleven patiënten? Welke glucoses zijn hiervoor genomen? Bij 23\% ( $n=211)$ werd helemaal geen uitslag gevonden: ontbrak deze uitslag even vaak bij wegblijvers $(n=71)$ als bij niet-wegblijvers? Of het wegblijven een 'echt probleem' is, wordt bovendien niet alleen bepaald door de glucoseregulatie. In grote prospectieve onderzoeken is aangetoond dat regulatie van cardiovasculaire risicofactoren minstens even belangrijk, zo niet belangrijker is $[2,3]$. Gesteld dat wegblijvers inderdaad een betere regulatie zouden hebben en gesteld dat dit zou kunnen leiden tot een terughoudend beleid van huisartsen bij het oproepen van patiënten, loopt men dan niet de kans mis om een gestoord cardiovasculair risicoprofiel te signaleren en te corrigeren? Gaat dan niet definitief een uitgelezen kans tot gerichte preventie van complicaties voorbij? 
L. Ubink-Veltmaat, B. Houweling, H.J.G. Bilo - Isala klinieken, Zwolle

Roel Rischen, MCC Klik Transmuraal Diabetes Project, Zwolle

(1) Rutten GEHM, Verhoeven S, Heine RJ, et al. NHG-Standaard Diabetes Mellitus Type 2 (eerste herziening). Huisarts Wet 1999;42:67-84. (2) Pyörâls K, Pedersen T, Klekshus J, el al. Cholesterol lowering with simvastatin improves prognosis of diabetic patients with coronary heart diabetes: a subgroup analysis of the Scandinavian Simvastatin Survival Study (4S). Diab Care 1997;20: 614-20. (3) UKPDS Group. Tight blood pressure control and risk of macrovascular and microvascular complications in type 2 diabetes (UKPDS 35). BMJ 1998;317:703-I3.

\section{Naschrift}

Ubink et al. plaatsen kanttekeningen bij onze conclusie die de suggestie wekt dat nalaten van controle geen nadelige invloed zou hebben. Hun kritiek richt zich voorts op het gebruik van nuchtere glucosewaarden in plaats van $\mathrm{HbA} 1 \mathrm{c}$-percentages, op het vergelijken van patiënten die wegbleven met patiënten die niet wegbleven, en op de aantallen patiënten met ontbrekende waarden.

In ons antwoord aan De Grauw et al. en Reenders zijn we hierop reeds ingegaan (Huisarts Wet 2000;43(13):580). Wij bepleiten niet om het oproepen van wegblijvers achterwege te laten.

Oproepen van wegblijvers heeft te maken met het zoeken naar de balans tussen de verantwoordelijkheid van de behandelend arts of het diabetesteam om goede diabeteszorg te leveren, en die van de patiënt om zelf te beslissen. Dit benadrukt het belang van partnerschap tussen patiënt en behandelteam. Vandaar onze suggestie om wegblijvers één- of tweemaal op te roepen, ook al is de effectiviteit van deze interventie niet onderzocht. Het ontslaat de huisarts niet van de plicht ieder contact aan te grijpen om wegblijven, diabetesregulatie en cardiovasculair risicoprofiel (lipiden, bloeddruk, roken, bewegen, voeding, etc.) te bespreken. Herhaald zij dat ons uitgangspunt systematische controle van alle type-2diabetespatiënten blijft, inclusief bewaking van terugkomtrouw, maar geen heksenjacht.

Henk van Dam, Harry Crebolder, Frans van der Horst, Irmgard Eijkelberg, Martijn van Nunen 


\section{CHAPTER 5}

Social support in diabetes - a systematic review of controlled intervention studies

(Sociale steun bij diabetes - een systematische literatuurstudie van gecontroleerde interventiestudies) 


\section{Social support in diabetes - a systematic review of controlled intervention studies}

(Sociale steun bij diabetes - een systematische literatuurstudie van gecontroleerde interventiestudies)

Henk A van Dam* Frans $\mathrm{G}$ van der Horst* Lut Knoops** Richard M Ryckman *** Harry FJM Crebolder * Bart HW van den Borne**

Patient Educ Couns - in press 2004/2005

Corresponding author: Henk A van Dam Gezondheidscentrum Withuis, Straelseweg 193, 5914 AL VENLO, the Netherlands Tel. +31 77 3517652, fax. +31 77 3589705, email: vandam-hylkema@home.nl.

$\left.{ }^{*}\right)$ Maastricht University, Department of General Practice - Maastricht, the Netherlands

$\left.{ }^{(* *}\right)$ Maastricht University, Department of Health Sciences, section Patient Education - Maastricht, the Netherlands $\left.{ }^{* * *}\right)$ University of Maine, Department of Psychology - Orono, Maine, USA 


\begin{abstract}
Systematic, computerized search in Medline, the Cochrane Library, Eric, PsychINFO and Embase files, 1980 through 2003, selecting descriptions of prospective controlled trials with good methodological design, testing effects of social support interventions on health outcomes in primary and outpatient care for type 2 diabetes. Six controlled trials were reviewed. They defined, modified, and measured social support in various ways, and scored outcomes with varying measures. Gender differences and the right amount of support seem important. Diabetes control did not improve by spouse support (more weight loss in women) and family and friends support (no differences). Men may have negative effects from spouse support. Promising new forms of social support are group consultations (better HbA1c), internet or telephone-based peer support (improved perceived support, increased physical activity, resp.), and social support groups (improved knowledge and psychosocial functioning).

It is tentatively concluded that this review supports the hypothesis that organizing specific social support interventions affect patient selfcare and diabetes outcomes. New forms of social support may be discussed and incorporated in the work of diabetes teams, and offered to patients as new possibilities to help them adjust to a life with (type 2) diabetes and make information-based decisions. More well-designed research testing the effects of specific social support interventions on patient selfcare, lifestyle adaptations, and outcomes of diabetes care, is warranted.
\end{abstract}

Key words: type 2 diabetes, social support, intervention, selfcare, outcomes, review

\title{
SAMENVATTING
}

Met een systematische, geautomatiseerde literatuurzoekactie in de bestanden van Medline, de Cochrane Library, Eric, PsychINFO en Embase files, van 1980 tot en met 2003, werd gezocht naar beschrijvingen van methodologisch goed opgezette, prospectieve, gecontroleerde studies naar de effecten van sociale steuninterventies op de gezondheidsuitkomsten van type 2 diabetespatiënten in de eerstelijn en poliklinieken. Zes van zulke gecontroleerde trials werden beoordeeld. Zij definieerden, veranderden, en maten sociale steun op uiteenlopende wijzen, en maten ook de uitkomsten met uiteenlopende instrumenten. Geslachtsverschillen en de juiste hoeveelheid steun leken van belang. Steun van de partner hing wel samen met meer gewichtsverlies bij vrouwen, maar niet met verbeterde diabetesregulatie, evenmin als steun van familie en vrienden. Mannen hebben misschien negatieve effecten van steun door hun partner. Nieuwe vormen van sociale steun zijn veelbelovend: groepsconsulten (beter $\mathrm{HbA1c}$ ), lotgenotensteun via internet of telefoon (verbeterde ervaren steun, respectievelijk toegenomen lichamelijke activiteit), en sociale steungroepen (toegenomen kennis en beter psychosociaal functioneren).

Voorzichtig wordt geconcludeerd dat deze review de hypothese ondersteunt dat het organiseren van specifieke vormen van sociale steun de patiëntenzelfzorg en diabetesuitkomsten kunnen beïnvloeden. Nieuwe vormen van sociale steun zouden in het werk van diabetesteams bediscussieerd en opgenomen kunnen worden, en aangeboden aan de patiënten als nieuwe mogelijkheden om hen te helpen zich aan het leven met type 2 diabetes aan te passen en keuzen te maken op basis van goede informatie. 


\section{INTRODUCTION}

\subsection{General introduction}

The dramatic increase of type 2 diabetes makes studying the factors influencing outcomes and effectiveness of diabetes care more and more relevant [1,2]. The epidemic of type 2 diabetes, projected to reach 333 million persons worldwide by 2025 , is causing alarm in both medical and political circles. Since increasing obesity and decreasing physical activity are responsible besides the ageing of populations, modification of lifestyle, focusing on diet and exercise, is the logical way of stemming the tide [3]. Patient lifestyle and health behaviour changes, and patient selfmanagement in concordance with professional treatment advices, are cornerstones of diabetes care - but also the most difficult tasks people with type 2 diabetes have to face $[4,5]$. Regardless of the diabetes care system applied, about a third to half of the patient group with type 2 diabetes shows inadequate control of blood glucose levels and cardiovascular risk factors [6,7]. As a consequence, many suffer from macroand microvascular diabetes complications, e.g. coronary heart disease, stroke, blindness, amputations, nephropathy, and peripheral neuropathy, as well as low levels of quality of life and functional status, emotional distress, and elevated death risk [8].

Untill recently, research and guidelines on the patient perspective, on patient-provider interaction, and on patient empowerment in diabetes care and education, did not receive enough consideration $[5,9,10]$. Even less attention was given to the role played by familial and other forms of social support in diabetes care [11-13]. Better knowledge of the ways in which social support operates seems of vital interest for enhancing diabetes patient selfcare, insuring adherence to professional advice, encouraging lifestyle adaptations, and helping to improve outcomes of diabetes care and increase personal freedom. For a number of other medical conditions, and for health care in general, the role of social support has been studied [14-28].

In this paper, the results of a systematic review of studies of the effects of social support focused interventions on outcomes of care for type 2 diabetes are presented. A focus on type 2 diabetes seems particularly relevant, as coping with this health problem requires special emphasis on patient self-management in daily life.

\subsection{Concepts and theories}

Social support has received attention as a mediator or moderator of health outcomes $[14,21]$. It has been a target of interventions in other conditions than diabetes [14-20]. Social support is related to coping [18-20,22-25].

The global notion of social support includes several related concepts. Social support must be distinguished from social network (size) [12,26-29]. The social network refers to a web of social relationships and social linkages. This is best measured through enumeration, or quantitative scoring of its size, the number or density of social support sources, and persons around a person. Social support can be defined by its observed or reported content, by the satisfaction about it, or by the perceived support given to a person. These concepts are best measured by observations and reports, by indices of satisfaction, or by scores of perceived support.

Not all social support is equally helpful. There is evidence that social support can have negative as well as positive effects [28-31]. When the term 'social support' is used, a positive influence supporting a certain, wanted behaviour is implicated. The 
lack of social support during times of need itself can be stressful. 'Social pressure' is used for positive (wanted), but more often negative (unwanted) influences, enhancing or rather inhibiting a certain, wanted behaviour [32].

In social support not only familial relations have their part. Peers, friends, neighbours, colleagues, fellow-patients, or even pen friends and internet contacts may play their role. Peer expectations are important, and may vary between men and women [2829,33-35]. Social support must be separated from any group-based activity, e.g. education group.

Three or four categories of social support can be distinguished: emotional support (warmth and nurturance expressing commitment, reassuring the person that he or she is a valuable individual who is cared for, including approval or appreciation for the patient's behaviour), appraisal support (helping a person understand a stressful event better and what resources and coping strategies may be mustered to deal with it) or informational support (giving advice and information), and tangible assistance or practical-instrumental support (material or other practical help such as services, financial assistance, or goods). [39]

\section{DEFINITIONS}

-'Social support is an exchange of resources between at least two persons, aimed at increasing the well-being of the receiver' - Shumaker and Brownell [36].

-'Social support (is) information from others that one is loved and cared for, esteemed and valued, and part of a network of communication and mutual obligations from parents, a spouse or lover, other relatives, friends, social and community contacts such as churches or clubs, or even a devoted pet' - Siegel [33,37].

-'Social support is the degree to which a person's basic social needs (affection, esteem or approval, belonging, identity, and security) are gratified through interaction with others by the provision of socioemotional (...) or (...) instrumental aid' - Thoits [38]

The possible association of social support with (better) glucose level control in type 2 diabetes may have more than one explanation. Some state that the social network provides a substantial part of the information that a patient receives on the diagnosis, treatment, expectations and complications of diabetes [13]. Besides these appraising and informative effects, the social network when offering emotional support, alters the perceived stress and physical reactions which the patient endures. A third effect of social support is that it might offer coping strategies and structure in daily routines, enabling the patient to cope with stressful events, follow-up the treatment regimen in times of stress, and reduce the likelihood that stress will lead to poor health [40]. 
The hypothesis of 'direct effect' adds to the hypothesis of general, 'indirect' or 'buffering effects' $[39,41]$. Social support may have direct effects on patients' health. They may receive support to cope with the health problems, show better adherence to the prescribed treatment, and make better use of health resources - especially if the social network has a positive attitude regarding this [39]. The 'buffer hypothesis' states that social support may have indirect effects on health as well, both in times of stress and nonstress [41-42]. A person may have experienced social support in times of stress, and the bare knowledge of this possibility has indirect, buffering, reassuring, and protecting effects. People with strong social support perceive their health as being better [41]. For both hypotheses supportive evidence was reported [39].

A 'social dimension' is implicated in most theories explaining health behaviour (change) and self-care [43-49]. Usually the direct influence of the social network is implicated as one of the determinants of health behaviour.

Intervention studies are direly needed Such studies with a controlled, prospective, intervention design, like randomised controlled trials, cross-over intervention studies, or quasi-experimental pre-/posttest studies, carry powerful evidence of effects of social support focused interventions on specific outcomes, e.g. measures of patient health outcomes or behaviour changes. Evidence from observational and explorative studies will never be equally strong $[32,50]$.

\subsection{Research questions}

Can we find methodologically sound studies with prospective intervention design, carrying evidence for effects of social support focused interventions on selfcare and health outcomes in type 2 diabetes, especially in primary and hospital outpatient diabetes care? What interventions were studied, and what outcome effects were reported?

\section{METHOD}

\subsection{General}

A literature search was conducted to retrieve publications on specific social support interventions and their effects on outcomes of care for people with diabetes (a, first selection). From these studies, we selected those with good methodological characteristics: randomised controlled intervention trials or quasi-experimental trials with pre-/post test design (b, second selection), and focused on type 2 diabetes in primary care or hospital outpatient care (c, third selection). Studies on hospital inpatients were excluded, as in many countries a growing majority of patients with type 2 diabetes receive care in primary care and general practice settings - from general practitioners/family physicians, practice nurses, and nurse practitioners (UK, Spain, the Netherlands, Scandinavia, Eastern European countries), or in outpatient settings - from diabetologists/internists, and diabetes nurses (USA, Germany, France, Italy) [51].

A computerized literature search through the internet was executed by two of the authors (HD,LK) in Medline Advanced and in the Cochrane Library (Central Register of Controlled Trials), covering 1980 through 2003, using Pubmed and Sumsearch as search machines. Besides this, the files of Medline, Eric, PsycINFO, Embase, and Cochrane were searched at the Central Library of Maastricht University through the 
internet, and at the Library of the Viecuri Hospital Venlo on CD ROM for the same time period, using the Webspirs and Winspirs search engines, respectively. Publications in the English language were preferred, but other languages were included as well. Free text search terms were applied: 'diabetes', 'social', 'support', and 'trial'. MESH terms were applied only when using Sumsearch: 'diabet', 'social' and 'support' for the first selection (a), and 'trial' for the second one (b). The third selection (c) was performed by hand, by studying each of the retrieved publications. The reference lists of all retrieved publications were checked for other articles.

\subsection{Criteria-based Analysis}

The methodological quality of the selected studies was assessed with a modified version of the Van Tulder criteria List $[52,53]$. This Cochrane instrument has proven to be a practical and valid assessment measure [10,53]. The maximum score is 19 , with 'yes' for any item $=1$ point, 'no' $=0$ points, and unclear, possibly or partly $=0.5$ points (Table 1).

\section{RESULTS}

\subsection{General}

From the 1,426 retrieved publications by the first selection (a), we selected sixty-nine on trials with sufficiently good methodological design: RCT or quasi-experimental design (b). From these, 63 studies were on hospital in-patients, on patients with type 1 diabetes, or on mixed groups of patients. These 63 were excluded, while six studies on persons with type 2 diabetes in primary care or outpatient hospital care were included for the review (c) [54-60]. The flow diagram for the selection process is depicted in Box 1.

The quality assessment of the selected publications was separately performed by three of the authors (LK, FH, and HD). Disagreement on ratings was resolved by discussion until consensus was reached. This occurred in five of six included studies. The studies had quality scores with a low of 13.5 and a high of 18.0 points: 71 - 95 per cent of the maximum score of 19 points (Table 1 ).

\subsection{Definitions and measures}

The six reviewed studies were all RCTs, applying and studying a variety of social support interventions (Tables 2-4): Support from peer patients in group visits of 9-10 patients to a physician, peer group support with telephone calls from peer counselor, organised internet peer group with personal coach support, support from spouse by participation in diabetes education, peer support group following diabetes education, and support from family \& friends in diabetes education - all compared to usual diabetes care or education, without the intervention.

The studies defined social support and its measures in different ways. Most scored it with questionnaires (items: perception of support, perception of the readiness of the network to come to one's aid, spouse's listening skills or provision of positive reinforcement, social network size), others scored interactions in face-to-face or internet-based support groups. Interventions on support both from family members, spouse, children, and friends, and from peers/fellow patients, and peer group, were studied. 
The reviewed studies assessed a variety of outcome measures. Four studies assessed changes in diabetes control $(\mathrm{HbA} 1 \mathrm{c})$ as one of the outcome measures, four assessed changes in weight or BMI, three blood lipids, three food and diet adherence, three diabetes knowledge, three quality of life and well-being, two support satisfaction, two physical activity level, and one blood pressure. None assessed 'hard' diabetes endpoints, e.g. macro- or microvascular complications, blindness, or death.

The included studies embraced a total number of 712 study patients. The mean number of participants per study was 118.6 (range 32-200), mean age 59.3 years (52.4-68), and mean duration of diabetes 9.2 years (8.8-11). One study gave no information on the duration of diabetes. Mean follow-up of studies after start of the intervention was 16.5 months (range 3-30 months). (Table 5). Quantitative pooling of the studies' social support interventions and outcome effects in a metanalysis proved not possible, because of their heterogeneity (Table 6). A narrative method of integrating and comparing was preferred.

\subsection{Content}

An overview of the content of the six studies is presented in Tables 2-4. The sequence of presentation of studies in this table is according to methodological quality score. In summary:

Study 1 [Trento et al., 54]: Intervention: support from fellow patients jointly participating in group visits of 9-10 patients with type 2 diabetes to physician. Controls: usual, individual visits. Patients in group consultations had stable diabetes control $(\mathrm{HbA} 1 \mathrm{c})$ as compared to control patients showing worsening of $\mathrm{HbA} 1 \mathrm{c}$. The intervention group had lower cardiovascular risk scores, improved diabetes knowledge, better quality of life, more appropriate health behaviour, and longer interaction with health-care providers, while the physicians spent less time seeing them as a group rather than individually. Brief references to the Patient Empowerment literature, the Health Belief Model, and the Group-processed Health Behaviour Change Theory (enhanced motivation, altered experience, peer identification) were offered.

Study 2 [Keyserling et al., 55]: Interventions: counseling from nutritionist for diet and physical activity, group sessions, and telephone calls from a peer counselor providing social support and reinforcement, for African-American women with type 2 diabetes. Control group: educational pamphlets by mail. Patients found interventions acceptable and showed increased physical activity. Diabetes control, risk factors, and health behaviour showed no improvements.

Study 3 [Barrera et al., 56-57]: Interventions: type 2 diabetes patients provided with computers and internet access to diabetes information, internet-based peer group social support and/or individual coaching support. Controls: internet access without social or individual support. Persons receiving internet-based social support, or both an internet personal coach and internet social support, showed greater increase in perceived social support. Changes in diabetes control, risk factors, or other outcomes not assessed.

Study 4 [Gilden et al., 58]: Intervention: a series of 18 monthly social support group sessions following a diabetes education program of 6 weekly sessions for older males with type 2 diabetes. Controls: no follow-up group sessions. Diabetes education, but not the social support sessions, improved diabetes control. Social 
support sessions improved diabetes knowledge and psychosocial functioning, so may act as a buffer for stress, and help improve diabetes knowledge.

Study 5 [Wing et al., 59]: Intervention: participation of spouse with obese type 2 patients in education groups for weight loss. Controls: no spouse participation. An incentive of US\$150 per couple was executed (deposit beforehand, fully earned back after succesful participation). Obese women with type 2 diabetes reached more weight loss in 'together' (with partner) groups, while men lost more weight in 'alone' groups. Outcome diabetes control did not differ between control and intervention group. Partners in both groups showed increase of readiness to listen and offer social support. Targeting of both patient and spouse for weight loss may help them both to initiate and maintain weight loss.

Study 6 [Gilliland et al., 60]: Intervention: participation of family and friends, as contrasted to 'one-on-one' setting (individual appointments), in the same culturally appropriate lifestyle group education program for Native Americans with type 2 diabetes. Controls: usual, not culturally adjusted education group. No difference in diabetes control $(\mathrm{HbA1c})$ between family-and-friends and individual setting. The culturally appropriate education, but not the social support intervention, improved diabetes control and risk factors. Education for minorities should include both clinical and culturally appropriate lifestyle interventions.

The conclusions can be classified into general effects of social support, and specific effects depending on the source of social support (Table 6).

\section{General effects}

Social support from peers and fellow patients, both in group consultations, peer group sessions, telephone peer contacts, or internet-based peer communication, may enhance life style adjustments and outcomes of care [54-55,58]. Worsening of diabetes control was only prevented in the study with patient group consultations to the physician [54]. This study also had the highest methodological quality score. Involving spouse, peers, and peer counselors, may act positively for certain patients [54-57,59]. There were no effects on diabetes control from family-and-friends participation in diabetes education groups, or from social support groups for older male patients $[58,60]$.

Negative effects from more social support were found in men: they may respond negatively to spouse participation in their diabetes education group for weight loss [59].

\section{Sources}

Support from the spouse may have positive effects for obese women with type 2 diabetes, but not for men [59]. In contrast, participation of family and friends in diabetes education group sessions had no effects on diabetes control in women with type 2 diabetes [60].

Peer counseling is explored as a possible new way to support patients with initiating and sustaining lifestyle changes. Studies researching the effects of patient group visits to a physician, 'live' peer support groups, internet-based peer group support, and individual telephone peer support, found distinct, subjective and objective improvements for participating patients and providers [54-57].

\section{Gender}


Social support may have different effects for men and women with diabetes. Support from the spouse (participating in the same education program) may act positively on weight loss for women, while participating without the spouse worked out better for men [59]. In older men, participating in support groups improved diabetes knowledge and psychosocial functioning, but not diabetes control [58].

\section{DISCUSSION AND CONCLUSION}

\subsection{Discussion}

This review shows that the effects of social support interventions in type 2 diabetes in general practice or outpatient settings have been studied in a surprisingly small number of controlled intervention trials. Most of the six reviewed studies carry evidence in support of the idea that social support is influential on selfcare and outcomes of diabetes care. The social support interventions show great heterogeneity, and are hardly comparable. One could classify them into two clusters: (a)interventions directed at spouse, family relatives, and friends; and (b)interventions directed at peers, and fellow patients. Both these groups of interventions could be executed inside diabetes care and educational situations, or in the private atmosphere. Despite the differences between trials, we can summarize the main results [Table 6]. Biomedical outcomes were assessed in only four of the trials, and improved in two.

As compared to the literature on other chronic diseases but type 2 diabetes, the six studies reviewed in this paper showed similar conclusions [14-28].

Surprisingly, the reviewed studies hardly referred to psychosocial health behaviour theories and models [43-49]. Newer, diabetes focused concepts, such as the Permanent Therapeutical Patient Education Model provided by the World Health Organisation, and the Patient Empowerment Model proposed by Anderson, Funnell, and others, were not addressed either $[9,61]$. No concise definition of social support could be derived from the review. In the Introduction section of this paper, we presented some definitions. Social support proves to be a complicated and tough subject to study.

Non-experimental papers reported that men want and receive more support from spouse, and women from friends and family relatives [29,62-63]. High social support satisfaction correlated positively with good diabetes control outcomes for women, but negatively for men [29]. Women may seek extrafamilial help (friends and relatives) to make suitable changes, whereas men seek support from their spouse to make fewer changes or disobey the regimen.

It can also be imagined that the higher the perceived stress level or threat (vulnerability) a person experiences from having diabetes, the better social support may help protect against worsening of selfcare and diabetes control, and vice versa [13]. This perceived stress level was not addressed in any of the reviewed trials.

Negative effects from social support were also found. Spouse participation in weight loss education groups worked out negatively for obese men with type 2 diabetes [59]. Observational studies suggest that bigger social network size negatively effects both men and women, and that higher social support satisfaction may cause worse diabetes control in men [29,64]. More social support than wanted may be experienced as nagging or harassment, and may act negatively on dietary adherence [64]. Receiving too much instrumental support may be associated with more 
depressive symptoms $[13,31,65]$. It may arouse feelings of dependency and loss of control. Too little or too much support may worsen diabetes outcomes. None of the reviewed intervention studies tested this.

Measurements of social support have been developed by others $[62,66]$. None of these were applied by the reviewed studies. What the most effective components of social support are, or the optimal amount of support with regard to what patients with diabetes want, remain unanswered questions. They were not addressed by the studies in this review. No clear cut-off points for optimal social network size, optimal amount, or best kind of social support, or most effective components of it, could be concluded.

Some limitations of this review deserve attention:

Differing kinds and measures of social support modifications were applied, and differing effects were scored, with varying measures, making it difficult to compare findings.

The low number of experimental studies on social support in this review makes drawing general conclusions risky.

Also, randomised controlled trials usually represent artificially selected patient populations and interventions under strictly controlled circumstances, both of which are not always comparable to real life where mixed patient populations in practical clinical diabetes care are treated in varying ways.

\subsection{Conclusion}

This review can not clarify which aspects of social support, and which active mechanisms behind it, are most effective for enhancing self-management and outcomes of care for people with type 2 diabetes. Future research should address this problem.

For weight reduction, involving the spouse may be useful in obese women with type 2 diabetes. With regard to diabetes control, group consultations with the diabetes care provider (physician, nurse) are promising. 'Live', telephone, and internet-based social support from peers also offers opportunities for enhancing patient selfcare and outcomes of diabetes care. They could be additives to other approaches, e.g. enhanced organisation of care, targeted patient empowerment, effective diabetes education (groups), and optimised patient-provider interaction.

Well-designed intervention studies of social support in diabetes care are warranted, to enhance the knowledge of the international diabetes community on the subject, to select the most effective forms, sources, components, and deposits of social support, to help improve patient self-care and coping and, by this, outcomes of diabetes care in general practice, family medicine, and outpatient care.

\subsection{Practice implications}

Diabetes care providers in their daily practice should strive for open communication about social support with their patients - keeping in mind that if the patient does not perceive the diabetes as a serious matter, he or she probably will not want and take up (more) social support or professional advice. Actively involving the spouse in diabetes self-care and education programs may be favourable in female patients, but not always in males. Also, what patients themselves want and need from social support should be openly discussed and be related to the perceived support and 
satisfaction with it. Men and women probably prefer social support from different sources and react differently to it.

Diabetes teams may consider to offer some of the promising new forms of social support that were found: patient group consultations with diabetes care providers, peer social support group sessions in or following diabetes education programs, and internet-based or telephone-based peer support and counseling programs.

Conflict of interest: none. 


\section{References}

1. Zimmet $\mathrm{P}$, Alberti KG, Shaw J: Global and societal implications of the diabetes epidemic. Nature 2001;414:782-7.

2. Renders CM, Valk GD, Griffin SJ, Wagner EH, van Eijk JThM, Assendelft WJJ: The effectiveness of interventions directed at improvement of the management of diabetes mellitus in primary care, outpatient and community settings: a systematic review. Diabetes Care 2001;24:1821-33. (Extended version in: Cochrane Collaboration, Cochrane Database Syst Rev.2001;1:CD001481).

3. Fox C, Kilvert A. Intensive Education for lifestyle change in diabetes. Br Med J 2003;327:1120-1. 4. Norris SL, Lau J, Smith SJ, Schmid CH, Engelgau MM. Self-Management Education for Adults with Type 2 Diabetes. Diabetes Care 2002;25:1159-71.

5. Wolpert HA, Anderson BJ. Management of diabetes: Are doctors framing the benefits from the wrong perspective? Br Med J 2001;323:994-6.

6. Hirsch IB: The Burden of Diabetes (Care). Diabetes Care 2003;26:1613-4.

7. Bouma M: Improving diabetes care in general practice. Thesis. Vrije Universiteit Amsterdam, Amsterdam 1999.

8. Winocour PH. Effective diabetes care: a need for realistic targets. Brit Med J 2002;324:1577-80.

9. Anderson RM: Patient empowerment and the traditional model: A case of irreconcilable differences? Diabetes Care 1995;18:412-5.

10. Dam $H$ van, Horst $F$ van der, Borne $B$ van den, Ryckman $R$, Crebolder $H$ : Provider-patient Interaction in Diabetes Care: Effects on self-care and outcomes. A systematic review. Pat Educ Couns 2003;51:17-28.

11. Fisher I, Bartz R: The family and Type 2 Diabetes: A Framework for intervention. The Diabetes Educ 1998;24:599-607.

12. Thoits PA: Social support and psychosocial well-being: Theoretical possibilities. In: IG Sarason and BR Sarason (Eds.), Social support: Theory, research and applications (pp.101-32), Boston 1985: Martinus Nijhoff.

13. Griffith LS, Field BJ, Lustman PJ: Life Stress and Social Support in Diabetes: Associations with Glycemic Control. Internat J Psychiatr Med 1990;20:365-372.

14. Berkman LF: Measures of social networks and social support: Evidence and measurement. In AN Ostfeld and ED Eaker (Eds.), Measuring psychosocial variables in epidemiologic studies of cardiovascular disease. (NIH Publication No. 85-2270, pp. 51-79). Washington DC 1985: Public Health Service.

15. Gotlieb B: Theory into practice: Issues that surface in planning interventions which mobilize support. In: IG Sarason and BR Sarason (Eds.), Social support: Theory, research and applications (pp.51-72), Boston 1985: Martinus Nijhoff.

16. Krol B, Sanderman R, Suurmeijer TPBM. Social support, rheumatoid arthritis, and quality of life: Concepts, measurements and research. Pat Educ Couns 1993;20:101-20.

17. Doeglas DM. Functional ability, social support, and quality of life: A longitudinal study in patients with early rheumatoid arthritis. Thesis. Rijks Universiteit Groningen, Groningen 2000.

18. Savelkouls M. The influence of coping on social support and quality of life of people with rheumatic diseases. Thesis, Maastricht University, Maastricht 2002.

19. Ros WJG. Social support in cancer patients. Thesis. Utrecht University, Utrecht, The Netherlands, 1989.

20. Holohan CJ, Moos RH, Holohan CK, Brennan PL. Social support, coping, and depressive symptoms in a late-middle aged sample of patients reporting cardiac illness. Health Psychol 1995;14:152-63.

21. Levy R: Social support and compliance: a selective review and critique of treatment integrity and outcome measurement. Soc Science Med 1983;17:1329-38.)

22. Billings AG, Moos RH. The role of coping responses and social resources in attenuating the stress of life events. J Behav Med 1981;4:139-57.

23. Dunkel-Schetter C, Folkman S, Lazarus RS. Correlates of social support receipt. J Pers Soc Psychol 1987;53:71-80.

24. Manne SL, Zautra AJ. Spouse criticism and support. Their association with coping and psychological adjustment among women with rheumatoid arthritis. J Pers Soc Psychol 1989;56:60817.

25. Schreurs KMG, De Ridder DTD. Integration of coping and social support perspectives: Implications for the study of adaptation to chronic diseases. Clin Psychol Rev 1997;17:89-112.

26. Sarason IG, Levine HM, Basham RB, Sarason BR: Assessing social support: The social support questionnaire. J Personality Social Psychol 1983;44:127-39. 
27. Wellman B: From social support to social network. In: IG Sarason and BR Sarason (Eds.), Social support: Theory, research and applications (pp.51-72), Boston 1985: Martinus Nijhoff.

28. Kaplan RM, Chadwick MW, Schimmel LE: Social learning intervention to promote metabolic control in Type 1 diabetes mellitus: Pilot experiment results. Diabetes Care 1985;8:152-5.

29. Kaplan RM, Hartwell SL: Differential Effects of Social Support and Social Network on Physiological and Social Outcomes in Men and Women With Type II Diabetes Mellitus. Health Psychol 1987;6:38798.

30. Hayes, RB: Improving patient adherence: State of the art, with a special focus on medication taking for cardiovascular disorders. In L.E. Burke and I. S. Ockene (Eds.) Compliance in healthcare and research (pp.3-21, Armonk, New York 2001: Futura Publishing Company.

31. Wortman CB, Lehman DR: Reactions of victims to life crisis: Support attempts that fail. In: IG Sarason and BR Sarason (Eds.), Social support: Theory, research and applications (pp.51-72), Boston 1985: Martinus Nijhoff.

32. Wills TA, Vaughan R. Social support and substance use in early adolescence. J Behav Medicine 1989;12:321-40.

33. Antonucci TC: Social support, theoretical advances, recent findings and pressing issues. In: IG Sarason and BR Sarason (Eds.), Social support: Theory, research and applications (pp.51-72), Boston 1985: Martinus Nijhoff.

34. Kessler RC, McLeod JD, Wethington E: The costs of caring: A perspective on the relationship between sex and psychological distress. In: IG Sarason and BR Sarason (Eds.), Social support: Theory, research and applications (pp.151-70), Boston 1985: Martinus Nijhoff.

35. Heitzmann CA, Kaplan RM: Interaction Between Sex and Social Support in the Control of Type II Diabetes Mellitus. J Consult Clin Psychol 1984;52:1087-9.

36. Shumaker SA, Brownell A: Towards a theory of social support: closing conceptual gaps. J Social Issues 1984;40:11-36.

37. Siegel JM. Companion animals: in sickness and in health. J Social Issues 1993;49:157-67.

38. Thoits PA, Conceptual, methodological and theoretical problems in studying social support as a buffer against life stress. J Health Soc Behav 1982;23:145-59.

39. Taylor, S.E. (1999): Health Psychology. 4th Edition. Boston, 1999: McGraw-Hill Companies. 40. Sarazon BR, Sarason IG, Gurung RAR. Close personal relationships and health outcomes. A key to the role of social support. In: S.Duck (Ed.), Handbook of personal relationships (pp.547-73). New York 1978: Wiley..

41. Goodall TA, Halford WK: Self-Management of Diabetes Mellitus: A Critical Review. Health Psychol 1991;10:1-8.

42. Cohen S. Hoberman HM: Positive events and social supports as buffers of life change stress. J Appl Social Psychol 1983;13:99-125.

43. Bandura A: Social foundations of thought and action: A social cognitive theory. Eaglewood Cliffs NJ,1986: NJ, Prentice-Hall.

44. Rosenstock IM: Historical origins of the Health Belief Model. Health Education Monographs 1974;2:1-8.

45. Brug J, Schaalma H, Kok G, Meertens RM, Molen HT van der: Gezondheidsvoorlichting en gedragsverandering: Een planmatige aanpak (Health education and behaviour change: A planned approach). In Dutch. Van Gorcum 2000, Assen.

46. Ajzen I: Understanding Attitudes and Predicting Social Behavior. Eaglewood Cliffs NJ, 1980: Prentice-Hall.

47. Lazarus RS, Folkman S: Coping and Adaptation. The handbook of behavioral medicine. New York 1984: New York Press.

48. Ruggiero L, Prochaska JO: Readiness to change: Application of the transtheoretical model to diabetes. Diabetes Spectrum 1993;6:22-60.

49. Vallis M, Ruggiero L, Greene G, Jones H, Zinman B, Rossi S, Edwards L, Rossi JS, Proschaska

JO: Stages of change for healthy eating in diabetes. Diabetes Care 2003;26:1468-74.

50. Tillotston LM, Smith MS: Locus of Control, Social Support, and Adherence to the Diabetes Regimen. The Diabetes Educ 1996;22:133-9.

51. UK Prospective Diabetes Study Group: Intensive blood-glucose control with sulphonylureas or insulin compared with conventional treatment and risk of complications in patients with type 2 diabetes (UKPDS 33). Lancet 1998;352:837-53.

52. Tulder MW van, Assendelft WJ, Koes BW, Bouter LM: Method guidelines for systematic reviews in the Cochrane Collaboration Back Review Group for Spinal Disorders. Spine. Editorial Board, 1997;22:2323-30. 
53. Haastregt JCM van, Diederiks JPM, Rossum E van, Witte LP de, Crebolder HFJM: Effects of preventive home visits to elderly people living in the community: systematic review. $\mathrm{Br}$ Med $\mathrm{J}$ 2000;320:754-8.

54. Trento M, Passera P, Tomalino M, Bajardi M, Pomero F, Allione A, Vaccari P, Molinatti GM, Porta M: Group visits improve metabolic control in type 2 diabetes: a 2-year follow-up. Diabetes Care 2001;24:995-1000.

55. Keyserling TC, Samuel-Hodge CD, Ammerman AS, Ainsworth BE, Henriquez-Roldan CF, Elasy TA, Skelly AH, Johnston LF, Bangdiwala SI: A randomized trial of an intervention to improve self-care behaviors of African-American women with type 2 diabetes: impact on physical activity. Diabetes Care 2002;25:1576-83.

56. Barrera M jr, Glasgow RE, McKay HG, Boles SM, Feil EG: Do internet-based support interventions change perceptions of social support? An experimental trial of approaches for supporting diabetes self-management. Am J Community Psychol 2002;30:637-54.

57. McKay HG, Glasgow RE, Fell EG, Boles SM, Barrera M jr: Internet-based diabetes selfmanagement and support: initial outcomes from the Diabetes Network project. Rehabilit Psychol 2002;47:31-48.

58. Gilden JL, Hendryx MS, Clar S, Casia C, Singh SP: Diabetes support groups improve health care of older diabetic patients. J Am Gerietr Soc, 1992;40:147-50.

59. Wing RR, Marcus MD, Epstein LH, Jawad A. (1991): A 'Family-Based' Approach to the Treatment of

Obese Type II Diabetic Patients. J Consult Clin Psychol 1991;59:156-62.

60. Gilliland SS, Azen SP, Perez GE, Carter JS: Strong in body and spirit: lifestyle intervention for Native American adults with diabetes in New Mexico. Diabetes Care 2002;25:78-83.

61. World Health Organisation: Therapeutic Patient Education: Report of a WHO Working Group. Copenhagen, World Health Org. 1988:1-77.

62. Kvam SH, Lyons JS: Assessment of Coping Strategies, Social Support and General Health Status in Individuals with Diabetes Mellitus. Psychol Reports 1991;68:623-32.

63. Rubin RR, Peyrot M: Men and Diabetes: Psychosocial and Behavioral Issues. Diabetes Spectr 1998;11:81-7.

64. Boehm S, Schlenk E, Funnell MM, Powers H, Ronis DL: Predictors of Adherence to Nutritional Recommendations in People With Non-Insulin-Dependent Diabetes Mellitus. The Diabetes Educ 1997;23:157-65

65. Bogat GA, Sullivan LA, Grober J: Application of social support to preventive interventions. In DS Glenwick and LA Jason (Eds), Promoting health and mental health in children, youth, and families (pp. 205-32). New York 1993: Springer.

66. Cohen S, Mermelstein R, Kamar CKT, Hoberman HM: Measuring the functional components of social support. In: IG Sarason and BR Sarason (Eds.), Social support: Theory, research and applications (pp.51-72), Boston 1985: Martinus Nijhoff. 


\section{Box 1:}

\section{Flow diagram of literature search and results}

(a) 1,426 selected using Pubmed, Sumsearch,

Webspirs, Winspirs ('diabetes', 'social', 'support'),

and manual search in reference lists

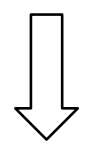

(b) 69 selected (prospective controlled intervention trials)

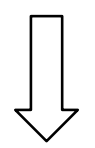

(c) 6 selected (type 2 diabetes, primary care, outpatient care) 
Table 1.

Methodological quality of trials assessed with Modified Van Tulder criteria (1997). ('yes' = 1 point; 'no' or unclear = 0 points; ? = partly or possibly = 0,5

points. Maximum score $=19$ points $=100 \%$ ).

\begin{tabular}{|c|c|c|c|c|c|c|}
\hline Criteria & $\begin{array}{l}\text { 1.Trento et } \\
\text { al., } \\
2002\end{array}$ & $\begin{array}{l}\text { 2.Keyserlin } \\
\text { g et al., } \\
2002\end{array}$ & $\begin{array}{l}\text { 3.Barrera } \\
\text { et al., } 2001\end{array}$ & $\begin{array}{l}\text { 4.Wing et } \\
\text { al., } 1991\end{array}$ & $\begin{array}{l}\text { 5.Gilden et } \\
\text { al., } 1992\end{array}$ & $\begin{array}{l}\text { 6.Gilliland } \\
\text { et al., } 2002\end{array}$ \\
\hline $\begin{array}{l}\text { 1.Were eligibility criteria } \\
\text { clearly specified? }\end{array}$ & yes & yes & yes & yes & yes & yes \\
\hline $\begin{array}{l}\text { 2.Was a method of } \\
\text { randomisation performed? }\end{array}$ & yes & yes & yes & yes & $?$ & no \\
\hline $\begin{array}{l}\text { 3. Were the groups similar } \\
\text { at baseline regarding the } \\
\text { most (potential) prognostic } \\
\text { indicators? }\end{array}$ & yes & yes & yes & yes & yes & $?$ \\
\hline $\begin{array}{l}\text { 4.Were index and control } \\
\text { interventions explicitely } \\
\text { described? }\end{array}$ & yes & yes & yes & yes & yes & yes \\
\hline $\begin{array}{l}\text { 5.Were providers of regular } \\
\text { care blinded to the } \\
\text { intervention? }\end{array}$ & yes & no & $?$ & $?$ & no & no \\
\hline $\begin{array}{l}\text { 6.Were there no co- } \\
\text { interventions? }\end{array}$ & yes & yes & yes & yes & yes & yes \\
\hline $\begin{array}{l}\text { 7.Was there good } \\
\text { compliance in all groups? }\end{array}$ & yes & yes & yes & yes & yes & yes \\
\hline $\begin{array}{l}\text { 8.Were respondents blinded } \\
\text { to the intervention? }\end{array}$ & $?$ & yes & $?$ & $?$ & yes & no \\
\hline $\begin{array}{l}\text { 9. Was outcome assessment } \\
\text { blinded to the intervention? }\end{array}$ & yes & yes & yes & $?$ & yes & $?$ \\
\hline $\begin{array}{l}\text { 10.Were most outcome } \\
\text { measures relevant? }\end{array}$ & yes & yes & yes & yes & yes & yes \\
\hline $\begin{array}{l}\text { 11. Were there no adverse } \\
\text { effects of the intervention } \\
\text { on the participants? }\end{array}$ & yes & yes & yes & yes & yes & yes \\
\hline $\begin{array}{l}\text { 12.Was the withdrawal or } \\
\text { drop-out rate acceptable? }\end{array}$ & yes & yes & yes & yes & $?$ & yes \\
\hline $\begin{array}{l}\text { 13.Was the withdrawal or } \\
\text { drop-out rate random? }\end{array}$ & yes & yes & yes & yes & $?$ & yes \\
\hline $\begin{array}{l}\text { 14.Were short term follow- } \\
\text { up measures performed? }\end{array}$ & yes & yes & yes & yes & yes & no \\
\hline $\begin{array}{l}\text { 15.Were long term follow- } \\
\text { up measures performed? }\end{array}$ & yes & yes & no & yes & yes & yes \\
\hline $\begin{array}{l}\text { 16. Was the timing of the } \\
\text { outcome assessment in both } \\
\text { groups comparable? }\end{array}$ & yes & yes & yes & yes & yes & yes \\
\hline $\begin{array}{l}\text { 17.Was the sample size for } \\
\text { each group described? }\end{array}$ & yes & yes & yes & yes & yes & yes \\
\hline $\begin{array}{l}\text { 18.Did the analysis include } \\
\text { an 'intention tot treat'- } \\
\text { analysis? }\end{array}$ & $?$ & $?$ & $?$ & no & no & $?$ \\
\hline $\begin{array}{l}\text { 19.Were point estimates } \\
\text { and measures of variability } \\
\text { presented for the primary } \\
\text { outcome measures? }\end{array}$ & yes & yes & yes & yes & yes & yes \\
\hline $\begin{array}{l}\text { Total score. Maximum } \\
\text { score }=19(100 \%)\end{array}$ & $\begin{array}{l}18.0 \\
(94.7 \%)\end{array}$ & $\begin{array}{l}17 \\
(89.5 \%)\end{array}$ & $\begin{array}{l}16.5 \\
(87 \%)\end{array}$ & $\begin{array}{l}16 \\
(85 \%)\end{array}$ & $\begin{array}{l}15.5 \\
(81.6 \%)\end{array}$ & $\begin{array}{l}13.5 \\
(71 \%)\end{array}$ \\
\hline
\end{tabular}


Table 2. Social support intervention studies in patients with type 2 diabetes

\begin{tabular}{|c|c|c|}
\hline Study & 1.Trento et al, 2001: RCT & 2.Keyserling et al, 2002: RCT \\
\hline Goal & $\begin{array}{l}\text { To evaluate wether group visits in diabetes care are } \\
\text { more effective than individual consultations in } \\
\text { improving self-care and metabolic control. }\end{array}$ & $\begin{array}{l}\text { To determine if a culturally appropriate clinic- and } \\
\text { community-based intervention for African-American } \\
\text { women with DM2 will increase moderate-intensity } \\
\text { physical activity (PA). }\end{array}$ \\
\hline $\begin{array}{l}\text { Hypothesis } \\
\text { and/or } \\
\text { Research } \\
\text { question }\end{array}$ & $\begin{array}{l}\text { Individual visits can be merged with interactive } \\
\text { group visits into a permanent therapeutic education } \\
\text { process, with interactive techniques, positive group } \\
\text { dynamics, and identification with other group } \\
\text { members, without increasing the workloads of health } \\
\text { care providers, in outpatient diabetes care. }\end{array}$ & $\begin{array}{l}\text { A community-based, culturally appropriate diabetes } \\
\text { education program with peer group support sessions } \\
\text { and peer counselor telephone support, combined } \\
\text { with traditional clinic-based counseling, helps } \\
\text { increase PA level. }\end{array}$ \\
\hline $\begin{array}{l}\text { Study } \\
\text { population }\end{array}$ & $\begin{array}{l}112 \text { Outpatients with DM2 (mean duration 9.6y.) in } \\
\text { a diabetes clinic ( } 61 \text { men, } 51 \text { women, mean age 60y.) } \\
\text { randomised to A.intervention or B.control condition. } \\
\text { Intervention: mean } 7.9 \text { group consultations with } \\
\text { doctors every } 3 \text { months in } 2 \text { years of } 56 \text { in } 6 \text { patient } \\
\text { groups of 9-10p. Control: mean } 8.2 \text { individual visits } \\
\text { of } 56 \text { persons plus standard diabetes education every } \\
3 \text { months. Controls had slightly higher level of } \\
\text { education and diabetes knowledge at baseline. Drop- } \\
\text { outs: } 22 \text {, not differing from study completers. } \\
\text { Group visits to doctor, offering peer social support. }\end{array}$ & $\begin{array}{l}\text { Of } 209 \text { eligibles, selected by their primary care } \\
\text { doctors, } 200 \text { African-American women with DM2 } \\
\text { (mean duration 10y.), age >40 years (mean age } \\
\text { 59y.), completed baseline data collection and were } \\
\text { included and randomized to } 1 \text { of } 3 \text { conditions: A: } \\
\text { Intervention, B: Clinic only, and C: Control: } 3 \\
\text { mailed diabetes education pamphlets only. } \\
\text { Drop-outs: } 25 \text { after } 6 \text { and } 33 \text { after } 12 \text { months: } 13 \text { in } \\
\text { A, } 7 \text { in B, and } 9 \text { in C. Drop-outs only differed in } \\
\text { duration of diabetes (drop-outs shorter) and known } \\
\text { coronary heart disease (drop-outs more). } \\
\text { A and B: } 4 \text { monthly clinic visits with nutrionist } \\
\text { providing counseling to enhance PA and dietary } \\
\text { intake, A: with } 3 \text { Group sessions (90 minutes) and } 12 \\
\text { monthly telephone calls from peer counselor. }\end{array}$ \\
\hline $\begin{array}{l}\text { Outcome } \\
\text { measures and } \\
\text { scoring } \\
\text { method }\end{array}$ & $\begin{array}{l}\text { Body Mass Index, fasting blood glucose, and HbA1c } \\
\text { every } 3 \text { months, blood creatinine, lipids, } \\
\text { microalbuminuria, and complications anually; } 3 \\
\text { questionnaires (Diabetes Related Quality of Life, } \\
\text { Diabetes Knowledge, Health Behaviours) at baseline } \\
\text { and after 1- and 2-years. } \\
\text { Follow-up } 2 \text { years. }\end{array}$ & $\begin{array}{l}\text { HbA1c, lipids. PA level measured by Caltrac } \\
\text { accelerometer during waking hours for } 1 \text { week } \\
\text { (electronic monitor considered to objectively } \\
\text { measure PA energy expenditure). Dietary intake by } 3 \\
\text { 24h telephone-administered recalls using Minnesota } \\
\text { Nutrition Data System. Diabetes Knowledge by } \\
\text { DKS-15. Diabetes Health Status Instrument for } \\
\text { mental and social well-being. Follow-up } 12 \text { months. }\end{array}$ \\
\hline Conclusions & $\begin{array}{l}\text { Providers of care spent less time per patient in group } \\
\text { A (group visits), and had no increase of workload. } \\
\text { Patients had longer interaction with provider, and no } \\
\text { increase of HbA1c, as compared to increase in } \\
\text { controls (A: } 7.4 \text { to } 7.5 \% \text { and B: } 7.4 \text { to } 8.3 \% \text {, resp.), } \\
\text { and improved lipids (HDL, TG), BMI, diabetes } \\
\text { knowledge, quality of life, diabetes health } \\
\text { behaviours. }\end{array}$ & $\begin{array}{l}\text {-The intervention group - A - showed modest } \\
\text { increase in PA level, being on average 15\% more } \\
\text { active than group C. Small decreases of PA in Clinic } \\
\text { only B and Control group C. } \\
\text {-All } 3 \text { groups showed weight gain, decrease of calory } \\
\text { intake from saturated fats, dietary cholesterol intake, } \\
\text { and total energy intake, as well as no changes for } \\
\text { HbA1c, lipids, and minimal improvements of } \\
\text { diabetes knowledge and mental well-being, and no } \\
\text { change of social well-being. }\end{array}$ \\
\hline $\begin{array}{l}\text { Implications } \\
\text { for diabetes } \\
\text { care }\end{array}$ & $\begin{array}{l}\text { Group visits are feasable in busy clinics and may be } \\
\text { more effective in managing DM } 2 \text { and preventing } \\
\text { complications, as compared to traditional, individual } \\
\text { visits. }\end{array}$ & $\begin{array}{l}\text { Behaviour support from peer group sessions and a } \\
\text { personal peer counselor, helps increase physical } \\
\text { activity level better than only mailing education } \\
\text { pamphlets }\end{array}$ \\
\hline
\end{tabular}


Table 3 (table 2 continued)

\begin{tabular}{|c|c|c|}
\hline Study & 3.Barrera et al, 2002: RCT & 4.Wing et al., 1991: RCT \\
\hline Goal of study & $\begin{array}{l}\text { To determine if a computer-based intervention is } \\
\text { successful in changing participants' perceptions of } \\
\text { social support. }\end{array}$ & $\begin{array}{l}\text { To test a family-oriented approach for obese patients } \\
\text { with DM2. Treatment: behavioural approach with } \\
\text { stimulus-control techniques, problem solving, } \\
\text { assertivity, goals setting, and coping techniques. }\end{array}$ \\
\hline $\begin{array}{l}\text { Hypothesis } \\
\text { and/or } \\
\text { Research } \\
\text { question }\end{array}$ & $\begin{array}{l}\text { Online (internet) exchanges between support group } \\
\text { members with DM2 enhance participants' } \\
\text { perceptions of social support. This might improve } \\
\text { quality of life and health care behaviours that are } \\
\text { relevant to diabetes management and prevention of } \\
\text { disease complications. }\end{array}$ & $\begin{array}{l}\text { Long standing weight loss can be enhanced by } \\
\text { involving the spouse in a group education program, } \\
\text { by teaching them supportive techniques, and by } \\
\text { offering these obese partners the same program. }\end{array}$ \\
\hline $\begin{array}{l}\text { Study } \\
\text { population }\end{array}$ & $\begin{array}{l}\text { Of } 650 \text { patients with DM2 recruited in primary care, } \\
\text { who were sent letters, } 265 \text { were eligible, and of } \\
\text { these } 160 \text { agreed ( } 75 \text { men, } 85 \text { women, mean age } \\
\text { 59y.) (mean duration of DM2 11y.), were provided } \\
\text { with computers and internet access, and randomized } \\
\text { to } 1 \text { of } 4 \text { conditions of } 40 \text { p. each: A:Diabetes } \\
\text { Information only (=control) group, B:Professional, } \\
\text { Personal Self-management Coach, C:Peer Social } \\
\text { Support intervention, or D:Combined, both B and C. } \\
37 \text { Dropped out, equally among the } 4 \text { conditions, } \\
\text { and comparable to completers }\end{array}$ & $\begin{array}{l}49 \text { Obese patients with DM2 (mean age } 52.4 \mathrm{y} .) \text { with } \\
\text { (49) obese spouses ( } 11 \text { of which had DM), recruited } \\
\text { by newspaper ads, randomized to A: 'alone' ( } 25 \\
\text { patients) or B: 'together' condition ( } 24 \mathrm{p} .), 20 \text { weeks, } \\
12 \text { weekly group sessions of } 8-10 \text { patients and, when } \\
\text { appropriate, spouses, then every fortnight, with } \\
\text { follow-up meetings in weeks } 24,28,40 \text {, and } 72 \\
(18 \mathrm{~m}) \text {. Patients and spouses in A and B were } \\
\text { comparable. } \\
\text { Drop-outs: } 6 \text { patients ( } 5 \text { in B, } 1 \text { in A) and } 7 \text { spouses } \\
\text { ( } 6 \text { in B and } 1 \text { in A). Completers and drop-outs did } \\
\text { not differ, as did not A and B patients or spouses. }\end{array}$ \\
\hline Intervention & Internet-based peer social support (C and D). & $\begin{array}{l}\text { Involvement of obese spouse in weight loss and } \\
\text { lifestyle education group program, to support DM2 } \\
\text { patients to lose weight and improve health } \\
\text { behaviour. } 150 \text { Dollar deposit required from each } \\
\text { couple, which could be earned back in full. }\end{array}$ \\
\hline $\begin{array}{l}\text { Outcome } \\
\text { measures and } \\
\text { scoring } \\
\text { methods }\end{array}$ & $\begin{array}{l}\text { Perceived social support by questionnares ISEL-6 } \\
\text { and DSS (Diabetes Support Scale). No biomedical } \\
\text { outcome measures applied. } \\
\text { Follow-up } 3 \text { months. }\end{array}$ & $\begin{array}{l}\text { Blood glucose, HbAlc, body weight, and BMI at } \\
\text { baseline, after } 20 \text { weeks, one year, and } 72 \text { weeks. } 3 \\
\text { Days self-report eating diaries pre- and post } \\
\text { treatment, caloric intake. Physical exercise - and } \\
\text { eating behaviour questionnaire on adherence to } \\
\text { weight loss strategies. Adherence to social support } \\
\text { questionnaire, for partners in both conditions. } \\
\text { Follow-up } 18 \text { months }\end{array}$ \\
\hline Conclusions & $\begin{array}{l}\text { Social support (and its perception) can be } \\
\text { manipulated. The Social Support-only condition C } \\
\text { experienced the greatest increase in perceived social } \\
\text { support, followed by the Combined condition D, the } \\
\text { Coach-only condition B, and finally Information- } \\
\text { only controls A. }\end{array}$ & $\begin{array}{l}\text {-Weight loss of A and B groups equal, also after } \\
\text { 1year. In men better in the 'alone' (A) group, in } \\
\text { women better in the 'together' (B) condition. Weight } \\
\text { loss in partners better in B, than in A ('alone'). } \\
\text {-Partners in both conditions reported more readiness } \\
\text { to listen and more use of social support. } \\
\text {-Partners in A participated in the measurements, } \\
\text { which in itself is an intervention -explaining the lack } \\
\text { of difference between groups. }\end{array}$ \\
\hline $\begin{array}{l}\text { Implications } \\
\text { for practice }\end{array}$ & $\begin{array}{l}\text { Internet-based peer (fellow patient) support } \\
\text { increases perceived social support better than } \\
\text { internet-based diabetes information or an internet- } \\
\text { based professional, personal self-management } \\
\text { coach. }\end{array}$ & $\begin{array}{l}\text { A family oriented approach (participation of spouse } \\
\text { in weight loss education group, B) may be useful in } \\
\text { obese DM2 female patients, but not in men. }\end{array}$ \\
\hline
\end{tabular}


Table 4 (table 3 continued)

\begin{tabular}{|c|c|c|}
\hline Study & 5.Gilden et al., 1992: RCT & 6.Gilliland et al., 2002 \\
\hline Goal of study & $\begin{array}{l}\text { To assess whether social support groups for older } \\
\text { patients enhance benefits of a diabetes education } \\
\text { program for diabetes control, knowledge, and } \\
\text { psychosocial functioning. }\end{array}$ & $\begin{array}{l}\text { To determine the effects of a culturally appropriate } \\
\text { diabetes lifestyle intervention for Native Americans } \\
\text { with DM2 on risk factors for diabetes } \\
\text { complications. }\end{array}$ \\
\hline $\begin{array}{l}\text { Hypothesis } \\
\text { and/or } \\
\text { Research } \\
\text { question }\end{array}$ & $\begin{array}{l}\text { Social support improves the effects of a diabetes } \\
\text { education program. }\end{array}$ & $\begin{array}{l}\text { A community-based lifestyle intervention for } \\
\text { Native Americans with DM2, with usual clinical } \\
\text { diabetes care, positively affects glycemic control. }\end{array}$ \\
\hline $\begin{array}{l}\text { Study } \\
\text { population }\end{array}$ & $\begin{array}{l}32 \text { Outpatients (all men, mean age 68y.) with DM2, } \\
\text { mean duration } 10 y \text {. Partly-randomly asigned to } \\
\text { A.intervention: } 18 \text { monthly social support sessions } \\
\text { following } 6 \text { weekly diabetes education group } \\
\text { sessions (11p.), B.control intervention: only } \\
\text { diabetes education program (13p.), or C.control } \\
\text { condition: no education program, no social support } \\
\text { sessions (8 persons). } \\
\text { No information on eligibility, blinding of providers } \\
\text { and patients, and drop-out. }\end{array}$ & $\begin{array}{l}\text { From target population of } 514 \text { Native Americans } \\
\text { with DM2, aged } 18 \text { years or over, } 206 \text { eligible and } \\
\text { volunteered. } 47 \text { Withdrew before intervention, } 42 \\
\text { dropped out, } 13 \text { missed information on covariates. } \\
159 \text { Participants, non-randomly assigned to a } \\
\text { Family-and-Friends condition (FF) in site A, One- } \\
\text { on-One (OO) in site B, and Usual Care/control } \\
\text { (UC) in site C; } 104 \text { (65\%) completed the study ( } 22 \\
\text { men, } 82 \text { women, mean age } 59.7 y ., \text { mean duration of } \\
\text { DM2 } 8.8 y .) \text {. Drop-outs: no difference with } \\
\text { participants, equally divided among conditions, but } \\
\text { more often male and/or nonobese }\end{array}$ \\
\hline Intervention & $\begin{array}{l}18 \text { Monthly self-directed support group sessions for } \\
\text { continuing education, discussion, and structured } \\
\text { social activities, following a } 6 \text { weeks education } \\
\text { program (A). }\end{array}$ & $\begin{array}{l}\text { Social (peer) support in family-and-friends (FF) } \\
\text { format ( } 5 \text { sessions) for culturally appropriate } \\
\text { diabetes education (materials, and skills training), } \\
\text { vs. one-on-one (OO) format with same program. }\end{array}$ \\
\hline $\begin{array}{l}\text { Outcome } \\
\text { measures and } \\
\text { scoring } \\
\text { methods }\end{array}$ & $\begin{array}{l}\text { HbAlc, diabetes knowledge, psychosocial scores } \\
\text { (self-care related quality of life, stress, family } \\
\text { involvement in carer, social involvement, and } \\
\text { depression) at baseline, after education program (A } \\
\text { and B), and } 2 \text { years later (all three groups). Follow- } \\
\text { up } 30 \text { months. }\end{array}$ & $\begin{array}{l}\text { Pre- and post intervention measures of HbA1c, } \\
\text { weight, blood pressure, lipids. Lifestyle scores by } \\
\text { in-person interviews. Follow-up } 12 \text { months. }\end{array}$ \\
\hline Conclusions & $\begin{array}{l}\text { Participation of older, male patients in diabetes } \\
\text { education (A and B) led to improved diabetes } \\
\text { control and knowledge, less stress, greater family } \\
\text { involvement, less involvement in social activities, } \\
\text { than group C. Social support (A): better diabetes } \\
\text { knowledge and quality of life, less depression. }\end{array}$ & $\begin{array}{l}\text { HbA1c: significantly smaller increase at } 1 \text { year: FF } \\
+0.5 \% \text {, OO }+0.2 \% \text {, and combined FF+OO }+0.4 \% \text { in } \\
\text { culturally appropriate setting, as comp. to controls } \\
(+1.2 \%) \text {. In the FF and OO and in the combined } \\
\text { FF+OO, weight significantly decreased, diastolic } \\
\text { blood pressure and lipids nonsignificantly } \\
\text { improved. Social support intervention (FF): no } \\
\text { extra HbA1c improvement as compared to OO. }\end{array}$ \\
\hline $\begin{array}{l}\text { Implications } \\
\text { for practice }\end{array}$ & $\begin{array}{l}\text { A combination of a diabetes education program and } \\
\text { a social support program may improve diabetes } \\
\text { knowledge and psychosocial functioning. }\end{array}$ & $\begin{array}{l}\text { Participation of friends and family relatives in } \\
\text { lifestyle education groups of persons with } \\
\text { DM2 hardly improved diabetes control. } \\
\text { But culturally appropriate education did. }\end{array}$ \\
\hline
\end{tabular}


Table 5.

Summary of patient characteristics of included trials

Study

$\mathrm{n}$

mean age

mean duration follow-up

of diabetes time

1.Trento

112

60 years

9.6 years

24 months

2.Keyserling

200

59

10

12

3.Barrera

160

59

11

3

4.Gilden

32

68

10

30

5.Wing

49

52.4

18

6.Gilliland

159

59.7

8.8

12

Total/mean

712

$59.3 y$

$9.2 \mathrm{y}$

$16.5 \mathrm{~m}$ 
Table 6.

INTERVENTIONS AND OUTCOMES OF REVIEWED STUDIES

\begin{tabular}{|c|c|c|c|c|c|}
\hline Study & Intervention & Outcomes & & & \\
\hline (Qual.score) & & Behaviour & $\begin{array}{l}\text { Psychosocial } \\
\text { and Qual.of L }\end{array}$ & $\begin{array}{c}\text { Knowledge } \\
\text { of DM }\end{array}$ & $\begin{array}{l}\text { Biomedical } \\
\text { (HbA, risk } \\
\text { factors) }\end{array}$ \\
\hline $\begin{array}{l}\text { 1.Trento } \\
(94.7 \%)\end{array}$ & $\begin{array}{l}\text { Group visits to } \\
\text { physician }\end{array}$ & + & + & + & $\begin{array}{l}++ \text { (HbA1c, } \\
\text { lipids) }\end{array}$ \\
\hline $\begin{array}{l}\text { 2.Keyserling } \\
(89,5 \%)\end{array}$ & $\begin{array}{l}\text { Peer group and } \\
\text { peer counselor }\end{array}$ & $+(\mathrm{PA})$ & $+/-$ & $+/-$ & -- \\
\hline $\begin{array}{l}\text { 3.Barrera } \\
(87 \%)\end{array}$ & $\begin{array}{l}\text { Internet peer } \\
\text { support and } \\
\text { internet personal } \\
\text { coach }\end{array}$ & & $\begin{array}{l}+ \text { (perceived } \\
\text { support) }\end{array}$ & & \\
\hline $\begin{array}{l}\text { 4.Wing } \\
(85 \%)\end{array}$ & $\begin{array}{l}\text { Spouse particip. } \\
\text { in diab.educ. }\end{array}$ & $+(\mathrm{PA})$ & $\begin{array}{l}+ \text { (use of } \\
\text { soc.support) }\end{array}$ & & $\begin{array}{l}+ \text { (weight } \\
\text { loss women) }\end{array}$ \\
\hline $\begin{array}{l}\text { 5.Gilden } \\
(81,6 \%)\end{array}$ & $\begin{array}{l}\text { Social support } \\
\text { group sessions } \\
\text { following diab.educ. }\end{array}$ & & ++ & + & -- \\
\hline $\begin{array}{l}\text { 6.Gilliland } \\
(71 \%)\end{array}$ & $\begin{array}{l}\text { Family and } \\
\text { friends particip. } \\
\text { in diab.educ. }\end{array}$ & & & & -- \\
\hline
\end{tabular}

(+: positive effect; ++: positive effect on more than one outcome measure; +/-: positive and negative, or minimal positive effect; --: no effect; blank: not assessed; PA: physical activity) 


\section{CHAPTER 6}

\section{Provider-patient interaction in diabetes care: effects on patient self-care and outcomes - a systematic review}

(De interactie tussen zorgverlener en patiënt in de diabeteszorg: effecten op patiënten-zelfzorg en uitkomsten - een systematische literatuurstudie) 


\section{Provider-patient interaction in diabetes care: effects on patient self-care and outcomes - a systematic review}

(De interactie tussen zorgverlener en patiënt in de diabeteszorg: effecten op patiënten-zelfzorg en uitkomsten - een systematische literatuurstudie)

Henk van Dam $\left({ }^{*}\right)$, Frans van der Horst $\left({ }^{*}\right)$, Bart van den Borne $\left({ }^{* *}\right)$, Rick Ryckman $\left({ }^{* * *}\right)$, Harry Crebolder $\left(^{*}\right)$

Reprinted from Patient Educ Couns 2003;51:17-28

$\left(^{*}\right)$ Department of General Practice, Maastricht University, the Netherlands.

$\left({ }^{* *}\right)$ Department of Health Sciences, Maastricht University, the Netherlands

$\left.{ }^{\star * * *}\right)$ Department of Psychology, University of Maine, United States of America

Correspondence: HA van Dam, GP

Primary Health Care Center 'Withuis'

Tel.++31.77.3517652, Fax.++31.77.3589705

P.O. Box 765, 5900 AT - Venlo, the Netherlands

Email: Rnhprk09@hag.unimaas.nl. 


\section{ABSTRACT}

A systematic review of the research literature using Medline, Embase, PsycLIT/PsycINFO and the Cochrane Library files 1980 through 2001, identified only eight publications based on well designed studies involving randomised controlled trials (RCTs) - testing the effects of modification of provider-patient interaction and provider consulting style on patient diabetes self-care and diabetes outcomes, in general practice or hospital outpatient settings. Review of these publications leads to the tentative conclusion that focusing on patient behaviour - directly enhancing active patient participation i.e. by assistant-guided patient preparation for visits to doctors, empowering group education, group consultations, or automated telephone management - is more effective than focusing on provider behaviour to change their consulting style into a more patient-centered one. The latter proves hard to sustain, needs intensive support, and is not very effective in improving patient self-care and health outcomes when executed alone. Patient behaviour focused interventions show good efficacy and efficiency, and improve patient self-care and diabetes outcomes. More well-designed intervention studies focusing on enhancing patient participation in diabetes care are needed.

\section{SAMENVATTING}

Systematisch literatuuronderzoek vond in meer dan twintig jaar medische, psychologische en gezondheidsliteratuur maar acht studies die gedragsinterventies in de diabeteszorg in de huisartspraktijk of op poliklinieken op wetenschappelijk grondige manier bestudeerden (RCT's). De voorzichtige conclusie van de auteurs is dat de meest effectieve interventies die zijn, die zich direct richten op activering van het patiëntgedrag in diabeteszorg: in het omgaan met en overwinnen van de belemmeringen en problemen in het dagelijks leven, en in actieve patiëntparticipatie en zelfzorg. Zulke interventies leidden tot verbeterde uitkomsten van zelfzorg en diabeteszorg. Interventies gericht op verandering van het gedrag van hulpverleners (om meer patiëntgericht te werken) waren slecht vol te houden en minder effectief. Meer goed opgezette interventiestudies die zich richten op verbetering van actieve patiëntenparticipatie in eerstelijns- en poliklinische diabeteszorg zijn nodig. 


\section{INTRODUCTION}

A substantial proportion of type 2 diabetes patients shows poor care outcomes [1-5]. An estimated 30 to 60 per cent of the type 2 diabetes patients in routine general practice have poor metabolic control ( $\mathrm{GlyHb}>8.5 \%$ or fasting blood glucose $>11$ $\mathrm{mmol} / \mathrm{l}$ ). Only intensive feedback and monitoring programs in selected practices with very motivated professionals can improve this situation [6-8]. Cardiovascular risk factors in type 2 diabetes patients at least double their risk to die from cardiovascular causes. Over the past decades the quality of diabetes care guidelines appears to have improved, and the rate of foot amputations has decreased - but there was no major improvement of survival rates and prevention of cardiovascular and other diabetes complications. Further improvements in diabetes care are needed to produce better outcomes - in terms of glycaemic control, cardiovascular risk factors, diabetes complications, survival, health related quality of life, psychological and functional status [9-10]. A thorough understanding of the elements that contribute to better diabetes outcomes is needed, including the role-functioning of general practitioners (GPs), and primary care and out-patient clinic diabetes teams [11-28].

The role of provider-patient interaction and provider consulting style in relation to patient self-care behaviour, is gaining increasing attention in research and care $[18,29]$.

Studies of the effects of interventions to improve provider-patient interaction and provider consulting style on diabetes outcomes are the subject of this review article.

Enhancing the patients' active participation in diabetes care, and their self-care behaviour, is regarded to be a key factor to outcomes improvement. Over the past decades, a shift in this direction has been advocated in books, lectures, comments, and review articles, on a wide field of health care subjects and chronic illnesses [1122], including diabetes [23-37]. Many researchers advocate radical changes in doctor-patient interaction in diabetes care, as this shift toward patient participation and empowerment is supposed to be necessary to enhance patient adaptation to the condition and adherence to professional advice, to help improve self-care and care outcomes [25,29-31].

Improving outcomes of type 2 diabetes health care is impossible without improving patient self-management behaviour. Ninety-five per cent or more of the many health decisions a diabetes patient must make daily are made without health care professionals even knowing them [21]. Decisions about foods and drinks, tobacco smoking, physical activity, adherence to drug prescription, insulin regimen, clinic attendance, blood glucose self-monitoring, and so on, have to be made on a daily basis. Personal, emotional, cultural and social elements play a role in this decisionmaking process. Type 2 diabetes is generally not a problem that requires emergency medical interventions, but support for patient health behaviour adaptations.

Health care providers and important others in the patients' social context, are probably those who have the greatest impact on patient behaviour. Still, for one adult to do what another one tells him to do, on a continuous basis, almost certainly indicates abnormal rather than normal behaviour. And this is exactly what diabetes care providers have expected patients to do, for many decades. No wonder they often failed $[21,29]$. To help patients gain real better control over their diabetes, in order to prevent (or postpone) complications, and to increase their quality of life, health care professionals should support patients by encouraging them to make 
informed personal decisions in their everyday life with diabetes. To reach these goals, major changes in provider-patient interaction are required, i.e., there must be movement away from interactions that are authoritarian to ones that are more supportive and sharing.

Knowledge alone is poorly related to behaviour [36,37]. Accurate diabetes knowledge can help patients make more informed decisions, but they will not act on this information unless they are strongly motivated to do so. Thus, a focus on the patients' motivation and intention to change health behaviour and life habits is critical and necessary.

Different health behaviour theories have been developed to understand patient selfcare behaviour. Most influential have been the Health Belief Model [38,39], the Theory of Planned Behaviour [40,41], and the Social Cognitive (Learning) Theory [42]. Testing these models and theories in research settings showed that the three strongest determinants of patient behaviour, acting through motivation and intention, are (1) attitudes (including patient health beliefs, perceived seriousness of the disease, outcome expectancies, perceived costs and benefits), (2) perceived social norms (opinions and beliefs of important others), and (3) perceived behavioural control, or self-efficacy (confidence in one's power to perform required behaviour and influence the progression of the disease) [41]. Professional interventions meant to effectively influence patient diabetes behaviour by the provider-patient interaction will have to address these three patient behaviour determinants.

The major research question of this paper is: Can we identify studies with high methodological quality, testing the effects of interventions on provider-patient interaction on patient diabetes health behaviour, patient self-care, delivered diabetes care, and health outcomes? And if so, what interventions prove to be the most effective ones to reach such improvements?

\section{METHOD}

A systematic literature search was executed to retrieve publications on studies of provider-patient interaction and communication and on provider consulting style, and their effects on (determinants of) patient self-care behaviour and diabetes outcomes. From these studies, we selected those that were methodologically well-designed.

\subsection{Search strategy}

The literature search was conducted through Medline Advanced (1980-10/2001), Embase (1989-10/2001), Psyclit/Psycinfo (1980-10/2001) and The Cochrane Library (1980-10/2001). Publications in the English language were preferred. Key words used were "diabetes" and "consulting", with "communic*", "interaction", "relation*", "style", "empower*", "particip*" and "negotiat*".

Combining these key words with "outcome" reduced the results of searches to virtually zero, and was abandoned. By cross-checking the results of the automated search with bibliographies of the original articles, we retrieved other publications. Some of these involved randomised controlled trials (RCTs), some were based on non-controlled trials and reviews, and many described observational, explorative and case control studies, or personal opinions, comments, and lectures.

\subsection{Selection}


In the first stage, we included all publications matching our inclusion key words. They were applied to abstracts, titles, and key words lists of articles in the computerised literature search and manual cross-checking of bibliographies.

In the second stage, publications on non-diabetes patients and non-type 2 diabetes patients were excluded, as were those expressing personal opinions, reports, or comments, and those reporting on non-experimental (explorative/cross-sectional) studies, case studies, and case control studies.

For the final stage, additional inclusion criteria were applied to select the publications for the review: (a) Experimental modifications of provider-patient interaction, provider consulting style, or patient education, with observation of obstacles, opportunities, and effects on diabetes outcomes and self-care in practical diabetes care for patients in general practice or outpatient clinics; (b) studies with strong methodological power (randomised controlled trials, or quasi experimental studies with pre-/posttest design); and (c) outcome measurements in any one of the categories: patient behaviours (participation in care, adherence or compliance to professional advises, self-care, self-monitoring of blood glucose, insulin or other medication use, and exercise, diet, or other lifestyle adaptations); patient biomedical issues (glycaemic control, cardiovascular risk factors, complications, admissions to institutions/hospitals, mortality); patient functional measures (physical, emotional, social, professional functioning); psychological measures (satisfaction, wellbeing, depression, anxiety, mental health, diabetes related quality of life scores); quality of care (self-assessed, panel assessed, patient assessed); provider adherence to guidelines (process); and provider behaviour, satisfaction and attitudes.

\subsection{Criteria based Analysis}

To assess the methodological quality of the included publications (criterion b) we applied a modified version of the 19 items Van Tulder criteria list $[43,44]$. It is presented in Table 1. The maximum quality score for any of the reviewed publications is 19 points $(100 \%)$, as "yes" = 1 point, "partly" = 0.5 point, and "no" or "unclear" $=0$ points for each of the criteria items. The actual scores can be any number from 0 to $19(0 \%$ to $100 \%)$.

\subsection{Data extraction}

In order to compare studies, specified data were extracted from the selected articles: year of publication, tested hypotheses and targeted health behaviour determinants, study design, research setting (e.g. general practice or hospital outpatient diabetes care) and study population (number and characteristics of study and control group), type of intervention, outcome measures, and outcome effects for providers and patients.

\section{RESULTS}

In the first stage of selection over 720 abstracts were retrieved, resulting in the inclusion of 140 potentially relevant articles after the second selection. After applying the third stage of selection to the full text of these articles, eight remained [6,45-51]. Table 2 shows the methodological quality scores of the selected studies, as assessed by the criteria listed in Table 1 . The quality scores range from a low of 13 to a high of 19 points (68 to $100 \%$ ), with a mean of $17.3(91 \%)$. The lower score of the Anderson study [50] is based on lacking blindation of providers, patients, and outcome assessment to the intervention, and on lacking long term follow-up. 
All eight studies aimed at enhancing patients' participation in their diabetes care. They showed different interventions on different levels of the provider-patient interaction in diabetes care. These interventions and their effects will be described here.

Study 1: Training of providers (GPs and nurses) for a more patient-centered consulting style in the research of Kinmonth et al, did not improve patient selfcare, life style, and diabetes control (GlyHb of experimental group after one year $7.07 \%$, of control group 7.17), did improve patient-reported care process and patient satisfaction, while weight and lipid control, and diabetes knowledge scores, even slightly worsened [45].

Study 2: Trained diabetes nurses in the same study (Study 1) delivered better patient-reported diabetes care and had more satisfied patients, but judged their own results, capacities, and patient satisfaction, as more negative than did control nurses, according to the research of Woodcock et al [46].

Study 3: Training of providers (GPs and nurses) for a patient-centered consulting style in the study of Pill et al had disappointing effects. After two years, only a minority $(19 \%)$ of the trained providers realised sustained behaviour change, and no improvements were found for patient outcome measures: diabetes control (GlyHb of experimental group $+0.69 \%$, of control group +1.14$)$, complications, satisfaction, lifestyle, and self-care [47].

Study 4: GPs being supported to negotiate realistic individual goals setting with their patients, and at the same time to improve follow-up and diabetes treatment by prompting, guidelines, feedback, and medical education, in six years time realised improved quality of diabetes care, risk factor scores, and diabetes control for their patients (Gly Hb of experimental group $-1.7 \%$, of control group -1.2 ), in the study of De Fine Olivarius et al [6].

Study 5: An automated telephone diabetes management programme in the study of Piette et al, offering patients feedback on blood glucose self-testing results, advice, and support from a computer and an external nurse, parallel to usual care, improved patient self-efficacy, diabetes control (GlyHb of experimental group $-0.7 \%$, of control group -0.2), satisfaction, emotional state, and work attention, and did not worsen anxiety and quality of life scores $[48,49]$.

Study 6: Anderson et al showed that their patient empowerment group education programme improved patient attitudes, self-efficacy, asking for social support, and diabetes control (GlyHb of experimental group $-0.73 \%$, of control group -0.04 ), in twelve weeks time [50].

Study 7: Greenfield et al presented an assistant-guided, short (20-minutes), structured, individualised, empowering patient preparation directly before two subsequent diabetes consultations to their doctors in outpatient clinics. This enhanced active patient participation (ask questions and negotiate decisions), improved patient satisfaction, perceived health, and diabetes control (GlyHb of experimental group $-1.53 \%$, of control group +0.35 ), and lowered functional limitations, without increasing the length of consultations, nine months after enrollment [51]. The control group received standard diabetes education in similar, 20-minutes, patient preparations before their diabetes consultations.

Study 8: Trenton et al found that group consultations over two years time kept diabetes control stable (GlyHb of experimental group $+0.1 \%$, of control group +0.9 ), and improved blood lipids, Body Mass Index, diabetes health behaviour, diabetes 
knowledge, quality of life scores, and efficiency of professional efforts, as compared to individual consultations [52].

Table 3 presents a summary of the selected studies in terms of focus of intervention on provider or patient behaviour, and outcome effects on provider and/or patient behaviour, patient self-care, and functional and biomedical outcomes. It shows that four studies (1-4) focused on provider consulting behaviour modifications, and four studies (5-8) focused directly on patient behaviour changes. Obviously, the effects on patient outcomes (consulting behaviour, self care behaviour, biomedical and psychosocial outcomes) from the directly patient focused interventions tested in the latter four studies, and the provider negotiation behaviour enhancing plus provider compliance supporting intervention tested in study 4 , are more positive as compared with the provider focused interventions tested in studies 1-3.

The Appendix table overviews all eight studies in more detail. This table shows the similarities and differences of the studies with regard to study populations, interventions, and outcomes measures. All studies were executed in practical diabetes care, three (6-8) in hospital outpatient clinics, and five in general practices. The studies of Kinmonth et al and of Woodcock et al included newly diagnosed type 2 diabetes patients, all others included patients with a longer history of diabetes.

A wide range of measures was involved in the eight reviewed studies. Baseline GlyHbs of study populations varied widely. Those in the studies of Pill et al, De Fine Olivarius et al, Anderson et al, and Greenfield et al, were substantially higher $(>10 \%)$ as compared with the studies of Piette et al and Trento et al $(<9 \%)$. For the study of Kinmonth et al baseline GlyHbs were not presented, but were probably below $8 \%$. Changes in GlyHbs were measured in seven studies, lipids in three, blood pressures in four, body mass indexes in four, smoking habits in three, physical activities in three, patient satisfaction in four, and eleven other patient outcome variables in one, two, or three studies. Twelve different provider outcome variables were measured in six studies.

\section{DISCUSSION AND CONCLUSION}

The research question was answered positively by this systematic literature review. Eight published studies with high methodological quality were identified and reviewed. They show that interventions on the provider-patient interaction in primary and outpatient clinic diabetes care, can improve (determinants of) patient diabetes behaviour, patient self-care, and diabetes outcomes. In this review the most effective interventions are those with a direct approach to support patient participation in diabetes care and self-care behaviour, while interventions which focus on change of provider behaviour were less effective.

A shift from the traditional medical model (doctor, disease, and glucose level centered model, blaming the patients for non-compliance), toward a patient participation, patient-centred, sharing, patient empowerment model, is advocated, as this is regarded as necessary to meet modern quality standards in the diabetes care of the 21th century. But it appears to be very difficult for providers to change their consulting style into one that is more suitable, even when supported by special training programmes - such behaviour changes require intensive and continuous support, and involve prolonged counselling, as these changes prove hard to sustain. 
More important, such provider changes show disappointing effects on patient selfcare and health outcomes when implemented alone (Studies 1-3 by Kinmonth et al, Woodcock et al, Pill et al). This finding is supported by a recent qualitative study by Paterson, showing that practitioners often but wrongly assume that merely inviting patients to participate is sufficient to guarantee their empowerment [53]. Provider behaviour change alone appears to be not the right way. Combining an intensive doctor-supportive programme for organisational and medical improvements (prompting system, guidelines, feedback, and medical education) with support of doctor and patient behaviour to negotiate more realistic individualised treatment goals with patients, shows clearer positive outcomes (Study 4 by De Fine Olivarius et al). Interventions directly focused on enhancing patients' participation in diabetes care prove to be the most powerful ones: the automated telephone management programme, the patient empowering group education, the guided preparation for diabetes consultations, and the group consultation experiment (Studies 5-8 by Piette et al, Anderson et al, Greenfield et al, and Trenton et al, respectively).

Our review has some limitations. The first limitation is the small number of reviewed studies. This forces us to make our conclusions tentative ones. It is suprising, even causing suspicion, to realize that we found no proof that any of the three most promising studies $[6,7,8]$ has been replicated by other researchers in different diabetes care settings, in different countries, and among different patient populations. Another limitation is the range of differences between the studies, which lowers the comparability of study populations, interventions, and outcome effects. The third limitation is that we limited our focus to RCTs. The evidence they bring to support their findings is methodologically strong, but the flaw of RCTs is that they often have an artificial design (inclusion of a defined and limited patient group, severe exclusion of other interventions but the index intervention, set duration of time), which make their findings often less feasible in real-life medical practice. On the other hand, assessment of the methodological quality of the reviewed studies shows high scores, and most of the reviewed publications describe their study populations as being representative for practice populations in usual settings. We intentionally excluded studies with other designs, e.g. qualitative, explorative, or case control studies. Such studies were retrieved abundantly in the first and second selections, they might have their merit, and they helped us better understand the interactional aspects of diabetes care at the commencement of our literature search - but they could not offer the requested methodological quality in testing the research question we formulated in the Introduction section of this paper.

We tentatively conclude that a direct approach to patient self-care behaviour and participation in diabetes care is effective, more effective than focusing on changing provider consultation behaviour.

Possibly, a combination of approaches (patient and provider, and organisation of care supportive) has considerable potential to produce even better, important and lasting outcome improvements. This could be achieved by offering: (a) support to directly enhance patient participation, (b) support to improve provider participatory behaviour in consultations and education, and (c) support to providers to improve organisation and quality of care by feedback of outcomes, and additional (para) medical education.

Our conclusion also generates the following, as yet unanswered, questions: Is it practically feasible for providers of diabetes care (physicians, nurses, dieticians, 
educators) in general practice or hospital outpatient clinics to implement in their daily work the most promising type of intervention presented in this review, which is directly addressing patient participation, information seeking and negotiating, for improving patients' self-care behaviour? Will this really help to improve the outcomes of diabetes care? Will it really matter? Will it be more effective for specific patient subgroups - e.g. those with bad diabetes control, high cardiovascular risk scores, low self-efficact, or low quality of life - then it will be for patient groups with better health characteristics? Answers can only be found by executing more, methodologically well-designed, provider-patient, and practical diabetes care based, implementation studies.

\section{PRACTICE IMPLICATIONS}

Primary care or outpatient clinic diabetes teams could consider to focus on programmes for directly enhancing patient participation - e.g. by assistant-guided patient preparation for patient-provider encounters, patient empowering group education, group consultations, or automated telephone management with nurse support. Such programmes should not be seen as competing with traditional diabetes patient education or enhanced diabetes care programmes. Diabetes teams may well be able to improve determinants of patient health behaviour, enhance patient diabetes management and self-care, and improve diabetes care outcomes with such programmes - possibly even more when combining them with support to improve provider partcipatory behaviour in consultations and education, and with support for organisation of care and (para) medical education to providers. Well-designed intervention studies are needed to support this conclusion with more evidence.

\section{Ackowledgments}

We are grateful for the contribution of Mrs. Lut Knoops, dietician and Master of Health Sciences, in our discussions on the results of the review. 
Table 1.

Criteria list for assessment of methodological quality of trials (Modified Van Tulder List)

('Yes'=1 point, 'no' or 'unclear' $=0$ points, and 'partly' $=0,5$ points. The maximum score of 19 points $=100 \%$ )

\section{Patient selection}

- 1. Were the eligibility criteria clearly specified?

- 2. Was a method of randomisation performed?

- 3 . Were the groups similar at baseline regarding the most (potential) prognostic indicators?

\section{Interventions}

- 4. Were the index and control interventions explicitly described?

- 5. Were providers of regular care blinded to the intervention?

- 6. Were there no co-interventions?

- 7. Was there good compliance in all groups?

- 8. Were the respondents blinded to the intervention?

\section{Outcome measurements}

- 9. Was outcome assessment blinded to the intervention?

- 10.Were most outcome measures relevant?

- 11.Were there no adverse effects of the intervention on the participants?

- 12.Was the withdrawal or drop-out rate acceptable?

- 13.Was the withdrawal or drop-out rate random?

- 14.Were short term follow-up measurements performed?

- 15.Were long term follow-up measurements performed?

- 16.Was the timing of the outcome assessment in both groups comparable?

\section{Statistics}

- 17.Was the sample size for each group described?

- 18.Did the analysis include an intention to treat analysis?

- 19.Were point estimates and measures of variability presented for the primary outcome measures? 
Table 2. Methodological quality of trials examining effects of provider-patient interaction interventions on diabetes outcomes (Modified Van Tulder criteria list).

\begin{tabular}{lllllll} 
Study & $\begin{array}{l}\text { Patient } \\
\text { Selection } \\
\text { (Max.3) }\end{array}$ & \multicolumn{2}{l}{ Interbention Outcomes } & Statistics & \multicolumn{2}{l}{ Total (\%) } \\
& (max.5) & (max.8) & (max.3) & (0-19)(0-100) \\
Kinmonth [45]3 & 5 & 7 & 3 & 18 & $(95)$ \\
Woodcock[46]3 & 5 & 7 & 3 & 18 & $(95)$ \\
Pill [47] 3 & 5 & 8 & 3 & 19 & $(100)$ \\
Olivarius [6] 3 & 4 & 8 & 3 & 18 & $(95)$ \\
Piette [48,49] 3 & 5 & 7 & 3 & 18 & $(95)$ \\
Anderson[50] 2,5 & 3 & 5 & 2,5 & 13 & $(68)$ \\
Greenfield[51]3 & 4 & 8 & 2 & 17 & $(89)$ \\
Trento [52] 3 & 4 & 8 & 3 & 18 & $(95)$
\end{tabular}


Table 3. Summary of main findings

Study

\section{Focus of Intervention}

Behaviour

Provider Patient

\section{Outcomes}

\section{Consultation Behaviour}

Provider
Patient diabetes outcomes

Biomedical Selfcare Psycho (determ.) social.

(*) $(* *)$

1.Kinmonth [45] +

2.Woodstock [46] +

3.Pill [47] +

4.Olivarius[6] +

5.Piette $[48,49]$

6.Anderson [50]

7.Greenfield [51]

8.Trento [52]

Legenda:

(+): Positive (effect)

( ): No, or negative effect

(?): No clear, or both positive and negative effects

+
+
+
+
+

$+$

$+$

? $\quad+$

$+\quad$ ?

$+$

$+$

$+$

$+$

$\begin{array}{lllll} & & & ? \\ & & & ? \\ + & & & ? \\ ? & + & ? & \\ + & + & + & ? \\ + & + & & + \\ + & ++ & & + \\ + & + & + & +\end{array}$

$(*)$ : Including diabetes knowledge, attitudes, selfefficacy, lifestyle (smoking, alcohol, exercise) ${ }^{* *}$ ): Including Quality of Life score, general health score, wellbeing score, functional status, sick leave, psychosocial/mental status, patient reported quality of care, satisfaction 


\section{(Appendix)}

\section{Intervention studies with Randomised Controlled Trial design}

\begin{tabular}{|c|c|c|c|c|c|c|}
\hline $\begin{array}{l}\text { Author/ } \\
\text { (year) } \\
\text { [reference } \\
\text { nr] }\end{array}$ & $\begin{array}{l}\text { Hypothesis } \\
\text { and } \\
\text { determinants } \\
\text { involved }\end{array}$ & $\begin{array}{l}\text { Design, } \\
\text { outcome } \\
\text { measures, } \\
\text { (follow-up) }\end{array}$ & $\begin{array}{l}\text { Interventions } \\
\text { a)providers } \\
\text { b)patients }\end{array}$ & \begin{tabular}{|l|} 
Setting, \\
numbers/ \\
populations \\
Exper./Contr
\end{tabular} & $\begin{array}{l}\text { Provider } \\
\text { outcomes }\end{array}$ & $\begin{array}{l}\text { Patient } \\
\text { outcomes }\end{array}$ \\
\hline $\begin{array}{l}\text { 1. Kinmonth } \\
\text { et al } \\
\text { (1998) [45] }\end{array}$ & $\begin{array}{l}\text { Training of } \\
\text { providers in } \\
\text { patient- } \\
\text { centred care } \\
\text { improves } \\
\text { communicati } \\
\text { on, patient } \\
\text { life style } \\
\text { choices, and } \\
\text { diabetes } \\
\text { outcomes. } \\
\text { Determ.: } \\
\text { provider- } \\
\text { patient } \\
\text { agreement, } \\
\text { perceived } \\
\text { diabetes } \\
\text { control, self- } \\
\text { care, } \\
\text { diabetes } \\
\text { knowledge }\end{array}$ & $\begin{array}{l}\text { RCT, } \\
\text { practices } \\
\text { randomised } \\
\text { Measures: } \\
\text { patient } \\
\text { biomedical } \\
\text { (BP, lipids, } \\
\text { weight/BMI, } \\
\text { GlyHb), } \\
\text { communicati } \\
\text { on, } \\
\text { satisfaction, } \\
\text { wellbeing, } \\
\text { lifestyle, } \\
\text { diabetes } \\
\text { knowledge. } \\
\text { (12months) }\end{array}$ & $\begin{array}{l}\text { a)Provider } \\
\text { training: GPs } \\
0.5 d, \text { nurses } \\
\text { 1.5d. Booklet } \\
\text { for GPs on } \\
\text { approaches } \\
\text { to } \\
\text { behavioural } \\
\text { change. } \\
\text { Booklet to } \\
\text { hand out to } \\
\text { patients to } \\
\text { encourage to } \\
\text { ask } \\
\text { questions, } \\
\text { and leaflet to } \\
\text { discuss } \\
\text { complication } \\
\text { s. } \\
\text { b)None. }\end{array}$ & $\begin{array}{l}\text { GP (UK): } 43 \\
\text { practices (21 } \\
\text { intervention } \\
\text { and } 20 \\
\text { control, } 19 \\
\text { and } 23 \text { GPs, } \\
28 \text { and } 32 \\
\text { nurses, } 142 \\
\text { and 108 30- } \\
70 y r \text { old, } \\
\text { newly } \\
\text { diagnosed, } \\
\text { unselected } \\
\text { DM2 } \\
\text { patients, } \\
\text { resp. Good } \\
\text { comparabilit } \\
\text { y of study } \\
\text { groups for } \\
\text { age, sex, } \\
\text { social class, } \\
\text { marital state, } \\
\text { previous } \\
\text { heart } \\
\text { disease, and } \\
\text { smoking. No } \\
\text { baseline } \\
\text { GlyHbs } \\
\text { given. }\end{array}$ & \begin{tabular}{|l} 
Method \\
assessed as \\
easily \\
applicable. \\
17 Nurses \\
and 15 \\
doctors \\
reported \\
extensive \\
use of the \\
patient- \\
centred \\
consulting \\
style after \\
12months
\end{tabular} & $\begin{array}{l}\text { No baseline } \\
\text { GlyHb given, } \\
\text { so diff. of } \\
\text { means } \\
\text { before/after } \\
\text { unknown. } \\
\text { Outcome } \\
\text { GlyHb } \\
7.07 \% \text { vs. } \\
7.17 \text { for } \\
\text { controls } \\
\text { (between } \\
\text { groups - } \\
0,1 \%, \\
\text { p=0.31). BP } \\
\text { no change, } \\
\text { triglycerids } \\
+0,4 \text { mmol/I, } \\
\text { no lifestyle } \\
\text { change, } \\
\text { better } \\
\text { wellbeing/ } \\
\text { satisfaction. } \\
\text { Diabetes } \\
\text { knowledge } \\
\text { and BMI } \\
\text { somewhat } \\
\text { worse. }\end{array}$ \\
\hline $\begin{array}{l}\text { 2. Woodcock } \\
\text { et al } \\
\text { (1998) [46] }\end{array}$ & $\begin{array}{l}\text { Training of } \\
\text { nurses in } \\
\text { patient- } \\
\text { centred care } \\
\text { improves } \\
\text { patient } \\
\text { involvement, } \\
\text { quality of } \\
\text { care, } \\
\text { diabetes } \\
\text { outcomes, } \\
\text { satisfaction } \\
\text { of nurses } \\
\text { and patients. } \\
\text { Determ.: } \\
\text { nurse beliefs } \\
\text { (relation } \\
\text { glucose } \\
\text { level- } \\
\text { complication } \\
\text { s), self- } \\
\text { efficacy, } \\
\text { attitudes of }\end{array}$ & $\begin{array}{l}R C T, \\
\text { practices } \\
\text { randomised } \\
\text { Same project } \\
\text { as 1. } \\
\text { Measures: } \\
\text { Nurse } \\
\text { beliefs, } \\
\text { attitudes, } \\
\text { behaviours, } \\
\text { patients' } \\
\text { perception of } \\
\text { delivered } \\
\text { care(shortly } \\
\text { and 12 } \\
\text { months after } \\
\text { the training). }\end{array}$ & $\begin{array}{l}\text { a)1,5 Days } \\
\text { group } \\
\text { training in } \\
\text { patient- } \\
\text { centred } \\
\text { consulting } \\
\text { style for } \\
\text { nurses, } \\
\text { Booklet for } \\
\text { patients to } \\
\text { encourage } \\
\text { them to ask } \\
\text { questions, } \\
\text { and leaflet to } \\
\text { discuss } \\
\text { complication } \\
\text { s. } \\
\text { b)None. }\end{array}$ & $\begin{array}{l}\text { GP (UK): } 43 \\
\text { practices (21 } \\
\text { intervention } \\
\text { and } 20 \\
\text { control, } 28 \\
\text { and } 30 \\
\text { nurses, } 142 \\
\text { and } 10830- \\
70 y r \text { old, } \\
\text { newly } \\
\text { diagnosed, } \\
\text { unselected } \\
\text { DM2 } \\
\text { patients, } \\
\text { resp.). See } \\
\text { under } \\
\text { 1.Kinmonth. }\end{array}$ & $\begin{array}{l}\text { Lower self- } \\
\text { efficacy to } \\
\text { deliver the } \\
\text { method, } \\
\text { lower nurse- } \\
\text { perceived } \\
\text { quality of } \\
\text { delivered } \\
\text { care, lower } \\
\text { nurse- } \\
\text { perceived } \\
\text { patient } \\
\text { satisfaction }\end{array}$ & \begin{tabular}{|l|} 
Better \\
satisfaction \\
with \\
diabetes \\
care, better \\
assessed \\
quality of \\
care (patient \\
reported)
\end{tabular} \\
\hline
\end{tabular}




\begin{tabular}{|c|c|c|c|c|c|c|}
\hline & nurse/patient & & & & & \\
\hline $\begin{array}{l}\text { 3. Pill et al } \\
\text { (1998) [47] }\end{array}$ & $\begin{array}{l}\text { Training of } \\
\text { providers in } \\
\text { patient- } \\
\text { centred care } \\
\text { improves } \\
\text { patient } \\
\text { participation } \\
\text { in decision } \\
\text { making and } \\
\text { diabetes } \\
\text { outcomes. } \\
\text { Determ.: } \\
\text { patient } \\
\text { attitudes } \\
\text { (perception } \\
\text { of diabetes, } \\
\text { readiness to } \\
\text { change, } \\
\text { outcome } \\
\text { expectancie } \\
\text { s, } \\
\text { satisfaction } \\
\text { with care }\end{array}$ & $\begin{array}{l}R C T, \\
\text { practices } \\
\text { randomised } \\
\text { Outcome } \\
\text { measures: } \\
\text { provider } \\
\text { behaviour } \\
\text { changes, } \\
\text { patient } \\
\text { biomedical, } \\
\text { functional, } \\
\text { psycho- } \\
\text { social, } \\
\text { lifestyle } \\
\text { changes, } \\
\text { attitudes, } \\
\text { (18-24 } \\
\text { months). }\end{array}$ & $\begin{array}{l}\text { a)Training } \\
\text { program for } \\
\text { doctors and } \\
\text { nurses(2yr) } \\
\text { on patient- } \\
\text { centredness; } \\
\text { with visual } \\
\text { agendachart } \\
\text { + readiness } \\
\text { to change } \\
\text { ruler, to } \\
\text { enhance } \\
\text { patient } \\
\text { participation. } \\
\text { b)None. }\end{array}$ & $\begin{array}{l}\text { GP (UK): } 29 \\
\text { practices (15 } \\
\text { intervention } \\
\text { and 14 } \\
\text { control, } 9 \\
\text { and } 9 \text { GPs, } \\
16 \text { and } 15 \\
\text { nurses). } 252 \\
\text { Patients with } \\
\text { >1yr DM2 } \\
\text { (95 } \\
\text { intervention, } \\
95 \text { control), } \\
172 \text { complete } \\
\text { d whole } \\
\text { study (77 } \\
\text { and } 95, \\
\text { resp.). Fairly } \\
\text { good } \\
\text { comparabilit } \\
\text { y of exper. } \\
\text { and control } \\
\text { group except } \\
\text { for sex } \\
\text { distribution, } \\
\text { alcohol.drinki } \\
\text { ng. Baseline } \\
\text { mean GlyHb } \\
11.39 \text { vs. } \\
11.87 \%\end{array}$ & $\begin{array}{l}\text { Appreciation } \\
\text { of the } \\
\text { training } \\
\text { positive. All } \\
\text { used visual } \\
\text { aids at } 9 \\
\text { months, but } \\
\text { only } 19 \% \text { at } \\
18 \text { months. }\end{array}$ & $\begin{array}{l}\text { Mean GlyHb } \\
\text { from } 11.39 \\
\text { up to } \\
12.08 \% \text { vs. } \\
11.87 \text { up to } \\
13.02, \text { diff. of } \\
\text { means }+0.69 \\
\text { vs. }+1.15 \% \\
(-0.9 \% \\
\text { between } \\
\text { groups, } \\
\text { p=0.3). No } \\
\text { change } \\
\text { number of } \\
\text { complication } \\
\text { s, } \\
\text { satisfaction, } \\
\text { function, } \\
\text { lipids, BMI, } \\
\text { and } \\
\text { smoking/ } \\
\text { alcohol } \\
\text { habits. More } \\
\text { often } \\
\text { initiating } \\
\text { discussion of } \\
\text { change. }\end{array}$ \\
\hline $\begin{array}{l}\text { 4. Olivarius et } \\
\text { al (2001) [6] }\end{array}$ & $\begin{array}{l}\text { Structured } \\
\text { care with } \\
\text { support to } \\
\text { GPs, and } \\
\text { help to } \\
\text { negotiate } \\
\text { realistic } \\
\text { goals setting } \\
\text { with } \\
\text { patients, } \\
\text { improves } \\
\text { outcomes. } \\
\text { Determ.: } \\
\text { doctor } \\
\text { diabetes } \\
\text { awareness, } \\
\text { knowledge, } \\
\text { and } \\
\text { interaction } \\
\text { with patient }\end{array}$ & $\begin{array}{l}R C T, \\
\text { practices } \\
\text { randomised } \\
\text { Measures: } \\
\text { diabetes } \\
\text { control, } \\
\text { complication } \\
\text { s, death, risk } \\
\text { factors, } \\
\text { health } \\
\text { behaviour, } \\
\text { general } \\
\text { health score, } \\
\text { drugs } \\
\text { prescription } \\
\text { (6yrs) }\end{array}$ & $\begin{array}{l}\text { a)Provider } \\
\text { behaviour } \\
\text { influenced in } \\
\text { many ways: } \\
\text { prompts by } \\
\text { questionnair } \\
\text { es 1month } \\
\text { before each } \\
\text { diabetes } \\
\text { consultation } \\
4 / y r, \\
\text { feedback } \\
\text { reports 1/yr, } \\
\text { guidelines, } \\
\text { education } \\
\text { course 1/yr, } \\
4 \text { patient } \\
\text { leaflets. } \\
\text { b)None. }\end{array}$ & \begin{tabular}{|l|}
$G P(D K):$ \\
311 \\
practices, \\
243 \\
intervention \\
and 231 \\
control GPs \\
with 874 (of \\
970 ) DM2 \\
patients \\
$\geq 40 y r s$. \\
Good \\
comparabilit \\
y of exper. \\
and control \\
group. \\
Baseline \\
mean GlyHb \\
10.2 and \\
$10.2 \%$.
\end{tabular} & $\begin{array}{l}\text { Better } \\
\text { compliance } \\
\text { to } \\
\text { guidelines, } \\
\text { postponed } \\
\text { start of drugs } \\
\text { after } \\
\text { diagnoses, } \\
\text { agreement } \\
\text { on small } \\
\text { weight } \\
\text { reduction } \\
\text { goals, more } \\
\text { frequent } \\
\text { prescription } \\
\text { of metformin, } \\
\text { less referrals } \\
\text { to clinics. }\end{array}$ & $\begin{array}{l}\text { Mean GlyHb } \\
\text { from } 10.2 \text { to } \\
8.5 \% \text { vs. } \\
10.2 \text { to } 9.0, \\
\text { diff. of } \\
\text { means }-1.7 \\
\text { vs }-1.2 \%, \\
\text { (between } \\
\text { groups - } \\
0.5 \%, \\
\text { p<0.0001). } \\
\text { Better risk } \\
\text { factor scores } \\
\text { (weight, BP, } \\
\text { lipids), no } \\
\text { changes nr. } \\
\text { of } \\
\text { complication } \\
\text { s, mortality, } \\
\text { health } \\
\text { behaviour, } \\
\text { and } \\
\text { gen.health }\end{array}$ \\
\hline $\begin{array}{l}\text { 5.Piette et al } \\
(2000) \\
{[48,49]}\end{array}$ & $\begin{array}{l}\text { Patient- } \\
\text { centred } \\
\text { telephone } \\
\text { feedback + } \\
\text { personal } \\
\text { nurse }\end{array}$ & $\begin{array}{l}R C T, \\
\text { patients } \\
\text { randomised } \\
\text { within clinic. } \\
\text { Measures: } \\
\text { clinical data, }\end{array}$ & $\begin{array}{l}\text { a)None. } \\
\text { b)Automated } \\
\text { tel.calls to } \\
\text { patients } \\
(2 / w k), \\
\text { computer }\end{array}$ & $\begin{array}{l}\text { GP(USA): } \\
290 \text { diabetic } \\
\text { patients } \\
(D M 1+2) \\
\text { visiting } \\
\text { health centre }\end{array}$ & \begin{tabular}{|l} 
None \\
reported.
\end{tabular} & $\begin{array}{l}\text { Mean GlyHb } \\
\text { from } 8.8 \text { to } \\
8.1 \% \text { vs. } 8.6 \\
\text { to } 8.4 \text {, diff. of } \\
\text { means - } \\
0,7 \%\end{array}$ \\
\hline
\end{tabular}




\begin{tabular}{|c|c|c|c|c|c|c|}
\hline & 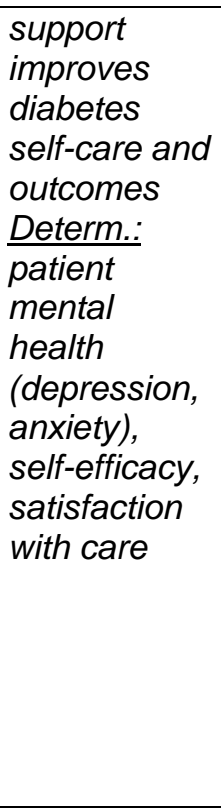 & \begin{tabular}{|l|} 
diabetes \\
behaviour, \\
impact of \\
diabetes, \\
mental \\
health, \\
satisfaction, \\
health \\
related \\
quality of life \\
scores \\
(telephone \\
survey) (12 \\
months)
\end{tabular} & $\begin{array}{l}\text { voice asking } \\
\text { questions, } \\
\text { push button } \\
\text { input of } \\
\text { responses, } \\
\text { automated } \\
\text { health tips, } \\
\text { interactive } \\
\text { dietary } \\
\text { education, } \\
\text { periodic } \\
\text { nurse tel. } \\
\text { follow-up } \\
\text { (feedback, } \\
\text { education, } \\
\text { problems/ } \\
\text { barriers). }\end{array}$ & \begin{tabular}{|l|} 
for diabetes \\
care \\
enrolled, 248 \\
completed \\
the study. \\
Good \\
comprarabilit \\
y of groups, \\
except for \\
insulin use \\
(exper.44\%, \\
control group \\
$31 \%)$. \\
Baseline \\
mean GlyHb \\
8.8 and \\
$8.6 \%$.
\end{tabular} & & \begin{tabular}{|l} 
(between \\
groups - \\
$0.3 \%$ p=0.1). \\
Better blood \\
glucose, \\
self-efficacy, \\
satisfaction; \\
self-care. \\
Less \\
diabetes \\
symptoms \\
and \\
depression, \\
less sick \\
days off- \\
work, no \\
change \\
anxiety and \\
HRQoL \\
scores
\end{tabular} \\
\hline $\begin{array}{l}\text { 6.Anderson } \\
\text { et al } \\
\text { (1995) [50] }\end{array}$ & $\begin{array}{l}\text { Empowerme } \\
\text { nt patient } \\
\text { education, } \\
\text { complement } \\
\text { ary to } \\
\text { traditional } \\
\text { diabetes } \\
\text { education, } \\
\text { improves } \\
\text { diabetes } \\
\text { outcomes. } \\
\text { Determ.: } \\
\text { attitudes, } \\
\text { social } \\
\text { support, } \\
\text { selfefficacy }\end{array}$ & \begin{tabular}{|l}
$R C T, 46$ \\
patients \\
randomised, \\
18 not \\
randomly \\
assigned. \\
Measures: \\
diabetes \\
control \\
(GlyHb) \\
patient self- \\
care, self- \\
efficacy, \\
attitudes ( 0, \\
6,12 wks).
\end{tabular} & $\begin{array}{l}\text { a)None. } \\
\text { b)Six weekly } \\
\text { empowerme } \\
\text { nt group } \\
\text { education } \\
\text { sessions. } \\
\text { Controls: } \\
\text { wait-list for } 6 \\
\text { weeks, then } \\
\text { entering } \\
\text { same } \\
\text { intervention } \\
\text { programme. }\end{array}$ & $\begin{array}{l}\text { Out-clinic } \\
\text { hospital and } \\
\text { primary care } \\
\text { (USA), } 64 \\
\text { diabetes } \\
\text { patients } \\
\text { enrolled } \\
\text { (64\% type2, } \\
54 \% \text { on } \\
\text { insulin). }\end{array}$ & $\begin{array}{l}\text { None } \\
\text { reported. }\end{array}$ & $\begin{array}{l}\text { Mean GlyHb } \\
\text { from } 11.75 \\
\text { to } 11.02 \% \text { vs } \\
10.82 \text { to } \\
10.78, \text { diff. of } \\
\text { means - } \\
0.73 \% \\
\text { (between } \\
\text { groups+0.14 } \\
\%, p<0.005) \text {. } \\
\text { Better } \\
\text { selfcare } \\
\text { (diet, } \\
\text { exercise, } \\
\text { and blood } \\
\text { glucose } \\
\text { monitoring), } \\
\text { better self- } \\
\text { efficacy and } \\
\text { attitudes, } \\
\text { less negative } \\
\text { attit. }\end{array}$ \\
\hline $\begin{array}{l}\text { 7. Greenfield } \\
\text { et al } \\
\text { (1988) [51] }\end{array}$ & $\begin{array}{l}\text { Active } \\
\text { patient } \\
\text { participation } \\
\text { improves } \\
\text { diabetes } \\
\text { behaviour } \\
\text { and } \\
\text { outcomes. } \\
\text { Determ.: } \\
\text { attitudes } \\
\text { (barriers), } \\
\text { patient- } \\
\text { provider } \\
\text { relation, } \\
\text { negotiation } \\
\text { skills, } \\
\text { satisfaction } \\
\text { with care, }\end{array}$ & \begin{tabular}{|l}
$R C T$, \\
patients \\
randomised. \\
Measures: \\
diabetes \\
control, \\
doctor- \\
patient \\
interaction \\
(audiotape), \\
patient \\
quality of life, \\
satisfaction, \\
diabetes \\
knowledge, \\
after 3 and 6 \\
months.
\end{tabular} & $\begin{array}{l}\text { a)None. } \\
\text { b)20min. } \\
\text { before } 2 \\
\text { visits to } \\
\text { doctor, } \\
\text { reviews } \\
\text { medical } \\
\text { record with } \\
\text { assistant, } \\
\text { systematic } \\
\text { identific. of } \\
\text { problems, } \\
\text { prepares to } \\
\text { negotiate } \\
\text { decisions } \\
\text { with doctor. } \\
\text { Controls:20 } \\
\text { min.standard }\end{array}$ & $\begin{array}{l}\text { Diabetes } \\
\text { outpatient } \\
\text { clinics in } 2 \\
\text { hospitals } \\
\text { (USA), } 19 \\
\text { and } 37 \\
\text { physicians, } \\
98 \text { patients } \\
\text { eligible, } 33 \\
\text { intervention } \\
\text { and } 26 \\
\text { control } \\
\text { patients } \\
\text { completed } \\
\text { the study } \\
\text { (type 1+2, } \\
80 \% \text { on } \\
\text { insulin). }\end{array}$ & $\begin{array}{l}\text { No provider } \\
\text { effects } \\
\text { reported. } \\
\text { (No increase } \\
\text { in length of } \\
\text { visits ( } 30 \\
\text { min). }\end{array}$ & $\begin{array}{l}\text { Mean GlyHb } \\
\text { from } 10.59 \\
\text { to } 9.06 \% \text { vs. } \\
10.26 \text { to } \\
10.61 \text {, diff. of } \\
\text { means - } \\
1.53 \% \\
\text { (between } \\
\text { groups - } \\
1.55 \%, p< \\
0.01) . \text { More } \\
\text { active } \\
\text { information } \\
\text { asking/receiv } \\
\text { ing, better } \\
\text { percepted } \\
\text { health, less } \\
\text { concerns, }\end{array}$ \\
\hline
\end{tabular}




\begin{tabular}{|c|c|c|c|c|c|c|}
\hline & $\begin{array}{l}\text { mental } \\
\text { health, self- } \\
\text { efficacy }\end{array}$ & & education. & & & \begin{tabular}{|l} 
less \\
functional \\
limitations \\
(days lost \\
from work), \\
no change of \\
diabetes \\
knowledge.
\end{tabular} \\
\hline $\begin{array}{l}\text { 8. Trento } \\
\text { (2001) [52] }\end{array}$ & $\begin{array}{l}\text { Interactive } \\
\text { group } \\
\text { consultation } \\
\text { s in stead of } \\
\text { individual } \\
\text { visits only } \\
\text { are feasible } \\
\text { in busy } \\
\text { diabetes } \\
\text { clinics and } \\
\text { effective for } \\
\text { educating } \\
\text { patients to } \\
\text { improve self- } \\
\text { care and } \\
\text { outcomes. } \\
\text { Determ.: } \\
\text { health } \\
\text { beliefs, self- } \\
\text { efficacy, } \\
\text { knowledge, } \\
\text { motivation }\end{array}$ & $\begin{array}{l}R C T, \\
\text { patients } \\
\text { randomised. } \\
\text { Measures: } \\
\text { diabetes } \\
\text { control, } \\
\text { lipids, } \\
\text { weightcontrol } \\
\text { diabetes } \\
\text { knowledge, } \\
\text { quality of life, } \\
\text { health } \\
\text { behaviours, } \\
\text { time pat. } \\
\text { spent on } \\
\text { interaction } \\
\text { with } \\
\text { providers } \\
\text { and time } \\
\text { providers } \\
\text { spent per } \\
\text { patient, after } \\
1 \text { and } 2 \\
\text { years }\end{array}$ & $\begin{array}{l}\text { a)None. } \\
\text { b)56 } \\
\text { Patients had } \\
\text { group } \\
\text { consultations } \\
\text { with doctors } \\
\text { every } 3 \\
\text { months. } 56 \\
\text { Controls had } \\
\text { individual } \\
\text { consultations } \\
\text { with } \\
\text { standard } \\
\text { diabetes } \\
\text { education } \\
\text { every } 3 \\
\text { months }\end{array}$ & \begin{tabular}{|l|} 
Outpatient \\
clinic of \\
internal \\
medicine of \\
hospital \\
(Italy), 112 \\
type 2 \\
diabetes \\
patients, \\
non-insulin- \\
treated, 56 \\
randomised \\
to group \\
visits (of 9- \\
10 patients) \\
and 56 to \\
individual \\
visits plus \\
standardised \\
education
\end{tabular} & $\begin{array}{l}\text { Greater } \\
\text { provider } \\
\text { efficiency: } \\
\text { less time per } \\
\text { patient in } \\
\text { group visits } \\
\text { as compared } \\
\text { to individual } \\
\text { visits. No } \\
\text { other } \\
\text { provider } \\
\text { effects } \\
\text { reported. }\end{array}$ & \begin{tabular}{|l} 
Mean GlyHb \\
from 7.4 to \\
7.5 vs. 7.4 to \\
$8.3 \%$, diff.of \\
means \\
$+0.1 \%$ \\
(between \\
groups - \\
$0.8 \%$, \\
$p<0.002)$ ) \\
Improved \\
lipids (HDL, \\
TG) and \\
BMl. Better \\
diab. \\
knowledge, \\
quality of life, \\
and diabetes \\
health \\
behaviours. \\
(Longer \\
interaction \\
with \\
provider)
\end{tabular} \\
\hline
\end{tabular}




\section{REFERENCES}

[1]Bouma M, Dekker JH, Van Eijk JTM. Metabolic control and morbidity of type 2 diabetic patients in a general practice network. Fam Pract 1999;16:402-6.

[2] Groeneveld Y. Introduction of structured diabetes care in general practice. Thesis, Leiden University, The Netherlands, 2000.

[3]Dam HA van, Crebolder HFJM, Eijkelberg I, Van Nunen M, Van der Horst FG. Nonattendance of patients with type 2 diabetes mellitus - A real problem? (in Dutch). Huisarts Wet 2000;43:380-4. [4]Khunti K, Ganguli S, Baker R, Lowy A. Features of primary care associated with variations in process and outcome of care of people with diabetes. Brit J Gen Pract 2001;51:356-60.

[5]UK Prospective Diabetes Study Group. Intensive blood glucose control with sulphonylureas or insulin compared with conventional treatment and risk of complications in patients with type 2 diabetes (UKPDS 33). Lancet 1998;352:837-53.

[6]De Fine Olivarius N, Beck-Nielsen H, Andreasen AH, Hørder M, Pedersen PA. Randomised controlled trial of structured personal care of type 2 diabetes mellitus. BMJ 2001;323:970-5.

[7]De Grauw WJC. The impact of type 2 diabetes mellitus in general practice: Long-term course of illness and outcome of care in an academic family medicine setting. The Nijmegen Monitoring Project. Thesis, Nijmegen, The Netherlands 2001.

[8]Cromme PVM. Type 2 diabetes and life expectancy, the Twello study 1986-1996. Diabetes in the new millenium, Proceedings of the Fourth International Conference of the St Vincent Declaration Primary Care Diabetes Group. Prague, October 13-14, 2000.

[9]Anonymous. Diabetes care and research in Europe: the Saint Vincent declaration. Diabetic Med 1990;7:360.

[10]Alberti KGMM, Gries FA. Management of non-insulin dependent diabetes mellitus in Europe: a consensus view. Diabetic Med 1988;5: 275-81.

[11]Balint M. The doctor, the patient and his illness. 2nd Edition; London, England: Pitman Medical Publishing Co Ltd, 1964.

[12]Stimson G, Webb B. Going to see the doctor - The consultation process in general practice. London/Boston, Routledge and Kegan Paul, 1975.

[13]Engel GL. The need for a New Medical Model: A Challenge for Biomedicine. Science 1977;196(4286):129-36.

[14]Bensing JM, Dronkers J. Instrumental and Affective Aspects of Physician Behavior. Med Care 1992;30:283-98.

[15]Roter DL. The influence of patient characteristics on communication between the doctor and the patient. Huisarts Wet 1991;34(7):295-301.

[16]Graugaard PK, Finset A. The significance of patients' trait anxiety for their emotional responses to and satisfaction with patient-centered and doctor-centered communication styles: An experimental study. Presentation at the International Conference on Patient Education and Counseling 1998. Pat Educ Couns 1998;34:Suppl S26-7.

[17]Silverman J, Kurtz S, Draper J. Skills for communicating with patients. Oxon: Redcliffe Medical Press, 1999.

[18]Steward M, Brown JB, Weston WW, McWhunney IR, McWilliam CL, Freeman TR. Patient Centered Medicine - Transforming the clinical method. Thousand Oaks, London, New Delhi: Sage Publications Inc, 1995.

[19]Roter DL, Hall JA. Doctors talking with patients/Patients talking with doctors - Improving communication in medical visits. Westport/London, Auburn House, 1992, 1993.

[20]Lipkin M, Putnam SM, Lazare A (eds.). The medical interview. Clinical Care, Education and Research, New York, Springer, 1995.

[21]Anderson RM. Patient empowerment and the traditional medical model: A case of irreconcilable differences? Diabetes Care 1995;18:412-5.

[22]Benbassat J, Pilpel D, Tidhar M. Patients' preferences for participation in clinical decision making: A review of published surveys. J Behav Med 1998;24:81-8.

[23]Rosenstock IM. Understanding and enhancing patient compliance with diabetic regimens. Diabetes Care 1985;8:610-6.

[24]Rutten GEHM, Verhoeven S, Heine RJ, De Grauw WJC, Cromme PVM, Reenders K. National Guidelines to Diabetes type 2. (NHG Standaard Diabetes Mellitus Type 2), first revision. (In Dutch). Huisarts Wet 1999;42:67-84].

[25]Fischer L, Chesla CA, Bartz RJ, Gilliss C, Skaff MA, Sabogal F, Kanter RA, Lutz CP. The family and Type 2 Diabetes: A framework for intervention. Diab Educ 1998;24:599-607.

[26]Lustman PJ, Frank BL, McGill JB. Relationship of personality characteristics to glucose regulation in adults with diabetes. Psychosom Med 1991;53:305-12. 
[27]Ciechanowski PS, Katon WJ, Russo JE. Depression and diabetes - Impact of Depressive Symptoms on Adherence, Function, and Costs. Arch Intern Med 2000;160:3278-85.

[28]Anderson LA. Health-care communication and selected psychosocial correlates of adherence in diabetes management. Diabetes Care 1990;13:66-76.

[29]Funnell MM, Anderson RM, Arnold MS, Barr PA, Donelly MB, Johnson PD, Taylor-Moon D, White N. Empowerment: an idea whose time has come in diabetes education. Diabetes Educ 1992;17:37-41. [30]Brown F. Counseling for patient empowerment. Guest Lecture: The 2nd Janet Kinson Lecture, BDA Education and Care Section Meeting. Practical Diabetes Int 1996;13:189-90.

[31]Golin CE, Dimatteo MR, Gelberg L. The role of patient participation in the doctor visit. Implications for adherence to diabetes care. Diabetes Care 1996;19:1153-64.

[32]Jenkins $C D$. An integrated behavioral medicine approach to improving care of patients with Diabetes Mellitus. J Behav Med 1995;21:53-68 (Review with discussion).

[33]Lutfey KE, Wishner WJ. Beyond "Compliance" is "Adherence". Improving the prospect of diabetes care. Diabetes Care 1999;22:635-9.

[34]Skinner TC, Cradock S. Empowerment: What about the evidence? Review article. Practical Diabetes Int 2000;17:91-5.

[35]Ciechanowski P, Katon W, Russo J, Walker E. The patient-provider relationship: Attachment Theory and Adherence to treatment in diabetes. Am J Psychiatry 2001;158:29-35.

[36]Day JL. Diabetic patient education: Determinants of succes. Diabetes Metab Res Rev 2000;16(Suppl 1):S70-4.

[37]Dunn SM, Beekey LJ, Hoskins PL, Turtle JR. Knowledge and attitude change as predictors of metabolic improvement in diabetes education. Soc Sci Med 1990;31:1135-41.

[38]Rosenstock IM. Historical origins of the health belief model. Health Educ Monogr 1974; 2:1-8.

[39]Wooldridge KL, Wallston KA, Graber AL, Brown AW, Davidson P. Diab Educ 1992;18:495-500.

The relationship between health beliefs, adherence, and metabolic control of diabetes.

[40]Fishbein M, Ajzen I. Belief, attitude, intention, and behavior. New York: Wiley, 1975.

[41]Ajzen I. Attitudes, personality and behavior. Milton Keynes: Open University Press, 1988.

[42]Bandura A. Social foundations of thought and action: A social cognitive theory. Englewood Cliffs,

NJ: Prentice-Hall, 1986.

[43]Van Tulder MW, Assendelft WJ, Koes BW, Bouter LM, and the editorial board of the Cochrane

Collaboration Back Review Group. Method guidelines for systematic reviews in the Cochrane

Collaboration Back Review Group for spinal disorders. Spine 1997;22:2323-30.

[44]Van Haastregt JCM, Diederiks JPM, Van Rossum E, De Witte LP, Crebolder HFJM. Effects of preventive home visits to elderly people living in the community: Systematic review. Brit Med J 2000;320:754-8.

[45]Kinmonth AL, Woodcock AJ, Griffin S, Spiegal N, Campbell MJ. RCT of patient-centred care of diabetes in general practice: impact on current wellbeing and future disease risk. The Diabetes Care From Diagnosis Research Team. Brit Med J 1998;317:1202-8.

[46]Woodcock AJ, Kinmonth AL, Campbell MJ, Griffin SJ, Spiegal N. Diabetes Care from Diagnosis: Effects of training in patient-centred care on beliefs, attitudes and behaviour of primary care professionals. Patient Educ Couns 1999;37:65-79.

[47]Pill R, Stott NC, Rollnick SR, Rees M. A Randomized Controlled Trial of an intervention designed to improve the care given in GP to Type II diabetic patients: patient outcomes and professional ability to change behaviour. Fam Pract 1998;15:229-35.

[48]Piette JD, Weinberger M, McPhee SJ. The effect of automated calls with telephone nurse followup on patient-centered outcomes of diabetes care; a Randomised Controlled Trial. Med Care 2000;38:218-30.

[49]Piette JD, Weinberger M, McPhee SJ, Mah CA, Kraemer FB, Crapo LM. Do Automated Calls with Nurse Follow-up Improve Self-Care and Glycemic Control among Vulnerable Patients with Diabetes? Am J Med 2000;108:20-7.

[50]Anderson RM, Funnell MM, Butler PM, Arnold MS, Fitzgerald JT, Feste CC. Patient Empowerment. Results of a randomized controlled trial. Diabetes Care 1995;18:943-9.

[51]Greenfield S, Kaplan SH, Ware JE, Yano EM, Frank HJL. Patients' Participation in Medical Care: Effects on Blood Sugar Control and Quality of Life in Diabetics. J Gen Intern Med 1988;3:446-57.

[52]Trento M, Passera P, Tomalino M, Bajardi M, Pomero F, Allione A, Vaccari P, Molinatti GM, Porta $M$. Group visits improve metabolic control in type 2 diabetes: a 2-year follow-up. Diabetes Care 2001;24:995-1000.

[53]Paterson B. Myth of empowerment in chronic illness. J Adv Nurs 2001;34:574-81. 


\section{CHAPTER 7}

Obstacles in the management of type 2 diabetes: the perspectives of patients and experts

(Belemmeringen in de aanpak van type 2 diabetes: de perspectieven van patiënten en experts) 


\section{Obstacles in the management of type 2 diabetes: the perspectives of patients and experts}

(Belemmeringen in de aanpak van type 2 diabetes: de perspectieven van patiënten en experts)

Henk A. van Dam, Frans van der Horst, Ilse Mesters, Harry Crebolder, Bart van den Borne.

Submitted 


\section{ABSTRACT}

Objectives. To study obstacles in living with type 2 diabetes and treatment reported by patients, and experts' opinions on this and their recommendations for improving diabetes care in Dutch general practice.

Methods. A 'twin' study on thirty-three patients in five focus groups, and thirteen diabetes experts in a three-round email-based Delphi study.

Results. Patients related obstacles to problems in knowledge and beliefs, providerpatient interaction, professional treatment and patient self-care, and to the impact of diabetes. Experts acknowledged patient obstacles - but seemed ignorant of patients' obstacles related to professional treatment and attitudes, and personal patient barriers. Experts proposed some obstacles and recommendations which the patients had not reported: insufficient access to records, failing monitoring of diabetes care, insufficient provider communication skills. This illustrates the differences between the patients' and experts'/professionals' perspectives. Experts recommended changes supporting individually-tailored and negotiated treatments, patient empowerment supporting patient responsibility and self-management skills, integrated biomedicalpsychosocial care, quality assessment of care, and limited number of providers around each patient.

Conclusion. Patients and experts reported many and different obstacles in managing type 2 diabetes. According to patients and experts, a patient activating and empowering approach, and quality monitoring of diabetes care, may be of help.

\section{SAMENVATTING}

Doel. Het bestuderen van door patiënten gerapporteerde belemmeringen in het leven met type 2 diabetes en met de professionele behandeling, en de commentaren van deskundigen en hun aanbevelingen voor verbetering van de diabeteszorg in de Nederlandse huisartsenpraktijk.

Methoden. Een 'tweeling' studie van 39 patiënten in vijf focusgroepen, en 13 diabetes experts in een email-Delphistudie van drie ronden.

Resultaten. De patiënten koppelden hun belemmeringen aan problemen in de eigen kennis en ideeën, aan de interactie tussen hulpverlener en patiënt, aan professionele behandeling, en aan de gevolgen van de diabetes zelf. De experts erkenden de patiëntbelemmeringen wel, maar leken onkundig van die belemmeringen die de patiënten aan de professionele behandeling, professionele attitudes, en persoonlijke patiënbelemmeringen toeschreven. De experts noemden enkele belemmeringen en aanbevelingen die niet door de patiënten waren gerapporteerd: onvoldoende toegang tot patiëntendossiers, gebrekkig bewaken van de diabeteszorg, onvoldoende communicatieve vaardigheden bij hulpverleners. Dit illustreert de verschillen tussen de perspectieven van patiënten en experts/professionals. De experts bepleitten werken aan individueel passende en onderhandelde behandeldoelen, patient empowerment, verantwoordelijkheid van de patiënt, zelfzorg-vaardigheden, geïntegreerde biomedische en psychosociale zorg, kwaliteitsbewaking, en een beperkt aantal hulpverleners rondom de patiënt.

Conclusie. Patiënten en experts rapporteerden vele en verschillende belemmeringen in het managen van type 2 diabetes. Volgens patiënten en experts zijn een benadering gericht op activering van de patiënt en patient empowerment, en kwaliteitsbewaking van de diabeteszorg, zinvol. 


\section{INTRODUCTION}

Patients with type 2 diabetes mellitus and providers of diabetes care often encounter barriers (or obstacles) to good diabetes (self-) care [ref.14-17]. We just begin to know a little more about the obstacles that patients encounter in living with type 2 diabetes and with its treatment, and about providers' and experts' views on, and solutions to those obstacles [21,39]. To improve this knowledge, a qualitative study was initiated of type 2 diabetes patients in Dutch primary care.

The research questions in the study were:

(1)What obstacles in living with the condition, including professional therapeutic advice, are reported by Dutch primary care patients with type 2 diabetes?

(2)What are the reactions of Dutch diabetes experts on these reported patient obstacles? To what degree do they acknowledge, ignore, deny, or extend these obstacles?

(3)What diabetes care adaptations and health policy changes do these experts recommend with regard to their views on the patient obstacles?

\section{METHOD}

A qualitative study design was utilised to explore obstacles as perceived by patients, how these obstacles were acknowledged by diabetes experts and health care professionals, and what recommendations those experts would have with regard to the patient obstacles. The study was part of an international project [box,39]. A master student of Health Education participated in managing the study. 


\subsection{Patient focus group interviews}

For the collection of data on the patients' perspective and their perception of obstacles to self-care, focus group interviews were used. The method is appropriate to produce more personal, honest, and intimate experiences and opinions, and more in-depth information about the participants' beliefs, attitudes, and thoughts, as compared to other ways of collecting patients' views [40-44]

\section{$\underline{\text { Recruitment }}$}

from the study as approved by the research ethics committee of the Maastricht University. Five groups of general practitioners (GPs) in the South-East part of the Netherlands (province of Limburg), were invited to recruit the first 15 of their lists of patients with type 2 diabetes. Variation in patient characteristics with regard to age, gender, educational level, duration of diabetes, complications, therapeutic regimen, and diabetes control, was aimed for. The drop-out numbers were estimated at 5-8 out of every fifteen invited patients, to reach a number of 6-10 participants in each focus group. One GP group dropped out because of time restraints, and instead patients were recruited by an ad in a door-to-door, weekly paper in the region.

Patients were included if they were diagnosed with type 2 diabetes according to the national guidelines of the Dutch College of General Practitioners, at least one year before inclusion into the study [45]. They had to be forty years of age and over, and physically and mentally able to participate in a focus group, have transportation, be not illiterate, have no recent serious life events or co-morbidity (psychiatric disease, life-threatening condition, physical handicap), and could express themselves well in the Dutch language. They would not be family relatives or acquaintances of each other. Residents of nursing homes were not included. 
Selected participants were sent an introduction letter by mail, and a short questionnaire on baseline characteristics. They were asked to sign a letter of informed consent for participation.

\section{Questions}

The patient focus group interviews followed an agreed upon format, tested and validated elsewhere [21,39,41-42,box]. Twelve semi-structured, open questions were addressed in the interviews. The main issues were:

- Impact of diabetes on your daily life

-Ttreatment recommendations for you? (do you have a say in the treatment)?

-Obstacles in adherence to treatment

Resistance against the prescribed treatment? (if so, with whom?)

\section{$\underline{\text { Procedure }}$}

A trained moderator (IM) led the interviews.. The groups met only once for a two hour session. The moderator encouraged equal involvement of all participants, and coverage of all the research questions of the study. An observer (NE) took notes about interactions of participants, and handled the recording machinery. An additional observer-physician (HD) supported this, and would answer diabetesrelated questions at the end of the sessions when asked. He was not provider of care to the participating patients.

\section{Data processing}

The sessions were audio-taped, and transcribed. These transcripts were analysed and clustered, using the QSR-NUD.IST software [46]. Three of the researchers (HD, $\mathrm{FH}, \mathrm{NE}$ ) performed additional content analysis and clustering of patient obstacles 
separately, and subsequently discussed their codings if they differed, in order to reach agreement.

\subsection{Experts Delphi study}

A group of selected diabetes care experts were invited to participate and to comment on the reported patient obstacles.

The Delphi study method enables researchers to collect individual comments and clusters of responses on a set of questions, as well as anonymous responses to each other's remarks and opinions, by subsequent (email) rounds of questions and feedback [47]. The method allows individuals to change their opinion. It prevents direct, unwanted personal influences from dominant individuals, and avoids constraints of distance and time as it is not necessary to organise live group meetings. Starting with a set of open-ended questions in the first round, the Delphi feedback of responses provokes either a consensus (collective) opinion, or a wide range of possible solutions to a policy problem.

Data sets subsequently collected in this part of the study were:

- First, the experts' reactions on the reported patient obstacles, and their first round recommendations for adaptations in diabetes care.

- Second, their level of agreement on the feedback of recommendations in the first round.

- Third, their selection of most wanted and most unwanted recommendations from the second round set.

\section{$\underline{\text { Recruitment }}$}


Fifteen regionally and nationally known diabetes experts were personally invited for participation by phone or letter. Experts were professionals in education, diabetes care, research, guidelines making, patient organisation, health insurance, commercial pharmaceuticals active in the field of patient education, and national government. Participants received an introduction letter with information on the study, and were included in the study after their written consent for participation.

\section{Questions}

In the first Delphi round, the experts were asked if they did or did not recognise the reported patient obstacles from the focus groups, if they would add items not mentioned by the patients, which ones they thought were most important, and if they had recommendations for diabetes care improvements relative to patient obstacles. In the second round, they were asked to indicate if they agreed, felt neutral, or disagreed, on each of their recommendations in the first round. In the third Delphi round, they had to select one or two items that they felt were most important from every one of three clusters of recommendations, and one or two that they felt were most unwanted.

\section{RESULTS}

\subsection{Patient focus groups}

From 60 selected adults with type diabetes invited by the GP practices, plus 12 responding to the advertisement, thirty-three patients (46\%) eventually participated in five focus groups. The study population showed sufficient variation of demographic and diabetes variables, as was aimed for. It was roughly representative for GP 
diabetes populations in other studies with regard to age, gender, educational level, duration, and treatment of diabetes (Table 1).

Major patient obstacles emerged from the transcripts. They were clustered into four sections that are presented here (Table 2).

\section{(A)Knowledge and perception.}

Patients expressed obstacles from insufficient levels of knowledge and beliefs about their condition, fears of complications and deterioration of their health. At the same time, they expressed eagerness to know more, to receive correct information from professionals, and to learn from other patients.

\section{(B)Impact.}

The diabetes may cause physical difficulties - and such difficulties undermine good self-care. Support from the social network can be positive or negative.

\section{(C)Provider-patient interaction.}

Consultation time is often perceived as too short, the provider does not listen, does not actively ask for problems or allow the patient to discuss fears and expectations, or fails to give necessary information.

\section{(D)Treatment and Self-care.}

Medication may have side-effects, some providers seem to give conflicting information, and self-monitoring, dietary, lifestyle, and medication prescriptions can be difficult.

In all five focus groups there was a remarkable atmosphere of willingness to cooperate, and openness toward each other and toward the researchers. Most patients 
were delighted with the opportunity to express their feelings and problems regarding living with diabetes and its treatment.

The patient reported obstacles to adequate diabetes self-care were summed up into a 52-item list (Table 2).

\subsection{Experts' views}

From 15 invited experts, one (GP, professor of diabetes care in GP) denied because of time restraints, and one (diabetes educator) dropped out during the first round, leaving 13 experts to complete the Delphi study: Table 3. Half the expert group were professional diabetes care providers, in addition to their expert jobs.

In the first Delphi round, the experts acknowledged most of the patient obstacles. They seemed to ignore some obstacles that patients linked to patient-provider interaction and treatment/self-care (Table 2 items 28, 29, 30, 44-47), and denied other obstacles directly linked to professionals' attitudes (item 31) or patients' barriers (items 6, 14-17, 48-52). Their first round responses called for improvements in provider adherence to guidelines, data registration, quality assessment of diabetes care, and communication skills of providers. They also called for providers to support patient skills to overcome obstacles and to self-management, to connect to the patient perspective, and to support patient empowerment and patient responsibility.

The experts' reactions and additions to patient obstacles in the first Delphi round, were summed by two of the researchers $(\mathrm{HD}, \mathrm{FH})$ into a list of statements and recommendations. In the second round, the list was fed back to the experts, and they were asked to indicate if they agreed or disagreed on each one of its items (Table 4). Once more, the experts called for improving diabetes care quality by better 
professional adherence to guidelines, financial incentives for good quality diabetes care programs, and improved professional communication skills to connect to patients about emotions, beliefs, and obstacles. Better implementation of computer technology into diabetes care for joint medical registration, quality assessment, and patient support, was advocated. Again, experts recommended patient empowerment (to enable patients to be full partners in diabetes teams, and to reach personal goals in life), and negotiating treatment targets. Also, they called for clearing away financial obstacles to patient diabetes education, lifestyle-supporting programs, and selfmonitoring materials. Experts wanted for a central role of diabetes group education and more financial support. Strikingly, some experts recommended extending diabetes teams with more professionals (e.g. psychologist, nurse), while others suggested to remove professionals from diabetes teams (Table 4 items 15, 17-18, $36)$.

In the third Delphi round, five or more experts out of thirteen prioritised three statements in particular: (1)patients should become full partners in their own diabetes teams; (2)patients deserve full support from professional providers of care for lowering $\mathrm{HbA} 1 \mathrm{c}$, for being empowered to make their own choices, for reaching personal goals in life, and for living life the way they want; and (3)financial support must be allocated to systematic diabetes care programs which, on a set of benchmarks, show good quality. Rejected by five or more out of thirteen experts were: (1)to add more professionals to diabetes teams, and (2)to implement biomedical guidelines first, only after which more attention to psychosocial elements would be possible. 


\section{DISCUSSION AND CONCLUSION}

\subsection{Discussion}

As expected, the present study showed differences between the views of patients and expert professionals [13-16]. Patients related obstacles to problems in their knowledge, beliefs, perceptions, to the physical impact of type 2 diabetes, and to provider-patient interaction, professional treatment and patient self-care. Experts (half were diabetes care providers) acknowledged most of the patient obstacles - but seemed ignorant of some obstacles that patients directly linked to professional treatment, and denied obstacles linked to professional attitudes and personal patient barriers. Also, experts proposed obstacles that the patients had not reported (e.g. bad adherence to guidelines, insufficient access to computerised patient data, inadequate monitoring of diabetes care and professionals' communication skills).

Experts recommended changes in diabetes care and education that support individually-tailored, negotiated treatment targets and health behaviour changes, patient empowerment, greater patient responsibility, patient skills to selfmanagement, integrated biomedical and psychosocial diabetes care, quality assessed forms of care, and limited numbers of providers around each patient. Other studies show that this approach may work [16,23,48-50]. Still, long term effectiveness is difficult to prove [7].

Strength of the study is that it connects patient-perceived obstacles, directly originating from focus group interviews, to experts' responses and recommendations. The assumption of internal validity was supported by the number of focus groups and patients, the patient variety, the content saturation, and the rigorous qualitative 
content analysis of the transcripts. Also, the recommendations made by experts fit to recent literature on the modernisation of diabetes care.

The study has one possible limitation because it was executed in a specific region of the Netherlands, On the other hand, there is no reason to assume that the study patients would react differently from patients elsewhere, the more as their characteristics were similar to those of patients in general practice studies elsewhere.

Persons with type 2 diabetes in our study indicated specific reasons, narrowly related to their personal views, goals, health beliefs, and fears, for following or not following the treatment regimen. Health care professionals should assess these reasons during consultations and education, to reach common ground for treatment goals $[25,49,51]$. Still, providers of care and researchers and policy makers possibly overestimate the impact of diabetes encounters on patient behaviour, and this needs correction. Many patient decisions on health behaviour are made outside the consulting room [35,51]. Patient health behaviour change needs long-term professional intervention and support $[52,53]$.

Any conscious change in the practice of medicine must take into account the validity of the patient's viewpoint. This involves taking the patient as a participant, rather than a recipient of medical care [52-59]. This is also what the patients in our focus group study demanded.

Not only by a patient-centred approach, but more so by an approach that activates patients to become active players in diabetes encounters, will providers achieve this [49,52,58-62]. Patient empowerment, shared decision-making, and motivational support methods may contribute to make patients active players in diabetes encounters [53,63-68]. To form a working therapeutic alliance, providers and patients 
need to recognise the distinction between their two perspectives as a first step $[13,15,64,69]$.

There is a voluminous research literature on the ways in which medical jargon and the language used by professionals can make patients feel uncomfortable, and cause obstacles to self-care $[17,68]$. This was not explicitely addressed by the researchers in the focus group interviews, which may be the reason why it was not mentioned.

\subsection{Conclusion}

From our study, we obtained a better understanding of the sometimes conflicting perspectives of patients and professionals in type 2 diabetes care. We explored patients' obstacles in living with type 2 diabetes and with professional treatment, and experts' views on these obstacles, and their recommendations for improvements. We call attention to the barriers in the life-world of patients in diabetes care, because health care providers too often neglect this perspective.

\subsection{Practice implications}

Based on the study findings, some recommendations for diabetes care providers and diabetes teams can tentatively be presented to improve (outcomes of) diabetes care: -Invite patients to express their fears, views, wishes, expectations, experiences, and obstacles regarding the condition and its treatment. Listen to what is important to them

-Invite patients to prepare diabetes encounters, to actively ask questions, and to see that they get answers 
-Share guidelines and treatment goals with patients, and contrast them to clinical findings

-Negotiate choices (options) in treatment goals, lifestyle changes, and therapies with patients. Apply shared decision-making with patients for personal and realistic treatment goals

-If possible, provide patients with general and personal diabetes information through internet and email

-Acquire and apply skills in therapeutic education, therapeutic alliance, patient empowerment, and brief motivational interviewing

-Organise evidence-based guidelines and sound diabetes care with outcomes assessment and monitoring for quality improvement.

\section{ACKNOWLEDGEMENT}

The authors would like to thank Nicole Ebben (NE in the text), then student of Health Education, now MSc. She executed a literature search, prepared and supported the patient focus group study, collected the data, co-analysed the transcripts, and produced a preliminary report on the patient obstacles. We are also grateful to Prof. Richard Ryckman, who was so kind as to check the manuscript, suggest some content adjustments, and improve our English.

\section{POSSIBLE CONFLICT OF INTEREST}

The study was supported by the European General Practice Research Network (EGPRN), covering the costs of attending meetings of the international Eurobstacles study group. The study was also supported by the department of General Practice of Maastricht University, and by an unconditional grant from Pfizer Pharmaceuticals 
Netherlands BV, for both of which we are grateful. The grant was used to cover the costs of preparing and executing the patient focus group interviews and the expert Delphi study, and to produce the preliminary report on the patient obstacles. 


\section{REFERENCES}

[1]Zimmet P, Alberti KG, Shaw J. Global and societal implications of the diabetes epidemic. Nature 2001;414:782-7.

[2]Dekker JM, Kraan M van der, Nijpels G, Vegt F de, Kostense PJ, et al. Schatting van het aantal nieuwe patiënten met diabetes mellitus type 2 in Nederland: ruim 65.000 per jaar in de leeftijdsgroep vanaf 50 jaar. (Estimation of the number of new patients with type 2 diabetes mellitus in the Netherlands: more than 65,000 per year in the age group of 50 years and over (in Dutch). Ned Tijdschr Geneesk 2003;147:1419-23.

[3]Wingard DL, Barrett Conner EL. Heart disease and diabetes. In: MI Harris, CC Cowie, MP Stern, et al (Eds.): Diabetes in America. $2^{\text {nd }}$ ed. Bethesda 1995. US Gov Printing Office, 429-48.

[4]Pan XR, Li GW, Hu YH, Wang JX, An ZX, et al. Effects of diet and exercise in preventing NIDDM in people with impaired glucose tolerance. The Da Qing IGT and Diabetes Study. Diabetes Care 1997;20:537-44.

[5]Knowler WC, Barrett-Connor E, Fowler SE, Hamman RF, Lachin JM, Walker EA, et al. Reduction in the incidence of type 2 diabetes with lifestyle intervention or metformin. N Engl J Med 2002;346:393403.

[6]Tuomilehto J, Lindstrom J, Eriksson JG, Valle TT, Hamalainen H, llanne-Parikka P, et al. Prevention of type 2 diabetes by changes in lifestyle among subjects with impaired glucose tolerance. $\mathrm{N}$ Engl $\mathrm{J}$ Med 2001;344:1343-50.

[7]Norris SL, Lau J, Smith SJ, Schmid C, Engelgau MM. Self-management Education for Adults with type 2 diabetes. Diabetes Care 2002;25:1159-71.

[8]Fox C, Kilvert A. Intensive education for lifestyle change in diabetes. Ongoing input is required to effect and maintain change in behaviour. Editorial. Br Med J 2003;324:1120-1.

[9]Pinkney J. Prevention and cure of type 2 diabetes. Editorial. Br Med J 2002;325:232-3.

[10]Griffin SJ. The management of diabetes: Moving beyond registration, recall, and regular review. Editorial. Br Med J 2001;323:946-7.

[11]Adriaanse M. Psychological aspects of targeted screening for type 2 diabetes - The Hoorn Screening Study. Thesis. Vrije Universiteit Amsterdam 2004.

[12]Van der Pligt $\mathrm{J}$. Perceived risk and vulnarability as pedictors of precautionary behaviour. $\mathrm{Br} \mathrm{J}$ Health Psychol 1998;3:1-14.

[13]Clark M, Hampson SE. Comparison of patients' and healhcare professionals' beliefs about and attitudes towards type 2 diabetes. Diabet Med 2003;20:152-4.

[14]Ary DV, Toobert D, Wilson W, Glasgow RE. Patient perspectives on factors contributing to nonadherence to diabetes regimens. Diabetes Care 1986;9:168-72.

[15]Shaughnessy AF, Slawson DC. Blowing the whistle on review articles. What should we know about the treatment of type 2 diabetes? Br Med J 2004;328:E280-2 Br Med J USA: Editorial.

[16]Wolpert HA, Anderson BJ. Management of diabetes: Are doctors framing the benefits from the wrong perspective? Br Med J 2002;323:994-6.

[17]Freeman J, Loewe R. Barriers to communication about diabetes mellitus: Patients' and physicians' different views of the disease. J Fam Pract 2000;49:507-12.

[18]Philipsen H, Stevens FCJ. Modernization, rationality and the continuity of care: theoretical concepts and empirical findings. Sociol Find 1997;30:189-204.

[19]American Diabetes Association. Screening for diabetes (Position Statement). Diabetes Care 2002;25(Suppl 1):S21-S24.

[20]Boekaerts M, Pintrich PR, Zeidner M. Handbook of Self-Regulation. Academic Press. San Diego, San Francisco, New York, Boston, London, Sydney, Tokyo.2003. 
[21]Vermeire E, Van Royen P, Coenen S, Wens J, Denekens J. The adherence of type 2 diabetes patients to their therapeutic regimens: a qualitative study from the patient's perspective. Pract Diab Int 2003;20:209-14.

[22]Anonymous. Diabetes care and research in Europe: the St.Vincent Declaration. Diabet Med 1990;7:360.

[23]Renders CM, Valk GD, Griffin S, Wagner EH, van Eijk JThM, Assendelft WJJ. Interventions to improve the management of diabetes mellitus in primary care, outpatient and community settings. (Cochrane Review). In: The Cochrane Library, Issue 1, 2003. Oxford: Update Software.[23]Hirsch IB. The burden of diabetes (care). Br Med J 2003;26:1613-4.

[24]Lauritzen T, Borch-Johnsen K. Multifactorial intervention in the management of type 2 diabetes. Int Diab Mon 2004;16:8-14.

[25]Winocour PH. Effective diabetes care: a need for realistic targets. Br Med J 2002;324:1577-80.

[26]Khunti K, Ganguli S, Baker R, Lowy A. Features of primary care asossiated with variations in process and outcome of care of people with diabetes. Br J Gen Pract 2001;51:356-60.

[27]UKPDS Group. Intensive blood glucose control with SU or insulin compared with conventional treatment and risk of complications in patients with type II diabetes. Lancet 1998;352:837-53.

[28]Bouma M, Dekker JH, Van Eijk JTM. Metabolic control and morbidity of type 2 diabetic patients in a general practice network. Fam Pract 1999;16:402-6.

[29]Groeneveld Y. Introduction of structured diabetes care in general practice. Thesis, Leiden University, the Netherlands, 2000.

[30]Goudswaard AN, Stolk RP, Zuithoff NPA, Rutten GEHM. Patient characteristics do not predict poor glycaemic control in type 2 diabetes patients treated in primary care. Eur J Epidemiol 2004; in press.

[31]Saydah SH, Fradkin J, Lowie CC. Poor control of risk factors for vascular disease among adults with previously diagnosed diabetes. JAMA 2004;291:335-42.

[32]Donovan JL. Patient decision making. The missing ingredient in compliance research. Int $\mathrm{J}$ Technol Ass Health 1995;11:443-55.

[33]Anderson RM, Funnell MM, Butler PM, Arnold MS, Fitzgerald JT, Feste CC. Patient empowerment: Results of a randomised controlled trial. Diabetes Care 1995;18:943-9.

[34]Holm S. What is wrong with compliance? J Medic Eth 1993;9:108-10.

[35]Murphy E, Kinmonth AL. No symptoms, no problem? Patients' understandings of non-insulin dependent diabetes. Fam Pract 1995;12:184-92.

[36]Snoek FJ. Breaking the barriers to optimal glycaemic control - What physicians need to know from patients' perspectives. Int J Clin Pract 2002;129 (Suppl.):80-4.

[37]Schoenberg NE, Drungle SC. Barriers to non-insulin dependent diabetes mellitus (NIDDM) selfcare practices among older women. J Aging Health 2001;13:443-66.

[38]Van Dam HA, Crebolder HFJM, Eijkelberg I, Van Nunen M, Van der Horst FG. Wegblijven van patiënten met type 2 diabetes - een echt probleem? (Non-attendance of patients with type 2 diabetes mellitus - a real problem?). Huisarts Wet 2000;43:380-4 (in Dutch).

[39]Hearnshaw H. Presentation of Eurobstacle Study to the 6th International Conference of Primary Care Diabetes Europe (satellite of the International Diabetes Federation Conference), Paris, August 23-24, 2003.

[40]Basch CE: Focus Groups Interviews: An underutilised research technique for improving theory and practice in health education. Health Education Quarterly 1987;14:411-48.

[41]Morgan DL. The Focus Group Guidebook: Focus Group Kit 1+2. Thousand Oaks 1998. Sage Publications.

[42]Krueger RA. Focus Group Kits 3-6, Thousand Oaks 1998. Sage Publications.

[43]Miles MB, Huberman AM. Qualitative data analysis: An expanded sourcebook. $2^{\text {nd }}$ ed. Thousand Oaks, Calif. Sage Publications, 1994. 
[44]Pope C, Mays N. Reaching the parts other methods cannot reach. An introduction to qualitative methods in health and health services research. Brit Med J 1995;311:42-5.

[45]Rutten GEHM, Verhoeven S, Henie RJ, De Grauw WJC, Cromme PVM, Reenders K. National guidelines on type 2 diabetes of the Dutch College of General Practitioners (Standaard Diabetes Mellitus Type 2. NHG). First revision. Huisarts Wet 1999;42:67-84 (in Dutch).

[46]Tak SH, Nield M, Becker $\mathrm{H}$. Use of a computer program for qualitative data analyses - Part 1: Introduction to NUD.IST, Part 2: Advantages and disadvantages. West J Nurs Res 1999;21:111-7 and 436-9.

[47]De Meyrick J. The Delphi method and health research. Health Educ 2003;103(1):7-16.

[48]Williams GC, Freedman ZR, Deci EL. Supporting Autonomy to motivate patients with diabetes for glucose control. Diabetes Care 1998;21:1644-51

[49]Stewart M, Brown JB, Weston W, McWhinney IR, McWilliam CL, Freeman TR. Patient-centered Medicine. Transforming the Clinical Method. Sage Publications. Thousand Oaks, London, New Delhi, 1995.

[50]De Fine Olivarius N, Beck-Nielsen H, Andreason AH, Hørder M, Pederson PA. Randomised controlled trial of structured personal care of type 2 diabetes mellitus. Br Med J 2001;323:970-5.

[51]Stimson G, Webb B. Going to see the doctor - The consultation process in general practice. London, Boston 1975. Routledge, Kegan Paul.

[52]Koenigsberg MR, Bartlett PD, Cramer JS. Facilitating Treatment Adherence with Lifestyle Changes in Diabetes. Am Fam Physician 2004;69:309-16,319-20,323-4.

[53]Funnell MM, Anderson RM. Working toward the next generation of diabetes self-management education. Am J Prev Med 2002;22(4 Suppl.):3-5.

[54]Glyn Elwyn. Shared Decision-making in GP. Thesis. Universiteit Nijmegen, the Netherlands, 2003.

[55]Royal Pharmaceutical Society of Great Britain. From compliance to concordance. Achieving goals in medicine taking. London, 1997.

[56]Van Dam HA, Van der Horst F, Van den Borne B, Ryckman R, Crebolder H. Provider-Patient Interaction in Diabetes Care: Effects on Patient Self-care and Outcomes. A systematic review. Pat Educ Couns 2003;51:17-28.

[57]Michie S, Miles J, Weinman J. Patient-centredness in chronic illness: What is it and does it matter? Pat Educ Couns 2003;51:197-206.

[58]Sanson-Fischer RW, Campbell EM, Redman S, Hennikus DJ. Patient-provider interactions and patient outcomes. Diab Educ 1989;15:134-8.

[59]Theunissen NCM, De Ridder DTD, Bensing JM, Rutten GEHM. Manipulation of patient-provider interaction: Discussing illness representations or action plans concerning adherence. Pat Educ Couns 2003;51:247-58.

[60]Cegala DJ, Post DM, McLure L. The effects of Patient Communication Skills Training on the Discourse of Elderly Patients During a Primary Care Interview. J Am Geriatr Soc 2001;49:1505-11.

[61]Funnell MM, Anderson RM, Arnold MS, Barr PA, Donelly MB, Johnson PD, et al. Empowerment: an idea whose time has come in diabetes education. Diab Educ 1992;17:37-41.

[62]Walker L. Consulting with NLP. Neuro-linguistic programming in the medical consultation. Radcliffe Medical Press. Oxon, 2002.

[63]Miller WR, Rollnick S. Motivational Interviewing. Preparing people for change. The Guilford Press. New York, London, 2002.

[64]Emmons KM, Rollnick S. Motivational Interviewing in Health Care Settings - Opportunities and Limitations. Am J Prev med 2001;20:68-74.

[65]Smith DE, Heckemeyer CM, Kratt PP, Mason DA. Motivational Interviewing to Improve Adherence to a Behavioral Weight-Control Program for Older Obese Women with NIDDM. Diabetes Care 1997;20:52-4. 
[66]Stott NCH, Rollnick S, Rees MR, Pill RM. Innovation in clinical method: Diabetes care and negotiating skills. Fam Pract 1995;12:413-8.

[67]Lacroix A, Assal JP. Therapeutic education of patients - New approaches to chronic illness. Éditions Vigot. Paris, 2000.

[68]Van Dulmen AM, Bensing JM. Health promoting effects of the physician-patient encounter. Psychol Health Med 2002;7:289-300.

\section{BOX}

The Eurobstacle EGPRN study and the Dutch study

In 2000, the European General Practice Research Network EGPRN, a collaboration of European researchers of general practice, and part of the European branch of WONCA (World Organisation of Primary Care/General Practice), launched the 'Eurobstacle Study'. This multinational study was initiated by Dr. Hilary Hearnshaw, professor of psychology and senior researcher at the Medical College of Warwick University in Coventry (UK), and Dr. Etienne Vermeire, general practitioner, lecturer and senior researcher at the Medical School of Antwerp University (B). In seven European countries, type 2 diabetes patient focus groups were organised, followed by exchanges of opinions between experts in diabetes care and health policy: Estonia, Slovenia, Croatia, UK, Belgium, France, and the Netherlands. The formats of the focus group interviews and expert interviews were agreed upon in two multinational meetings of researchers from these countries, before the studies actually started.

This paper presents the results of the Dutch study.

$==$ 
TABLE 1

CHARACTERISTICS OF FOCUS GROUP PARTICIPANTSISTUDY PATIENTS

$N=33 ; 5$ focus groups, mean number of participants: 6.6 per group, range: 5-12 per group

\begin{tabular}{|c|c|}
\hline ITEM & \%, MEAN, OR NUMBER (RANGE) \\
\hline Gender (\%) & Male 61 \\
\hline Age (years) & Mean 65 (41-80) \\
\hline Living situation (\%) & $\begin{array}{l}\text { With partner } 70 \\
\text { With other person } 3 \\
\text { Alone } 27\end{array}$ \\
\hline Education (\%) & $\begin{array}{l}\text { Low } 61 \% \\
\text { Middle 33\% } \\
\text { High ( } \geq \text { high school ) 7\% } \\
\text { Missing } 3 \\
\end{array}$ \\
\hline Duration of diabetes (years) & Mean $8(1-31)$ \\
\hline Membership of PatientsAssociation DVN (\%) & 21 \\
\hline Patient-reported principle provider (\%) & $\begin{array}{l}\text { GP: } 94 \text { (GP + internist: 18; GP + nurse: 3) } \\
\text { Specialist of internal medicine: } 6\end{array}$ \\
\hline Treatment type (\%) & $\begin{array}{l}\text { Diet only: } 12 \% \\
\text { Tablets: } 52 \% \\
\text { Insulin: } 21 \% \text { (insulin only: } 6 \% \text { ). }\end{array}$ \\
\hline Self-reported quality of diabetes control (\%) & $\begin{array}{l}\text { Good: } 21 \\
\text { Moderate: } 55 \\
\text { Bad: } 21 \\
\text { Missing: } 3\end{array}$ \\
\hline Self-reported self-efficacy for selfcare (\%) & $\begin{array}{l}\text { Good: } 52 \\
\text { Moderate: } 36 \\
\text { Bad: } 12\end{array}$ \\
\hline General perception of one’s own health (\%) & $\begin{array}{l}\text { Good: } 46 \\
\text { Moderate: } 42 \\
\text { Bad: } 12\end{array}$ \\
\hline
\end{tabular}




\title{
TABLE 2
}

\section{PATIENT OBSTACLES FROM FOCUS GROUP INTERVIEWS AND FIRST DELPHI ROUND EXPERTS' REACTIONS}

\author{
Experts were asked if they recognised the patient reported obstacles or not, and \\ which ones they prioritised as most important.
}

\begin{tabular}{|c|c|c|}
\hline & Types (A-B-C-D) of Patient Obstacles: & Experts $(*)$ \\
\hline A & KNOWLEDGE AND PERCEPTION OF ILLNESS ( 6 ITEMS) & \\
\hline 1 & The way you handle your diabetes depends on how serious you think it is. & +4 \\
\hline 2 & $\begin{array}{l}\text { You try to live with diabetes. Some think it is not too hard. But adaptations must be } \\
\text { made, and complications may cause problems. }\end{array}$ & +1 \\
\hline 3 & Doubt: can diabetes be cured, or is it possible that it disappears? & $+1 ;-1$ \\
\hline 4 & $\begin{array}{l}\text { Most threatening is the fear of eye complications, blindness, and foot or leg } \\
\text { amputation. }\end{array}$ & $+1 ;-1$ \\
\hline 5 & $\begin{array}{l}\text { Adhering to the complete dietary regimen is highest in the beginning, but lessens } \\
\text { after some time. You need constant reinforcement and attention for it. }\end{array}$ & 0 \\
\hline 6 & $\begin{array}{l}\text { I feel good, so why lose weight? If I would lose weight, I might feel bad and } \\
\text { become ill, and than what? }\end{array}$ & -2 \\
\hline $\mathrm{B}$ & IMPACT (11 ITEMS) & \\
\hline 7 & $\begin{array}{l}\text { My social network, especially family members like spouse and children, express a } \\
\text { need for information about diabetes }\end{array}$ & +3 \\
\hline 8 & $\begin{array}{l}\text { When my personal caregivers or my social network intrude in my food habits or } \\
\text { show no understanding of my diet, I perceive their help as negative and nagging (as } \\
\text { interference). }\end{array}$ & +1 \\
\hline 9 & $\begin{array}{l}\text { On the other hand, when my partner shows knowledge of my dietary regimen, } \\
\text { support from her is positive. }\end{array}$ & +1 \\
\hline 10 & $\begin{array}{l}\text { Hyperglycaemia, I don't consciously recognise. Physically, you don’t feel anything. } \\
\text { This limits my motivation for regular tablet taking, more physical activity, food } \\
\text { adaptations, or administration of extra insulin. }\end{array}$ & 0 \\
\hline 11 & $\begin{array}{l}\text { Being a younger patient with a family, and I find it hard to follow-up dietary advice } \\
\text { because of the burden it might impose on the other family members. }\end{array}$ & 0 \\
\hline 12 & $\begin{array}{l}\text { I don’t consciously feel hypoglycaemia/I never had one; this slows timely } \\
\text { interventions and limits my motivation for health behaviour adaptations. }\end{array}$ & 0 \\
\hline 13 & Tiredness and lack of energy limits the level of activities (travelling, sports). & 0 \\
\hline 14 & Blindness/retinopathia is an obstacle for reading, and a threat. & -1 \\
\hline 15 & $\begin{array}{l}\text { It is a continuous downhill slope for your job. Diabetes forced me to discontinue my } \\
\text { work. }\end{array}$ & -1 \\
\hline 16 & $\begin{array}{l}\text { The female partner of a male patient adapts to the dietary regimen of the male } \\
\text { patient - while the male partner of a female patient usually does not. }\end{array}$ & -1 \\
\hline 17 & $\begin{array}{l}\text { Erectile dysfunction is hard to discuss. Your sex life changes; sex phantasies may } \\
\text { replace real sex. }\end{array}$ & -2 \\
\hline $\mathrm{C}$ & PATIENT-PROVIDER INTERACTION (14 ITEMS) & \\
\hline 18 & $\begin{array}{l}\text { Some providers (doctors) don’t allow discussion of (details of) the treatment } \\
\text { regimen. For me, not being allowed to speak freely is the biggest problem. }\end{array}$ & +6 \\
\hline 19 & $\begin{array}{l}\text { A difference of opinions about the treatment between providers shows, and this is } \\
\text { bad. }\end{array}$ & +6 \\
\hline 20 & $\begin{array}{l}\text { Information and explanation on the treatment is often not provided. When I get this, } \\
\text { it lowers my fears and worries, and I find it positive. }\end{array}$ & +5 \\
\hline 21 & I doubt whether information is well-communicated from one provider to another & $+5 ;-1$ \\
\hline 22 & $\begin{array}{l}\text { The time doctors and other providers take for the patient seems to shows huge } \\
\text { variations - and it is generally too short. }\end{array}$ & +4 \\
\hline 23 & $\begin{array}{l}\text { Providers don't always actively ask the patient about their sex life or complaints, } \\
\text { and so they don't know about them }\end{array}$ & +2 \\
\hline 24 & $\begin{array}{l}\text { Receiving a leaflet on diabetes as the only information, gives me contradictory } \\
\text { feelings }\end{array}$ & +2 \\
\hline 25 & $\begin{array}{l}\text { I received insufficient or incorrect information on the time schedule of medication } \\
\text { taking or insulin injecting, or the exact location of insulin injections. This gave me }\end{array}$ & +1 \\
\hline
\end{tabular}




\begin{tabular}{|c|c|c|}
\hline & doubts, and caused possible risk of mistakes & \\
\hline 26 & $\begin{array}{l}\text { Information on the possible diabetes damage to the eyes is not always provided. I } \\
\text { think this is a big failure }\end{array}$ & +1 \\
\hline 27 & $\begin{array}{l}\text { I feel that I am not properly informed on new diabetes care developments, i.e. new } \\
\text { drugs, by providers. I have a want of this information. Perhaps the internet might } \\
\text { help }\end{array}$ & $+2,-1$ \\
\hline 28 & $\begin{array}{l}\text { The dietician sometimes gives advice that does not fit in my lifestyle. This makes } \\
\text { adhering to the advice more difficult, even to the point of non-attendance to } \\
\text { appointments }\end{array}$ & 0 \\
\hline 29 & $\begin{array}{l}\text { I get the impression that my GP knows little or nothing about diabetes, and so I } \\
\text { don’t take his advice seriously }\end{array}$ & 0 \\
\hline 30 & $\begin{array}{l}\text { Usually the GP refers the patient to a hospital specialist (ophtalmologist) for eye } \\
\text { tests. This is a pity, could he not do it himself? }\end{array}$ & $+1,-2$ \\
\hline 31 & I feel anger toward all doctors, because they don’t really listen & -4 \\
\hline $\mathrm{D}$ & TREATMENT AND SELFCARE (21 ITEMS) & \\
\hline 32 & $\begin{array}{l}\text { The costs of self monitoring materials usually are not reimbursed for patients treated } \\
\text { with oral blood glucose lowering drugs but not insulin. This was an obstacle for me }\end{array}$ & +6 \\
\hline 33 & $\begin{array}{l}\text { I regret that this is a one time only meeting, because I gained much from } \\
\text { participating in this focus group. There is a desire to continue or repeat such } \\
\text { meetings to learn from fellow patients }\end{array}$ & +4 \\
\hline 34 & $\begin{array}{l}\text { Of all professional advice, dietary advice is the most difficult to follow up. You } \\
\text { must be aware of the food regimen all the time, and that is nasty }\end{array}$ & +4 \\
\hline 35 & $\begin{array}{l}\text { I encounter a vicious circle: following dietary advice makes me feel bad, then I } \\
\text { become non-compliant, and this causes raised blood glucose levels }\end{array}$ & +4 \\
\hline 36 & I have feelings of guilt when not following the dietary rules & +4 \\
\hline 37 & $\begin{array}{l}\text { The health insurance does not reimburse for more than a certain number of test } \\
\text { strips, so when I want to perform self monitoring more often, there are extra costs }\end{array}$ & +4 \\
\hline 38 & Losing weight with dietary advice is troublesome or impossible & +3 \\
\hline 39 & Not everyone is able to adapt his whole life to the diabetes; I can’t quit smoking & +3 \\
\hline 40 & It takes self discipline to initiate sporting, which in my case is lacking & +1 \\
\hline 41 & $\begin{array}{l}\text { Higher costs i.e. for expensive dietary foods, assurance, or test material for blood } \\
\text { glucose self monitoring, are obstacles for me }\end{array}$ & +1 \\
\hline 42 & $\begin{array}{l}\text { My insurance company did not immediately reimburse a self- monitoring machine } \\
\text { when I started with insulin therapy. Because of the waiting time I postponed self } \\
\text { monitoring }\end{array}$ & $+3,-2$ \\
\hline 43 & $\begin{array}{l}\text { I get nervous from self-monitoring of blood glucose, because I fear being occupied } \\
\text { with it continuously, everyday, and because it is painful and nasty }\end{array}$ & $+2,-2$ \\
\hline 44 & $\begin{array}{l}\text { For me, tablets had side-effects, causing raised metabolism or bowel activity, or } \\
\text { stomach aches }\end{array}$ & 0 \\
\hline 45 & From insulin administration I got weight gain and bruises & 0 \\
\hline 46 & Being forced to follow fixed times for eating and taking tablets or insulin is nagging & 0 \\
\hline 47 & I have a fear of shooting insulin & 0 \\
\hline 48 & For me, the waiting lists for guided exercise is an obstacle & $+1,-3$ \\
\hline 49 & Mood swings are an obstacle for following up the professional advice & -2 \\
\hline 50 & $\begin{array}{l}\text { For me 'forbidden items ' (sweets, fatty meats, smoking) are extra attractive, and } \\
\text { hard to say 'no' to }\end{array}$ & -3 \\
\hline 51 & $\begin{array}{l}\text { When I live alone or when I am on my own, it is even more difficult. You must do it } \\
\text { yourself, because there is no-one to help }\end{array}$ & -4 \\
\hline 52 & $\begin{array}{l}\text { Advice for increased physical activity is ineffective because I feel unable to follow } \\
\text { it up by limitations from stroke and hemiplegia. The same would be true for } \\
\text { blindness, cardiovascular disease, obesity, or joint problems }\end{array}$ & -4 \\
\hline
\end{tabular}

$\left({ }^{*}\right)$

+: The number of positive (recognised, priority) experts' reactions on the item.

-: The number of negative (not recognised) experts' reactions on the item.

0 : None of the experts recognised or not recognised the item

$==$ 


\section{TABLE 3}

\section{DIABETES EXPERTS IN DELPHI STUDY}

Pediatrician, Chairman of Dutch Diabetes Federation

General Practitioner, university teacher, researcher of general practice

Specialist of Internal Medicine, diabetologist, diabetes researcher

Clinical Psychologist, university teacher, diabetes researcher

Diabetes Nurse, executive manager of Diabetes General Practitioner Expert

Group

Diabetes Nurse, former Chairman of First Association of Diabetes Nurses

Diabetes Educators (2), employees of Dutch Diabetes Patient Association

(responding as one, in joint action)

Managing director of Dutch Diabetes Patient Association

Chairman of Dutch Diabetes Patient Association

Director of Care Innovation and Chronic Disease in the Ministry of Public Health

Director of Care Innovation and Diabetes Care of a health insurance company

Director for diabetes products of an international pharmaceutical company

Diabetes expert of an international pharmaceutical company

$=\mathbf{=}=\mathbf{=}$ 


\section{TABLE 4}

\section{FIRST AND SECOND DELPHI ROUNDS OF EXPERT STUDY: ADDITIONS, SUGGESTIONS, RECOMMENDATIONS AND STATEMENTS, SUPPORT AND REJECTION (*)}

$\mathrm{N}=13$.

\begin{tabular}{|c|c|c|c|}
\hline & $\begin{array}{l}\text { PROVIDER-PATIENT INTERACTION AND PROFESSIONAL } \\
\text { TREATMENT (1-19) }\end{array}$ & $\begin{array}{l}1^{\text {st }} \text { Round }(* *) \\
\text { (Additions \& } \\
\text { recommend.) }\end{array}$ & $\begin{array}{l}2^{\text {nd }} \text { Round }(* *) \\
\text { (Agree \& } \\
\text { disagree) }\end{array}$ \\
\hline 1 & Health care providers must always relate to the patient’s perspective. & $5 \mathrm{x}$ & $13+$ \\
\hline 2 & $\begin{array}{l}\text { Because initial treatment determines later outcomes, diabetes teams must } \\
\text { rigorously treat and guide new patients with diabetes, focusing on all } \\
\text { aspects of the condition - instead of only on hyperglycaemia. }\end{array}$ & $3 \mathrm{x}$ & $13+$ \\
\hline 3 & $\begin{array}{l}\text { The totality of diabetes care both in primary care/GP, and in hospital care, } \\
\text { must be monitored in one central (regional, local) computerised medical } \\
\text { record system, thus enabling benchmarking for accessing and improving the } \\
\text { quality of care. }\end{array}$ & $2 \mathrm{x}$ & $13+$ \\
\hline 4 & $\begin{array}{l}\text { Diabetes care providers must acquire the necessary skills to communicate } \\
\text { with patients in order to help them overcome their perceptions of obstacles } \\
\text { in diabetes self-care. }\end{array}$ & $2 \mathrm{x}$ & $13+$ \\
\hline 5 & $\begin{array}{l}\text { Diabetes care providers must actively ask about possible sexual problems } \\
\text { related to diabetes }\end{array}$ & $1 \mathrm{x}$ & $13+$ \\
\hline 6 & $\begin{array}{l}\text { The effectiveness of diabetes care must be improved in order to better } \\
\text { prevent diabetes complications. }\end{array}$ & $4 \mathrm{x}$ & $12+$ \\
\hline 7 & $\begin{array}{l}\text { Providers (of diabetes care) must master the necessary skills to } \\
\text { communicate effectively with patients about their perceptions of obstacles } \\
\text { to self-care and lifestyle changes, and their fears and sexual problems.. }\end{array}$ & $1 \mathrm{x}$ & $12+$ \\
\hline 8 & $\begin{array}{l}\text { Communication, cooperation, and the coordination } \\
\text { of efforts between diabetes care providers is often ineffectiveand needs } \\
\text { improvement. }\end{array}$ & $5 x$ & $11+$ \\
\hline 9 & Implementation of guidelines can begin immediately. & $1 x$ & $11+, 1-$ \\
\hline 10 & $\begin{array}{l}\text { Diabetes care does not sufficiently follow guidelines (like those of the } \\
\text { Netherlands Diabetes Federation, and Dutch Association of General } \\
\text { Practitioners). }\end{array}$ & $3 x$ & $10+$ \\
\hline 11 & $\begin{array}{l}\text { Well- performing, multidisciplinary diabetes teams deserve financial } \\
\text { support.. }\end{array}$ & $2 \mathrm{x}$ & $10+, 1-$ \\
\hline 12 & $\begin{array}{l}\text { All diabetes care providers must have access to a central (regional, local) } \\
\text { computeriased medical record system. }\end{array}$ & $2 \mathrm{x}$ & $10+, 2-$ \\
\hline 13 & $\begin{array}{l}\text { Culturally appropriate diabetes information and education group meetings in } \\
\text { minority languages for immigrant groups are needed. }\end{array}$ & $1 \mathrm{x}$ & $10,1-$ \\
\hline 14 & $\begin{array}{l}\text { The patient's perspective encompasses his/her fears, shames and perceived } \\
\text { obstacles in living with diabetes and with professional advice. }\end{array}$ & $2 x$ & $8+, 2-$ \\
\hline 15 & $\begin{array}{l}\text { More and new professionals must be added to diabetes teams. } \\
\text { (Which new professionals? dietician 3x, psychologist } 6 x \text {, diabetes nurse } 3 x \text {, } \\
\text { practice nurse } 4 x \text {, lifestyle counsellor } 1 x \text {, general practice supporter } 2 x \text {, } \\
\text { physiotherapist } 1 x \text { ). }\end{array}$ & $3 x$ & $7+, 2-$ \\
\hline 16 & $\begin{array}{l}\text { Weekend and evening diabetes clinics are needed to enhance patient } \\
\text { attendance. }\end{array}$ & $1 \mathrm{x}$ & $7+, 5-$ \\
\hline 17 & $\begin{array}{l}\text { On the contrary, fewer professionals on diabetes are needed. } \\
\text { (Which professionals do you think should be removed from diabetes teams? } \\
\text { psychologist } 1 \mathrm{x} \text {, dietician } 1 \mathrm{x} \text { ) }\end{array}$ & $3 x$ & $5+, 7-$ \\
\hline 18 & $\begin{array}{l}\text { There is an uncontrolled growth of the number of providers caring forthe } \\
\text { diabetes patient, and this must be stopped. }\end{array}$ & $3 x$ & $3+, 6-$ \\
\hline
\end{tabular}




\begin{tabular}{|c|c|c|c|}
\hline 19 & $\begin{array}{l}\text { Medical diabetes care must first be improved by implementing the } \\
\text { guidelines - and only after this is done should more attention be paid to } \\
\text { psychosocial elements. }\end{array}$ & $1 \mathrm{x}$ & 10- \\
\hline & SELFCARE (20-38) & & \\
\hline 20 & $\begin{array}{l}\text { Patient lifestyle and behaviour changes and practical training for these } \\
\text { should be offered on a systematic and continuous basis, supported and } \\
\text { guided by the whole diabetes care network: providers, patients, diabetes } \\
\text { teams, health institutions, clinics, and local, regional, or national } \\
\text { government. }\end{array}$ & $6 x$ & $13^{+}$ \\
\hline 21 & $\begin{array}{l}\text { Patients need more opportunities to discuss their personal obstacles in living } \\
\text { with diabetes and following professional treatment and lifestyle advice. }\end{array}$ & $5 x$ & $13^{+}$ \\
\hline 22 & $\begin{array}{l}\text { Patient self-management, self-care, and taking personal responsibility } \\
\text { deserve to be priorities in diabetes care }\end{array}$ & $3 x$ & $13^{+}$ \\
\hline 23 & $\begin{array}{l}\text { Patient self-care and self-management deserve support from the Netherlands } \\
\text { Diabetes Federation NDF, Diabetes Patients Association of the Netherlands } \\
\text { DVN, governments, and health insurance companies. }\end{array}$ & $3 x$ & $13^{+}$ \\
\hline 24 & $\begin{array}{l}\text { Patients must be provided with reliable information on the seriousness and } \\
\text { risks associated with diabetes and obesity. }\end{array}$ & $2 x$ & $13^{+}$ \\
\hline 25 & $\begin{array}{l}\text { Patients must be granted access to the computer records with their own } \\
\text { medical data. }\end{array}$ & $1 x$ & $13^{+}$ \\
\hline 26 & $\begin{array}{l}\text { Patients deserve full support from professional providers not only for } \\
\text { lowering HbA1c, but even more for reaching their personal goals in life, for } \\
\text { living their lives the way they want it, and for being enabled (empowered) } \\
\text { to make their own choices. }\end{array}$ & $4 x$ & $12+$ \\
\hline 27 & $\begin{array}{l}\text { Patient satisfaction with diabetes care (quality and outcome, respect, support } \\
\text { for self-management and quality of life) deserves periodical and } \\
\text { independent measurement. }\end{array}$ & $1 \mathrm{x}$ & $12+, 1-$ \\
\hline 28 & Patients must become full partners on their own diabetes teams. & $2 \mathrm{x}$ & $11+, 1-$ \\
\hline 29 & Home monitoring with internet support deserves more research attention. & $1 \mathrm{x}$ & $11+, 1-$ \\
\hline 30 & $\begin{array}{l}\text { Internet- supported peer groups or chat groups deserve more research } \\
\text { attention. }\end{array}$ & $1 \mathrm{x}$ & $10+, 1-$ \\
\hline 31 & Diabetes teams must provide patients with reliable internet sites on diabetes. & $1 \mathrm{x}$ & $10+, 3-$ \\
\hline 32 & $\begin{array}{l}\text { More patient self-management will eventually lead to better quality of life, } \\
\text { better self-care, better outcomes of care, lower levels of utilisation of } \\
\text { medical care, and lower costs of professional diabetes care. }\end{array}$ & $1 x$ & $10+, 1-$ \\
\hline 33 & $\begin{array}{l}\text { For all patients, systematic diabetes education is needed, with evidence- } \\
\text { based programs, and there should be also a gradual shifting from education } \\
\text { to self-management and motivation. }\end{array}$ & $2 \mathrm{x}$ & $9+$ \\
\hline 34 & $\begin{array}{l}\text { Members of diabetes patients' social networks also need information and } \\
\text { education on risks, prevention, and lifestyle changes regarding diabetes. }\end{array}$ & $1 \mathrm{x}$ & $9+$ \\
\hline 35 & $\begin{array}{l}\text { Participation in systematic diabetes education must be a condition } \\
\text { (obligation) for optimal diabetes care. }\end{array}$ & $3 x$ & $8+, 2-$ \\
\hline 36 & $\begin{array}{l}\text { The self-management perspective calls for participation by psychologists on } \\
\text { diabetes teams and for psychosocial counselling. }\end{array}$ & $3 x$ & $7+, 4-$ \\
\hline 37 & Group education deserves a central role in diabetes care. & $2 \mathrm{x}$ & $7+, 1-$ \\
\hline \multirow[t]{2}{*}{38} & $\begin{array}{l}\text { Peer support and contact with fellow patients (in group meetings) deserve a } \\
\text { central role in diabetes care. }\end{array}$ & $2 \mathrm{x}$ & $6+, 1-$ \\
\hline & POLITICS AND HEALTH INSURANCE (39-44) & & \\
\hline 39 & $\begin{array}{l}\text { The costs for blood glucose self- testing materials must be reimbursed for } \\
\text { patients with or without insulin therapy }\end{array}$ & $2 \mathrm{x}$ & $13^{+}$ \\
\hline 40 & $\begin{array}{l}\text { Discrimination againstpersons with diabetes e.g. for insurance, jobs, driving } \\
\text { licenses, must be forbidden. }\end{array}$ & $2 \mathrm{x}$ & $13^{+}$ \\
\hline 41 & $\begin{array}{l}\text { Extra and special financing must be allocated to systematic diabetes care } \\
\text { which, on a set of benchmarks, shows good compliance to certain quality } \\
\text { criteria. }\end{array}$ & $4 x$ & $12+$ \\
\hline 42 & Health authorities and health insurance companies must invest more in & $2 \mathrm{x}$ & $12+, 1-$ \\
\hline
\end{tabular}




\begin{tabular}{|l|l|l|l|}
\hline & $\begin{array}{l}\text { lifestyle change programs for prevention of diabetes and obesity, on national } \\
\text { and local/regional levels. }\end{array}$ & & \\
\hline 43 & $\begin{array}{l}\text { Good diabetes education programs must be reimbursed by health authorities } \\
\text { and health insurance companies. }\end{array}$ & $3 \mathrm{x}$ & $11+, 1-$ \\
\hline 44 & $\begin{array}{l}\text { Research and application of evidence-based guidelines in diabetes care must } \\
\text { be boosted and financially supported by health authorities and health } \\
\text { insurance companies. }\end{array}$ & $1 \mathrm{x}$ & $10^{+}, 1-$ \\
\hline
\end{tabular}

$\left({ }^{*}\right)$ Constructed from patient obstacles (Table 2 ) and first round expert additions and recommendations.

$\left.{ }^{(* *}\right)$ Each item is presented with the number of experts adding or proposing it in the first Delphi round, and the number of experts agreeing or disagreeing in the second round (five point Likert scale from 'strongly agree' to 'strongly disagree', with 'doubt', 'no opinion', and 'missing' left out from the table). Sequences per chapter in accordance to rate of agreement.

In the third round, the most prioritised items from this table (by $\geq 5 / 13$ experts) were: Nrs. 26, 28, and 41. The most rejected items were: Nrs. 15 and 19. 


\section{CHAPTER 8}

Patient-centredness and the dialectical process in diabetes care - a review

(Patiëntgerichtheid en dialectiek in diabeteszorg) 


\title{
Patient-centredness and the dialectical process in diabetes care - a review
}

\author{
(Patiëntgerichtheid en dialektiek in diabeteszorg)
}

Henk A van Dam*, Richard M Ryckman ${ }^{* *}$, Bart HW van den Borne ${ }^{* * *}$, Harry FJM Crebolder*, Frans G van der Horst ${ }^{\star}$

Submitted, under revision

Corresponding author: Henk A van Dam Gezondheidscentrum Withuis, Straelseweg 193, 5914 AL Venlo, Netherlands Tel.+31 77 3517652, fax +31 77 3589705, email vandam-hylkema@home.nl

${ }^{*}$ ) Maastricht University, Faculty of Medicine, Department of General Practice Maastricht, Netherlands

$\left.{ }^{* *}\right)$ University of Maine, Department of Psychology - Orono, Maine, USA $\left.{ }^{* * *}\right)$ Maastricht University, Faculty of Health Sciences, Department of Patient Education - Maastricht, Netherlands 


\begin{abstract}
In this paper, the changing roles of patients and providers in (type 2) diabetes care are discussed. The changes over time from a doctor-centred to a more negotiation and patient-centred model are reviewed briefly. Care providers and patients may disagree on the best course of action and on the management of the condition and coping with its consequences. They may perceive problems, obstacles, and solutions related to diabetes quite differently. We make a plea for a dialectical approach. In diabetes encounters, such an approach may produce a true dialogue. We advocate an exchange of the sometimes opposing views or ideas, a discussion or struggle about these views, and negotiation about some resolution or agreement. Along this road 'objective' outcomes of health care as seen by the provider, and 'subjective' outcomes as perceived by the patient, will become of equal value. This will lead to a consultation model characterized as a co-centred model. The resulting outcome agreement or synthesis will be a dynamic, living one, with temporary effects only - as the process of managing the condition will continue forever.
\end{abstract}

\title{
SAMENVATTING
}

In dit artikel bespreken we de veranderende rollen van patiënten en hulpverleners in de (type 2) diabeteszorg. De veranderingen in de loop der tijd van een artsgericht naar een meer op onderhandelen en patiënten gericht model, worden kort besproken. Zorgverleners en patiënten kunnen gemakkelijk verschillen in hun opvattingen over de beste aanpak en de beste behandeling van de aandoening, en over hoe om te gaan met zijn gevolgen. Ze kunnen problemen, belemmeringen en oplossingen betreffende diabetes heel verschillend ervaren. Wij bepleiten een dialektische benadering. In diabetesconsulten zou zo'n benadering een echte dialoog kunnen voortbrengen. We pleiten voor uitwisseling tussen de soms uiteenlopende visies en ideeën, bespreking of discussie van deze gezichtspunten, en onderhandeling over een of andere oplossing of overeenkomst. Langs die weg kunnen 'objectieve' uitkomsten van de zorg, zoals ze gezien worden door de hulpverlener, en 'subjectieve' uitkomsten zoals ze door de patiënt ervaren worden, gelijkwaardig zijn. Dat kan leiden tot een consultatiemodel dat gekenschetst wordt als een 'co-centred' model. De resulterende overeenkomst of synthese zal een dynamische, levende zijn, met slechts tijdelijke effecten - omdat het proces van het hanteren van de aandoening steeds zal blijven doorgaan. 


\section{Introduction: from doctor- to patient-centredness}

The traditional biomedical model of disease management embraced the paternalistic idea that the doctor makes the diagnosis and prescribes the treatment, while the patient would be passive, supplies answers to the doctor's questions, and complies with his or her prescription. This model targeted acute medical conditions that were common up until the 1950s [1,2]. Later on, criticism of the unbalance of power in the traditional medical model increased. In part, this criticism was driven by a change in the epidemiological features of health and illness, with chronic and degenerative conditions and unhealthy behaviours becoming the dominant health problems in most Western countries by the 1980s and 1990s [3-5]. The traditional consulting model in medicine was no longer self-evident. Specifically, health care professionals in sections of medicine that frequently deal with unspecified health problems, uncertainty of medical outcomes, lack of empirical evidence, unpredictable interactions between medical treatment and human factors (values, emotions and opinions) seemed to become more sensitive to another approach to the patient. Engels was one of the first to describe the patient-centred biopsychosocial model [4,6-9]. Particularly those who provide continuous care to patients rather than single or episodic interventions, such as professionals in primary care, are aware of this trend.

Also, the causal role of behavioural factors for chronic diseases became more and more recognised. There can be no doubt that healthcare decisions nowadays are being made on a quite different basis as compared to the period up till the 1970s. Not only the content of decisions in medical encounters is shifting since then, but also the way in which decisions are made [7,10-28]. In the final decades of the $20^{\text {th }}$ century, the traditional medical model has, to a certain degree, been replaced by a more negotiation and patient-centred model. Nevertheless, elements of the traditional model of consulting were still present in many health care encounters, as Byrne and Long in 1976, Kaplan and Ware in 1989, and others demonstrated [29-35].

In this paper the need to pay attention to the patients' preferences and the patients' active involvement in decision-making with respect to his diabetes is emphasised. The issue of miscarried helping is addressed because it may explain why patients sometimes resort to an inactive attitude with respect to self-care and involvement in their treatment. Many obstacles may hinder adequate self-care and treatment uptake by patients, and optimal treatment by professionals. It is argued that patients as well as care providers need to contribute in trying to overcome such obstacles. We describe why type 2 diabetes needs a specific chronic care approach. The paradox of medicine is addressed because it may explain why an effective and 'harmonious' communication between provider and patient in diabetes care may be difficult. Communication between provider and patient in a more dialectical process, as a method towards a more effective approach to managing type 2 diabetes in primary care, is discussed. The paper concludes with a suggestion for more active patient involvement and a dialectical, co-centred approach.

\section{Patient preferences}

Many providers and patients characterise type 2 diabetes as a self-managed, 'do-ityourself' condition - even if they admit that one 'cannot-do-it-without-help'. More than 
ever before, professional care must be open towards patient needs and preferences $[14,15,26,28,37-51]$. To be more open and responsive to patient needs, providers must examine their own values, attitudes, and beliefs in an attempt to increase their own self-understanding, and facilitate patient care. Providers' medical training may lead them to see themselves as superior to their patients, not only in terms of medical knowledge, but in terms of personal qualities as well. This may well block their openness and receptivity to the needs of patients, and result in poorer health care outcomes. Both parties have strengths and weaknesses, which must be grasped and understood if the patient is to benefit. A poor fit between the two sides, and failing to reach mutual understanding and concordance, will result in poor quality of patient outcomes. This goes for medication uptake and information utilisation, active patient participation in the information exchange and decision-making processes, and patient outcomes of care $[38,47,52-63]$.

In reflecting on the patient population with type 2 diabetes, providers need to be aware that a majority proportion of patients probably can and will perform good selfcare, adapt their lifestyle, follow-up health behaviour and medical treatment advice that is provided to them, and gain positive outcomes of diabetes care with minimal input from providers [64]. They prefer to be actively involved, and act according to it. In contrast, another part of the patient group will not be able or willing to do the same, and will show poor self-care, poor diabetes care results, and may end up with diabetes complications and poor quality of life.

\section{Activating}

In newly diagnosed patients and those with poor diabetes control, perhaps a more activating approach might be wise, as patient self-care is the key to improvement and requires such active involvement. Many patients need encouragement to become active participants in their diabetes encounters to the extent that they are capable to and wish to do. A flexible approach regarding patient preferences is the key - as patients deserve to be respected and allowed to decide for themselves. This is next to impossible if providers are aloof and arrogant, seeing themselves as superior to the patients they care for.

Some studies revealed that health care providers often underestimate the patient's wish to receive information about the health problem and treatment options, and the need for active involvement in decision making - but also that as a general rule patients have a greater wish to receive information than to participate in decision making $[51,65,66]$. Active question asking by the patient relates more strongly to good outcomes, as compared to shared decision making in itself $[61,67,68]$.

Not all patients want to be active and independent decision makers in their diabetes care all the time. Some prefer to be less active and want to be looked after for some time. Reviews by Benbassat and others on surveys in the US showed that this 'less active' preference is more common in the elderly, in male patients, and in those with lower education, and worse health [69-73]. Such a preference for a less active patient role seems to be linked to a higher risk of bad self-care, non-adherence to treatment, and worse outcomes of care [74]. So, one might conclude that yielding too easily to a less active role preference may be a pitfall. It is suggested that providers must not accommodate to it without resistance. The studies by Greenfield and 
Kaplan in the 1980s demonstrated that a sense of control or mastery in illness situations is related to better subjective and objective health status: tolerating pain, reporting less physical complaints, recovery from illness, decreased tumour growth, and effective daily functioning $[22,30,75]$.

\section{Miscarried helping}

One of the factors calling forth a 'passive' patient preference could well be the interaction behaviour of the provider. The concept of 'miscarried helping' sheds light on this phenomenon [10]. A health care provider's well-intended but too forceful efforts to help, motivate and advise another person (the patient), may paradoxically elicit the opposite of what is aimed for. It may even lead to interactions that turn out detrimental to the recipient. For example, a diabetes care provider may put strong emphasis on numeric and long-term treatment goals, use disease-oriented terms, dwell on potential threats, impose targets formulated from his professional perspective and guidelines, and forcefully advise the patient to change certain daily habits - and the patient's focus may shift from the escalating demands that they include towards maintaining personal autonomy. This may provoke either what is called 'learned helplessness' and dependency, or deviation from the professional advice or even complete disengagement from the interaction with the provider and from the patient's own responsibility of diabetes self-care [10]. In other words, when the provider becomes too active and confrontational in diabetes encounters, the risk of the patient becoming less active emerges ('miscarried helping'). Sensitivity on the side of the provider to patient needs appears more affective in such cases, and sensitivity is certainly needed when it comes to discussing changes of health behaviour with patients [37]. 


\section{Obstacles in the way}

Patients frequently show partial or complete dropout from the professional treatment and self-care advices and prescriptions [76-79]. In the 1970s, studies showed that 'non-compliant' or 'non-adherent' patients could not be distinguished from 'compliant' patients by any personality, social-psychological or social-demographic characteristics $[80,81]$. It also became clear that strict compliance to prescribed treatment as was assumed by the traditional medical model, is unusual rather than normal behaviour [5,10,37-39,52,53,77,82-88]. Many practitioners' daily experiences with diabetes care confirm this, and many studies in the Netherlands and elsewhere acknowledge the existence of a fairly large proportion of the diabetes population showing poor self-care and treatment uptake over longer periods of time $[76,82,83,89-94]$. Persons may move in and out of this group, as they vary over time in their motivations and skills with regard to different treatment and behavioural items, and stages of change [91,92]. Apparently, obstacles can get in the way of good diabetes care. Certain things may stop patients and providers, and prevent them from doing what they need to do for good outcomes, in all cases [95-107]. 'Barriers', 'difficulties', 'obstacles', 'resistance', and other names have been used to indicate such problems.

Obstacles may be localized inside the person (motivational problems, cognitive limitations, physical problems like comorbid disease or disability, or emotions like fears), or in the person's social environment (relational, or social support problems, cultural habits, living and working conditions, financial barriers, access to health care, interaction with the provider) $[10,27,37,38,50-54,63,64,69,77,86-88,90,98,99,106]$. Obstacles can get in the way of professional diabetes caregivers too. Providers may be prevented from delivering high quality diabetes care to all of their patients - or from effective translation of evidence from studies and guidelines into their daily diabetes care $[8,10,52,83,86,100-107]$.

The reasons for inadequate behaviour of people with type 2 diabetes and professional providers of diabetes care can be manifold. One line of thought is that deviation from a prescribed treatment, or 'non-adherence', may be an act of reasoned decision-making. People adhere to their own decisions, values, norms and beliefs, rather than to someone else's [33,39,52,53,77,82,84-88,95-99]. This goes for both patients and providers, e.g., when someone prescribes a certain change of lifestyle or treatment which the person silently or overtly disagrees with, resistance against it and deviating from it will easily be elicited. This can be regarded as an act of defending one's autonomy $[6,10,21,40-42-44,48,49,51,52,93]$. Given the importance of treatment, it would be wise for patients to discuss such disagreements with their providers, instead of simply going it alone. On the other hand, even when patients agree with the professional recommendation and want to perform it, they may still fail. Both situations are good reasons for patients to consult their diabetes care providers, or the other way around, for professionals to engage in discussions about these problems with the patient. Unfortunately, this often does not happen. For professionals, it seems wise to learn the skills needed to cope with and overcome these disagreements $[37,108]$.

\section{Chronic care approach}


Type 2 diabetes is a continuous, progressive, and lifetime problem in the patient's life. It requires an approach different from the traditional medical model $[64,109]$. Both health care providers and patients must abandon the concept of curing it, at least for the time being. An exception must be made for acute or chronic diabetes-related complications like cardiovascular events, loss of vision, foot ulcers, derangements of blood glucose levels, or non-related co-morbidity like infection or trauma. These problems need acute attention and curing forms of medical care. But type 2 diabetes itself needs a long standing caring and counselling approach, supporting lifestyle adaptations, long term self-management, and choices in the patient, rather than cure $[27,28,110]$. From a psychological point of view, emotional acceptance by the patient that it will not disappear is a key factor - and this may involve a long maturation process in which different emotional reactions come forward. Shock, denial, revolt, bargaining, sadness, and eventually acceptance, are the phases that a person may go through in the process towards adaptation and acceptance of having diabetes even if they do not necessarily follow a linear course with a fixed order and duration $[11,112]$.

A social dimension is present as well, as acceptance of diabetes and its treatment may affect one's behaviour, interactions with others, and familial, social and occupational functioning. The patients' difficulties in accepting the illness and its dangers, and their coping process in living with it, correlate with the health care providers' difficulties in accepting the patients as they are. Providers need to connect to the personal views and reactions of the patients, in order to better support them.

\section{Paradox of medicine}

Patients need professionals for health care and treatment, and for support to find their way in living with the condition. And professionals need patients to validate themselves as helpful and caring human beings who are satisfactorily fulfilling their roles. Progress in the health of their patients is tremendously gratifying to providers in their roles as physicians or nurses. Because both parties realize the mutual dependency, they will not easily confront each other directly with the outcomes of a critical evaluation of the consultation, and overt conflicts usually are avoided. Differences in their judgments often remain hidden, especially if they include a negative evaluation. This reproduces 'the Paradox of Medicine', which includes, according to Stimson and Webb, that in the consultation room or the clinic (the professional's space) it is the professional who usually is in control of what happens, deciding on the agenda and treatment decisions - while outside the clinic it is the patient who is in control (the patient's space) and does the decision-making [81].

Do we need to resolve this paradox? Harmony and dialogue are not all that matters. Just being kind to patients all the time is not sufficient for professionals to cope with all the patients' and their own obstacles to good diabetes care. Kinmonth, Mead, and others have demonstrated that the evidence for positive health outcomes from patient-centred care ('being kind') is ambiguous [54,113-115]. Other research suggests that expressing affect and emotion during health care encounters - be it positive or negative - or some difference of opinion between provider and patient, relate to better outcomes, as compared to complete concordance and harmony 
$[24,29,30,55,68,73,75]$. Perhaps some conflict and emotional involvement from the side of the professional reflects interaction on a more equal basis and a more active interpersonal engagement of patient and provider, which the patient may perceive as a stronger professional commitment and as more supportive.

Would an effective dialogue help both the providers and the patients to reach good outcomes and satisfaction with the interaction?

\section{A dialectical process}

A dialectical process in diabetes encounters emerges when one acknowledges that the ideas of patients often differ from or even clash with those of their care providers. Their views may be alike in some situations - but opposite in many $[2,5,10,11,14,17$ $22,26,27,30,32,37,39,43,44,60,62,68,83,97,98]$. Will discrepancies in ideas between patients and providers be resolved by a dialectical process that results in the formation of 'a new, truer, more comprehensive concept'?[116]. In that case the two parties apparently reach an agreement, find common ground and mutual understanding, e.g. on the definition of a problem, a change of treatment, a piece of patient self-care, or a certain behaviour change. Or will both parties leave the encounter still clinging to their own ideas? In that case there is another kind of outcome agreement: both follow up their own ideas. Or will the agreement be that the patient 'surrenders' to the treatment advice of the provider - or the other way around, that the provider 'gives in' to the ideas of the patient?

Whatever the content of the outcome agreement, in diabetes encounters a dialectical process takes place with exchanges of the opposing or not opposing views, with discussion, struggle, or concordance, and some sort of resolution. In this process one may recognise the Hegelian dialectics of 'thesis, antithesis, synthesis' [117]. The resulting balance of ideas, the outcome agreement or synthesis, will usually be a dynamic, living one, with temporary effects only - in diabetes care that is.

Paolo Freire and his followers theorized that the dialectical process could be put into effect in processes of individual self-determination and social empowerment [117121]. Freire started with oppressed people and illiterates in developing countries as clients of his pedagogy. More recently, a 'Freirean empowerment philosophy and method' has been developed, with socially disadvantaged groups or individuals as clients [122,123]. The method applies a communication approach along the way of receptive learning, dialogue and action. These three steps are crucial elements of the Freirian approach, representing a conscious dialectical process in health education and community organizing for health. Such a dialectical approach has been applied to group work in socially deprived areas, in particular targeting alcohol and drug abuse in youngsters, and proved to be successful in guiding social transformation processes towards empowerment. Empowerment is a philosophy that recognizes the fundamental right and responsibility of persons to be the primary decision-makers in the management of their daily life and social or health problems (e.g. diabetes) [60].

Baxter and Montgomery have studied and described the dialectical process in human interactions [124]. They demonstrated the dialectical process of interaction between patient and provider as being one of putting out feelers and of struggle, even if there is trust. The process may lead to a tentative, transitory resolution between the provider and the patient - a process that hopefully results in increased mutual 
understanding and progress in the relationship. Just as there is no cure for diabetes, there is no ultimate balance, just continual struggle and increased understanding and progress towards better management control of diabetes. Progress is not an end state; there is no final balance. Instead, issues are being continually confronted mutually and are resolved within the context of the general struggle, which leads only to a new focus on new issues to struggle with and resolve. Diabetes care then is a non-ending battle for the lifetime of the patient in a dialectical process of interacting with professionals. Professional diabetes care providers often regard themselves as the experts of diabetes and the providers of solutions, which they are to a certain degree - while at the same time there is still much to learn and know for them about the condition and its treatment, and especially about the ways it affects a patient's life. At the same time, patients will eventually become experts as well with regard to their personal diabetes, its care and self-care, their personal back grounds, and the ways the condition affects their personal life.

From the 1980s on, Miller and Rollnick developed the motivational interviewing method from working with individuals who wanted help for behaviour changes in cases of alcohol or drugs dependency, criminal problems, and damaging gambling or smoking habits. The method proved effective in working with individuals attempting at changes, including self-care and lifestyle changes, in chronic diseases [108]. Rollnick translated the dialectical sequence of 'listening-dialogue-action' and the methods of motivational interviewing, stages of change, and patient-centredness, into a 'brief motivational interviewing method' for practitioners in primary care, to support individual clients for health behaviour changes [37]. The method provides tools for motivation, active involvement, and empowerment, and opens up new pathways for diabetes care. Its dialectical approach surely may enable providers to perform a more effective, dialectical dialogue in diabetes encounters.

\section{Active patient involvement}

Behaviour plays an important role in the causation as well as in the further course of type 2 diabetes. Patient behaviour has great impact on the outcomes of prevention and treatment interventions of type 2 diabetes, as well. In order to help patients who are at risk to engage in favourable health behaviour changes, providers need to build a longstanding relationship for care, build trust, and support patients' active questionasking and decision-making in diabetes encounters. They also need to perform effective risk communication when needed, and counsel the person for self-care and self-management. At the same time, high quality professional expertise of diabetes management and diabetes treatment is requested from them, as well as communication about their own personal views and beliefs regarding diabetes care. Such a dialectical approach of diabetes care may enable a greater proportion of the population of persons with type 2 diabetes treated in primary care to benefit. The goals are to support patients to more effectively treat symptoms and complications, prevent or postpone complications, gain patient empowerment, and enable them to make personal choices, reach personal life goals, and ensure good quality of life and functional status. This may result in protecting autonomy and independence of patients, and job satisfaction of professionals $[3,10,12,13,37,38,65,66,83,91,92,108]$. 
Approaches that activate patients and enhance active patient participation may improve lifestyle changes and patient-oriented outcomes, as contrasted to a more traditional approach that focuses on medical treatment and disease-oriented, intermediate outcomes (with patients being less active participants). A number of studies produced evidence for this [54-56,67-75,125-128]. Negotiating treatment targets to make them more personally suited improves outcomes as well, both for perceived quality of life, prevention of complications, and survival - even if such targets differ from evidence-based targets in official guidelines [10,35$37,39,58,65,128,130]$. Joint agreements on treatment goals imply a more active patient participation and commitment. More than fifteen years ago, Greenfield and Kaplan demonstrated that a patient-empowering approach, teaching patients to become more active in the dialectical process of health care in a variety of chronic conditions, including diabetes, really works $[55,75]$. It improves patient-oriented subjective and clinical outcomes. Such an approach supports patients to achieve personal goals, which may include that they remain in control of their lives, and live longer and healthier.

This implies that not only diabetes care, but medicine as a whole, is under pressure to focus more and more on patients' lives rather than on patients' bodies and intermediate clinical outcomes. Evaluation of its effectiveness will more and more occur within patients' lives rather than within doctors' clinics. The emphasis on subjective patient judgements will be regarded valid - not despite but because of their subjectivity [7]. This goes especially for chronic conditions, like type 2 diabetes.

\section{A co-centred model}

Out of the biopsychosocial model that is currently dominating the medical literature, an increasing interest in examining the interaction of the two perspectives within a dialectical process in health care encounters arises:

- On one side there is the professional's perspective, including professional knowledge, adherence to guidelines and lifestyle recommendations, and performance, and the professional's personal values and beliefs, and personal commitment to the patients wellbeing. This perspective is usually more diseaserelated, embedded in a professional medical frame of reference, but includes the professional's personal goals, emotions and views.

- And on the other side there is the patients' perspective, in which patient decisions and health behaviour changes are being made, including the patient's knowledge, skills, personal values and beliefs, preferences, and social support. It is usually related to the personal perception of illness and sickness, the consequences and threats of the condition for daily life and psychosocial functioning, embedded in a layframe of reference [81,95-99].

Professionals and patients need to come to a mutual agreement of what is going on and what must be done, recognizing both perspectives [10,37]. Awareness of this is not automatically present, and even if both parties are aware, it normally is not discussed in consultations. An important part of forming collaborative alliances is to recognize the distinction between practitioner and patient perspectives in type 2 diabetes [97]. 
In case the consultation process gets stuck in an overt conflict or disengagement, the professional may 'blame the victim' by reasoning that the patient is 'unwilling' to follow up his good advice, is stubborn, or lacks the intelligence and skills needed. The provider may well see himself as superior to the patient, and this may lead to his disengaging from attempts to reach a true dialogue. There is a need for providers to examine their own attitudes and prejudices and how they may impact positively or negatively on the patient. The patient in turn may judge that the practitioner did not spend enough time, was not willing to listen, or did not explain elements which he considers essential. Before, during, and after a consultation, both live in the realm of their own reference system, their separate 'spaces' - the lay and the professional perspectives. Both parties evaluate the interaction in the consultation and the contribution of the other. This includes comparison of each encounter with prior ones, and with experiences of important others (relatives, colleagues or fellow-patients). Providers and patients also make explicit or implicit assessments of their own performance [32,33,81].

A new balance between the providers' and patients' roles within a dialectical interaction process in health care encounters may be required $[37,39]$.

Providers will increasingly have to learn to cope and guide the dialectical process, in order to make it work in the patients' and their own interest. For handling this socalled 'co-centred interaction model', professionals need skills such as patientcentredness, empowerment, and genuine interest in the patients, and tools such as methods of brief motivational consulting, patient activation, effective risk communication, and shared decision-making [54-56,61,62,67,68,75,114,115,125129]. These features are now widely valued as important for medicine, especially in general practice - although practising them seems not a simple thing to do $[3,4,8,9,12,13,37,38,65,83,91,92,108,130]$.

\section{Challenge}

Is it possible to improve the quality and outcomes of the interactions of the patient's and the professional's perspectives in diabetes encounters, by guiding the interaction into a more effective, dynamic, dialectical way, in a dialogue which enables shifts in gears? We believe this is possible. Patients and care providers are involved in this process during health encounters all the time, and recognising it may be the starting point for finding new pathways when needed. In diabetes consultations, the practitioner and the patient can operate as partners, each with an expertise and responsibility of his own $[18,19,21,39,110]$. The degree to which this works depends largely on the willingness and competence of the professional provider: When he can be open towards the patient, and give him space and time to express his feelings, personal goals, experiences and expectations, he may help the patient change from being a passive object of generalized biomedical procedures into an active subject with existential and psychosocial perspectives of his own. In the meantime, patients already get ever better access to comprehensive and reliable patient information sources ouside the diabetes encounters, in the public media and especially on the internet [131]. 
One may also conclude that there seems to be a paradoxical trait to this. Our plea is for the professionals to recognize and guide a dialectical interaction in diabetes encounters - while at the same time it is the patients that should become more active and empowered partners. To activate the patients would be a task for the professionals. This paradox can be resolved only if both perspectives are recognized and discussed in an open and true dialogue. The different perspectives of patients and providers are embedded in different social positions. In their interactions during diabetes encounters, both actors are 'condemned' to live with each other. Defining the perspective of the patient and his active or passive utterances in the diabetes encounter the 'thesis', one could interpret the provider perspective and his utterances the 'antithesis' - sometimes denying, and sometimes joining or reinforcing the thesis [117].

Depending on one's position, one might just as well define the professional's position the 'thesis' and the patient's the 'antithesis'.

The challenge for both parties is to engage in an effective, true dialogue that enables the virtual conflict and difference between the two to result in a joint agreement, a mutual understanding, and a shared vision. Then a 'synthesis' is found in which both perspectives are rewarded, and something good may come out - even if this balance will usually be a temporal one $[37,81]$. Both parties can learn from one another, when the interaction can be made a negotiative and dialectical one. Patients can learn from professionals' clinical knowledge and skills - providers can learn from patients' personal views, skills, and what they perceive as personal or professional barriers. When providers truly try to understand the less articulate patients, they might provide them with advice and treatment that better suites them, and reciprocity in the communication might evolve. Patients then can participate as more open and active listeners, question askers, and information providers.

The dialectical approach of dialogue between professional and patient clearly is a promising concept in the care of persons with type 2 diabetes. It describes and promotes an ongoing, dynamic process. Progress in understanding how it operates in the patient-provider interactions to improve patient health is very much needed.

\section{Practice implications}

(1)The use of patient activation methods can help to support professionals in their communications with patients in such a way that the latter perceive the possibility of getting equally involved in the dialectical process. The diagnostic and therapeutic process of diabetes encounters, both in objective and subjective terms, must tap into the daily life experiences of patients with the illness. In that way it may help patients to make choices which are recognisable to them, and reinforce their sense of personal responsibility for the management of their illness. This helps increase patient control and empowerment. One of the warranted methods for attaining this goal is to organize systematic, brief patient preparation for diabetes consultations, supported by experienced and trained diabetics as lay counsellors (or professional assistants/nurses), to enable patients to ask questions and get answers, and to bring in their frame of reference including emotions, cognitions, and responsibilities. Group consultations to diabetes professionals, and empowering group training of patients, 
may also be of help. Another method for patient empowerment may be to organize mutual social support in 'live', internet or telephone social support groups.

(2)Inside diabetes encounters, professionals should guide the dialectical process by applying a motivational and patient-centred approach. Through a motivational approach, the professional encourages the patient to find and produce arguments for health behaviour change and ways to achieve and sustain it. Patient-centredness focuses on what is important for the patient, including his social context. In a dialectical, Freirean approach, the professional applies reflective listening, dialogue, and action, to guide the communication into a true dialogue. Both the professional and the patient should have their input of personal goals, visions, and expectations, in a mutual information exchange. After a discussion of concordances and differences, and a negotiation phase, joint agreements and actions are aimed for.

(3)Education of professionals will increasingly have to cover the learning of skills to perform motivational conversation methods, patient activation and empowerment, patient-centredness, guiding the dialectical process of dialogue in diabetes encounters, and investigation and discussion of both the provider's and the patient's personal goals, views, knowledge, and expectations regarding diabetes care. To achieve these ends, a major part of this training would involve an active examination of the provider's own personality i.e., his/her values, attitudes, and beliefs as they impact the patient's willingness to accept help and direction from him/her. This training would aim at enabling professionals to create a therapeutic atmosphere within consultations and educational encounters characterized by mutual openness and trust. It also aims at teaching professionals to guide an ongoing, dialectical decision making process in which provider and patient jointly agree on the reason for the encounter, the diagnosis, and the therapeutic or self-care sequala. Finally, training aims at helping providers anticipate the consequences of diagnostic findings, therapeutic recommendations, and decisions for the patient's daily life.

\section{PRACTICE SUGGESTIONS FOR DIABETES TEAMS}

- Create a therapeutic atmosphere within consultations and educational encounters, characterized by mutual openness and trust.

- Increase patient perceived control and empowerment by organizing systematic, brief patient preparation for diabetes consultations, supported by experienced and trained diabetics as lay counsellors (or by professional assistants or nurses), to enable patients to ask questions and get answers, and to bring in their frame of reference including emotions, cognitions, and responsibilities.

- Reinforce patient empowerment by organizing mutual social support in 'live', internet or telephone support groups, group consultations to diabetes professionals, and empowering group trainings for patients.

- Acquire and apply motivational and patient-centred approaches to guide the dialectical process. Encourage patients to find and produce arguments for health behaviour change and find ways to perform and sustain it. Apply reflective listening, dialogue, and action, to guide the communication into a true dialogue. 


\section{REFERENCES}

1-Parson T. The Social System. The Free Press: Glencoe 1951.

2-Armstrong D. The patient's view. Soc Sci Med 1984;18:737-44.

3-Sullivan M. The new subjective medicine: taking the patient's point of view on health care and health. Soc Sci Med 2003;1595-1604.

4-Stewart M, Brown JB, Weston WW, McWhinney IR, McWilliam CL, Freeman TR. Patient-Centered Medicine. Transforming the Clinical Method. Thousand Oaks CA: Sage Publications 1995; Abingdon: Radcliffe Medical Press $20032^{\text {nd }}$ Edn.

5-Stimson GV. Obeying doctor's orders: a view from the other side. Soc Sci Med 1974;8:97-104 .

6-Engel GL. The need for a new medical model: a challenge for biomedicine. Science 1977;196:12936

7-Engel GL. The clinical application of the biopsychosocial model. Am J Psychiatry 1980;137:535-43.

8-Greenhalgh P. 'Is my practice evidence-based?'. Editorial. Br Med J 1996;313:957-8.

9-Freeman G, Car J, Hill A. The Journey towards Patient-centredness. Editorial. Br J Gen Pract 2004;54:651-2.

10-Wolpert HA, Anderson BJ. Management of diabetes. Are doctors framing the benefits from the wrong perspective? Br Med J 2002;323:994-6.

11-Clark M, Hampson SE. Comparison of patients' and healthcare professionals' beliefs about and attitudes towards type 2 diabetes. Diabet Med 2003;20:152-4.

12-Charles C, Gafni A, Whelan T. Shared decision-making in the medical encounter: What does it mean? (or it takes at least two to tango). Soc Sci Med 1997;44(5):681-92.

13-Charles C, Gafni A, Whelan T. Decision-making in the physician-patient encounter: Revisiting the shared treatment decision-making model. Soc Sci Med 1999;49(5):651-61.

14-Balint M. The doctor, his patient and the illness. London: Pitman 1957. (De dokter, de patiënt, de ziekte. Utrecht: Het Spectrum 1975).

15-Freidson E. Profession of Medicine. New York: Dodd, Mead 1970.

16-Johnson TJ. Professions and Power. London: Macmillian 1972.

17-Ilich I. Medical Nemesis - The expropriation of health. London: Marion Boyars 1975. (Grenzen aan de geneeskunde. Bussum: Het Wereldvenster 1975-1978).

18-Schneider CE. The practice of autonomy: patients, doctors, and medical decisions. New York: Oxford University Press 1998.

19-Coulter A. Paternalism or partnership? Br Med J 1999;319:719-20.

20-Guadagnoli E, Ward P. Patient participation in decision-making. Soc Sci Med 1998;47:329-39 .

21-De Haes HC, Molenaar S. Patient participation and decision control: are patient autonomy and well-being associated? Med Decis Making 1997;17:353-4 .

22-Kaplan SH, Greenfield S, Ware JE. Assessing the effects of physician-patient interactions on the outcomes of chronic disease. Med Care 1989;27(Suppl):S110-127 .

23-Kaplan SH, Ware JE. The patient's role in health care and quality assessment. In: Goldfield N, Nash DB (Eds). Providing quality. Philadelphia, Pennsylvania: American College of Physicians 1989.

24-Armstrong D. What do patients want? Br Med J 1991;303:261-2.

25-Nationale Raad voor de Volksgezondheid. Algemeen begrippenkader kwaliteit van zorg. (General conceptual framework for quality of care). Utrecht: NRV 1990. (In Dutch) .

26-Sixma HJ, Kerssens JJ, Van Campen C, Peters L. Quality of care from the patients' perspective: from theoretical concept to a new measuring instrument. Health Expect 1998;1:82-95 .

27-Rutten GEHM. Huisarts en Patiënt - Richtlijnen en uitgangspunten (General Practitioner and Patient - Guidelines and points of view). (in Dutch). Utrecht: NHG 1996.

28-Nederlandse Diabetes Federatie. Zorgstandaard voor goede diabeteszorg. (Standard of Care for good diabetes care). NDF: Amersfoort 2003 [In Dutch] [Free Full Text/diabetesfederatie.nl].

29-Byrne PS, Long BEL. Doctors talking to patients: a study of the verbal behaviour of general practitioners consulting in their surgeries. London: HMSO 1976.

30-Kaplan SH, Greenfield S, Ware JE. Assessing the effects of physician-patient interactions on the outcomes of chronic disease. Med Care 1989;27(Suppl):S110-127.

31-Kaplan SH, Ware JE. The patient's role in health care and quality assessment. In: Goldfield N, Nash DB (Eds). Providing quality. Philadelphia, Pennsylvania: American College of Physicians 1989.

32-Jung HP, Wensing M, Olesen F, Grol R. Comparison of patients' and general practitioners' evaluation of general practice care. Qual Saf Health Care 2002;11:315-9.

33-Wensing M, Grol R, Smits A. Quality judgements by patients on general practice care: a literature analysis. Soc Sci Med 1994;38:45-53. 
34-Lehr H, Strosberg M. Quality improvement in health care: is the patient still left out? Qual Rev Bull 1991;17:326-9.

35-Elwyn GJ, Edwards A, Kinnersley P. Shared decision-making in primary care: the neglected second half of the consultation. Br J Gen Pract 1999;49:477-82.

36-Sullivan FM, MacNaughton RJ. Evidence in consultations: interpreted and individualised. Lancet 1996;348:941-3.

37-Rollnick S, Mason P, Butler C. Health Behaviour Change - a guide for practitioners. Edinburgh, London, New York, Oxford, Philadelphia, St Louis, Sydney, Toronto: Churchill Livingstone 1999-2004.

38-Koenigsberg MR, Bartlett D, Cramer JS. Facilitating treatment adherence with lifestyle changes in diabetes. Am Fam Phys 2004;69:309-16,323-4.

39-Tuckett D, Boulton M, Olson C, Williams A. Meeting between experts: an approach to sharing ideas in medical consultations. London: Tavistock Publications 1985.

40-Lipsky ML, Sharp LK. Preventive Therapy for Diabetes: lifestyle changes and the primary care physician. Editorial. Am Fam Phys 2004;69:269-71.

41-Tversky A, Kahnemann D. The framing of decisions and the psychology of choice. Science 1981;211:453-8.

42-Llewellyn-Thomas H, Sutherland HJ, Tibshirani R, Ciampi A, Till JE, Boyd NF. The measurement of patients' values in medicine. Med Decis Making 1982;2:449-62.

43-Kassirer JP. Incorporating patients' preferences into medical decisions. N Engl J Med 1984;330:2895-6.

44-Wensing M. What can patients do to improve health care? Health Expect 1998;1:37-49 .

45-Benbassat J, Pilpel D, Tidhar M. Patients' preferences for participation in clinical decision making: a review of published surveys. J Behav Med 1998:24:81-8.

46-Jung HP. Quality of care in general practice: the patient perspective. Thesis, Nijmegen: Katholieke Universiteit Nijmegen 1999.

47-Britten N. Patients' expectations of consultations - Patient pressure may be stronger in the doctor's mind than in the patient's. Editorial. Br Med J 2004;328:416-7.

48-Deber RB, Kraetschmer N, Irvine J. What role do patients wish to play in treatment decision making? Arch Intern Med 1996;156:1414-20.

49-Degner LF, Sloan JA. Decision making during serious illness: what role do patients really want to play? J Clin Epidemiol 1992;45:941-50.

50-De Clerq PA, Hasman A, Wolffenbuttel BH. A consumer health record for supporting the patientcentered management of chronic diseases. Med Inform Internet Med 2003;28:117-27.

51-Ruzicki DA. Relationship of participation preference and health locus of control in diabetes education. Diabetes Care 1984;7:372-7.

52-Hunt LM, Pugh J, Valenzuela M. How patients adapt diabetes self-care recommendations in everyday life. J Fam Pract 1998;46:207-15.

53-Donovan JL. Patient decision-making. The missing ingredient in compliance research. Int $\mathrm{J}$ Technol Assess Health 1995;11:443-55.

54-Van Dam HA, Van der Horst FG, Van den Borne HW, Ryckman R, Crebolder HFJM. Providerpatient interaction in diabetes care: effects on patient self-care and outcomes. A systematic review. Pat Educ Couns 2003;51:17-28. Chapter 7 in this thesis.

55-Greenfield S, Kaplan SH, Ware JE, Yano EM, Frank HJL. Patients' participation in medical care: effects on blood sugar control and quality of life in diabetics. J Gen Intern Med 1988;3:446-57.

56-Anderson RM, Funnell MM, Butler PM, Arnold MS, Fitzgerald JT, Fesle CC. Patient empowerment: results of a randomized controlled trial. Diabetes Care 1995;18:943-9.

57-Trento M, Passera P, Tomalino M, Bajardi M, Pomero F, Allione A, et al. Group visits improve metabolic control in type 2 diabetes: a 2-year follow-up. Diabetes Care 2001;995-1000 .

58-De Fine Olivarius N, Beck-Nielsen $\mathrm{H}$, Andreasen AH, Hørder M, Pederson PA. Randomized controlled trial of structured personal care of type 2 diabetes mellitus. $\mathrm{Br}$ Med J 2001;323:970-5.

59-Piette JD, Weinberger M, McPhee SJ. The effect of automated calls with telephone nurse follow-up on patient-centred outcomes of diabetes care: a randomised controlled trial. Med Care 2000;38:21830.

60-Funnell MM, Anderson RM, Arnold MS, et al. Empowerment: an idea whose time has come in diabetes education. Diabetes Educ 1992;17:37-41.

61-Bensing J. Doctor-patient communication and the quality of care. An observation study into affective and instrumental behaviour in general practice. Thesis. Rotterdam: Erasmus Universiteit Rotterdam 1991.

62-Royal Pharmaceutical Society of Britain. From compliance to concordance: achieving shared goals in medicine taking. London: RPS 1997. 
63-Britten N, Stevenson F, Barry C, et al. Misunderstandings in prescribing decisions in general practice. Br Med J 2000;320:484-8.

64-Holt TA. A chaotic model for tight diabetes control. Diabet Med 2002;19:274-8.

$65-S h a u g h n e s s y$ AF, Slawson DC. Blowing the whistle on review articles. What should we know about the treatment of type 2 diabetes? Editorial. Br Med J 2004;328:280-2.

66-Elwyn GJ, Edwards A, Kinnersley P. Shared decision-making in primary care: the neglected second half of the consultation. Br J Gen Pract 1999;49:477-82.

67-Michie S, Miles J, Weiman J. Patient-centredness in chronic illness: what is it and does it matter? Patient Educ Couns 2003;51:197-206.

68-Roter DL. Patient participation in the patient-provider interaction: the effects of patient question asking on the quality of interaction. Ann Intern Med 1977;5:281-315.

69-Benbassat J, Pilpel D, Tidhar M. Patients' preferences for participation in clinical decision making: a review of published surveys. J Behav Med 1998:24:81-8.

70-Al-Bashir MM, Armstrong D. Preferences of healthy and ill patients for style of general practitioner care: implications for workload and financial incentives under the new contract. Brit $\mathrm{J}$ Gen Pract 1991:41:6-8.

71-Mold JW, Looney SW, Viviani NJ, Quiggins PA. Predicting the health-related values and preferences of geriatric patients. J Fam Pract 1994;39:461-7.

72-Jung HP, Wensing M, Grol R. What is important to patients? Aspects of general practice care, seen from the patient's perspective. Huisarts Wet 1996;39:594-9 (in Dutch).

73-Bensing JM, Verhaak PF, Van Dulmen AM, Visser AD. Communication: the royal pathway to patient-centred medicine. Patient Educ Couns 2000;39:1-3.

74-Boyd I, Yeager M, McMillan M. Personality styles in the post-operative course. Psychosom Med 1973;35:23-40.

75-Greenfield S, Kaplan SH, Ware JE. Expanding patient involvement in care: Effects on patient outcomes. Ann Int Med 1985;102:520-8.

76-Cramer J. A systematic review of adherence with medication for diabetes. Diabetes Care 2004;27:1218-24.

77-Vermeire E, Royen P van, Coenen S, Wens J, Denekens J. The adherence of type 2 diabetes patients to their therapeutic regimens: a qualitative study from the patient's perspective. Pract Diab Int 2003;20:209-14.

78-Vermeire E, Hearnshaw H, Rätsep A, Levasseur G, Petek D, van Dam H, van der Horst F, VinterRepalust N, Wens J. Obstacles to adherence in living with type 2 diabetes. An international study using qualitative meta-analysis (submitted 2005).

79-Henk A van Dam, Frans G van der Horst, Ilse Mesters, Harry F Crebolder, Bart W van den Borne. Obstacles in the management of type 2 diabetes: the perspectives of patients and experts. Submitted 80-Holm S. What is wrong with compliance? J Med Eth 1993;9:108-10.

81-Stimson G, Webb B. Going to see the doctor - the consultation process in general practice. London: Routledge \& Kegan Paul 1975.

82-Murphy E, Kinmonth AL. No symptoms, no problem? Patients' understandings of non-insulin dependent diabetes. Fam Pract 1995;12:184-92.

83-Winocour PH. Effective diabetes care: A need for realistic targets. Br Med J 2002:324:1577-80.

84-Dunn SM, Beeney LJ, Hoskins PL, Turtle JR. Knowledge and attitude change as predictors of metabolic improvement in diabetes education. Soc Sci Med 1990;31:1135-41.

85-Boekaerts M, Pintrich PR, Zeidner M. Handbook of Self-Regulation. San Diego, San Francisco, New York, Boston, London, Sidney, Tokyo: Academic Press 2000.

86-Snoek FJ. Breaking the barriers to optimal glycaemic control - What physicians need to know from patients' perspectives. Int J Clin Pract 2002;129(Suppl):S80-4.

87-Schoenberg NE, Drungle SC. Barriers to non-insulin dependent diabetes mellitus (NIDDM) selfcare practices among older women. J Aging Health 2001;13:443-66.

88-Van Dam HA, Crebolder HFJM, Eijkelberg I, Van Nunen M, Van der Horst FG. Wegblijven van patiënten met diabetes mellitus type 2 - een echt probleem? (Non-attendance of patients with type 2 diabetes - a real problem?). Huisarts Wet 2000;43:380-4. (in Dutch).

89-Roter DL, Hall JA, Merisca R, et al. Effectiveness of Interventions to Improve Compliance: A metaanalysis. Med Care 1998;36:1138-61.

90-Harris M. Health care and health status and outcomes for patients with type 2 diabetes. Diabetes Care 2000;23:754-58.

91-Diclemente CC, Prochaska J. Towards a comprehensive transtheoretical model of change: stages of change and addictive behaviours. In: Miller WR, Heather N (Eds): Treating addictive behaviours. $2^{\text {nd }}$ Edition. New York: Plenum 1998. 
92-Prochaska J, Diclemente C. Stages and processes of self-change of smoking: Towards an integrated model of change. J Consult Clin Psychol 1983;51:390-5

93-Jones $\mathrm{H}$, Edwards I, Vallis TM, et al. Changes in diabetes self-care behaviours make a difference in glycemic control. The Diabetes Stages of Change (DISC) study. Diabetes Care 2003;26:732-7.

94-Vallis M, Ruggiero L, Greene G, et al. Stages of change for healthy eating in diabetes: relation to demographic, eating-related, health care utilization and psychosocial factors. Diabetes Care 2003;26:1468-74.

95-Ary DV, Toobert D, Wilson W, Glasgow RE. Patient perspectives on factors contributing to nonadherence to diabetes regimens. Diabetes Care 1986;9:168-72

96-Cohen MZ, Tripp-Reimer T, Smith C, Sorofman B, Lively S. Explanatory models of diabetes: patient-practitioner variation. Soc Sci Med 1994;38:59-66.

97-Clark M, Hampson SE. Comparison of patients' and healthcare professionals' beliefs about and attitudes towards type 2 diabetes. Diabet Med 2003;20:152-4.

98-Freeman J, Loewe R. Barriers to communication about diabetes mellitus: patients' and physicians' different views of the disease. J Fam Pract 2000;49:507-12.

99-Garay-Sevilla ME, Malacara JM, Gutiérrez-Roa A, González E. Denial of disease in type 2 diabetes mellitus: its influence on metabolic control and associated factors. Diabet Med 1999;16:23-44.

100-Freeman AC, Sweeney K. Why GPs do not implement evidence. Qualitative study. Br Med J 2001;323:1100-2.

101-Konings GPJM, Rutten GEHM, Wijkel D. Waarom houden huisartsen zich niet aan de NHGStandaard Diabetes Mellitus Type II? Huisarts Wet 1995;38:602-7 (Why don't general practitioners comply with the NHG-Standard Diabetes Mellitus Type II?) (in Dutch).

102-Grol R, Dalhuijsen J, Thomas S, et al. Attributes of clinical guidelines that influence use of guidelines in general practice: observational study. Br Med J 1998;317:858-61.

103-Dunn S, Pickering R. Does good practice organization improve the outcome of care for diabetic patients? Br J Gen Pract 1998;48:1237-40.

104-Larme AC, Pugh JA. Attitudes of primary care providers toward diabetes: barriers to guideline implementation. Diabetes Care 1998;21:1391-6.

105-Helseth LD, Susman JL, Crabtree BF, O'Connor PJ. Primary care physicians' perceptions of diabetes management. A balancing act. J Fam Pract 1999;48:37-42.

106-Pringle M, Stewart-Evans C, Coupland C, et al. Influences on control in diabetes mellitus: patient, doctor, practice, or delivery of care? Br Med J 1999;16:54-9.

107-Groeneveld Y, Petri H, Hermans J, Springer M. An assessment of structured care assistance in the management of patients with type 2 diabetes in general practice. Scan Prim Health Care 2001;19:25-30.

110-Peterson KA, Vinicor F. Strategies to improve diabetes care delivery. J Fam Pract 1998;47:Suppl S55-61.

108-Miller WR, Rollnick S. Motivational Interviewing: Preparing people for change. $2^{\text {nd }}$ Edn. New York, London: The Guildford Press 2002.

109-Pawlson LG. Chronic illness: implications of a new paradigm for health care. J Qual Improvem 1994;20:33-9.

111-Kübler-Ross E, On Death and Dying. New York: Macmillan 1969.

112-Lacroix A, Assal JP. Therapeutic education of patients - New approaches to chronic illness. Paris: Vigot 2000.

114-Mead N, Bower P. Patient-centredness: a conceptual framework and review of the empirical literature. Soc Sci Med 2000;51:1087-1110.

115-Montori VM. Review: interventions focusing on patient behaviours in provider-patient interactions improve diabetes outcomes. Quality Improvement. J EBM 2004;9:60/ACP J Club 2004;140:51.

116-Webster's New Encyclopedic Dictionary of the English Language, New Revised Edition Unabridged. New York: The Publisher's Guild 1996.

117-Störig HJ. Kleine Weltgeschichte der Philosophie. Stuttgart: W.Kohlhammer Verlag 1959 (in Dutch: Geschiedenis van de Filosofie. Utrecht: Het Spectrum 1959-2000).

118-Freire P. Education for critical consciousness. New York: Seabury Press 1973.

119-Freire P. Pedagogy in process: the letters from Guinea-Bissau. New York: Seabury Press 1978.

120-Sartre JP. L'être et le Néant - Essai d'ontologie phénoménologique. Paris: Gallimard 1943.Wallerstein N, Bernstein E. Empowerment Education: Freire's ideas adapted to Health Education. Health Educ Quart 1988;15:379-94.

121-Machie-Literacy R. Revolution: the pedagogy of Paolo Freire. New York: Continuum Press 1981. 122-Wallerstein N, Bernstein E. Empowerment education: Freire's ideas adapted to health education. Health Educ Quart 1988;15:379-94. 
123-Buroway M. An invitation to public sociology. 2004 ASA Annual Meeting Program Committee (San Francisco), Washington: American Sociological Association 2004.

124-Baxter LA, \& Montgomery BM. Relating: Dialogues and Dialectics. New York: Guilford Press 1996.

125-Edwards A, Unigwe S, Elwyn GJ, Hood K. Effects of communicating individual risks in screening programmes: Cochrane systematic review. Br Med J 2003;327:703-10.

126-Stewart M, Brown JB, Donner A, McWhinney IR, Oates J, Weston WW. The impact of patientcentred care on patient outcomes in family practice. London, Ontario: Centre for Studies in Family Medicine (Final Report) 1995.

127-Burke BL, Arkowitz H, Menchola M. The efficacy of motivational interviewing: a meta-analysis of controlled clinical trials. J Consult Clin Psychol 2003;71:843-61.

128-Botelho R. A negotiation model for the doctor-patient relationship. Fam Pract 1992;9:210-8.

129-Rost KM, Flavin KS, Cole K, McGill JB. Change in metabolic control and functional status after hospitalization. Impact of Patient Activation Intervention in Diabetes Patients. Diabetes Care 1991;14:881-9.

130-Elwyn G. Shared decision making - Patient involvement in clinical practice. Thesis, Nijmegen: Katholieke Universiteit Nijmegen 2001.

131-Jadad AR. Promoting partnership: challenges for the internet age. Br Med J 1999;319:761-4. 


\section{CHAPTER 9}

Discussion

(Beschouwing) 


\section{Discussion}

(Beschouwing) 


\section{Main findings and conclusions from the studies}

The studies in this thesis examined various aspects of the care of type 2 diabetes patients in general practice (GP). Interrelations of diabetes control, and patient perceived diabetes control and support, patients' functional status, and quality of life have been studied. The phenomena of patient non-attendance to diabetes care, and obstacles in the management of type 2 diabetes from the perspectives of patients and experts, are elucidated. Patient self-care and outcomes of care as a result of interventions on social support and provider-patient interaction have been researched by systematic reviews. In a final chapter, the perspectives of patients and professionals are framed in a dialectical interaction process. These findings are reflected upon, in an attempt to inspire new ways to enhance the effectivity of primary diabetes care for those who most need it.

And for that matter, we prudently suggest that our conclusions for diabetes care might be relevant to the care of persons with other chronic conditions as well.

\section{Belangrijkste bevindingen en conclusies uit de studies}

De studies in dit proefschrift onderzochten verschillende aspecten van de diabeteszorg in de huisartspraktijk. De samenhang tussen diabetesregulatie, door de patiënt ervaren regulatie en ondersteuning, functionele toestand en kwaliteit van leven, werden onderzocht. De verschijnselen van het wegblijven door patiënten van diabetescontroles, en belemmeringen in het omgaan met type 2 diabetes vanuit het perspectief van patiënten en deskundigen, worden toegelicht. Patiëntenzelfzorg en uitkomsten van zorg als resultanten van interventies in sociale steun en in de interactie tussen professional en patiënt werden onderzocht in systematische reviews. In een slothoofdstuk worden de perspectieven van patiënten en hulpverleners in het kader geplaatst van een dialectisch interactieproces. De bevindingen worden besproken en een poging wordt gedaan om inspiratie te bieden voor nieuwe manieren om de effectiviteit van de eerstelijns diabeteszorg te verbeteren, juist voor hen die dat het meest nodig hebben.

Voorzichtig stellen wij dat onze conclusies misschien ook geldigheid kunnen hebben voor de zorg voor mensen met andere chronische aandoeningen dan type 2 diabetes. 


\section{INTERACTION}

A key conclusion is that systematic activation and empowerment of patients towards greater participation, active question-asking, and influence in the dialectical process of interaction in diabetes encounters, may improve self-care and diabetes outcomes while helping providers of diabetes care to consult in a more patient-centred way surprisingly did not (chapter 6). Few (eight) controlled trials on this issue met the inclusion criteria we set. Five demonstrated improvements from patient activation by means of:

-systematic, brief, assistant-guided patient preparation of diabetes visits, -patient empowering education classes,

-joint group consultations to professional providers of diabetes care, -negotiating realistic and patient-tailored treatment targets, and -automated, telephone-based, empowering feedback of diabetes data and nurse advice.

\section{SOCIAL SUPPORT}

Another finding was that organizing better conditions for social support for patients might contribute to improved self-care and outcomes of care (chapter 5). Only six controlled trials met the inclusion criteria. Enhancing spouse support was found to be beneficial in women, but not in men. Four studies demonstrated positive effects from new forms of social support for patients:

-dedicated social support groups following a diabetes education course,

-joint group consultations to professional providers of diabetes care, and

-telephone, or internet-based, peer social support.

\section{METABOLIC CONTROL AND PATIENT OUTCOMES}

In our exploratory study (chapter 2) we did find relationships between glycemic diabetes control and functional status and quality of life of patients, although their causality was unclear. One of our conclusions was that the patient's perspective ('patient factors' such as functional status, quality of life, and perceived diabetes control and professional support) deserves more attention from the providers in diabetes encounters.

Recent studies found differing relationships between metabolic diabetes control and quality of life, or other subjective outcomes. Some show that improved diabetes control relates to fewer symptoms and better quality of life [1,2]. However, other studies find no (negative) effect of improved diabetes control on patients' quality of life [3-7]. Most of these studies describe multifactor interventions (including more professional attention devoted to diabetes care, professional adherence to protocols, recalls, diabetes education, dietary advice, and treatment with tablets and insulin). Often, both glycemic control and quality of life are outcome variables in the studies, besides body weight, blood pressure and blood lipids. This makes assessing the direct influence of diabetes control on quality of life ambiguous [8,9].

Our own findings of 1995 fit into the range of conclusions from those studies, varying from 'positive' to 'no' influence of diabetes control on subjective well being of patients. The applied thresholds for 'good', 'moderate' and 'poor' HbA1c-levels in our study (8 
and $10 \%$, respectively) were not unusual at that time. Since 1999 , new guidelines recommend lower thresholds ( 7 and $8.5 \%$, respectively) [10].

\section{NON-ATTENDANCE}

The studies in chapters 3 and 4 refer to the phenomenon of patient non-attendance in diabetes care.

- On the average, about one in twelve patients (nearly 8 per cent) did not show up to GP diabetes care for one year or longer.

- $\quad$-As a group these patients seemed to have a somewhat better general health and diabetes control, and fewer health problems preceding the drop-out period, as compared to patients showing better clinic attendance (chapter 4).

- Critical remarks made in letters to the editor of the journal that published our paper on the study addressed some methodological flaws. These have been dealt with by the authors' answers to these letters. For future studies on the issue of patient non-attendance, we do advocate a prospective, controlled study design with data sampling independent from care providers, and at similar times across study groups.

Recent studies that looked into non-attendance to diabetes care concluded that higher dropout rates were associated with a variety of characteristics of patients, doctors, and practices. Non-attendance related to either better [11] or poorer glycemic control (HbA1c-level) [12,13]. Some studies found it related to higher blood pressure [13], having no symptoms at diagnosis [14], being assigned to control condition (no extra intervention or information provided) [15-17], being younger, or being smoker [12]. According to Griffin, other factors that may predispose to nonattendance are certain patients' health beliefs and health professionals' attitudes, sub-optimal organization of the clinic, financial costs of attendance, and lower degree of patient participation within consultations [18].

These findings do not contradict the outcomes of our study. After all, ours was one of the first to address the complex phenomenon of patient non-attendance. Its tentative conclusion is still justified: in case of non-attendance while good quality diabetes care has been provided, panic on the side of the diabetes team is not necessary. As health behaviour (change) is the issue here, it must be respected that it is the patient who is in control. Ongoing motivational support that encourages good self-care and taking up professional diabetes care is useful, but in the end it is the patient who decides $[19,20]$. Such an approach respects the patient's perspective, reinforces patient autonomy, and increases the probability of good patient self-care and patientoriented outcomes of diabetes care in the long run [21,22]. This matter is more extensively dealt with in chapter 8.

\section{OBSTACLES}

The study in chapter 7 concluded that patients report a range of obstacles to good self-care and adherence to professional treatment - with emphasis on barriers in the provider-patient interaction, in the professionals' attitudes, behaviour and expertise, and in the patients' own lives. Experts (considered key persons) recognize and acknowledge most of these patient obstacles, ignore some of them, and add some that the patients did not mention. They recommend improvements of diabetes care through better professional adherence to guidelines, combined with applying patient- 
centred and patient empowerment methods. To our knowledge, this is the first study in which key persons (some of whom professional care providers) were confronted with the opinions and perceptions of patients. Replication is needed with involvement of more sub groups of patients (e.g. from cultural and ethnic minorities), a greater number of participants, and a wider variety of diabetes experts including providers.

A paper on comparison of the study's findings with those from parellel studies in six other European countries may soon be expected [23].

\section{PATIENT CENTREDNESS AND THE DIALECTICAL PROCESS}

Keeping the studies presented in this thesis in mind, one may assume that for better outcomes of diabetes care in general practice and outpatient clinics, providers could try harder to connect their own personal perspective to the patients'. Living with type 2 diabetes is a complex and difficult task [25,26]. A more effective dialogue between the two sides (the provider's and patient's), in a true dialectical process, is needed. This concept is described in an essay on patient-centredness and the dialectical process in diabetes care (chapter 8 ). The concept of dialectical interaction in diabetes encounters includes the Freirean steps of active listening, true dialogue, and joint action planning. Such a dialectical approach may help improve patient self-care and self-motivation, build patient empowerment, patient and provider satisfaction, patient perceived quality of life and functional status, and other patient-oriented outcomes of diabetes care [22-24]. These subjective, patient-oriented outcomes of care are considered to be as important as (objective) disease-oriented outcomes [24].

The dialectical approach transcends the concepts of patient participation, patient empowerment, risk communication, patient-centredness, negotiation, and motivational interviewing. It includes elements of these concepts, but binds them into something new. All have their merit for diabetes care. E.g. patient activating, empowering, and participating approaches can be more effective to improve lifestyle changes and patient-oriented outcomes, as contrasted to a more traditional approach that focuses on medical treatment and disease-oriented, intermediate outcome goals [26-37]. Effective risk communication methods may contribute to active patient involvement in decision-making and better outcomes [38,39]. The same goes for patient-centredness, being a special attitude of professionals towards patients $[40,41]$. Negotiated target levels of blood glucose, HbA1c, blood pressure, or weight loss, when endorsed by the patient, are often more successfully realized than rigidly kept guidelines-based targets, and contribute to better diabetes outcomes - even if they differ from the targets in official guidelines [21,22,31,35,37,42-44]. The evidence for the effectivity of patient-centred care is ambiguous $[41,48,49]$. Other research suggests that expressing affect and emotion during health care encounters - be it positive or negative - or some difference of opinion between provider and patient, relate to better health outcomes of care, as compared to complete concordance and harmony [27,31,50-52]. Perhaps, health encounters that carry some conflict and emotional involvement reflect a more active interpersonal engagement of patient and provider, a truer dialogue, and patient perception of stronger professional commitment, as compared to discussions missing this personal encounter. This line of thought is endorsed by evidence that active question asking by the patient relates more strongly to good outcomes, than shared decision making in itself [33,50-54]. Just being kind to patients is not sufficient to cope with all of the patients' and professionals' obstacles to good diabetes care. And finally, methods adapted from 
motivational interviewing proved to be effective for enhancing patient health behaviour changes in diabetes care as well [45-47].

Autonomy support from physicians improved several patient outcomes [56]. Also, a dialectical approach proved effective in improving communication and outcomes of care in general practice consultations with patients of different ethnic backgrounds [57].

One could question if it is necessary to apply the dialectical approach that is advocated in this thesis to encounters with all patients - even those who already seem to be 'empowered', take good care of themselves and their diabetes, take up active participation in diabetes encounters and diabetes self-care, and show good diabetes control and other positive outcomes? Or should the approach be dedicated to the less active patients with poor self-care and treatment uptake, high risk of complications, and poor outcomes? We do advocate a general, in-grained, flexible dialectical attitude of professionals towards all patients. In daily practice it will show that this will be easier in some patients than in others. The latter perhaps deserve more attention and effort from the diabetes team. A flexible attitude is wanted from providers of care to connect to each individual patient's goals, needs, view, knowledge, and stage of change, and to adapt to changes over time. When the professional succeeds in discussing the patient's perspective relative to his own perspective, an effective dialectical interaction may occur. Both application of evidence-based guidelines and sound diabetes care organization, and true providerpatient dialogue, will then contribute to improved outcomes.

\section{METHODOLOGICAL CONSIDERATIONS}

A strength of the studies presented in this thesis is that they did what they were designed to do: to elucidate and explore the patient perspective relative to the professional perspective, inspired by practice-based problems and research questions. The studies were practice oriented and their findings suggest different ways to improve daily diabetes care in GP in the $21^{\text {st }}$ century.

The studies presented in the chapters 2, 3, 4, and 7 helped generate hypotheses, studied some of the theoretical concepts in practice, and endorsed directions for further work. Still, the validity of their conclusions is limited because of their observational and exploratory design. Strictly posed: such studies cannot demonstrate or test causal relations. It is for that reason why we wish to be cautious in drawing too far-stretching conclusions from them. The systematic literature reviews as presented in the chapters 5 and 6, carry more evidence of cause-effect relationships $[54,55]$. Some of their interventions seem very promising, but their effectiveness still needs to be tested in primary diabetes care in the Netherlands.

A final remark to be made is that our suggestions for improving the patientprofessional dialogue in primary type 2 diabetes care could very well be applicable to the care for persons with other (chronic) medical conditions but type 2 diabetes mellitus as well. Research attention for this is needed. 


\section{IMPLICATIONS AND RECOMMENDATIONS:}

\section{FOR DIABETES TEAMS IN PRIMARY CARE}

- Consider activating and empowering patients e.g. by offering assisted preparations of diabetes visits, group consultations, empowering education courses, negotiation for realistic and personally-tailored treatment targets, and internet or telephone-supported feedback.

- Consider organizing new forms of social support, e.g. group consultations, or peer social support of patients in live support groups (e.g. following a regular diabetes education course), or telephone- or internet-based peer social support.

- Offer and deliver effective health risk communication, after the patient indicates that he judges this appropriate. Check if it works for the patient. Discuss treatment and self-care options and negotiate the best-suiting choice.

- Discuss favourable health behaviour changes with patients, apply brief motivational interviewing techniques, and offer sustained support.

- Discuss outcomes and goals of diabetes care for both objective, clinical issues and subjective, patient-oriented issues.

- In the case of non-attendance ('no-show') to diabetes care, study the patient record. If adequate diabetes care was delivered and control of diabetes, blood pressure, lipids, prevention of complications, lifestyle, and so on, have been good and stable so far, one or two recalls may suffice. Does the patient sustain in his non-attendance? Consider accepting this. In the case of poor or moderate control and very high risk level, try outreaching activities (home visits, telephone recalls, personal letters, approaching the social support network), and try to find out why the patient did not attend. Use any further health encounter with non-attending patients to discuss their opinion on diabetes care and taking it up again. Are there any adaptations to be made that might persuade the patient to take up professional diabetes care? Consider offering longer intervals than the standard three months between diabetes visits to patients who are 'well controlled' and who possibly prefer this (6-12 months).

- Strive for a dialectical interaction with the patient, especially in new type 2 diabetes patients and in diabetes patients with poor control, who prefer it. It includes active listening, true dialogue, and joint action planning. The provider would express acceptance of, and attention to the patient's personal goals and social network, and discuss the his own personal views and goals as well as the patient's.

\section{FOR RESEARCH}

Well-designed controlled trials in general practice diabetes care settings are wanted to study the effectiveness on outcomes of diabetes care from:

- a more dialectical interaction between patient and provider, with explicit exchange of patient's and professional's views and wants in a true dialogue, using brief motivational interviewing, and negotiating approaches.

- patient activation and empowerment to support active question asking and patient control of diabetes care.

- new forms of social support for diabetes patients, including peer support. 
- new ways to handle patient non-attendance, e.g. active and repeated outreaching, the use of brief motivational interviewing methods, and negotiation of longer intervals between diabetes visits for patients showing non-attendance who may prefer this.

\section{FOR PROFESSIONAL EDUCATION}

New and high demands are posed on diabetes care professionals. They are expected to deliver high quality, evidence-based diabetes care in an ever developing field of work, and new ways of interaction with patients as well: connecting to the patient perspective, developing and handling an effective dialectical interaction and dialogue, applying brief motivational interviewing and negotiation methods, and organizing patient empowerment, patient activation, patient motivation, patient participation in decision-making, and perhaps new forms of social support. A new set of professional skills is needed to deliver these tasks, including organizational skills for new functional task arrangements within diabetes care teams. Professional education and training must adapt to this perspective. Schools, educational courses, and training classes of diabetes care professionals and semi-professional patient representatives, cannot but focus their curricula on this set of skills.

It is suggested that authorities, professionals, health and diabetes organizations, and health insurance companies, cooperate to finance these adaptations of education. 


\section{REFERENCES}

1.Does FJ, de Neeling JN, Snoek FJ, Kostense PJ, Grootenhuis PA, et al. Symptoms and well-being in relation to glycemic control in type II diabetes. Diabetes Care 1996;19:204-10.

2.Goudswaard AN, Stolk RP, de Valk HW, Rutten GEHM. Improving glycaemic control in patients with type 2 diabetes mellitus without insuling therapy. Diabet Med 2003;20:540-4.

3.Weinberger M, Kirkman MS, Samsa GP, Lowper PA, Shortliffe EA, et al. The relationship between glycemic control and health-related quality of life in patients with non-insulin dependent diabetes mellitus. Med Care 1994;32:1173-81.

4.de Sonnaville JJ, Snoek FJ, Colly LP, Deville W, Wijkel D, Heine RJ. Well-being and symptoms in relation to insulin therapy in type 2 diabetes. Diabetes Care 1998;21:919-24.

5.UK Prospective Diabetes Study Group (UKPDS 37). Quality of life in type 2 diabetic patients is affected by complications but not by intensive policies to improve blood glucose or blood pressure control. Diabetes Care 1999;22:1125-36.

6.Goddijn PP, Bilo HJ, Feskens EJ, Groeniert KH, van der Zee KI, Meyboom-de Jong B. Longitudinal study on glycemic control and quality of life in patients with Type 2 diabetes mellitus referred for intensified control. Diabet Med 1999;16:23-30.

7.De Grauw WJC, van de Lisdonk EH, van Gerwen W, van den Hoogen HJM, van Weel C. Insulin therapy in poorly controlled type 2 diabetic patients: does it affect quality of life? Br J Gen Pract 2001

8.Testa MA, Simonson DC. Health economic benefits and quality of life during improved glycemic control in patients with type 2 diabetes mellitus: a randomized, controlled, double-blind trial. JAMA 1998;280:1490-6.

9.Lemon CC, Lacey K, Lohse B, Hubacher DO, Klawitter B, Palta M. Outcomes monitoring of health, behavior, and quality of life after nutrition intervention in adults with type 2 diabetes. J Am Diet Assoc 2004;104:1805-15.

10.Rutten GEHM, Verhoeven S, Heine RJ, De Grauw WJC, Cromme PVM, et al. NHG-Standaard Diabetes Mellitus Type 2. Huisarts Wet 1999;42:67-84. Dutch Association of General Practitioners Guidelines for type 2 diabetes mellitus). (in Dutch).

11.Litwak LE, Mileo Vaglio R, Alvarez A, Gutman RA. Self monitoring of capillary blood glucose. Evaluation of long-term results (3-7 years). Medicina (B Aires) 1999;59:71-8.

12.Dy er PH, Lloyd CE, Lancashire RJ, Bain SC, Barnett AH. Factors associated with clinic nonattendance in adults with type 1 diabetes mellitus. Diabet Med 1998;15:339-43.

13.Benoit SR, Ji M, Fleming R, Philis-Tsimikas A. Predictors of dropouts from a San Diego diabetes program: a case control study. Prev Chron Dis 2004;1:A10.

14.Simmons D, Fleming C. Prevalence and characteristics of diabetic patients with no ongoing care in South Auckland. Diabetes Care 2000;23:1791-3.

15.New JP, Hollis S, Campbell F, McDowell D, Burns E, et al. Measuring clinical performance and outcomes from diabetes information systems: an observational study. Diabetol 2000;43:836-43.

16.Soma J, Sugawara T, Huang YD, Nakajima J, Kawamura M. Tranilast slows the progression of advanced diabetic nephropathy. Nephron 2002;92:693-8.

17.Domenech MI, Assad D, Mazzei ME, Kronsbein P, Gagliardino JJ. Evaluation of the effectiveness of an ambulatory teaching/treatment programme for non-insulin dependent (type 2) diabetic patients. Acta Diab 1995;32:143-7.

18.Griffin SJ. Lost to follow-up: the problem of defaulters from diabetes clinics. Diabet Med 1998;15 Suppl 3:S14-24.

19.Rollnick S, Mason P, Butler C. Health Behavior Change - a guide for practitioners. Edinburgh, London, New York, Oxford, Philadelphia, St Louis, Sydney, Toronto: Churchill Livingstone 1999-2004.

20.Schneider CE. The practice of autonomy: patients, doctors, and medical decisions. New York: Oxford University Press 1998.

21.Shaughnessy AF, Slawson DC. Blowing the wistle on review articles. What should we know about the treatment of type 2 diabetes? Editorial. Br Med J 2004;328:280-2.

22. Wolpert HA, Anderson BJ. Management of diabetes. Are doctors framing the benefits from the wrong perspective? Br Med J 2002;323:994-6.

23.Vermeire E, Hearnshaw H, Rätsep A, Levasseur G, Petek D, van Dam H, van der Horst F, VinterRepalust N, Wens J. Obstacles to adherence in living with type 2 diabetes. An international study using qualitative meta-analysis (submitted 2005).

24.Sullivan M. The new subjective medicine: taking the patient's point of view on health care and health. Soc Sci Med 2003;1595-1604.

25. Holt TA. A chaotic model for tight diabetes control. Diabet Med 2002;19:274-8. 
26.Department of Health. The expert patient: a new approach to chronic disease management for the $21^{\text {st }}$ century. In Department of Health (Ed.). London: DoH 2001.

27.Greenfield S, Kaplan SH, Ware JE, Yano EM, Frank HJL. Patients' participation in medical care: effects on blood sugar control and quality of life in diabetics. J Gen Intern Med 1988;3:446-57.

28.Greenfield S, Kaplan SH, Ware JE. Expanding patient involvement in care: Effects on patient outcomes. Ann Int Med 1985;102:520-8.

29.Anderson RM, Funnell MM, Butler PM, Arnold MS, Fitzgerald JT, Fesle CC. Patient empowerment: results of a randomized controlled trial. Diabetes Care 1995;18:943-9.

30.Trento M, Passera P, Tomalino M, Bajardi M, Pomero F, Allione A, et al. Group visits improve metabolic control in type 2 diabetes: a 2-year follow-up. Diabetes Care 2001;995-1000.

31.De Fine Olivarius N, Beck-Nielsen H, Andreasen AH, Hørder M, Pederson PA. Randomized controlled trial of structured personal care of type 2 diabetes mellitus. Br Med J 2001;323:970-5.

32.Piette JD, Weinberger M, McPhee SJ. The effect of automated calls with telephone nurse follow-up on patient-centred outcomes of diabetes care: a randomised controlled trial. Med Care 2000;38:21830 .

33.Rost KM, Flavin KS, Cole K, McGill JB. Change in metabolic control and functional status after hospitalization. Impact of Patient Activation Intervention in Diabetes Patients. Diabetes Care 1991;14:881-9.

34.Michie S, Miles J, Weiman J. Patient-centredness in chronic illness: what is it and does it matter? Patient Educ Couns 2003;51:197-206.

35.Armstrong D. What do patients want? Br Med J 1991;303:261-2.

36.Edwards A, Elwyn GJ, Wood F, Atwell C, Prior L, et al. Shared decision-making and risk communication in practice - A qualitative study of GPs' experiences. Br J Gen Pract 2005;55:6-13.

37.Botelho R. A negotiation model for the doctor-patient relationship. Fam Pract 1992;9:210-8.

38.Edwards A, Unigwe S, Elwyn GJ, Hood K. Effects of communicating individual risks in screening programmes: Cochrane systematic review. Br Med J 2003;327:703-10.

39.Paling J. Strategies to help patients understand risks. Br Med J 2003;327:745-8.

40.Freeman G, Car J, Hill A. The Journey towards Patient-centredness. Editorial. Br J Gen Pract 2004;54:651-2.

41.Mead N, Bower P. Patient-centredness: a conceptual framework and review of the empirical literature. Soc Sci Med 2000;51:1087-1110.

42. Elwyn GJ, Edwards A, Kinnersley P. Shared decision-making in primary care: the neglected second half of the consultation. Br J Gen Pract 1999;49:477-82.

43.Say RE, Thomson R.The importance of patient preferences in treatment decisions - challenges for doctors. Clinical Review. Br Med J 2003;327:542-5 [Free Full Text].

44.Stewart M, Brown JB, Donner A, McWhinney IR, Oates J, Weston WW. The impact of patientcentred care on patient outcomes in family practice. London, Ontario: Centre for Studies in Family Medicine (Final Report) 1995.

45.Burke BL, Arkowitz H, Menchola M. The efficacy of motivational interviewing: a meta-analysis of controlled clinical trials. J Consult Clin Psychol 2003;71:843-61.

46.Rubak S, Sandbaeck A, Lauritzen T, Christensen B. Motivational interviewing: a systematic review and meta-analysis. Brit J Gen Pract 2005;55:305-12.

47.Doherty Y, Roberts S. Motivational interviewing in diabetes practice. Diabet Med 2002;19 Suppl 3:S1-6.

48.Kinmonth AL, Woodcock AJ, Griffin S, Spiegel N, Campbell MJ. RCT of patient-centred care of diabetes in general practice: impact on current well-being and future disease risk. The Diabetes Care from Diagnosis Research Team. Br Med J 1998;317:1202-8.

49.Pill R, Stott NC, Rollnick SR, Rees M. A randomized controlled trial of an intervention designed to improve the care given in GP to type II diabetic patients: patient outcomes and professional ability to change behaviour. Fam Pract 1998;15:229-35.

50.Bensing J. Doctor-patient communication and the quality of care. An observation study into affective and instrumental behavior in general practice. Thesis. Rotterdam: Erasmus Universiteit Rotterdam 1991.

51. Hall JA, Roter DL, Rand CS. Communication of affect between patient and physician. J Health So Behav 1981;22:18-30.

52.Roter DL. Patient participation in the patient-provider interaction: the effects of patient question asking on the quality of interaction. Ann Intern Med 1977;5:281-315.

53.Michie S, Miles J, Weiman J. Patient-centredness in chronic illness: what is it and does it matter? Patient Educ Couns 2003;51:197-206. 
54.Van Dam HA, Van der Horst FG, Van den Borne HW, Ryckman R, Crebolder HFJM. Providerpatient interaction in diabetes care: effects on patient self-care and outcomes. A systematic review. Pat Educ Couns 2003;51:17-28. Chapter 7 in this thesis.

55.Montori VM. Review: interventions focusing on patient behaviours in provider-patient interactions improve diabetes outcomes. J EBM 2004;9:60.

56.Williams GC, McGregor HA, King D, Nelson CC, Glasgow RE. Variation in perceived competence, glycemic control, and patient satisfaction: relationship to autonomy support from physicians. Patient Educ Couns 2005;57:39-45.

57. Harmsen $\mathrm{H}$, Bernsen R, Meeuwesen $\mathrm{L}$, et al. The effect of educational intervention on intercultural communication: results of a randomised controlled trial. Br J Gen Pract 2005;55:343-50. 


\section{Chapter 10}

SUMMARY

(SAMENVATTING) 


\section{Chapter 10}

SUMMARY

The purpose of this thesis is to investigate some issues on type 2 diabetes care in general practice, related to the perspectives of patients and providers, and the dialectical process and dialogue between the two.

In chapter 1 a general introduction is given to the scope and impact of the condition on a person's life, family, and other parts of his personal environment. Type 2 diabetes as a chronic condition and its growing epidemic has an increasing impact on societies as well. Care, not cure, is the central focus.

Although the quality of professional type 2 diabetes care has vastly improved, two out of every three patients show poor self-care, lifestyle, and treatment adherence, and one out of every three shows poor control of hyperglycemia, blood pressure, and/or blood lipids. This group is exposed to high risks, and actually suffers from avoidable complications and morbidity - despite the efforts of GPs and other professionals to deliver good diabetes care and to protect patients from those risks.

This observation resulted in studies of 'doctor' and 'patient' related aspects of type 2 diabetes care, of non-attendance, of social support and the provider-patient communication, and of obstacles with regard to (self-) care and professional support. Subsequently, the idea of a dialectical process in diabetes encounters is presented, a dialogue in which patient and provider have their respective inputs - sometimes in concordance, often differing or even opposite - and try to reach new, shared arrangements.

Chapter 2 describes an explorative study on the interrelations of diabetes control, complications, comorbidity on one hand (reported by the GP: from the professional perspective), and functional status and quality of life, perceived diabetes control and professional support on the other (patient-reported: from the patient perspective). Almost half the study patients' group had poor 'objective' diabetes control, while a much greater part reported good 'subjective' control. Logistic regression analyses demonstrated the patient-oriented elements 'perceived diabetes control' and 'perceived professional support' (from GPs) to most strongly contribute to good 'objective' diabetes control. More attention of providers to elements of the patient perspective is warranted.

In chapters 3 and 4 , the balance between the patients' and providers' responsibilities with regard to diabetes clinic attendance is discussed. Two studies of non-attendance are presented. A literature review shows that up to that time the phenomenon had hardly been studied in type 2 diabetes (chapter 3 ). The consulted diabetes experts give estimates of non-attendance rates of about 5 per cent of all GP-treated patients. In an observational study (chapter 4 ) in 38 Dutch GP practices, a mean of 8 (range 030) per cent of 960 patients showed non-attendance to GP diabetes clinics for a year or longer. Non-attendance was not related to worse diabetes control or more diabetes complications (even the contrary). The tentative conclusion is drawn that, if diabetes teams delivered good diabetes care, and recalled non-attending patients 
once or twice - tehy may then accept sustained non-attendance. This acknowledges the patient's responsibility and autonomy. Non-attendance apparently is a deliberate decision by the patient, and fits into the patient's world. Other, later studies support this view. It is advised that in later health encounters with non-attending patients the professionals could engage in discussions to find out why the patient decided not to visit the diabetes clinic, and to discuss how to support adequate self-care and attendance.

The study was criticised for methodological shortcomings, and with some cogency. But the paper's conclusions with regard to accepting non-attendance and respecting the patients' autonomy after some recalls, still stand.

Chapter 5 describes a sytematic literature review of controlled trials of social support interventions in type 2 diabetes care, published in more than twenty years. Only six studies were retrieved. Traditional forms of social support (from spouse, relatives, or friends) show little or no positive influence. In men, spouse support seems to have negative effects, while in women it may have some positive effects (weight loss). Newer forms of social support had clearer positive effects: live social support groups, group consultations to doctors, and telephone or internet-based peer support. Perhaps, these forms of support reinforce the patients' active participation in diabetes care.

Chapter 6 presents a systematic literature review of controlled trials of patientprovider interaction interventions in diabetes care encounters, published in more than twenty years. Only eight studies were retrieved. The review showed that interventions focusing directly on systematic patient activation, to enhance active participation in diabetes encounters (approach from the patient's perspective), did improve outcomes. Interventions focusing on providers to change their consulting behaviour into a more patient-centred one (approach from the professional's perspective) did not, or perhaps even worsened the situation. Clear improvements resulted from systematic, brief, assisted patient preparation to diabetes consultations, empowering diabetes education groups, empowering telephone or computer based individual feedback and support, group consultations to doctors, and negotiating realistic, personally-tailored treatment targets. These forms of patient activation reinforce active patient involvement and question asking in diabetes care.

Chapter 7 focuses on obstacles experienced by type 2 diabetes patients and the views of Dutch diabetes experts on these obstacles. A diversity of obstacles and restrictions in living with type 2 diabetes and with the professional diabetes care advises are reported, as seen from the patient's perspective. The experts recognise most of those patient obstacles, but deny some that patients connected to attitudes and communication behaviour of professionals, and add some new obstacles. Their recommendations for improvements strongly embrace the ideas of better professional adherence to guidelines, better monitoring and quality assessment of diabetes care, better structural patient education for self-care, as well as patient empowerment and patient-centred models of care. They stress that the patient perspective deserves more attention.

Chapter 8 is a paper reflecting on the changing roles of patients and providers in diabetes care: from a once doctor-centred into a now more negotiation and patientcentred model. Providers and patients may disagree on the best course of action and 
management of diabetes, as well as on the outcomes. In (primary) diabetes care, utilizing a dialectical approach would be useful in enhancing a true dialogue between the two perspectives: a co-centred model. This dialogue would facilitate active patient involvement and question asking in diabetes encounters, patient empowerment to make shared decisions, patient self-care, and professional satisfaction with care. Both 'objective' clinical outcomes of diabetes care such as intermediate outcomes $\mathrm{HbA1c}$, blood pressure - and 'hard' end points like complications or mortality rates (provider-centred), and 'subjective' outcomes such as patient perceived quality of life, functional status, or making personal choices and achieving personal goals (patientcentred), would then be valued as equally important outcome criteria for the quality of care. The practice implications of this approaches are briefly discussed.

Chapter 9 offers the general discussion of the thesis. It summarizes the main findings from the studies with regard to provider-patient interaction, social support, metabolic control and patient-centred outcomes, non-attendance, and obstacles. It stresses the importance of finding a true dialogue between the patient's and the professional's perspective. A patient-activating approach for helping the patient to become an active, asserted partner in his or her own diabetes care, is advocated. Both the views and goals of the patient and of the professional deserve a place in the encounter, and after a phase of mutual information exchange and one of dialogue, an attempt for joint action (treatment, self-care, health behaviour change) could be made. Methods from the brief Motivational Interviewing and Patient-centred models are at the professionals' disposal. Professional diabetes care providers are challenged to study and share these views, and to start working with them

Implications and recommendations for diabetes teams' practical work, research, and education are discussed.

\section{Practice implications}

For reinforcing the patient perspective and patient empowerment in diabetes care, certain changes in the work of diabetes teams are recommended. The diagnostic and therapeutic process of diabetes encounters, both in objective and subjective terms, must tap into the daily life experiences of patients with the illness. In that way it may help patients to make choices which are recognisable to them, and reinforce their sense of personal responsibility for the management of their illness. This helps increase patient control and empowerment. One of the warranted methods for attaining this goal is to organize systematic, brief patient preparation of diabetes encounters, supported by trained and experienced diabetes patients as lay counsellors (or professional assistants/nurses), to enable patients to become more assertive, actively ask questions and get answers, and to bring in their frame of reference including emotions, cognitions, and responsibilities. Group consultations to diabetes professionals, and empowering group training of patients, may also be of help. Another method for patient empowerment may be to organize new forms of mutual social support ('live', internet or telephone social support groups). Inside diabetes encounters, professionals should apply a motivational and patient-centred approach to guide the dialectical process. Through a motivational approach, the professional encourages the patient to find and produce arguments for health behaviour change and ways to achieve it. Patient-centredness focuses on what is important for the patient, 
including his social context. In a dialectical, Freirean approach, the professional applies reflective listening, dialogue, and action, to guide the communication into a true dialogue. Both the professional and the patient should have their input of personal goals, visions, and expectations, in a mutual information exchange. Systematic negotiation of personally suiting, realistic treatment targets and methods (e.g. weight reduction, $\mathrm{HbA} 1 \mathrm{c}$, blood pressure, medication, or self-care) could support patients to regain the sense of control over their lives and to better utilize the professional treatment. After a discussion of concordances and differences, and a negotiation phase, joint agreements and actions are aimed for.

\section{Research}

Well-designed controlled trials and qualitative studies in primary diabetes care settings are recommended to research the effectivity of different ways to handle non-attendance, of different social support interventions, of patientactivating and empowering interventions, risk communication, and systematic negotiation of diabetes care management. Studies of guiding the dialectical process towards a true dialogue in diabetes (and perhaps other conditions) care encounters in primary care settings are also recommended.

\section{Education and training}

Education of professionals will increasingly have to cover the learning of skills to perform motivational conversation methods, patient activation and empowerment, patient-centredness, guiding the dialectical process of dialogue in diabetes encounters, and investigation and discussion of both the provider's and the patient's personal goals, views, knowledge, and expectations regarding diabetes care. To achieve these ends, a major part of this training would involve an active examination of the provider's own personality i.e., his/her values, attitudes, and beliefs as they impact the patient's willingness to accept help and direction from him/her. This examination could have different forms, e.g. attending courses or workshops, or interviewing professionals and patients. This training would aim at enabling professionals to create a therapeutic atmosphere within consultations and educational encounters, characterized by mutual openness and trust. It also aims at teaching professionals to guide an ongoing, dialectical decision making process in which provider and patient jointly agree on the reason for the encounter, the diagnosis, and the therapeutic or self-care sequela. Finally, training aims at helping providers anticipate the consequences of diagnostic findings, therapeutic recommendations, and decisions for the patient's daily life. 


\section{SAMENVATTING}




\section{SAMENVATTING}

Het doel van dit proefschrift is het onderzoeken van aspecten van type 2 diabeteszorg in de huisartspraktijk, met betrekking tot de dialoog en het dialectisch proces tussen de perspectieven van patiënten en hulpverleners.

Hoofdstuk 1 geeft een algemene inleiding over de gevolgen van het hebben van type 2 diabetes op iemands dagelijks leven, zijn familie, en andere onderdelen van de persoonlijke omgeving. Type 2 diabetes als chronische aandoening en zijn aanzwellende epidemie hebben ook een steeds grotere invloed op de maatschappij als geheel. 'Zorg' en niet 'genezing' staat centraal.

De kwaliteit van de professionele type 2 diabeteszorg is sterk verbeterd. Toch vertoont gemiddeld tweederde van de groep patiënten met type 2 diabetes slechte zelfzorg, ongunstige leefstijl en ongunstige therapietrouw, en ongeveer eenderde slechte diabetesregulatie, te hoge bloeddruk en/of ongunstig lipidenprofiel. Deze patiënten staan bloot aan hoge risico's, en gaan ook feitelijk gebukt onder vermijdbare complicaties en sterfte - ondanks de inspanningen van huisartsen en andere diabeteshulpverleners om goede zorg te leveren en hen te behoeden voor die complicaties.

Evidence-based richtlijnen ontstonden - die echter maar ten dele lijken te worden nageleefd. De rol van de patiënt onderging belangrijke veranderingen en vanuit vele gezichtspunten werd en wordt gezocht naar methoden om de balans tussen de perspectieven van patiënt en hulpverlener te (her)vinden.

Deze observaties leidden tot de studies. $\mathrm{Na}$ een eerste exploratief onderzoek van 'dokter'- en 'patiënt-gerichte' aspecten van diabeteszorg, volgden studies van het wegblijven van diabeteszorg door patiënten, van sociale steun, en van de interactie tussen hulpverlener en patiënt, evenals een studie van de belemmeringen voor goede diabetes(zelf)zorg gezien vanuit de perspectieven van patiënten en experts. Vervolgens wordt het idee gepresenteerd van een dialectisch proces in diabetescontacten, een oprechte dialoog waarin patiënt en hulpverlener elk hun eigen inbreng hebben - soms harmoniërend, vaak verschillend of zelfs botsend - en samen tot nieuwe, gezamenlijke regelingen moeten zien te komen.

Hoofdstuk 2 beschrijft een exploratieve studie naar de relatie tussen diabetesregulatie, complicaties en comorbiditeit enerzijds (gerapporteerd door de huisarts: 'dokter'gericht'), en functionele toestand en ervaren kwaliteit van leven, ervaren diabetesregulatie en professionele steun anderzijds (door de patiënten gerapporteerd: 'patiënt-gericht'). Bijna de helft van de studiepopulatie had een slechte objectieve diabetesregulatie terwijl bijna tweederde de regulatie subjectief als goed bestempelde. Logistische regressie-analyses toonden dat de patiëntgerichte elementen 'ervaren diabetesregulatie' en 'ervaren professionele steun' (van de huisarts) het sterkst bijdroegen aan goede objectieve diabetesregulatie. Meer aandacht van de hulpverleners voor elementen uit het patiëntperspectief wordt aangeraden.

Hoofdstukken 3 en 4 richten zich op de afbakening van verantwoordelijkheid tussen professionele hulpverleners (artsen, verpleegkundigen) en patiënten ten aanzien van de terugkomtrouw. Een tweetal studies naar het wegblijven wordt gepresenteerd. Een literatuuroverzicht (hoofdstuk 3) laat zien dat tot dan toe het fenomeen van 
wegblijven in huisartspraktijken niet of nauwelijks onderzocht was. De geraadpleegde experts geven schattingen van wegblijven door gemiddeld $5 \%$ van het aantal behandelde patiënten. In het observationeel onderzoek in 38 Nederlandse huisartspraktijken (hoofdstuk 4) blijkt gemiddeld 8\% (spreiding 0-30\% per praktijk) van de 964 patiënten een jaar of langer weg te blijven van diabetescontroles. Wegblijven bleek in deze studie niet gerelateerd aan slechtere diabetesregulatie of meer complicaties, misschien juist integendeel. De voorzichtige conclusie wordt getrokken dat wanneer diabetesteams goede diabeteszorg leverden en wegblijvende patiënten enkele malen actief hebben opgeroepen, zij wegblijven daarna wellicht kunnen accepteren. Verantwoordelijkheid en autonomie van de patiënt worden dan voldoende gerespecteerd. Het lijkt een bewuste keuze van de patiënt en past in de wereld van de patiënt. Andere, latere studies ondersteunen dit. Geadviseerd wordt dat in latere contacten met wegblijvende patiënten de professional het onderwerp aansnijdt om te horen waarom de patiënt besloot geen gebruik meer te maken van de professionele diabeteszorg, en hoe hij of zij gesteund kan worden voor goede zelfzorg en terugkomtrouw.

De studie werd met enig recht gekritiseerd op methodologische tekortkomingen, maar de conclusies ten aanzien van het accepteren van wegblijven en respecteren van het patiëntenperspectief staan nog overeind.

Hoofdstuk 5 beschrijft het resultaat van een systematisch literatuuronderzoek van gecontroleerde trials van sociale steuninterventies in de zorg voor mensen met type 2 diabetes, gepubliceerd in een periode van meer dan twintig jaar. Slechts zes van zulke trials worden gevonden. Traditionele vormen van sociale steun lijken weinig of geen positieve effecten te hebben. Bij mannen lijkt steun van de partner eerder negatieve effecten te hebben; bij vrouwelijke patiënten positieve (op gewichtsreductie). Nieuwe vormen van steun toonden positievere effecten (sociale steungroepen, gezamenlijke consulten, onderlinge internet- of telefoonsteun). Zulke nieuwe steunvormen versterken misschien de actieve rol van de patiënt in zijn diabeteszorg.

Hoofdstuk 6 presenteert een systematisch literatuuronderzoek van gecontroleerde trials van interventies in de interactie tussen hulpverlener en patiënt in diabetescontacten, eveneens gepubliceerd in meer dan twintig jaar. Slechts acht van zulke trials werden gevonden. Review van die studies toont dat interventies die zich richten op de professionals om hun consultgedrag meer 'patiëntgericht' te maken (benadering vanuit het professioneel perspectief) geen positieve invloed hebben op patiëntenzelfzorg en andere uitkomsten van diabeteszorg - maar dat systematisch activeren van patiënten om hun deelname aan diabetesconsulten te vergroten (benadering vanuit het patiëntperspectief) wel positief effect heeft. Duidelijke verbeteringen werden gevonden in de studies die interventies toepasten als: systematische, korte, ondersteunde voorbereiding van patiënten op diabetesconsulten, empowerende groepseducatie, empowerende individuele telefoon- en computerterugkoppeling met ondersteuning, groepsconsulten, en onderhandelen over haalbare, op maat gesneden individuele behandeldoelen. Waarschijnlijk versterken dergelijke patiënt-activerende methoden de actieve betrokkenheid van patiënten in hun diabeteszorg.

Hoofdstuk 7 richt zich op de door patiënten met type 2 diabetes ervaren belemmeringen en onderzoekt de visie van diabetesexperts op die belemmeringen. 
Patiënten rapporteerden diverse obstakels en beperkingen in het leven met type 2 diabetes en in het omgaan met de aanbevelingen vanuit de professionele diabeteszorg (patiëntenperspectief). Experts erkenden de meeste patiëntenbelemmeringen wel, maar ontkenden enkele die patiënten juist toeschreven aan het professioneel en communicatief functioneren van hulpverleners, en ze voegden eigen belemmeringen toe. Hun aanbevelingen gaan in hoge mate in de richting van beter volgen en uitvoeren van richtlijnen, betere toetsing en kwaliteitsbewaking (effect-/resultaatmeting) en betere, structurele patiënteneducatie, maar ook in de richting van integrale, patient-empowerende en patient-centred modellen van diabeteszorg. Zij vinden dat het perspectief van de patiënt meer aandacht verdient.

Hoofdstuk 8 is een artikel dat reflecteert op de veranderende rollen van patiënten en hulpverleners in de eerstelijns diabeteszorg, van vroeger een 'arts-gericht' naar nu een meer onderhandelings- en patiëntgericht model. Hulpverleners en patiënten zullen het vaak oneens zijn over de beste aanpak en aansturing van diabeteszorg, evenals over de interpretatie van de uitkomsten. Het toepassen van een dialectische benadering in de eerstelijnsdiabeteszorg zou een oprechte dialoog tussen die twee perspectieven kunnen bevorderen (een 'co-centred model'). Dat zou op zijn beurt de actieve betrokkenheid van de patiënt en het actief vragen stellen in diabetesconsulten, de macht van patiënt om zelf mee te beslissen, de zelfzorg, en de professionele tevredenheid over de zorg, kunnen versterken.

'Objectieve' klinische uitkomsten van diabeteszorg zoals getalsmatige zaken HbA1c, bloeddruk, en complicaties- en mortaliteitscijfers - (hulpverlener-gericht), en 'subjectieve' uitkomsten zoals kwaliteit van leven, functionele toestand of het maken van persoonlijke keuzen en bereiken van eigen doelen (patiënt-gericht), zouden dan als even belangrijke criteria voor de kwaliteit van zorg gebruikt kunnen worden.

Hoofdstuk 9 geeft de algemene discussie van dit proefschrift en presenteert de belangrijkste conclusies van de studies. Het benadrukt het belang van het streven om een echte dialoog tussen het perspectief van de patiënt en dat van de professional tot stand te brengen. Een patiëntgerichte aanpak - met als doel de patiënt te helpen een actieve, assertieve partner in de eigen diabeteszorg te worden - wordt aanbevolen. Zowel de visie en doeleinden van de patiënt als die van de professional dienen aan de orde te komen, en na een fase van informatieuitwisseling en dialoog daarover kan een volgende fase leiden tot pogingen om gezamenlijke actie te formuleren (behandeling, zelfzorg en leefstijlverandering). Methoden afkomstig uit de concepten van beknopte Motiverende Gespreksvoering en Patient Empowerment staan de professionels ter beschikking. Het hoofdstuk eindigt met de uitdaging aan professionele diabeteshulpverleners om deze visie te bestuderen en te delen, en hun inspanningen te vergroten om ermee te werken. De mogelijke implicaties voor de dagelijkse praktijk van de diabeteszorg, voor verder onderzoek, en voor de opleidingen van professionals worden genoemd.

\section{Implicaties voor de praktijk}

Voor het versterken van het patiëntperspectief en de macht (invloed) van de patiënten in hun diabeteszorg worden bepaalde veranderingen in het werk van diabetesteams aanbevolen. Het diagnostisch en therapeutisch proces in diabetesconsulten moet zowel in objectieve als in subjectieve termen aansluiten bij de dagelijkse levenservaringen van de patiënt met de ziekte. Op die manier kan het de patiënt helpen om keuzes te maken die voor hem of 
haar herkenbaar zijn en het gevoel van persoonlijke verantwoordelijkheid voor het hanteren van de aandoening versterken. Dit vergroot invloed en empowerment van de patiënt.

Een van de aanbevolen methoden om dit doel te bereiken is het organiseren van systematische, korte voorbereiding van patiënten op hun diabetesconsulten. Getrainde en ervaren medepatiënten zouden daarbij als leken-begeleiders een rol kunnen spelen - of eventueel professionele assistenten of verpleegkundigen - om de patiënten in staat te stellen assertiever te zijn, actief vragen te stellen en antwoorden te krijgen, en om hun referentiekader in te brengen (waaronder hun doelen, gevoelens, ideeën en verantwoordelijkheden). Groepsconsulten bij diabetesprofessionals, en empowerende patiëntengroepstrainingen, zouden ook overwogen kunnen worden. Een andere methode voor patient empowerment kan het organiseren van nieuwe vormen van sociale steun zijn ('live', telefoon- of internetsteungroepen). Binnen diabetescontacten zouden professionals het best een motiverende en patiëntgerichte aanpak kunnen toepassen om het dialectisch proces te leiden. Door een motiverende benadering moedigt de professional de patiënt aan om zelf argumenten voor eventuele verandering van zijn gezondheidsgedrag te zoeken en te noemen, en manieren om dit te realiseren. Patiëntgerichtheid richt zich op dat wat belangrijk is voor de patiënt, inclusief diens sociale contekst. In een dialectische, Freireaanse aanpak past de professional de methode van achtief luisteren, dialoog en gezamenlijke actie toe, om de communicatie richting oprechte dialoog te voeren. Zowel professional als patiënt moeten hun inbreng kunnen hebben van persoonlijke doelen, visies en verwachtingen, in een wederkerige uitwisseling van informatie. Het systematisch onderhandelen over bij de persoon passende, realistische behandeldoelen en methoden (zoals gewichtsreductie, HbA1c, bloeddruk, medicatie of zelfzorg) zou patiënten kunnen helpen om hun gevoel van controle over hun leven terug te winnen en beter gebruik te maken van de professionele behandeling.

\section{Verder onderzoek}

Goed opgezette gecontroleerde trials in de eerstelijns diabeteszorg worden aanbevolen om de effecten te bestuderen van verschillende manieren om met wegblijvende patiënten om te gaan, van sociale steuninterventies, van patiëntactiverende, motiverende en empowerende interventies, en van systematisch onderhandelen over op de persoon toegesneden behandeldoelen. Ook wordt interventieonderzoek aanbevolen van het bewust leiden van het dialectisch proces om in de zorg voor mensen met diabetes of andere (chronische) aandoeningen in de eerstelijnszorg een echte dialoog tot stand te brengen.

\section{Opleiding en training}

De opleidingen van professionals zullen in toenemende mate vaardigheden moeten aanleren om motiverende gespreksmethoden toe te kunnen passen, alsmede patiëntenactivering en empowerment, patiëntgerichtheid, het leiden van het dialectisch proces van de dialoog in diabetescontacten, en het onderzoeken en bespreken van de persoonlijke doelen, visie, kennis en verwachtingen van zowel de hulpverlener als de patiënt met betrekking tot de diabeteszorg. Om deze doelen te bereiken kan in de opleiding een actieve kennismaking met het perspectief van hulpverleners (studenten) en patiënten 
belangrijk zijn, bijvoorbeeld van de eigen waarden, houdingen en opvattingen, omdat die grote invloed hebben op de bereidheid van patiënten om in de interactie de hulp en aanwijzingen van de professional te aanvaarden. Die kennismaking zou kunnen gebeuren in de vorm van cursussen, werkgroepen of interviews met hulpverleners en met patiënten. Zo'n training is erop gericht de professionals in staat te stellen om binnen consulten en educatiebijeenkomsten een therapeutische sfeer te creëren die openheid en vertrouwen biedt. Ze is er ook op gericht de professionals te leren hoe zij het continue, dialectische besluitvormingsproces kunnen leiden - op zo'n manier dat hulpverlener en patiënt het samen eens worden over, of tenminste de wederzijdse visies erkennen op de reden voor het consult, de diagnose of het probleem, en de therapeutische en zelfzorgconsequenties. Tenslotte richt de training zich erop de professionals te helpen beter voorbereid te zijn op de gevolgen van bepaalde diagnostische bevindingen, therapeutische adviezen, en beslissingen voor het dagelijks leven van de patiënt. 
DANKWOORD EN CURRICULUM VITAE 


\section{DANKWOORD}

Ik wil dit Dankwoord beginnen met te zeggen dat ik het een groot voorrecht vind om dit proefschrift te kunnen maken. Dat ik de gelegenheid vond om naast en vanuit de dagelijkse praktijk als huisarts ook wetenschappelijk onderzoek te doen en te promoveren, is iets bijzonders. Steeds heb ik de combinatie huisartspraktijk en onderzoek als boeiend en inspirerend ervaren. Ik meen dat er van 'kruisbestuiving' sprake is - over en weer geven de twee exponenten van mijn werk positieve impulsen om met des te meer plezier en motivatie verder te gaan. Mijn gezondheid en belangstelling hebben er zeker niet onder geleden - eerder integendeel. Voor dokteren en voor promoveren moet je zelf sterk en gezond zijn, maar ook dienen de randvoorwaarden gunstig te zijn. En dat waren ze. Ik heb dit werk alleen kunnen doen dankzij de steun die ik ondervond in het Gezondheidscentrum Withuis in Venlo en bij de Universiteit in Maastricht. Als ik terugkijk op dertien jaar onderzoek, met de promotie als afronding, dan ervaar ik die als een prachtige, leerzame en produktieve periode. Huisartsen met belangstelling voor het doen van onderzoek of voor promoveren maar met twijfel of ze het wel moeten doen, kan ik van harte aanbevelen: doen!

Promoveren wordt door sommigen een 'eenzame weg' of een 'zware bevalling' genoemd, maar ik heb die weg zeker niet eenzaam gevonden en ik legde hem niet alleen af. Ook verliepen conceptie en bevalling voor mijn gevoel niet zwaar. Wel staat vast dat ik zonder de steun van vele anderen wellicht onderweg zou zijn vastgelopen of afgedwaald. Heel wat mensen hebben me gesteund en geholpen bij het tot stand brengen van dit proefschrift. Op deze plaats past een dankwoord aan al die vrienden. Mocht ik een enkeling ten onrechte niet noemen, dan hoop ik me dat vergeven wordt.

Allereerst mijn promotoren Harry Crebolder en Bart van den Borne en co-promotor Frans van der Horst: jullie verdienen mijn grote dankbaarheid. Harry, jij was steeds een gedreven leraar. Je hebt me telkens weten te enthousiasmeren voor de volgende stap, zowel in de onderzoeken als in het schrijven van artikelen en het proefschrift. Je bent een groot voorbeeld. Bart, als gezondheidswetenschapper en onderzoeker wist jij steeds op inspirerende en kalme wijze vooruitgang in de studies en artikelen te stimuleren. En Frans, je bent onovertroffen als klankbord, aanspreekpunt en medegenerator van ideeën, onderzoeksvragen, methoden en beschrijvingen. Samen deden we heel wat brainstormend en uitvoerend werk. Jullie drie wisten me uiteindelijk te overtuigen van het idee te promoveren. Dank voor de tijd en aandacht, en het eindeloze geduld dat je had bij lezen en herlezen van concepten. Jullie beantwoordden mijn vele vragen, deden suggesties voor verbeteringen en vooral: jullie boden me warme aanmoediging in een dialectisch proces van discussie en dialoog. Ik voel me empowered door jullie aanpak. Je sloot aan bij mijn perspectief, toonde respect voor mijn ideeën, wensen en verwachtingen, daagde me uit en wist me positief te motiveren, terwijl je de uiteindelijke beslissingen aan mezelf overliet. Empowerment en dialectiek blijken niet alleen in diabetesconsulten goed voor de uitkomsten. Ik ben vooral dankbaar voor jullie consequente steun aan het principe dat ik beschouw als de kern van de geneeskunde en van de huisartsgeneeskunde in het bijzonder: de persoonlijke interactie en echte dialoog tussen arts en patiënt in het consult. Dankzij jullie steun ben ik zover gekomen als ik nu ben. 
Rick Ryckman: You became a friend, albeit a faraway one. Being a professor of psychology in Boston, you work and live in a country with a different health care system as compared to what we have here. Enthusiastically, you supported my research of the patient-provider interaction in diabetes care. Our emails and (too few) personal discussions of empowerment, activation, social support, dialogue, balancing act, dialectical process, and meeting of two worlds, helped me to grasp an understanding of the sometimes confusing information from my studies. In our discussions, I recognised much of the subjects of the thesis. You too have 'empowered' me.

De leden van de beoordelingscommissie - Prof.dr.A. Nieuwenhuijzen Kruseman (voorzitter), Prof.dr.G.E.H.M. Rutten, Prof.dr.J. van Eijk, Prof.dr.J. Metsemakers en Prof.dr.P. Curfs - verdienen mijn dank. Hun opmerkingen en suggesties hebben bijgedragen tot sterke verbetering van het proefschrift.

Al direct bij het begin van mijn onderzoek onder diabetespatiënten raakte ik onder de indruk van het enthousiasme van mijn voorlopers: de Withuisoprichters Harry Crebolder en Remy van der Grinten. Jullie twee praktiseerden aanvankelijk nog in het Withuis toen ik hier in 1991 mijn tweede leven als huisarts begon. Jullie bleven toegewijd aan onderzoek en verdere ontwikkeling van de huisartsgeneeskunde, aan samenwerking van huisartsen met anderen, en aan de arts-patiënt relatie in het bijzonder. Jullie vertrokken uit het Withuis enkele jaren nadat ik er kwam, maar je bent tot op heden betrokken en beschikbaar. Voor jullie steun ben ik erg dankbaar.

Diverse mensen hebben op de achtergrond bijgedragen aan de studies en publicaties die in dit proefschrift zijn opgenomen. Sommigen van jullie waren betrokken bij opzet en uitvoering van de studies, anderen bij beschrijven van resultaten, meedenken over statistiek, of meebeoordelen van manuscripten, en sommigen bij data-invoer of statistische bewerkingen. Angela Wouters, Sem Külcü, Haske van Veenendaal, Irmgard Eijkelberg, Martijn van Nunen, Lut Knoops, Nicole Ebben, Ilse Mesters, Hubert Schouten, Karin Aretz, Veronique Schrijnemaekers, Paula Rinkens en Margreet Janssen: dank jullie wel!

Een speciaal dankwoord verdient het team van Gezondheidscentrum Withuis in Venlo. Ik ben er trots op met jullie te werken. In de eerste plaats mijn vrienden en naaste collega's Tonnie van Kessel en Gijsbert de Koning; verder Koen Vanwersch, Ilse Beekenkamp en Edith Craenmehr. Ook Hans Vlek, na ruim vier jaar terug als vaste invaller: dank. Ik ben dankbaar voor de steun die ik de afgelopen jaren van jullie ondervond tijdens het doen van onderzoek en het schrijven van dit proefschrift. En voor het accepteren en opvangen van het ongemak dat dit onvermijdelijk soms met zich meebracht. We pakten samen heel wat problemen aan en maakten leerzame, warme, soms muzikale momenten door. Laten we dat blijven doen!

Andere teamleden gaven me eveneens de nodige warme steun zonder welke ik niet had kunnen slagen: centrumassistentes Sonja van Giersbergen en Marie-José Nefkens, Latifa El Gachi, Anneke Maas, Corrie Verstegen, Yvonne Hendriks, Daniëlle Quellhorst, Janneke Minten en Amber Verbeek, en ex-assistentes Toos van Gerwen en Annie Hendriks. Diëtiste July Baggen; maatschappelijk werker Peter van Mierlo; unithoofden Thuiszorg Marie-Jeanne Smeets, Silbie Koreman en Hans Boes; wijkverpleegkundigen Hanny Verstegen, Christine van Heur, Pieter van Heugten en 
Astrid van de Camp (deze vier tevens praktijkverpleegkundigen/POH); exwijkverpleegkundigen Anneke Hendriks, Marian Janssen en Wim Elferink (†), en wijkziekenverzorgenden Nel Noach, Liesbeth Vaessen, Sandra Kaumanns, Angelique van der Steen en Marij Koopmans. Verder diabetesverpleegkundige Hannie Geven en diabeteswijkverpleegkundige Ans Draaisma; en andere Withuisteamleden. Administrateurs José Bijker, Peter-Paul Vallen en nu Jan Vercoulen, alsmede directie en bestuur van het Withuis: jullie faciliteerden mijn onderzoek en promotie stilletjes maar effectief. Alle mensen van het Withuis: dank!

Heel wat diabetespatiënten hebben deelgenomen aan mijn studies, en ik ben hen daarvoor zeer erkentelijk. Enkele Venlose patiënten in het bijzonder, met of zonder diabetes, inspireerden en versterkten mijn wetenschappelijk denken over dialoog en dialectiek: Pierre, Ger, Ien, Ber, Margriet, Wim, Koos, Lei, Farogh, Frans, Marjos, en een paar anderen. Uit privacy-overwegingen noem ik hier alleen jullie voornaam. Dank voor voorbeeldfunctie en aandacht die je had wanneer ik vragen had over zelfzorg, arts-patiëntcontact of onderzoek. Jullie stelden en beantwoordden vragen en gaven me je ervaringen of suggesties. Dat versterkte mijn interesse, motivatie en inzicht. Ik heb veel van jullie geleerd.

Informatie en morele steun kreeg ik ook van enkele bestuursleden van de afdeling Venlo en omstreken van de Diabetes Vereniging Nederland (DVN). Stef, Mia en Theo, dank jullie daarvoor. Ik hoop dat dit proefschrift bijdraagt aan verbetering van de diabeteszorg voor jullie en heel veel andere mensen met diabetes - zodat professionele hulpverleners hun patiënten behalve optimale behandeling volgens richtlijnen ook een echte dialoog kunnen bieden - nog beter dan zij nu doen. De DVN verdient hierin, naar mijn mening, een veel prominentere plaats dan ze nu heeft.

De leden van de Regionale Diabeteswerkgroep Noord-Limburg hebben me waarschijnlijk zonder dat zij zich daarvan bewust waren - geholpen dit proefschrift af te maken: Harry Schraven, Peter Janssen, Jan Maarten Tolk, Ad van Heeswijk, Joep Jansma, Jacques Janssen, Anette Spitz, Joop van den Bergh en Ronald van der Velden. Onze moeizame, jarenlange pogingen om te komen tot een goed en breed gedragen regionaal diabetesbeleid gaven me het gevoel dat we tenminste met deze groep pal staan voor goede diabeteszorg. Met sommigen van jullie werk ik samen om het jaarlijkse regionale Diabetes 'Maassymposium' te organiseren, wat veel voldoening en inspiratie brengt.

De Capaciteitsgroepen Huisartsgeneeskunde en Gezondheids Voorlichting \& Opvoeding/Patiënteneducatie, en de onderzoeksgroep Caphri van de Universiteit Maastricht, verdienen vermelding vanwege de vele 'onzichtbare' steun die zij me boden tijdens het werk aan onderzoek en proefschrift. Zij deden dit door ruimte en tijd plus aandacht van stafleden ter beschikking te stellen.

Ik wil niet nalaten ook de DiHAG (Diabetes Huisartsen Advies Groep) hier te noemen. Voorzitter Guy Rutten, ex-leden Simon van der Hoeven, Klaas Reenders en Paul Cromme; verder Ymte Groeneveld, Wim de Grauw, Lisette Romijn, Raynold Bruessing, Geert Eisma, Marianne van Brederode, Roelf Holttrop en Peter Wessels, alsmede coördinator Bep Bakker: dank voor jullie enthousiasme. Ik ben erg trots temidden van jullie te kunnen bijdragen aan het DiHAG-werk om kwaliteit en uitkomsten van de Nederlandse huisartsen-diabeteszorg continu te verbeteren. 
Enerzijds is beter uitvoeren van evidence-based richtlijnen nodig - anderzijds optimaliseren van de dialoog tussen patiënt en hulpverlener en centraal stellen van het patiëntperspectief, zodat zelfzorg tot zijn recht komt. Deze twee impulsen kunnen elkaar ontmoeten en, in een dialectisch proces zoals in dit proefschrift onderzocht, samen tot iets moois komen: een diabeteszorg die effectiever is dan de huidige. De DiHAG bezit grote potentie om hieraan bij te dragen.

Dik de Jong, mijn vriend, studiegenoot en oude maat: je behoudt een speciale plaats in mijn hart. We deelden onze 'vormingsjaren' in de jaren '70 in Rotterdam, werkten daarna bijna zeventien jaar als huisartsen samen en bouwden een gezondheidscentrum op. We deelden onze belangstelling en betrokkenheid bij de sociale achtergrond van de mensen, en zetten ons in voor het beter begrijpen en waar mogelijk verbeteren van hun woon- en werkomstandigheden. Jij was het die mijn interesse wekte voor gezin en sociale contekst van de patiënt. Het spijt me dat je gezondheid je zo in de steek heeft gelaten. Je bent er niet meer, terwijl we nog lang niet klaar waren. We hadden nog heel wat zeilweekends en lange gesprekken willen doen maar dat kan nu niet meer. Ik zal je niet vergeten.

Mijn vriend Kees Keller, broeder in diverse avonturen en muzikale maat: ook voor jou behoud ik warme gevoelens. Wij kennen elkaar al vanaf de HBS in 1962. Wij tonen dat het mogelijk is een vriendschap op afstand goed te houden. En jij leerde me dat de balans tussen ziekte en gezondheid niet alleen een kwestie is van medicijnen slikken en leefstijl en ritme aanpassen - maar ook van genieten van de kleine dingen, van muziek, van de natuur en van het bijstaan van je medemens: het realiseren van persoonlijke levendoelen.

Last, but not least, verdienen diegenen die aan dit proefschrift op een meer persoonlijk en emotioneel vlak hebben bijgedragen hier aandacht.

In de eerste plaats Nelleke, mijn levensgezellin. We leerden elkaar eind 1971 in Rotterdam kennen. Hier startten we in de jaren '80 ons fijne gezin. Later verlieten we deze thuisstad en begonnen in Venlo een nieuw leven. De laatste paar jaar voelde ik me soms schuldig over mijn frequente afwezigheden, ook als ik aanwezig was. Maar je gunde me deze 'absences' en hebt mijn promotiewerk enorm gesteund. Je nam gewoon een groter deel van het werk thuis op je, naast je drukke onderwijsbaan. Zonder jou was dit proefschrift vast niet tot stand gekomen - en ik weet dat gewoon 'dank je wel' zeggen niet volstaat. Daarom zeg ik hier alleen: je bent fantastisch.

In de tweede plaats zijn daar mijn ouders Huig en Floor, 82 jaar oud. Jullie hebben een leven van noeste arbeid, bescheiden eisen en tevredenheid geleefd. Jullie stelden mij in staat te studeren en boden mij vrijheid en ruimte. Daarmee zorgden jullie op unieke wijze dat ik arts kon worden en zelfvertrouwen en intellectuele nieuwsgierigheid kon ontwikkelen. Jullie gezondheid wordt minder, maar je blijft betrokken. Ik ben trots op jullie, en hoop dat jullie een beetje trots kunnen zijn op mij. (Helaas, bij het ter perse gaan van dit proefschrift overleed mijn moeder).

Verder onze kinderen Daan, Peter, Loes en Hanneke, en schoonkind Willemijn. Fijn dat jullie er zijn. En wat zou Liesbeth ervan genoten hebben wanneer ze hier ook bij had kunnen zijn! Geweldig zijn jullie! Aan jullie draag ik dit proefschrift mede op. Jullie hebben wellicht geleden onder mijn concentratie op dit werk in plaats van op jullie. Ik kan je verzekeren dat ik van jullie veel steun ondervond om dit werk af te maken doordat jullie gewoon zijn wie je bent. Een stel prachtige, authentieke jonge mensen, en het beste promotie-onderwerp van alles. Ik ben heel trots op jullie allemaal. We hebben nog een toekomst voor ons. Dank jullie wel. 


\section{List of publications 1995-2005}

1. HA van Dam, HFJM Crebolder, RF van der Grinten, A Wouters, FG van der Horst. Metabole regulatie, functionele toestand en kwaliteit van leven bij type 2 diabeten. Een exploratieve studie in de huisartspraktijk. Huisarts Wet 1995;38(13):618-22. (Diabetes control, functional status, and quality of life in type 2 diabetes. An explorative study in general practice).

2. HA van Dam, HFJM Crebolder, S Külcü, S van Veenendaal, FG van der Horst. Wegblijvende diabeten. Een literatuuronderzoek en raadpleging van Nederlandse huisarts-deskundigen. Huisarts Wet 1998;41(1):10-5. (Nonattending diabetics. A literature search, and consultation of Dutch general practice diabetes experts).

3. HA van Dam, ME Biegstraaten, HFJM Crebolder. Op zoek naar het insulineresistentiesyndroom bij hypertensiepatiënten. Tijdschr.Huisartsgeneeskd 2000;17(7/8):253-8. (In search of the Insulin Resistance Syndrome among patients with hypertension).

4. HA van Dam, HFJM Crebolder, I Eijkelberg, M van Nunen, FG van der Horst. Wegblijven van patiënten met diabetes mellitus type 2 - een echt probleem? Huisarts Wet 2000;43(9):380-4. (Non-attendance of patients with type 2 diabetes mellitus - a real problem?).

5. Henk A van Dam, Frans $G$ van der Horst, Bart HG van den Borne, Richard Ryckman, Harry FJM Crebolder. Provider-patient interaction in diabetes care: Effects on patient self-care and outcomes. A systematic review. Pat Educ Couns 2003;51:17-28.

6. HA van Dam. Patiëntgedrag belangrijker dan hulpverlenersgedrag - Zelfzorg en uitkomsten van type 2 diabeteszorg. EADV-Magazine 2003 sept. 110-3.

7. Henk van Dam, Lut Knoops. Social support in diabetes care in general practice. A qualitative pilot study (submitted, 2004).

8. Henk van Dam, Frans van der Horst, Lut Knoops, Richard Ryckman, Harry Crebolder, Bart van den Borne. Social Support in diabetes: A systematic review of controlled intervention studies (in print, Patient Education and Counseling, 2004-2005).

9. Henk van Dam, Frans van der Horst, Ilse Mesters, Harry Crebolder, Bart van den Borne. Obstacles in the management of type 2 diabetes: the perspectives of patients and experts (submitted, 2004).

10. Henk A van Dam, Richard M Rickman, Bart HW van den Borne, Harry FJM Crebolder, Frans $G$ van der Horst. Patient-centredness and the dialectical process in diabetes care (submitted, 2005). 


\section{CURRICULUM VITAE}

In 1949.werd ik als oudste van vijf kinderen geboren in Schoonhoven (ZH). Vader was horloge- en klokkenmaker en graveur, moeder naaister. We verhuisden in 1954 naar Rotterdam-Noord (Schiebroek), ik groeide daar op en deed er tussen 1961 en 1966 de middelbare school (HBS-B) aan wat nu de Melanchton Scholengemeenschap heet. Mijn hobbies waren rondbanjeren in de natuur en gitaar spelen. Van 1964 tot 1973 maakte ik met ondermeer vriend Kees Keller muziek in een band. De medische studie deed ik van 1966 tot 1973 aan de toen net opgerichte Medische Faculteit Rotterdam (Erasmus Universiteit). In 1971 organiseerde ik met medestudenten een kritische medische zomeruniversiteit, Pinkeltje. Daarin kwam de patiënt als mens centraal te staan en werd de autoriteit van de arts en de eenzijdige aandacht voor biomedische aspecten gekritiseerd en een integrale, biopsychosociale benadering van gezondheid en ziekte benadrukt. Betere samenwerking van medici, maatschappelijk werkers en verpleegkundigen werd bepleit. In 1972-73 verrichte ik samen met Dik de Jong en enkele andere medische studenten mijn eerste studie: naar de relatie tussen slechte woonsituatie en slechte gezondheid in de wijk Bloemhof, Rotterdam-zuid. Een vijf maanden durende medische stage in Tanzania (East African Institute of Malaria and Tropical Diseases, Amani-Tanga) in 1972-73 versterkte mijn verbondenheid met de Derde Wereld. Medio 1973 was ik wel (huis)arts, maar schreef toch in voor de toen experimentele huisartsopleiding van zes maanden - en deed een prachtige stage bij solohuisarts Wim Rinck in Rotterdamwest. Daarna was ik waarnemer in verschillende praktijken.

In Rotterdam-zuid startte ik eind 1974 na praktijkovername een solopraktijk. Studievriend Dik de Jong ging daarin meewerken. Nadat wij een jaar samen in mijn praktijk werkten en daarna een jaar in twee aparte praktijken, vormden we begin 1977 een duopraktijk en maatschap. Toen wijkverpleging en maatschappelijk werk gingen meedoen noemden we ons Medisch Centrum Bloemhof-Hillesluis. In 1989 werd het Medisch Centrum een Gezondheidscentrum met o.a. loondienstverband voor de artsen. Het heet nu 'GC Lange Hille'.

Nelleke en ik kregen vijf kinderen. In 1986 verloren wij ons tweede kind, de bijna driejarige Liesbeth, tijdens vakantie in Turkije. Dit verlies heeft ons gezin en mijzelf een tijd ernstig van slag gebracht en mijn kijk op sterven en rouwen in de huisartspraktijk beínvloed.

In 1991 stapte ik over naar het Gezondheidscentrum Withuis in Venlo en kon ik met diabeteszorgonderzoek beginnen. Ik kreeg een onderzoeksaanstelling bij de Vakgroep Huisartsgeneeskunde van de Universiteit Maastricht van eerst een halve en later een hele werkdag per week. Sinds 1996 ben ik lid van de Werkgroep Psychosociale Diabetologie (WPD), de Diabetes Huisartsen Advies Groep (DiHAG), en de Regionale Werkgroep Diabeteszorg Noord-Limburg. 


\section{ABSTRACT}

Dit proefschrift presenteert enkele studies van, en reflecteert op de zorg voor mensen met type 2 diabetes in de huisartspraktijk. Het bepleit een echte dialoog tussen de leefwereld van de patiënten en de 'medische' wereld van de hulpverleners.

$\mathrm{Na}$ een algemene inleiding komt eerst een studie aan bod van de samenhang tussen enerzijds ziekte- en hulpverlenergerichte items (zoals metabole regulatie, diabetescomplicaties en comorbiditeit die in de medische dossiers geregistreerd zijn), en anderzijds patiëntgerichte items (zoals door patiënten gerapporteerde kwaliteit van leven, functionele toestand, ervaren diabetesregulatie en steun). Meer aandacht van de professionals voor de leefwereld van de patiënt wordt bepleit. In twee hoofdstukken komt het wegblijven van diabetescontroles door patiënten aan bod. De risico's van lang wegblijven lijken voor patiënten, anders dan verwacht, beperkt. Daarna volgt een tweetal systematische literatuuronderzoeken. Een over de effectiviteit van interventies in sociale steun, en een over de effectiviteit van interventies in de interactie tussen hulpverlener en patiënt. Nieuwe vormen van sociale steun (onderlinge patiëntensteun in live, telefoon- of internetgroepen) geeft betere resultaten voor de uitkomst van diabeteszorg dan 'klassieke' vormen van steun (van partner of familie/vrienden). Het actiever en assertiever maken van patiënten heeft positievere invloed op de uitkomsten van diabeteszorg dan het patiëntvriendelijker maken van professionals.

Een studie naar de door patiënten gerapporteerde belemmeringen voor het goed uitvoeren van de adviezen voor zelfzorg en behandeling, en de commentaren en aanbevelingen van experts daarop toont dat patiënten veel belemmeringen ervaren, o.a. door de gevolgen van de diabetes zelf en door slechte interactie met hulpverleners. Experts bepleiten beter uitvoeren van de diabetesrichtlijnen maar ook meer 'empowerment' van patiënten.

Een artikel dat reflecteert op het patiëntgericht werken, de patient empowerment, en de dialectische kenmerken van de dialoog tussen patiënt en hulpverlener, is het volgende. De waarden, verwachtingen, wensen en visies van patiënt en hulpverlener verdienen aandacht, zodat ze samen tot gezamenlijke afspraken kunnen komen. De Algemene Discussie sluit hierop aan. Daarin worden ook enkele methodologische punten die niet eerder aan de orde kwamen besproken. Aanbevelingen voor 'empoweren' van patiënten in het dagelijks werk van diabetesteams in de huisartspraktijk, voor opleidingen van professionals, en voor verder onderzoek, worden geformuleerd.

This thesis presents some studies and reflections on the care for people with type 2 diabetes in general practice. It advocates a true dialogue between the life world of patients and the 'medical'world of providers.

After a general introduction, a study of the relationships between disease and provider oriented items on one hand (such as diabetes control, diabetes complications, and comorbidity as registered in the medical records), and patient oriented items on the other hand (such as patient reported quality of life, functional status, perceived control and support), is presented. More attention of professionals for the life world of patients is advocated. Aspects of patient non-attendance are studied in two subsequent papers. Non-attendance appears to be less rsky for patients than was expected. A systematic literature review on effectivity of social support interventions in diabetes care is presented after that, as well as a systematic review on effectivity of patient-provider interaction interventions. New forms of social support (mutual patient support in 'live', telephone, or internet groups or group visits 
to diabetes providers) appears to affect outcomes of diabetes care better tha 'classical' forms of support (from spouse, family, or friends). Activating and asserting patients has a more positive effect on outcomes of care than changing professionals' attitudes into a more patient-centred direction.

A study of patient-reported obstacles to following up the profesiona advices for selfcare and treatment, and experts' comments and recommendations for improvements, showed that patients perceive many obstacles - partly caused by the sequela of the condition diabetes itself, and partly by poor communication with professionals. Experts advocate efforts for better implementation of guidelines, as well as for patient empowerment.

A paper reflecting on patient-centredness, patient empowerment, and the dialectical features of the patient-provider dialogue in diabetes care, is next. The values, expectations, wishes and views of patient and professional deserve discussion, so as to enable common plans to be made. The General Discussion chapter connects to this paper. Some methodological issues that had not been addressed in previous chapters, are put forward as well. Recommendations are given for patient empowerment in the daily practice of diabetes teams in general practice, for education of professionals, and for further research. 